\title{
Haiti: Poverty Reduction Strategy Paper
}

Poverty Reduction Strategy Papers (PRSPs) are prepared by member countries in broad consultation with stakeholders and development partners, including the staffs of the World Bank and the IMF. Updated every three years with annual progress reports, they describe the country's macroeconomic, structural, and social policies in support of growth and poverty reduction, as well as associated external financing needs and major sources of financing. This country document for Haiti, submitted in French on November 30, 2007, is being made available on the IMF website by agreement with the member country as a service to users of the IMF website.

Copies of this report are available to the public from

International Monetary Fund • Publication Services

$70019^{\text {th }}$ Street, N.W. • Washington, D.C. 20431

Telephone: (202) 623-7430 • Telefax: (202) 623-7201

E-mail: publications@imf.org • Internet: http://www.imf.org

Price: $\$ 18.00$ a copy

\section{International Monetary Fund Washington, D.C.}





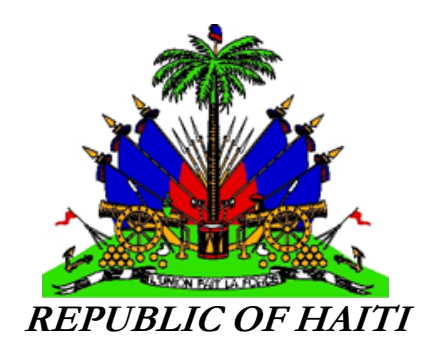

PREPARATORY COMMITTEE - GROWTH AND POVERTY REDUCTION STRATEGY PAPER

\title{
TECHNICAL SECRETARIAT OF THE PREPARATORY COMMITTEE FOR THE DSNCRP
}

\author{
MINISTRY OF PLANNING AND EXTERNAL COOPERATION \\ (MPCE)
}

\section{GROWTH AND POVERTY REDUCTION STRATEGY PAPER \\ (DOCUMENT DE STRATEGIE NATIONALE POUR \\ LA CROISSANCE ET POUR LA REDUCTION DE LA PAUVRETE}

(DSNCRP)

(2008-2010)

\section{Making a Qualitative Leap Forward}

November 2007

English Translation of Official Original Document in French Official Original Document in French Available at http:/www.mpce.gouv.ht/dsrp.htm 



\section{Table of Contents}

Foreword by the Prime Minister

\section{Executive Summary}

\section{Introduction}

1. The Context

2. The Participatory Process

3. The Structure of the Paper

\section{PART ONE}

The Dual Challenge of Poverty and Inequality

CHAPTER 1: The Scope of Poverty and Inequality

CHAPTER 2: The Characteristics and Driving Factors of Poverty and Inequality

CHAPTER 3: The Poverty and Inequality Situation between 1986 and 2006

\section{PART TWO \\ Major Challenges}

CHAPTER 4: The Major Challenges to be Faced by 2015

\section{PART THREE \\ Growth and Poverty Reduction Strategy}

CHAPTER 5: PILLAR 1: Growth Vectors: Agriculture and Rural Development; Tourism; Infrastructure; Science and Technology

CHAPTER 6: PILLAR 2: Human Development - Priority Accorded to Basic Services

CHAPTER 7: PILLAR 3: Democratic Governance - Priority Accorded to Justice and Security

CHAPTER 8: Targeted and Cross-Cutting Policies and Strategies

\section{PART FOUR \\ Growth and Poverty Reduction Strategy Objectives}

CHAPTER 9: Macroeconomic Policy Framework

\section{PART FIVE \\ Strategy Financing, Implementation, and Monitoring}

CHAPTER 10: 1. Quantification and Financing of the DSNCRP

2. Monitoring and Implementation 


\section{ANNEX I}

1. Schema of Overall Planning Framework

2. Matrix of Objectives and Measures (2008-2010)

3. Matrix of Objectives of Public Finance Reforms

4. Economic Accounts Tables Gross Domestic Product Account

Summary of Financial Operations of the Central Administration

Summary of Haiti's Balance of Payments (2002-2011)

Monetary Survey

5. Summary Table of DSNCRP Costs

6. Schema of Institutional Framework for Implementation

7. Table of DSNCRP Monitoring Indicators

ANNEX II

Detailed Matrix of Priority Actions of DSNCRP

ANNEX III

Detailed Matrix of Public Finance Reforms

\section{List of Tables}

1. Poverty and Extreme Poverty in Haiti

2. Incidence of Poverty in Haiti by Place of Residence

3. Unemployment Rate by Population Age Group (age 10 and over) and by Gender and Place of Residence

4. Access to Social Services by Department

5. Coverage of Water and Sanitation Needs

6. Growth and Development Regions/Hubs (2007-2015)

7. Major National Objectives (2010-2015)

8. Number of tourists and same-day visitors to Haiti.

9. Progress Toward Achieving the MDGs in Haiti (June 2007)

10. Financing Requirements 2008-2010 period. 10.1. Characteristics of macroeconomic scenarios for 2007-2011. 10.2 Anticipated evolution of global demand's components

\section{List of Figures}

10.1 Growth and Inflation in \%

10.2 Tax Revenue and Public Expenditure 


\section{LIST OF ABREVIATIONS}

ABD

ACP

ACS

AIICF

AITIC

ANAMAH

BON

BRH

CARICOM

CARIFORUM

CARLI

CBI

CDB

$\mathrm{CEDH}$

CEP

CONATE

CONHANE

CSP

DDR

DG Trade

DGI

DSNCRP

EC

ECBM

ECD

$\mathrm{ECVH}$

EIB

EMMUS

EPA

GSHDI

HDI

HIPC

HPI

ICF
Budgetary Development Assistance

Africa, Caribbean, Pacific

Association of Caribbean States

Assistance with Implementation of the Interim Cooperation Framework Agency for International Trade, Information, and Cooperation

National Association of Haitian Magistrates

Office of the National Authorizing Officer

Bank of the Republic of Haiti

Caribbean Community

Caribbean Forum of African, Caribbean, and Pacific States

Lawyers Committee for the Respect of Individual Freedoms

Caribbean Basin Initiative

Caribbean Development Bank

Ecumenical Center for Human Rights

Provisiona1/Permanent Electoral Council

National Council for Territorial and Environmental Development

Haitian Council of Non-State Actors

Country Strategy Paper

Disarmament, Demobilization and Reintegration

Directorate General for Trade

Directorate General for Taxes

Growth and Poverty Reduction Strategy Paper

European Commission

Survey on Household Consumption Budgets

European Commission Delegation

Survey on Living Conditions in Haiti

European Investment Bank

Survey on Mortality, Morbidity, and Use of Services

Economic Partnership Agreement

Gender-Specific Human Development Index

Human Development Index

Heavily Indebted Poor Countries

Human Poverty Index

Interim Cooperation Framework 


\begin{tabular}{|c|c|}
\hline ICRC & International Committee of the Red Cross \\
\hline IDB & Inter-American Development Bank \\
\hline IHSI & Haitian Institute for Statistics and Data Processing \\
\hline IMF & International Monetary Fund \\
\hline I-PRSP & Interim Poverty Reduction Strategy Paper \\
\hline LA & Latin America \\
\hline MDGs & Millennium Development Goals \\
\hline MDRI & Multilateral Debt Relief Initiative \\
\hline MEF & Ministry of Economy and Finance \\
\hline MENFP & Ministry of National Education and Professional Training \\
\hline MJSAC & Ministry of Youth, Sports and Civic Action \\
\hline MPCE & Ministry of Planning and External Cooperation \\
\hline MSPP & Ministry of Public Health and Population \\
\hline NGLC & NGO Liaison Committee \\
\hline NICT & New Information and Communication Technologies \\
\hline NSA & Non-State Actors \\
\hline PRGF & Poverty Reduction and Growth Facility \\
\hline PRSP & Poverty Reduction Strategy Paper \\
\hline RGDH & General Population and Housing Survey \\
\hline SNCRP & Growth and Poverty Reduction Strategy \\
\hline SWAp & Sector-Wide Approach \\
\hline TA & Technical Assistance \\
\hline TDI & Technology Development Indicator \\
\hline UBN & Unmet Basic Needs \\
\hline ULCC & Anti-Corruption Unit \\
\hline WB & World Bank \\
\hline
\end{tabular}




\section{PRIME MINISTER'S FOREWORD}

The Growth and Poverty Reduction Strategy (SNCRP) presented in this paper is the most complete version of the document articulating the vision and resources required to lift Haiti out of poverty and destitution.

This strategy is an extension of the Statement of General Policy ratified by Parliament in June 2006 and the document prepared for the International Conference on Economic and Social Development held in Haiti in July 2006 (CIDES I) and the Madrid Conference (CIDES II, November 2006), at which Haiti and its international partners acknowledged their joint responsibility with respect to aid effectiveness.

The fact that the DSNCRP is the product of a broad participatory process makes it a clearly representative document that sets forth the commitment of all members of Haitian society. It therefore represents first and foremost a commitment of the Government, which I head.

Our task is to make a qualitative leap forward. We must demonstrate the drive to seize the window of opportunity created by the restoration of constitutional rule, the establishment of state institutions, and the mobilization of Haitian men and women, in order to leave an indelible footprint on the history of the country.

We face considerable challenges: building strong momentum in order to overcome the lag with respect to Millennium Development Goals, providing the country with a modern economy, modernizing all state institutions, and using our creativity and cultural heritage to develop our country.

We have reason to be optimistic, while at the same time being cognizant of the fact that there will be no grace period. We can build on those areas in which clear progress has already been made. The security situation is improving and citizens can now lead fairly normal lives. Although progress remains to be made, we are on the right track.

Strict management of the economy, tireless efforts to combat corruption, and work done to revitalize our public service are all converging to create the conditions required for our country to close the necessary gap.

This document provides the framework that should allow our international partners to calibrate their programming in order to respond appropriately to the needs of our country.

It should be borne in mind that implementation of this strategy will be better facilitated if we are able to implement this new form of cooperation to which we committed in Port-au-Prince in July 2006.

Our unequivocal acceptance of the Paris Declaration on Aid Effectiveness, reaffirmed in Madrid that same year, and in particular our joint responsibility, need to be borne in mind. We must put in place suitable mechanisms for intervention and dialogue that are capable of channeling efforts aimed at enhancing the well-being of the Haitian people. We are lagging in this area.

My Government is conducting a thorough assessment of the difficult task that lies ahead and intends to fully assume Haiti's leadership role in order to ensure the success of the strategy proposed. We expect to enjoy a relationship of ongoing trust and cooperation with our partners, continuing with the efforts undertaken thus far.

We therefore make a commitment to this joint endeavor, the results of which will be measured by the improvement in the living conditions of the Haitian people. 


\section{EXECUTIVE SUMMARY}

Over the past twenty years, Haiti has undergone profound change that has affected all aspects of national life, particularly in the political, economic, social, and environmental spheres.

The political stability restored in 2006, the successful establishment of a macroeconomic framework, the reduction in insecurity, and modest but sustained economic growth over the past four years represent significant strides. However, they are not enough to cope with the myriad challenges facing the country. The Growth and Poverty Reduction Strategy Paper (DSNCRP) has been drafted with a view to tackling these challenges and providing satisfactory responses to the aspirations of the Haitian people.

The paper is broken down into five parts. The first provides an assessment of poverty and inequality on the basis of the data gathered from the most recent surveys. The second outlines the vision of state and non-state actors as well as the challenges to be met by 2015 . The third essentially summarizes the major areas of work decided upon by the Government of Haiti at the July 25, 2006 International Conference, which have been reorganized into three pillars: growth vectors, human development, and democratic governance supported by targeted and cross-cutting strategic areas of intervention. The fourth pertains to the macroeconomic framework and policies. Lastly, the fifth covers the financing, implementation, and monitoring of the DSNCRP.

\section{Overview of Poverty in Haiti}

Data on poverty and inequality in Haiti show that in 2001, 56 percent of the Haitian population (4.4 million persons of a total population of 8.1 million) lived below the extreme poverty line of US\$1 PPP per person, per day. It was estimated that for every ten persons, 7.6 are considered poor; that is, they do not receive US\$2 PPP per person, per day, and that 40 percent of the poorest population groups have access to only 5.9 percent of total income, while the most affluent 20 percent control 68 percent of this income. Consequently, 80 percent of the population controls a mere 32 percent of income, while it is projected that 2 percent of the wealthiest segment controls 26 percent of total income.

Haiti was reported to have regressed on the human development scale, falling from position 146 in 2000 to 153 in 2005. The IHSI, in conjunction with the Latin American and Caribbean Demographic Center [Centre Latino Américain de Démographie CELADE] and the UNFPA, estimated life expectancy at birth to be 58.1 percent (2000-2005), based on data taken from the 2003 survey.

Other indices, such as the gradual increase in deforestation, infant malnutrition, and the annual average decline in real per capita income and average consumption, point to a deterioration in living conditions.

The Republic of Haiti, faced with the dire consequences of poverty and documented social inequalities, has pledged to face the challenge by seeking, through a participatory process that includes all the different population groups, the most effective national strategy for achieving sustainable growth and a substantial reduction in poverty.

\section{The Participatory Process}

The participatory approach adopted for the drafting of the DSNCRP ensured broad-based stakeholder involvement. All activities took place in two phases. The first, which was called awareness-building/consultation, took place at the departmental and sectoral levels. The consultation process included more than 2,000 persons throughout the country. Officials elected 
at both the local and national levels, representatives of cross-cutting or targeted thematic areas, and in particular the most vulnerable groups actively participated in this process.

The second phase of the process (the participatory phase) was conducted on a thematic basis in the municipalities (communes) and departments (départements), and at the national level, with a view to building as broad a consensus as possible around this strategy paper. This phase involved more than 3,000 participants from the different sectors: NGOs, businesspersons, state actors, cooperative associations, universities, financial institutions, farmers and producers associations, and artistes.

\section{Challenges}

In order to give concrete expression to the strategic vision of the DSNCRP, Haitian society will have to tackle four major challenges successfully: (i) making an all-out effort to overcome the lag with respect to the Millennium Development Goals (MDGs) by moving toward more meaningful social development; (ii) creating a modern, competitive economy with a broad territorial base in order to handle the rapid modernization of Caribbean economies, which is making it essential for Haiti to rebalance its competitiveness in a regional context; (iii) modernizing the State in order to place it, once and for all, at the service of all citizens by calling for a greater effort to modernize and reshape the public management system; and (iv) making full use of our two big comparative advantages, namely our cultural creativity and historical heritage, on the one hand, and our Diaspora, on the other. Revival of the development process should be based on potential existing in the area of cultural creativity and expression. Our cultural capital is a major asset in our bid to take advantage of globalization.

\section{Phases Required to Meet the Challenges}

These factors lead to the identification of two major phases in the measures to be adopted to reduce poverty and stimulate growth in Haiti in the coming decades.

\section{First Phase: 2007-2009}

This phase corresponds to the 2007/08 - 2009/10 period, covering the three years of implementation of economic and financial commitments made under the IMF's PRGF, namely: (i) maintaining the current macroeconomic framework built around sound management of the economy with prudent fiscal and monetary policies in order to reduce significantly major internal and external economic imbalances; and (ii) modernizing agriculture and stepping up efforts to modernize transport infrastructure, improve the supply of electricity, and develop telecommunications services. However, the promotion of greater social equity through education and health will prove to be key to reducing poverty and inequality during this period.

Second Phase: 2010-2015

The main focus of this phase will be to strive for accelerated growth and greater control over social development. Consequently, the emphasis during this phase will be on reducing both monetary and human poverty. The macroeconomic framework will be reoriented in such a way as to make it more attractive to those economic sectors whose potential could be more easily exploited, such as the highly promising areas of the agricultural sector, agro-industry, tourism, and the textile subsectors of the manufacturing industry, which will benefit if they are accorded priority. During this second phase of the economic and social development strategy, the focus of the Central Bank should no longer be mainly on lowering inflation; it should also target growth and job creation. 


\section{Priority Pillars of a Growth and Poverty Reduction Strategy}

\section{Pillar 1: Growth Vectors}

The growth strategy, which includes the need to work toward poverty reduction, is based on four key areas or growth vectors: agriculture and rural development, tourism, infrastructure modernization, and science, technology, and innovation.

\section{Agriculture and Rural Development}

The strategy for this sector calls for a series of actions, including the development of the rural area with zoning that guarantees protection of our environment, the diversification of revenuegenerating activities, and legal measures in order to ensure the sustainability of progress made in the area of development and a more equitable distribution of the wealth generated.

\section{Tourism}

Tourism remains a development area, given that this activity is now considered a growth industry. In order to be able to take advantage of this opportunity, Haiti must make a number of choices, including streamlining aimed at efficiency, and in particular adjusting decisions to their implementation context. General approaches are emerging in a new national tourism landscape.

\section{Infrastructure}

One priority of the strategy developed by the Government is to achieve, through the national road network, true control over urban and interurban transport. The need for balanced development of the network has prompted the Government to establish broad guidelines for regional land transport by: (i) according priority to the development of regional potential and boosting the competitiveness of the Haitian economy; (ii) reestablishing balance within national territory by fostering the emergence of big regional metropolises; (iii) guaranteeing consistent connections throughout the country; (iv) maintaining current infrastructure; and (v) protecting the environment.

\section{Pillar 2: Human Development}

Human development is based on a significant increase in opportunities, including social services, provided to individuals so that they can better develop their capacities.

\section{Education and Training}

Improving the yield of the system entails: (i) retraining teachers and school principals; (ii) providing adequate guidance to schools, students, and parents; and (iii) establishing synergy between the State and other actors operating in the sector.

\section{Health}

What are known as priority illnesses have a major impact on the state of health of the population and produce major economic effects. This situation is all the more unacceptable since it can be improved through the adoption of appropriate measures. The objectives sought will therefore be to: (i) strengthen two areas - prevention and information; and (ii) assume greater responsibility for and develop intersectoral collaboration.

The strategic lines of action selected for achieving these objectives are: (i) the drafting of a national health policy and updating of all laws necessary for its regulation; (ii) the establishment 
of procedures for inspecting and assessing health activities at all levels; (iii) the drafting of a Charter of Partnership with the other state and non-state actors; and (iv) the modernization of the health information system.

\section{Water and Sanitation}

The performance of the water and sanitation sector is unsatisfactory. Coverage rates are clearly insufficient, financial results have been continually negative, investments are most often made using external funding, and the quality of service is generally mediocre. The institutional objectives identified are aimed at replacing the entities currently in charge at the national level with regional offices, which could be managed through the conclusion of contracts with the private sector.

\section{Persons with Disabilities}

According to available statistics, Haiti has approximately 800,000 persons with disabilities (approximately 10 percent of its total population). The Government has decided to tackle this problem through the following strategic lines of action: (i) better prevention of incapacity through vaccination, nutrition, early detection, and timely intervention, so as to minimize the risks of disability; (ii) creation of medical rehabilitation departments in the main hospitals in the country and promotion of subsidies to obtain prostheses, medications, and other targeted forms of support; and (iii) establishment of a home for the disabled in each departmental administrative district.

\section{Childhood Poverty}

Survey data show that in 2005, 2.7 million children aged 0-18 did not have access to at least one known basic social service. Progress in the areas of transport, health, education, agriculture, and finance will undoubtedly benefit children either directly or through the households in which they live. Policy and institutional reforms will target: (i) the removal of obstacles to investments that benefit children and young people; (ii) ongoing support for families and communities (transfers and public or non-public investments); and (iii) efforts to promote participation and foster the independence of adolescents.

\section{Young People}

Young people constitute one of the population groups most affected by the current multidimensional crisis. Demographically, they account for more than 50 percent of the overall population. The objectives sought are to: (i) improve the living conditions of young people through their economic and socio-cultural integration; and (ii) promote physical and sporting activities. The strategic lines of action identified are aimed at: (i) developing a program for the socioeconomic and socio-cultural integration of young people throughout Haiti; (ii) establishing and executing a program for the development of sports; and (iii) establishing and executing a program to foster a sense of civic duty with a view to shaping responsible Haitian citizens.

\section{HIV/AIDS}

The focus of implementation of the strategic area to lower the risk of infection is on educational activities aimed at changing behaviors. In the risk-reduction area, outreach activities must take into account all non-medical risk factors, which are more familiar to other sectors, given that they are more involved with them and can thus carry them out with greater credibility. 


\section{Gender Equity}

The main actions identified consist of: (i) taking initiatives to introduce sex education as a way of preventing early pregnancies and violence through new training programs, basic education, or even basic classes; and (ii) recommending general laws on all aspects of education, with a gender-based perspective.

With regard to health, the actions are: (i) promoting the establishment of a national plan to reduce the level of maternal mortality and encourage the MSPP to offer women high-quality reproductive health services; (ii) developing an information, education, and communication strategy and services in partnership with the MSPP and non-state institutions targeting sexual and reproductive health specially geared toward young adolescents (male and female) and women of child-bearing age; and (iii) encouraging the MSPP to adopt a policy to provide free medical and paramedical services in all public hospitals and health centers with a view to the prevention of breast cancer, cervical cancer, and cancer of other female organs, particularly to women in modest circumstances.

\section{Pillar 3: Democratic Governance}

The Haitian State should invest in democratic governance. In this regard, the DSNCRP accords priority to modernization of the State and establishment of the rule of law, in particular in the area of the justice system and security. The establishment of an equitable justice system and a general climate of security are prerequisites for growth and poverty reduction.

\section{The Justice System}

In order to restore the confidence of citizens in the justice system, it would be helpful to evaluate all judges and public prosecution officials currently working in the system from the standpoint of academic training, professional experience, and moral and ethical standards, and to consolidate the mechanisms for the oversight and monitoring of courts. Five main priority areas have been identified: (i) restructuring and modernizing of the MJSP through the drafting of a new organic law and the establishment of a Supreme Council of the Judiciary [Conseil Supérieur de la Magistrature CSM]; (ii) restoration of the judiciary; (iii) improving access to the courts and to an efficient court system; (iv) rehabilitation and consistent development of the incarceration system; and (v) modernization of legislation.

\section{Security}

Combating insecurity through the restoration of the police force is therefore a key element of the SNCRP. Six lines of action have been identified: (i) Improving the status and conditions of life and work of the staff of the Haitian National Police (HNP); (ii) restructuring the HNP and strengthening the chain of command structures, management, and oversight of the police force; (iii) deploying the HNP throughout the country; (iv) continuing the clean up of the police force; and (v) combating internal corruption and misconduct.

\section{Modernization of the State}

The rapid restoration of the capacity for action by the State and public sector in general has become essential. The strategic approach to modernizing the state apparatus entails a comprehensive approach structured around the following actions: (i) according a prominent role to the development and promotion of human resources; (ii) conducting a parallel process of managerial reform in order to lend impetus to the operations of all essential public services at the 
central and local levels; (iii) modernizing administrative technology and the physical infrastructure in which public agents work.

\section{Territorial Development}

Territorial development is the sensible response to the problem of economic growth and the society's security. In this regard, political and economic decentralization should be synchronized so that territorial development includes the proper spatial distribution of activities and guarantees a coherent rural renewal policy. Specifically, this will entail rebuilding the country over time based on the integration of national areas, linkages between rural and urban areas, and development of the competitiveness offered by different territorial areas.

\section{The Macroeconomic Framework}

Macroeconomic stability is a prerequisite for the implementation of a growth and poverty reduction strategy. Low inflation is curbing the erosion of the real value of wages and assets of economic agents, in particular the poor. Owing to the quality of macroeconomic management in recent years, growth of the Haitian economy is resuming in a context of stronger economic fundamentals. The objective in this area is to increase tax ratio from 10 percent currently to 14 percent by 2011, and to seek an increase in tax revenue by building the institutional capacity of relevant government agencies and combating smuggling. At the same time, the State will ensure that public expenditure is better allocated through a more targeted approach aimed at lending impetus to the growth process. With regard to the effectiveness and quality of public expenditure, the Government is proposing to draft, beginning in 2008, a medium-term expenditure framework (MTEF) with a view to harmonizing sectoral and macroeconomic policies, programmed public expenditure, and actual expenditure.

\section{Financing, Implementation, and Monitoring of the Strategy}

The implementation cost of the Growth and Poverty Reduction Strategy (SNCRP) during the 2007-2010 period is G154,560,000,000 (US\$3,864,000,000). Its implementation cost is indicative of resource needs. The process has consisted of prioritizing targeted actions with a view to creating conditions conducive to keeping the country on an economic growth path and reaching the most vulnerable groups affected by poverty.

The structure of the implementation and monitoring of the DSNCRP includes two levels: one that is strategic, supported by the President of the Republic with arbitration responsibility assigned to the Prime Minister, and another that is operational, spearheaded by the Ministry of Planning and External Cooperation and the Ministry of Economy and Finance. These levels include the main development partners, namely, the private sector, the local authorities, and the aid sector, including international agencies and NGOs.

Overall, this implementation level is under the ultimate control of the President, who supports, in order to achieve his objective, a National Investment Commission that seeks to make Haiti's resources more competitive and to boost the performance of its public investments, among them those involving the major work areas [Grands Chantiers]. Within this commission is an arbitration committee run by the Office of the Prime Minister, whose primary mission is ensure that its public investments are well targeted. Similarly, the Ministry of Planning and External Cooperation and the Ministry of Economy and Finance, through their respective technical units, ensure the coordination, implementation, execution, and monitoring of activities in conjunction with the sectoral ministries, through the research and programming units. 


\section{INTRODUCTION}

1

The Context

1 Over the past twenty years, Haiti has undergone profound change that has affected all important aspects of national life, particularly in the political, economic, social, and environmental spheres. These changes have taken place in a global context affected by the sudden and multifaceted impact of rapid demographic growth resulting from a sequence of events, in particular: $i /$ the failure to manage the effects of the 1980-1982 international economic crisis, ii/ internal political instability resulting from the collapse of the political regime, iii/ the dramatic process of liberalization that started in 1987 and, iv/ the 1991-1994 trade embargo imposed by the international community.

2 As a result of this multidimensional and protracted crisis, Haiti has been rapidly and greatly surpassed by the majority of small Latin American and Caribbean economies, so much so that currently, it is the only LDC in the Western Hemisphere. At the same time, a process of widespread impoverishment has gradually taken hold. This strong and adverse trend is fueled largely by economic decline that is impacting all economic subsectors that were in a growth phase during the 1970s, such as the manufacturing, tourism, agro-industry, and agricultural export industries. The decline has also been reflected in a simultaneous process of decapitalization of the other branches of the rural economy. Now that political stability has been restored, while the establishment of a macroeconomic framework and modest but sustained economic growth over the past four years represent significant strides, they fall short of meeting the legitimate aspirations of the Haitian people for a better life.

3 The drafting of the Growth and Poverty Reduction Strategy Paper (DSNCRP) reflects the desire of the Haitian Government to respond appropriately to the aspirations of the Haitian people and to the major growth and poverty reduction challenges. The DSNCRP is therefore a follow up, first, to the Interim Cooperation Framework (ICF) prepared with the help of the International Community in 2004, second, to the strategy targeting the major work areas [Grands Chantiers] submitted by the Government to the International Conference on Economic and Social Development in Haiti held in Port-au-Prince on July 25, 2006, and third, to the Interim Poverty Reduction Growth and Poverty Reduction Strategy Paper of September, 2006. The drafting has benefited from a long participatory process involving the principal state and non-state actors, ensuring its ownership by the entire population.

\section{The Participatory Process}

The participatory process was identified on the basis of previous experience with Haiti, lessons learned, and recommendations made at information/training workshops held during the I-PRSP drafting process in 2005. It was conducted through a series of meetings, gatherings, seminars, workshops, and forums held at all levels (sectoral, local, departmental, and national) with the aim of ensuring the broadest possible participation of the various partners.

These partners, particularly the poor themselves, include vulnerable groups; organized civil society groups: the press, trade unions, cooperative entities, professional associations, chambers of commerce and industry, human rights organizations, women, young people, etc.; the formal and informal business sectors; central, deconcentrated, and decentralized state administrations; autonomous state institutions; universities; NGOs; members of parliament; locally-elected officials (Mayors and CASEC [Conseil d'administration de section communal], grassroots organizations and/or associations, aid or multilateral and bilateral cooperation agencies, etc. 


\section{Description of the Process}

6 This participatory process, one of the major components of the Growth and Poverty Reduction Strategy Paper (DSNCRP), entailed two phases: awareness-building/consultation and participation. The first phase - awareness-building/consultation - involved three kinds of workshops: awareness-building workshops, thematic workshops, and departmental workshops. The second phase (participation) entailed a three-step process: municipal validation forums [forums communaux de validation FCV], departmental validation forums [forums départementaux de validation FDV], and the national validation forum [forum national de validation $\mathrm{FNV}]$.

\section{First Phase}

7 Ten awareness-building workshops were organized in Port-au-Prince with a view to providing information to the various actors on the objectives, issues, and features of the DSNCRP. These workshops brought together 350 representatives from the Government, Parliament, central, deconcentrated, and decentralized administrations, NGOs, and organized civil society groups.

8 Ten thematic workshops were organized with the participation of more than 200 specialists from the public and private sectors, as well as associations, for purposes of stocktaking, assessment, analysis, and identification of alternative policies with respect to the different sectors. Human development, good governance, and growth vectors were the main topics discussed.

9 Ten departmental workshops were also held with the aim of building the awareness of participants regarding the process, sharing or testing the outcomes of thematic workshops, and identifying assessment, analytical, and forecasting tools for each geographic department in the country. These workshops brought together 1,500 participants representing the state sectors and civil society.

\section{Second Phase}

10 Ten municipal validation forums (FCVs) were organized in the ten municipalities classified as the poorest (in terms of access to educational services, health, running water, and sanitation), with a view to discussion and validation by the local and sectoral actors of the outcomes of thematic and departmental workshops. These forums brought together a total of 1,000 participants, and discussions naturally revolved around the poverty existing in these municipalities and ways to address it.

11 Four departmental validation forums (FDVs) took place (North, Central, West, and South), with the aim of validating public policy proposals in the areas of education, health, agriculture, rural development, and infrastructure, along with one AGORA, which entailed proposals in the areas of tourism, the environment, risk and disaster management, gender equality, and territorial development. Participating in these forums were 1,400 locally-elected officials, women's associations, youth associations, and other groups representing the four geographic departments in question.

12 At the end, the national validation forum (FNV), which was held in Port-au-Prince on September 26, 2007, brought together more than 800 participants representing the main national and international actors in the public and private sectors and associations. The objective was to validate and build a consensus around the outcomes of all the preceding phases.

13 The outcomes of the nine-month participatory process involving 5,200 persons can be summarized as follows:

- Better understanding of the objectives of the DSNCRP;

- Provision of information to and mobilization of the contributors, populations, and development partners with respect to the themes of growth and poverty reduction;

- Coming together of the various stakeholders for purposes of discussion, participation, prioritization, decision-making, implementation, and monitoring and evaluation of the activities identified to assist with growth and poverty reduction; 
- Buy in by the population of the public policies and priority actions selected for implementation and monitoring and evaluation of the DSNCRP;

- Commitment to build capacity to gather, process, and disseminate information at both the levels of the public sector and civil society organizations through the establishment of an Observatory of Poverty and Social Exclusion [Observatoire de la Pauvreté et de l'exclusion sociale ONPES]; and

- Commitment to build the capacity of civil society organizations with a view to having them participate fully in the process through the identification and ongoing evaluation of groups and/or grassroots organizations.

14 The departmental, sectoral, and national gatherings, meetings, and workshops focused on the following themes and sectors:

o Pro-poor growth (agriculture, industry/trade/crafts, roads/transport, electricity, tourism, and science and technology);

o Governance and institutional reforms (justice system/rule of law, fiscal transparency, public management modernization/decentralization, and territorial management);

- Development of the social sectors (health/HIV/AIDS, education, water/sanitation;

- Sectoral and departmental socio-economic assessments (development constraints, assets and potential, main intervention areas, and priority actions;

- Sectoral and departmental assessments of human poverty (access to educational services, health services, running water, sanitation services, and housing;

o Cross-cutting sectors (poverty and children, gender issues, border, maritime, and adjacent island problems, urban and rural development, the environment, and risks and disasters.

15 Several information, orientation, and summary documents on these themes and sectors were prepared by the Technical Secretariat of the DSNCRP Drafting Committee and distributed as widely as possible to partners for purposes of consideration, discussion, analysis, feedback, and advice, with a view to the improvement and ownership of these documents. 


\section{Institutional Framework}

\section{National Level: DSNCRP Drafting Committee}

16 Established by Presidential Decree on December 5, 2006, this committee spearheads the entire PRSP process. Its mission is to determine major political and strategic thrusts and to lead the DSNCRP drafting process at the national, departmental, and local levels. The Drafting Committee's composition is as follows:

- The Prime Minister or his representative (Chairman);

- The Minister of Planning and External Cooperation or his representative (Vice Chairman);

- The Minister of Economy and Finance or his representative, (Vice Chairman);

- The President of the Haitian Medical Association, representing the socio-professional sector (Member);

- The President of the Haitian Chamber of Commerce and Industry, representing the commercial private sector (Member);

- The President of the Administrative Council of the VETERIMED Non-Governmental Organization, representing the NGO sector (Member);

- The rector of QUISQUEYA University, representing academia (Member); and

- One trade union leader, representing the trade union sector (Member).

\section{Donor Support Committee (CABF)}

17 The committee guided and supported the drafting process of the full DSNCRP. It was composed of the resident representatives of seven bilateral and multilateral development assistance agencies in Haiti whose mission is to support the coordination and harmonization of donor involvement in the preparatory process and the drafting of the DSNCRP. Consultative meetings were held on a regular basis with the coordination office of the Drafting Committee operating under the oversight of the Minister of Planning and External Cooperation in order to share ideas, government guidelines, information, and progress made with the drafting of the full DSNCRP. These meetings also facilitated joint identification and programming of the technical and financial assistance activities that may be requested by the Government to assist with the drafting of the full DSNCRP.

\section{Technical Secretariat (TS)}

18 The Technical Secretariat spearheaded all activities related to the planning and drafting of the Growth and Poverty Reduction Strategy Paper (DSNCRP). This Technical Secretariat was composed of a core group of experienced technical experts specializing in the management of development programs and projects and was headed by a coordinator. A certain number of local part-time specialists were hired on an as-need basis and received assistance from officials serving as focal points in ministries and institutions. The Haitian Government assumed responsibility for the operating procedures of the Technical Secretariat, with financial and technical support from bilateral and multilateral assistance agencies.

\section{Departmental and Local Levels: Departmental Coordination (DC)}

19 The Ministry of Planning and External Cooperation (MCPE), working through its various departmental offices and with the assistance of the representatives of the relevant sectors, coordinated departmental participatory workshops and forums in each geographical department in order to draft the departmental component of the DSNCRP. "Departmental Consultation Tables (DCTs)," which provide a forum for the participation of all state and non-state actors in the various departments, were included in the process. 
20 DCTs are expected to allow the various local development actors to receive the appropriate technical training and guidance that would allow them to play a liaison role with respect to the National Observatory on Poverty and Social Exclusion (ONPES) and to be able to monitor, based on the key indicators established, trends in the poverty and social exclusion situation as well as the MDGs in the localities included in the DSNCRP's Three-Year Action Plan. Every institution or resource individual participating in this forum will do so as a member of a grassroots network that gathers information and assimilates practices that can help monitor DSNCRP priority actions, with coordination work being handled by the departmental office of the Ministry of Planning and External Cooperation.

\section{The Structure of the Paper}

21 The paper contains six sections. The first provides an assessment of poverty and inequality using the most recent survey data available. The second outlines the vision of state and non-state actors as well as the challenges to be met by 2015 . The third presents the policies and strategic sectoral areas of intervention which include the major work areas [Grands Chantiers] identified by the Haitian Government at the July 25, 2006 International Conference. These areas have been reorganized in such a way as to fall under three main pillars: growth vectors, human development, and governance. These three pillars are supported by twelve targeted or crosscutting thematic areas, namely: (i) gender equity; (ii) human rights; (iii) the environment; (iv) disaster and risk management; (v) combating HIV/AIDS; (vi) scientific and technological innovation; (vii) childhood poverty; (viii) youth employment; (ix) local border development; and (x) capacity-building. The fourth section pertains to the macroeconomic framework and stabilization and growth objectives. The fifth section covers the quantification, financing, and institutional framework for implementation and monitoring of the growth and poverty reduction strategy. 


\section{CHAPTER 1}

\section{The Scope of Poverty and Inequality}

22 Haiti is mired in abject poverty which is driven by sharp inequalities. This is borne out by any method used to measure poverty - monetary, human, or even a subjective method.

\section{Income, Poverty, and Inequality}

23 Available indicators for assessing monetary poverty were prepared on the basis of three surveys: the two Surveys on Household Consumption Budgets (ECBMs) conducted in 1986-1987 and 1999-2000 and the Survey on Living Conditions in Haiti (ECVH) conducted in 2001. At the moment, the Haitian population stands at over 9.6 million, 5 million of whom live in rural areas (4.96 million according to the IHSI 2003). Based on the findings of the ECVH, in 2001, 56 percent of the Haitian population (4.4 million of a total population of 8.1 million) lived below the extreme poverty line of US\$1 PPP per person, per day. Approximately 7.6 of every 10 persons are considered poor and live on less than US\$2 PPP per person, per day. Among the poorest population groups, 40 percent have access to a mere 5.9 percent of total income, a situation that points to a high concentration of the population in the low-income group, while the most affluent 20 percent controls 68 percent of this income. Consequently, 80 percent of the population controls a mere 32 percent of income. The middle class is therefore very small, particularly in light of the fact that 2 percent of the wealthiest segment controls 26 percent of total income.

Table 1

Poverty and Extreme Poverty in Haiti

\begin{tabular}{|c|c|c|c|}
\hline \multicolumn{2}{|c|}{ Index by number of inhabitants } & \multicolumn{2}{c|}{ Number of persons } \\
\hline $\begin{array}{c}\text { Extremely poor } \\
\text { (less than US\$1 PPP per day) }\end{array}$ & $\begin{array}{c}\text { Poor } \\
\text { (less than US\$2 PPP per day) }\end{array}$ & & Poor \\
\hline $\mathbf{5 6 \%}$ & $\mathbf{7 6 \%}$ & $\mathbf{4 , 4 5 0 , 0 0 0}$ & $\mathbf{6 , 2 0 0 , 0 0 0}$ \\
\hline
\end{tabular}

Source: ECVH and EBCM

24 The decline in GDP over the past 20 years explains why the situation of wage earners has not changed much. This situation is offset by self-employment, which accounts for 43 percent of the income earned in rural areas. The income structure seems to be more diversified in the metropolitan area, with a breakdown of approximately 30 percent for each main source of income, namely self-employment, wage earners, and remittances. Although remittances account for only 19 percent of total income, their contribution to income inequality relative to other sources of income is over 50 percent.

25 The structure of household expenditure indicates that a much bigger portion goes toward food expenditure among the poor, as happens in any other poor economy. For the bottom quintile, this figure is 53.4 percent, while for the top quintile, it is only 9.8 percent. The same applies to educational expenditure, which accounts for 3.1 percent for the bottom quintile compared to 1.2 percent for the top quintile. The percentage of income spent on food is also much higher in rural areas (55.6 percent) compared to 32.8 percent in the metropolitan area and 41 percent in other cities. In general, health and education and leisure expenditure is low, accounting for 3.3 percent and 3.2 percent respectively of actual household consumption throughout the country. Education and leisure expenditure is lower in rural areas (2.7 compared to 3.7 percent elsewhere).

26 Income or consumption inequalities among regions (metropolitan area, other urban or rural areas) account for 17 percent of overall inequalities, while inequalities within these various areas account for 83 percent of inequalities. Inequalities among the socio-professional categories account for 6.38 percent of overall inequalities. Inequalities relative to age and gender play a much less significant role (1 percent in the case of age). 


\section{Human Poverty and Inequality}

27 For Haiti, the indicators included in the human poverty index are alarming. Life expectancy at birth is estimated at 58.1 percent (2000-2005). Maternal mortality rose from 457 to 630 per 100,000 live births between 1990 and 2005. The illiteracy rate, which stood at 39 percent in 2003, remains high, even though progress has been made from one generation to the next. Only 49 percent of school age children attend school. This low level of instruction is reflected in limited capacities. In 2001-2002, only 45 percent of the population between the ages of 6 and 24 was enrolled in a school or university. The degree to which food needs are met in Haiti is low. More than half the population is unable to obtain the minimum food ration established by FAO of 225 kcal per year, per individual. A WFP report on food security and vulnerability showed that households that face food insecurity ${ }^{1}$ do not have adequate income and have a low level of access to such basic essential services as drinking water and health facilities, particularly in rural areas and shantytowns, where only 25 percent of inhabitants have access to drinking water and very few persons have access to adequate health facilities. Overall, these households have a low level of access to health care and markets and low levels of education and schooling. Access to basic social services remains very limited - more than 77 percent in the 133 municipalities (2002) lack basic services.

\section{The Perception of Poverty by Households}

28 In the view of households, the degree to which their basic needs are met is very limited, particularly in rural areas. The problem is even more acute in the case of food and health. In rural areas, only 13.1 percent of households think that they can meet their basic food needs and 9 percent think that they can address their health problems, compared to 33 percent and 28 percent in the metropolitan area (La parole des Haïtiens, Haiti, p.54). Throughout Haiti, four of every five households indicated that they are unable to properly meet their foods needs. These households indicated that a reduction in their food ration is their first line of action in such situations. Approximately 32 percent of households indicated that they would use potential additional income to improve their food situation; 24 percent, for the education of their children; and 23 percent, for housing. Barely 9.6 percent of self-employed heads of household working in agriculture indicate that they are able to meet their food needs. Data indicate that poverty and vulnerability are widespread in both the rural and urban areas.

29 More than 70 percent of heads of household think that poverty has increased, particularly in recent years. Job creation, controlling inflation, and access to land are the primary measures recommended by households to address poverty. They appear to view the problem largely in terms of purchasing power and access to the means of production.

\footnotetext{
${ }^{1}$ This survey was conducted in four departments: West, North, North-East, and Central Plateau.
} 


\section{CHAPTER 2 \\ The Characteristics and Driving Factors of Poverty in Haiti}

\section{Poor Groups and Vulnerable Groups}

30 The poverty profile indicates that rural areas (63 percent of the population) account for a higher level of extreme poverty. For every 100 persons in Haiti who indicate their inability to meet their basic food needs, 77 live in rural areas, 9 in the metropolitan area, and 14 in other cities. Selfemployed workers, particularly agricultural workers, account for a much bigger portion of extreme poverty, a situation that reflects the lack of opportunities in rural areas, the low level of agricultural yield owing to small size of land plots, the lack of access to credit and inputs, the use of unsophisticated tools, isolation, and scant infrastructure.

31 The situation of street children, orphans (particularly those affected by HIV/AIDS), and juvenile delinquents is disturbing. In the absence of assistance, these persons are in a very precarious situation. Their situation extends the cycle of poverty from one generation to the next and exacerbates urban crime. These children, who live in difficult circumstances, are often from the rural areas and usually have lost their mother or are living with their mother only.

32 The population over age 65 stands at 5.1 percent. This group is very vulnerable. Widespread unemployment and the absence of a social security system account for the very precarious situation in which many of these elderly people find themselves. Urban households where a woman is the main wage earner are vulnerable. According to the ECVH, 61 percent of households in the metropolitan area that have a woman as the main wage earner live in extreme poverty. In households in provincial cities, this figure is 59 percent.

\section{Poverty and Inequality by Place of Residence}

33 The incidence of poverty and extreme poverty is clearly higher in rural areas. Extreme poverty is almost three times higher in rural areas than in the metropolitan area. The vast majority of the poor ( 74 percent) live in rural areas where agriculture is the main activity and basic services are virtually non-existent. Agriculture provides a source of employment for 69 percent of working individuals in rural areas, 25 percent of whom work in the tertiary sector (commerce, services). In cities, working individuals are found mainly in the commercial and service sectors.

Table 2

Incidence of Poverty in Haiti by Place of Residence

\begin{tabular}{|l|c|c|c|c|c|}
\hline \multicolumn{1}{|c|}{$\begin{array}{c}\text { Place of } \\
\text { Residence }\end{array}$} & $\begin{array}{c}\text { Incidence of } \\
\text { extreme } \\
\text { poverty }\end{array}$ & $\begin{array}{c}\text { Incidence of } \\
\text { overall } \\
\text { poverty }\end{array}$ & $\begin{array}{c}\text { Contribution } \\
\text { to extreme } \\
\text { poverty }\end{array}$ & $\begin{array}{c}\text { Depth of } \\
\text { poverty }\end{array}$ & $\begin{array}{c}\text { GINI } \\
\text { Index }\end{array}$ \\
\hline $\begin{array}{l}\text { Metropolitan } \\
\text { Area }\end{array}$ & 23 & 45 & 9 & 0.10 & 0.523 \\
\hline $\begin{array}{l}\text { Other Urban } \\
\text { Areas }\end{array}$ & 57 & 76 & 14 & 0.33 & 0.639 \\
\hline Rural Area & 67 & 88 & 77 & 0.37 & 0.629 \\
\hline Total & $\mathbf{5 6}$ & $\mathbf{7 7}$ & $\mathbf{1 0 0}$ & $\mathbf{0 . 3 1}$ & $\mathbf{0 . 6 5 3}$ \\
\hline
\end{tabular}

Source: Poverty profile, FAFO 2005.

34 According to a WFP study, ${ }^{2}$ the average distance of zones in relation to main roads is positively correlated with the level of food insecurity. Cities, other than the metropolitan area, also have high poverty rate, although their contribution to poverty is much lower than in rural areas -14 percent compared to 77 percent.

\footnotetext{
${ }^{2}$ World Food Program, Rapport d'évaluation de la vulnérabilité et de l'insécurité alimentaire, Sept-Oct 2004.
} 


\section{Gender, Poverty, and Inequality}

35 The incidence of extreme poverty in households where a female is the main wage earner (58 percent) is significantly higher than in households where the main wage earner is male (53 percent according to ECVH data). The incidence of extreme poverty is 26 percent among households where a female is the main wage earner in the metropolitan area, as opposed to 17 percent where the main wage earner is male. In other urban areas, the percentages are as follows: 64 percent among females and 48 percent among males.

36 According to the 2000 Survey on Household Consumption Budgets, almost 48 percent of consumption inequality is attributable to the gender of the head of household. Average consumption is therefore much lower for those households where the main wage earner is a female, and inequalities in the social sphere and in the area of skills seem more marked among women than men. For the most part, women are in low-skilled professions. They represent a mere 43.9 percent of persons in intellectual and scientific professions; 36.5 percent in mid-level professions; and 32.3 percent in administrative positions. The level of education of women is generally lower than that of men, which explains in part their more unfavorable position in the employment market.

37 Almost 40 percent of the population age 10 and over is illiterate (IHSI 2003). This is the case of 42 percent of women versus 36 percent of men. Disparities between the sexes are lower at the primary level but become more pronounced at the higher educational levels. At the moment, boys spend more time in school than girls during the first two cycles. The duration of time spent in school by girls is two years and eight months compared to a general average of three years and nine months.

\section{Education and Poverty}

38 The education system in Haiti is a highly exclusionary one that contributes to the perpetuation and reinforcement of inequalities through limited access to schools, particularly in rural areas, and differences in the quality of schools, the result being that generally, poorer children have access to low-quality education only and the cost of education is relatively high in relation to the income of families, who cover most of their educational expenses. Only 21.5 percent of the population age five and over will be educated at the secondary level and barely 1.1 percent at the university level (1.4 percent for men against 0.7 percent for women).

39 At the moment, almost one-third of children between the ages of six and twelve $(500,000$ children) do not attend school. This percentage climbs to 40 percent for the five to fifteen age group (approximately one million children). The dropout rate is particularly high in the first basic cycle (29 percent). Close to 60 percent of children drop out of school before receiving their primary education certificate. Of the two million children enrolled in the basic level, only 56 percent are at the required age for the first cycle (ages six to eleven).

40 Most schools do not have adequate facilities and are under-equipped. According to the 2003 school survey, five percent of schools are housed in a church or an open-air shaded area. Some 58 percent do not have toilets and 23 percent have no running water. This situation is highly prejudicial to girls. In addition, only 36 percent of schools have libraries. The vast majority of workers ( 80 percent) do not meet the existing criteria for the selection of training programs or are not accepted in these programs because of the lack of space in professional schools. Only 6 of every 1,000 workers on the labor market have a diploma or certificate in a technical or professional field. 


\section{Employment and Poverty}

41 The open unemployment rate, estimated at approximately 30 percent for the entire country, is higher in urban areas (62 percent among young people ages 15 to 19). Demographically, the population is young (the fact that 56.4 percent is at most age 18 makes unemployment one of the country's main social problems).

Table 3

Unemployment Rate by Population Age Group (Age 10 and over) and by Gender and Place of Residence

\begin{tabular}{|c|c|c|c|c|c|c|}
\hline & Overall & \multicolumn{2}{|c|}{ Gender } & \multicolumn{3}{|c|}{ Place of residence } \\
\hline & & Women & Men & Rural Area & $\begin{array}{c}\text { Urban Area } \\
\text { (outside } \\
\text { metropolitan } \\
\text { area) }\end{array}$ & $\begin{array}{c}\text { Metropolitan } \\
\text { Area }\end{array}$ \\
\hline $10-14$ yrs. & 48.6 & 62.9 & 39.4 & 36.5 & 59.5 & 88.5 \\
\hline $15-19$ & 61.9 & 70.7 & 54.5 & 44.8 & 65.2 & 89 \\
\hline $20-24$ & 50 & 55.9 & 45.1 & 35.5 & 52 & 66 \\
\hline $25-29$ & 36.3 & 41.9 & 31.6 & 24 & 35 & 50.5 \\
\hline $30-34$ & 25.9 & 30.3 & 21.6 & 19.2 & 19.7 & 36.1 \\
\hline $35-39$ & 18.2 & 23.9 & 12.7 & 14.3 & 13.4 & 26.1 \\
\hline $40-44$ & 13.1 & 16.3 & 10.2 & 10.4 & 10.5 & 20 \\
\hline $45-49$ & 13.4 & 18 & 8.9 & 11.2 & 3.8 & 22.7 \\
\hline $50-54$ & 13.8 & 17.7 & 10.5 & 8.5 & 9.1 & 34.4 \\
\hline $55-59$ & 15.4 & 17.8 & 13 & 14 & 17.3 & 24.8 \\
\hline $60-64$ & 10.3 & 11.8 & 9.2 & 8.4 & 14 & 19 \\
\hline 65 years + & 8.1 & 8.5 & 7.6 & 7.2 & 7.4 & 19.1 \\
\hline Total & 27.4 & 32.1 & 23.4 & 18.9 & 26.7 & 45.5 \\
\hline
\end{tabular}

Source: IHSI/ECVH (2001)

42 Women have fewer employment opportunities regardless of their age. As a result, a bigger proportion of women are self-employed (83 percent compared to 73 percent for men), largely in the field of business.

43 Although agriculture accounts for 51 percent of total agriculture, this sector accounts for only approximately 25 percent of GDP. In addition, one-quarter of household income is derived from remittances which are generally not received on a regular basis; 37 percent comes from selfemployment involving varied activities which, for the most part, are small-scale and do not provide a stable source of income. According to ECVH data, in 24 percent of households, there are no individuals who work.

\section{Access to Basic Services}

44 The country is greatly deficient in such basic social services as education, water, health, and sanitation. In 2002, only two of the 133 municipalities had a greater level of access. 
Table 4

Access to Social Services by Department

\begin{tabular}{|l|c|c|c|c|c|c|}
\hline \multirow{3}{*}{ Department } & \multicolumn{6}{|c|}{ Level of access to basic social services/number of municipalities } \\
\cline { 2 - 7 } & $\begin{array}{c}\mathbf{1} \\
\text { Extremely low }\end{array}$ & $\begin{array}{c}\mathbf{2} \\
\text { Very low }\end{array}$ & $\begin{array}{c}\mathbf{3} \\
\text { Low }\end{array}$ & $\begin{array}{c}\mathbf{4} \\
\text { Fairly low }\end{array}$ & $\begin{array}{c}\mathbf{5} \\
\text { Not } \\
\text { very low }\end{array}$ & Total \\
\hline Artibonite & 2 & 8 & 4 & 1 & & 15 \\
\hline Center & 5 & 5 & 1 & 1 & & 12 \\
\hline Grande Anse & & 10 & 5 & 3 & & 18 \\
\hline North & 1 & 2 & 11 & 5 & & 19 \\
\hline North East & 1 & 1 & 5 & 5 & 1 & 13 \\
\hline North West & 1 & & 5 & 4 & & 10 \\
\hline West & 1 & 4 & 5 & 7 & 1 & 18 \\
\hline South & 1 & 2 & 13 & 2 & & 18 \\
\hline South East & 2 & 5 & 2 & 1 & & 10 \\
\hline Total & $\mathbf{1 4}$ & $\mathbf{3 7}$ & $\mathbf{5 1}$ & $\mathbf{2 9}$ & $\mathbf{2}$ & $\mathbf{1 3 3}$ \\
\hline
\end{tabular}

Source: 2004 version of the poverty map

45 Several health indicators reflect the acute problem with health care access. Trained medical staff assist with only 24 percent of births, a factor that in large measure explains the high maternal mortality rate. Infant mortality has declined significantly but remains high. The risk of dying before age 5 is 86 percent. Acute respiratory infections (colds, pneumonia), malnutrition, and infectious diarrhea and gastroenteritis are among the mains causes of infant deaths.

46 Despite the implementation of an expanded vaccination program, only 41 percent of children between the ages of 12 and 23 have been fully vaccinated (against 34 percent in 2000), and 11 percent have not received any vaccinations at all. This coverage differs by area. It is higher in the secondary cities (48 percent) than in the metropolitan area (41 percent) and rural areas (40 percent). In the 5 to 14 age group, mortality and morbidity rates have fallen. However, infectious diseases, typhoid, tuberculosis, and malaria, along with respiratory infections, pose the biggest problem. For young people, sexually transmitted infections and unwanted pregnancies are major areas of concern. The prevalence of HIV/AIDS is clearly higher in urban areas than in rural areas. Poverty increases the risk of infection given that the poor, in particular women, are more vulnerable.

47 Health problems are compounded by inadequate drinking water coverage, although some improvement is being made in this area. Coverage rates are estimated at 54 percent for Port-auPrince, 46 percent in secondary cities, and 46 percent in rural areas. Drinking water systems put in place in rural areas in the 1980 s are deteriorating owing to a lack of maintenance.

Table 5

Coverage of Water and Sanitation needs

\begin{tabular}{|l|c|c|}
\hline & Coverage of water needs & Coverage of sewage needs \\
\hline Port-au-Prince & $54 \%$ & $46 \%$ \\
\hline Other cities & $46 \%$ & $23 \%$ \\
\hline Rural areas & $48 \%$ & \\
\hline
\end{tabular}

Source: PAHO/WHO 


\section{CHAPTER 3}

\section{The Poverty and Inequality Situation between 1986 and 2006}

\section{Growth, Poverty, and Inequality}

48 Between 1987 and 2000, poverty dipped slightly while inequality increased. The decline in the incidence of poverty from 55.5 percent to 50.56 percent was accompanied by a smaller reduction in the severity and depth of poverty. The more marked nature of inequality became a critical factor in poverty reduction in 2000 relative to 1987 , owing largely to the rise in inequality. Heightened inequality between 1987 and 2000 dampened the positive effect of the increase in average consumption. While the increase in average consumption is projected to have led to a 12.79 percent increase in poverty, inequality increased by 6.7 percent; consequently, the net impact on the incidence of poverty was only 4.96 percent, allowing for the negative effect of unidentified residual factors.

49 It is a fact that growth promotion is a guaranteed way to reduce poverty. However, tackling redistribution also is twice as efficient as a growth policy only, if the situation of the most disadvantaged is to be improved. A sustainable poverty reduction strategy should focus on both growth and proactive equity policies.

\section{The Driving Factors of Poverty in Haiti}

50 Poverty, monetary inequality, and living conditions are closely associated with unequal opportunities in terms of access to resources and such benefits as credit, infrastructure, social capital, and education. Haiti's system of values, the low level of basic social services, poor housing conditions, actual poverty traps, the inability to participate in and guide public decisions, and the lack of social networks for the poorest are all factors that contribute to poverty and inequality. This situation is also the result of public policies that affect redistribution and guide the development and allocation of resources. In Haiti, poverty is essentially tied to a historical process of building political power and organizing the economy around the interests of a minority.

\section{Income and Asset Distribution}

51 Poverty is essentially linked to the unavailability and underutilization of assets, particularly education, labor, physical capital, credit, social capital, and basic services. The marginal benefit of education is, however, greater in the urban setting, more so in secondary cities than in the metropolitan area, which points to disparities in the conditions and opportunities for using capacities, particularly available socioeconomic infrastructures, markets, and access to credit. Income distribution is often linked to the distribution of assets.

52 Analysis of the situation relative to the main factors: work, education, capital, and socioeconomic infrastructures (electricity, communication routes, running water) support the view that the root causes of poverty and inequality lie essentially in the lack of opportunities, unequal distribution of assets, and constraints related to their use.

\section{Structural Changes and Poverty}

53 Trends in poverty are linked to structural changes that have accompanied growth/decline cycles and restructuring of the Haitian economy. Policy weaknesses and shortcomings also play a role. The structural reforms undertaken since the early 1980s have not adequately measured their impact on distribution and the structural constraints of the economy. Liberalization and deregulation policies implemented have rarely been followed up by initiatives to strengthen the supply area. 


\section{Demography and Poverty}

54 The demographic picture can be described as follows: (i) Rapid growth - annual average demographic growth rose from 1.4 percent between the 1971-1982 surveys to 2.5 percent during the 1982-2003 period; (ii) rapid urbanization, at the rate of 4.9 per year, with 40 percent of the current population living in cities compared to 25 percent in 1982; and (iii) a young population. Only 7.4 percent of the population is over age 60 while a figure of 20 percent of the population in this group is required to label a population as aging. Persons under age 15 account for 36.5 percent of the population, while 58.4 percent of the population is between the ages of 15 and 64 . While such a structure should offer potential for future growth of the economy, in the present context it constitutes a powder keg, given that demographic growth is most rapid among the poorest, which creates a situation of entrapment in terms of population growth and increased poverty, since demographic growth fuels greater poverty.

55 At the present rate, the population should double in approximately 30 years. The preliminary results of the EMMUS IV point to a decline in the average number of children per woman, although this number still remains high. The synthetic fertility index is projected to be four children per woman. The decline is too slow to contain rapid demographic growth. Furthermore, female fertility is high among the 15 to 19 age group (69 percent), and peaks at 180 per thousand in the 30 to 34 age group. The birth rate of 28 live births per 1,000 inhabitants is higher in rural areas (30 percent) and among low-income groups. Changing demographic patterns therefore pose a major challenge which entails fostering social development by providing opportunities to the poorest and young people. 


\section{CHAPTER 4}

\section{The Major Challenges to be Faced by 2015}

56 Endemic and widespread poverty among the population serves as a conscience call for all Haitians in the country as well as those in the big Haitian Diaspora. However, any poverty reduction effort, in order to be effective, must take into account the following four major challenges: (i) placing Haiti in a strong position to make up for time lost with respect to the MDGs.

57 Assessments done of the food, health, education, and gender issues indicate that in 2015, Haiti will still fall well short of meeting its goals, despite certain areas of progress; (ii) developing a modern and dynamic economy that has a broad territorial base and is competitive. The changes seen in Haiti in recent decades have destroyed the main branches of its economy in cities and rural areas and have led to rapid deterioration of all services; (iii) undertaking a far-reaching overhaul of the public management system. The political, economic and social upheavals that have taken place in the country in recent decades have undermined its administrative system and, as a result, have seriously compromised its capacity to deliver.

58 The 1987 Constitution includes a series of provisions that can lead to in-depth reform of the public administration and trigger a meaningful process of decentralization; and (iv) developing skills in Haiti. Over time, the country has demonstrated tremendous cultural creativity. Its cultural capital, which is diverse and internationally recognized, has been inadequately developed. Haiti's cultural capital is a major asset that it can use to take advantage of globalization.

59 Meeting these major challenges requires the unprecedented mobilization of human, organizational, and financial resources. Work to be done will be adjusted based on time and on the numerous other constraints hobbling Haiti's development. Strategic choices must be made based on essential priorities, given the opportunities available.

\section{First Phase}

\section{Laying the Foundation for Future Development}

60 This phase covers the 2007/08 - 2009/10, the three-year period of implementation of economic and financial commitments made in the context of the IMF's PRGF. During this phase, growth will be slow or modest (according to the Ministry of Economy and Finance, an annual average of 4 percent). The focus will be mainly on accelerating social development.

61 A campaign to promote the DSNCRP will be conducted on two fronts: (i) disseminating a vision of development as a way to put Haiti on a path of hope and building a new form of national unity; and (ii) establishing leadership alliances around the development strategy selected.

62 The main mechanism to ensure consistency of the overall strategy adopted is the central, deconcentrated, and decentralized public administration system, which is stymied by a number of problems that prevent it from effectively delivering the results expected. For this reason, in order to pursue and diversify the recently-adopted initiative to improve governance, priority will be given to the public administration capacity-building process. This first phase involves maintaining the current macroeconomic framework centered on sound management of the economy with prudent fiscal and monetary policies being applied to reduce significantly major internal and external economic imbalances. For example, according to MEF forecasts, the downward trend in inflation should continue until it reaches 7 percent in 2008/2009.

63 In order to reduce monetary poverty and promote pro-poor growth, the Government, while pursuing its activities in the various areas of intervention, has identified the following economic sectoral priorities for this period: (i) modernizing agriculture by upgrading rural infrastructure and making a number of services available to farmers through training, research, and dissemination of technological packages, as well as the provision of credit, inputs, equipment, and tools; (ii) reestablishing food production in order to better ensure the food security of the population; (iii) strengthening the effort to modernize transportation infrastructure; (iv) improving the provision 
of electricity and developing telecommunications services; and (v) promoting greater social equity through education and health, which will constitute the main approach to reducing poverty and inequality during the period.

64 The education strategy will emphasize: (i) reorganizing access to schools in a way that benefits poor children; (ii) retraining teachers and school principals; (iii) guiding schools, teachers, and parents more effectively; and (iv) improving coordination among operators in the sector and the regulation of the system.

65 The health strategy seeks to give priority to: (i) strengthening municipal health units [Unité Communale de Santé, UCS]; (ii) focusing on endemic illnesses; (iii) strengthening governance of the sector; and (iv) developing human resources and implementing a hospital management policy.

\section{Second Phase}

\section{Strengthening Progress and Taking Systematic Advantage of the Main Identified Opportunities}

66 This phase will begin at the start of FY 2009-2010. The main focus of this phase will be on striving for accelerated growth and greater control over social development. Consequently, the emphasis during this phase will be on reducing both monetary and human poverty. Once severe constraints are lifted owing to the progress made during the first phase, a more optimistic growth scenario can be expected - strong trend growth of 7.5 percent until 2015 (two and a half times the growth rate in the 1970s) and a decrease in the fertility rate, falling to two or three children per family instead of the big families that are now commonplace.

67 The macroeconomic framework will be reoriented to make it more attractive to the other economic sectors where potential can be more easily used, such as the highly promising areas of the agricultural sector, agro-industry, tourism, and the textile sector of the manufacturing industry, which will benefit if they are accorded priority. In such a context, the Central Bank should no longer focus solely on reducing inflation. During this second phase of the social and economic development strategy, it should also focus on growth and job creation.

68 In a bid to foster a rapid increase in productivity, an important factor in competitiveness in this globalized world, targeted and cross-cutting sectoral policies will be aimed at developing appropriate services while contributing to the establishment of a completely reformed business environment.

69 The earlier effort to overhaul basic infrastructure will continue in the areas of drinking water and sanitation, among others. At the same time, the Government will forge ahead with its effort to modernize the educational and health systems, and will set as a priority objective the provision of more accessible and better quality services to the population as a whole and in particular to vulnerable groups. Taking into account the difficulty in identifying significant savings and investment resources within a limited timeframe while great pressures are being felt (for example, to create widespread employment in a context of growing competition from the Dominican Republic), one of the strategies for creating the markets that will support the new Haitian economy will be to develop several growth hubs around targeted groups of activities that are specific to each zone identified. These hubs could serve as a powerful stimulant to growth acceleration in Haiti. 
Table 6

GROWTH AND DEVELOPMENT REGIONS/HUBS (2007 - 2015)

\begin{tabular}{|c|c|c|}
\hline NO. & IDENTIFICATION & POTENTIAL GROWTH \\
& & SECTORS \\
\hline 1 & Metropolitan Region & Industry/Commerce \\
2 & Cap-Haïtien/Fort-Liberté Axis & Tourism/Industry \\
3 & South-East Region & Tourism/Crafts \\
4 & Côte des Arcadins/La Gonâve Axis & Tourism/Technology \\
5 & Artibonite Valley & Agriculture \\
6 & Border zones & Commerce \\
7 & Nippes Region & Agriculture/Industry/Tourism/ \\
8 & Port- Salut/Dame-Marie Axis & Crafts/Agriculture \\
9 & Aquin Region & Commerce/Tourism \\
10 & Central Plateau & Agriculture/Livestock \\
11 & Port de Paix/Môle St Nicolas Axis & Farming/Commerce \\
\hline
\end{tabular}


Table 7

Major National Objectives - 2010-2015

\begin{tabular}{|c|c|c|c|}
\hline INDICATORS & 2006 & 2010 & 2015 \\
\hline Human Development Index (HDI) & $\begin{array}{l}132 \text { out of } 177 \\
\text { countries }(2006) \\
0.5559(2000- \\
2005)\left(^{*}\right) \text { HDI } \\
\text { ranking }\end{array}$ & $\begin{array}{c}120 \text { out of } 177 \\
\text { countries } \\
0.653 \text { (current } \\
\text { ranking of } \\
\text { Equatorial Guinea) }\end{array}$ & $\begin{array}{l}109 \text { out of } 177 \\
\text { countries } \\
0.709 \text { (current } \\
\text { ranking of } \\
\text { Vietnam) }\end{array}$ \\
\hline \multicolumn{4}{|l|}{$\begin{array}{l}\text { Extreme poverty rate }(\% \text { of the population } \\
\text { living on less thanUS } \$ 1 / \text { day) }\end{array}$} \\
\hline \multicolumn{4}{|l|}{$\begin{array}{l}\text { Poverty rate ( } \% \text { of the population living on less } \\
\text { than US } \$ 2 / \text { day) }\end{array}$} \\
\hline Family size (fertility index) & $\begin{array}{c}4 \\
(* *)\end{array}$ & $3.5(2005-2010)(* *)$ & $\begin{array}{l}2.9(2015- \\
2020)(* *)\end{array}$ \\
\hline Life expectancy & $\begin{array}{l}(2000-2005)\left({ }^{* *}\right) \\
58.1(\text { men and } \\
\text { women) } \\
56.4(\mathrm{M}) \\
59.9(\mathrm{~W})\end{array}$ & $\begin{array}{l}(2005-2010)(* *) \\
60.6(\text { men and } \\
\text { women) } \\
59(\mathrm{M}) \\
62.4(\mathrm{~W})\end{array}$ & $\begin{array}{l}(2015-2020)(* *) \\
64.2(\text { men and } \\
\text { women) } \\
62.4(\mathrm{M}) \\
66.2(\mathrm{~W})\end{array}$ \\
\hline Illiteracy rate (age 15 and over) & $\begin{array}{l}(2003)(* * *) \\
58.7 \% \text { (entire } \\
\text { country); } 63.1 \% \\
(\mathrm{M}) \text { and } 54.9 \% \\
(\mathrm{~W}) ; \\
79.5 \% \text { (urban) } \\
\text { and } 42.8 \% \text { (rural) }\end{array}$ & $\begin{array}{l}(* * * * *) \\
68.6 \%(\text { men and } \\
\text { women) } \\
71.1 \%(\mathrm{M}) \text { and } \\
66.2 \%(\mathrm{~W})\end{array}$ & $\begin{array}{l}(* * * * *) \\
76.8 \%(\text { men and } \\
\text { women) } \\
78.3 \%(\mathrm{M}) \text { and } \\
66.2 \%(\mathrm{~W})\end{array}$ \\
\hline \multicolumn{4}{|l|}{$\begin{array}{l}\text { Percentage of students who have completed the } \\
\text { basic school cycle }\end{array}$} \\
\hline \multicolumn{4}{|l|}{$\begin{array}{l}\text { Percentage of students who have completed the } \\
\text { secondary cycle }\end{array}$} \\
\hline \multicolumn{4}{|l|}{ Economic growth rate } \\
\hline \multicolumn{4}{|l|}{ GNP (US\$) } \\
\hline $\begin{array}{l}\text { Per capita GDP (in millions of gourdes - } \\
\text { 1986/87) }\end{array}$ & $\begin{array}{c}2005-2006 \\
13,079(* * * *)\end{array}$ & & \\
\hline \multicolumn{4}{|l|}{ Foreign Direct Investment (US\$) } \\
\hline $\begin{array}{l}\text { Ranking of the Business Environment (World } \\
\text { Bank) - Doing Business (Economic Rankings), } \\
\text { World Bank }\end{array}$ & 139 of 175 & $\begin{array}{l}117 \text { out of } 175 \\
\text { (current ranking of } \\
\text { the Dominican } \\
\text { Rep.) }\end{array}$ & $\begin{array}{l}105 \text { out of } 175 \\
\text { (current } \\
\text { ranking of } \\
\text { Costa Rica) }\end{array}$ \\
\hline $\begin{array}{l}\text { Corruption Perceptions Index (Transparency } \\
\text { International) }\end{array}$ & $\begin{array}{l}1.8 \text { (163 out of } \\
163)\end{array}$ & $\begin{array}{l}2.8 \text { (current ranking } \\
\text { of the Dominican } \\
\text { Rep.) }\end{array}$ & $\begin{array}{l}3.7 \text { (current } \\
\text { ranking of } \\
\text { Jamaica) }\end{array}$ \\
\hline Population & $\begin{array}{l}9,662,304(2007) \\
(* *)\end{array}$ & $\begin{array}{l}10,085,214(2010) \\
(* *)\end{array}$ & $10,911,819(* *)$ \\
\hline Urban population & $4,018,000(2005)$ & $4,818,000(2010)$ & $5,667,686$ \\
\hline Rural population & $5,274,000(2005)$ & $5,268,000(2010)$ & $5,244,133$ \\
\hline
\end{tabular}




\section{Chapter 5 \\ Pillar 1: Growth Vectors}

70 The National Growth and Poverty Reduction Strategy (DSNCRP) is part of a comprehensive vision of development in Haiti which entails two fundamental options: (i) sustainable human development based on the triptych of Economic Growth/Social Justice/ Environment; and (ii) a completely renovated public management system. It covers four key areas or growth vectors: agriculture and rural development; tourism; infrastructure modernization; and science and technology and innovation.

\section{AGRICULTURE AND RURAL DEVELOPMENT}

\section{Overall intervention strategy}

71 In the area of agriculture and rural development, the dual perspective of growth and poverty reduction is predicated on an approach that is at once both economic and social, and is aimed at scaling back the high degree of social polarization unfavorable to rural areas and at reducing the resulting exclusion. The choice entails the adoption of a system that combines various components of modern agriculture and takes account of the simultaneous existence of small, medium-sized, and large production units of various kinds.

72 This strategy requires that a number of conditions be met, including the redevelopment of the rural environment with zoning that guarantees the protection of our environment, the diversification of income-generating activities, and legal measures aimed at preserving the gains made in respect of development and improving the distribution of the wealth generated. Quite specifically, the redevelopment strategy must target two types of zones: those with a significant agricultural potential, and disadvantaged zones.

73 In the high potential zones (irrigated and humid plains, humid mountains), sustained efforts will be deployed with a view to intensifying production through the granting of loans for modernizing farms and agricultural enterprises and for enhancing their productivity. The less favored zones (dry and semi-arid plains, dry and semi-arid hills) will benefit from systematic and sustained extension work through various forms of declining subsidies either at the production level (prices of inputs such as seeds, fertilizer, tools, and equipment) or at the level of marketing production (harvests or processed products) for school canteens or for mixture with strategic imported products (wheat flour).

74 In both types of zones, food crops, livestock farming, and activities deemed likely to produce appreciable gains will be systematically developed (export crops, food crops, fisheries) while small and medium-sized enterprises (SMEs) engaged in agroprocessing will be strongly encouraged in the form of cooperatives in the less favored zones or private firms in the high potential zones, so as to capture the value added that heretofore has been largely unavailable in the rural world. Clustering will be strongly encouraged in the short term for training small enterprises and cooperatives of all kinds (whether or not they are multifunctional or focus on production or processing) in branches of activity such as flours suitable for bread-making, iodized salt, fruit juices and preserves, goat cheese, and structures for fish preservation or salting. In the medium term, the State will encourage the development of medium-sized enterprises.

75 This overall strategy will take the specific form of policies defined for each of the nine following intervention areas: (i) the environment and land tenure; (ii) agricultural production; (iii) rural infrastructure; (iv) fisheries and aquaculture; (v) agroprocessing; (vi) marketing; (vii) land management; (viii) institution building and organization of the agricultural world; and (ix) rural finance. The objectives and strategic lines of action corresponding to each of these policies are set forth below. 
PROMOTION OF SUSTAINABLE AGRICULTURE AND IMPROVED LAND TENURE MANAGEMENT

\section{Objectives}

76 State interventions will be aimed at achieving three major objectives: (i) developing environmentally friendly agriculture; (ii) facilitating access to land and combating the absentee ownership phenomenon; and (iii) making working the land more secure and promoting reparcelling. Priority will be accorded to two lines of action:

\section{Strategic lines of action}

o Improved land management and watershed protection;

o More secure land tenure, combating absentee ownership, and seeking to identify types of farming that ensure sustainable development.

\section{REVITALIZED AGRICULTURAL PRODUCTION}

\section{Objectives}

77 To revitalize agriculture production, the following two objectives will be pursued: (1) recapitalization of farms; and (2) ensuring the broader availability of basic foodstuffs.

\section{Strategic lines of action}

o Stimulation of agricultural production

o Encouragement of livestock farming

o Poultry production

o Goat, sheep, and cattle production

\section{MODERNIZATION OF RURAL INFRASTRUCTURES}

\section{Objectives}

78 In order to modernize rural infrastructures, the State's interventions will seek to ensure that three important outcomes are guaranteed: i/ ensuring hydro-agricultural improvements; ii/ establishing major water storage structures; iii/ improving rural roads and rural markets.

\section{Strategic lines of action}

o Rehabilitation and improvement of the major existing irrigation systems in order to facilitate the maximum tapping of their potential;

o Construction of new systems in all areas where there is a need to do so;

o Improvement of the major water storage structures such as watershed ponds and impluvia so as to mitigate the water shortage in some parts of the country and stimulate market-garden and food-crop production in their proximity;

o Construction/rehabilitation of farm roads in production areas so as to facilitate products reaching markets and reduce transport costs;

o Construction /improvement of rural markets. 


\section{PROMOTION OF FISHERIES AND AQUACULTURE}

\section{Objectives}

79 Fisheries and aquaculture continue to be areas with great earning potential but which currently are not being tapped or are poorly implemented. Through the DSNCRP, the aim will be: i/ stimulate their development with a view to generating significant income; ii/ improve food security.

Strategic lines of action

o Maritime fishery

o Aquaculture and inland fishery

o Combined policy

\section{VIGOROUS REVITALIZATION OF AGROPROCESSING}

\section{Objectives}

80 The introduction of Food Sciences and Technologies in Haiti should facilitate the establishment of businesses in this area. Accordingly, the following objectives will be pursued: i/ more vigorous revitalization of agroprocessing in Haiti; ii/ encouragement of training in agricultural and food sciences and technologies.

\section{Strategic lines of action}

o Encouragement of the reopening of existing plants (tomato paste and essential oils) and the creation of new ones (biodiesel, etc.)

o Modernization and upgrading of SMEs (mills, guildives)

o Granting of equipment loans for the development of small preservation and processing units in all branches of agricultural production: fruits and vegetables, meat products, seafood, milk products, aromatic plants

o Promotion of entrepreneurial training in university centers, and providing facilities to recent graduates for the establishment of farms and agricultural and processing enterprises.

\section{PROMOTION OF A NEW MARKETING STRATEGY}

\section{Objectives}

81 Bringing harvested products to market constitutes the most problem-laden issue for the various subsectors. It is therefore necessary to have a strategy aimed at: (1) revising customs policy; (2) bringing a sufficient quantity of high quality products to market; and (3) obtaining remunerative prices.

\section{Strategic lines of action:}

- Modulation of tariff policy depending on whether imports are competing with local products or are convenience goods not produced in sufficient quantity domestically

- Upgrading and standardization of high-quality products

- Search for niche markets for the vast majority of our "bio" products

- Consultation with national producers' associations in the course of international trade negotiations

- Development of a commercial communications and information system

- Promotion of products at international expositions

- Granting of loans to women 


\section{STRENGTHENED PRODUCTION SUPPORT STRUCTURES}

\section{Objectives}

82 Research, training, extension services, small farmer organizations, and cooperation platforms are crucial aspects of any increase in agricultural production. Consequently, the strategy will target achievement of the following objectives: (1) promoting research and training of direct benefit to agricultural development; (2) relaunching State agricultural extension services; and (3) encouraging improved organization of the private structures supporting the sector.

\section{Strategic lines of action}

o Agricultural research

o Agricultural training

o Agricultural Extension services

o Strengthening of small farmer organizations

o Encouragement of the establishment of cooperation platforms

\section{AGRICULTURAL FINANCE}

\section{Objectives}

83 The flawed conditions for agricultural finance show how necessary it is to introduce a financial system that can guarantee savings and the recapitalization of farms in such a way as to provide investment and coverage of the basic needs of the rural community in general and small farmer families in particular. The thrust at this level should prompt the State to take action in two directions: i/ relaunching "supervised or controlled credit," particularly to benefit cooperative associations in order to avoid any misappropriation or misuse of the funding requested; ii/ In the context of this policy, devoting special attention to women's associations, as women bear particularly heavy responsibilities in rural areas.

\section{Strategic lines of action}

- Promotion of decentralized financing structures

- Granting of loans

- Prioritization of activities within the context of the policy adopted by the public authorities

- Prioritization of small farmers and producers with a view to improving their economic situation and living conditions

- State assumption of the financing of the experiments to be conducted in research centers.

\section{TOURISM}

84 Haiti is one of the first Caribbean countries to have reaped the benefits of the international tourism that emerged following the rebuilding of the global economy in the aftermath of World War II. This sector became vital for the national economy, representing over 20 percent of exports in the ---0s. Estimates at the time spoke of over 60,000 direct and indirect jobs. The share of tourism in GDP amounted to 3.5 percent, and annual tourism receipts amounted to US\$50 million.

85 The tourism master plan, entitled "Strategic Thrusts," brought together a package of proposals in four major areas: tourist products, the development of priority areas, tourist circuits, and human resources. An additional component, known as "Implementation Modalities," made reference to the streamlining of budget choices, the creation of a National Tourism Authority, the 
establishment of an institutional framework, and the implementation of short-term actions. New national spatial upgrading of tourism is thus called for in Haiti.

In terms of the spatial distribution of Haitian tourism, the new vision involves development in four departments: Ouest, Nord, Sud-Est, and Sud, which will serve as the launching pad for national tourism activity. These priority departments have a number of assets in common and, at the same time, may enjoy comparative advantages in respect of one another in view of some of their special characteristics. Sectoral improvements in tourist sites deemed promising and accorded priority are currently being planned, and include:

- The National Historical Park of the North, around the global patrimony site of the Citadelle, Sans-Souci, and les Ramiers

- The Arcadin Coast northwest of Port-au-Prince, where there is already sizable national investment in the hotel sector

- The Old Town Center of Jacmel, and

- Port-Salut and the Pointe-Sable beach.

87 The policies to be pursued and implemented cover:

- Tourism promotion focused on local destinations

- Tourism promotion targeting the Haitian diasporas

- Graduated tourism promotion in response to regional Caribbean, U.S., European, and Asian supply

- Partnership between the public sector and national and international investors

- A decentralized tourism dynamic that is nonetheless part of a national logic of cohesiveness

- An equitable framework that is respected within the sector. This entails administrative and regulatory strengthening. The Priority Tourism Zones (ZTPs) will be classified as General Interest Projects (GIPs)

- Orientation toward mass tourism.

The associated supportive measures include:

- Capacity building for enterprises

- Training in the tourism and hotel trades.

- Creation of a National Training Institute (INF) in the Ouest department

- Development of a marketing plan for promoting and marketing the Haitian tourism product

- Project documents will be prepared as bankable draft projects to be submitted to potential investors or to apply for funds.

\section{INFRASTRUCTURE}

\section{TRANSPORT SECTOR}

89 The strategy in this area is focused on gaining control of urban and interurban transport systems in the interests of territorial continuity within the country. Mass transit thus remains a priority for economic, urban, and territorial development. Three major objectives have been identified for this sector:

\section{Major objectives and focal areas of transport policy}

\section{Objective 1: Contribute to poverty reduction and crisis prevention}

i/ Make essential services accessible to users threatened by exclusion and create highly labor-intensive structuring jobs, requiring a certain degree of participation on the part of women. 
ii/ Guarantee reliable links between the small and medium-sized landlocked localities and access to disadvantaged urban neighborhoods under satisfactory accessibility and security conditions.

iii/ Broaden participation in the decision-making process to counteract the domination of gangs and fill the void created by the absence of the State.

iv/ Oversight over the network, user information, disaster emergency plan, mapping of sensitive zones.

i/ Take demand-side measures to spread demand better or its better distribution over space and time..

ii/ Take supply-side measures through a balanced territorial development policy and through the development of suitably adapted and integrated transport infrastructure networks, prioritized on the basis of strategic planning.

iii/ Promote the development of regional potentials and enhancing the competitiveness of the Haitian economy

iv/ Restore the balance of the national territory through the emergence of major regional metropolises by guaranteeing the continuity of national territory by protecting existing infrastructure and the environment.

v/ Promote of multimodal transport by developing a strategy that emphasizes integration and complementarity so as to facilitate multimodal trade.

i/ Develop Haiti's international ports by improving the capacities of the other international ports in the provinces and foster the emergence of safe and regulated sea traffic in the Caribbean.

ii/. Develop the airport sector by strengthening the institutional capacities of the entities responsible for air transport.

iii/ Develop the road network for improved regional integration with the Dominican Republic for promoting tourism, and permitting the emergency of other poles of activity with investments under way making it possible subsequently to take medium-term requirements into account or needs in the longer term (the construction of crossing roads interconnecting the main roads).

iv/ Attract foreign investors and international enterprises by granting port and airport concessions.

\section{ELECTRICITY SECTOR}

93 On the technical level, stress should be placed on the proven potential of hydroelectric, wind, solar, and even thermal energy. Such opportunities should be seized, and could well result in a significant improvement in the overall situation. DSNCRP is addressing all these issues in a comprehensive manner by laying out a modulated strategy focused on four types of objectives, six basic options, and an investment program prepared on a consensual basis.

94 The objectives are:

- Move away from the existing management system by definitively abandoning no-bid contracts, modifying the architecture of the EDH Board of Directors, and establishing a Directorate of Urban Commercial Grids at the MTPTC to exercise oversight over investment and regulatory decisions affecting this subsector.

- Introduce a balanced pricing system consistent with the investments made so that the operator might receive adequate remuneration to: (a) have sufficient revenue to cover operating, maintenance, and investment costs and the costs of enhancing quality and service efficiency; and (b) contribute to the share of the social costs that the authorities may decide to assume in order to benefit low-income users. 
- Include in the partnership system between the organizing authority and operators the following basic obligations: (a) public service obligations; (b) maintaining plant, equipment, and materials in a good state of repair so as to permit proper operation; and (c) renovation of rolling stock, vehicles, mechanical equipment, and meters.

- Reflect in deeds the DSNCRP's vision of a more just society demonstrating greater solidarity by providing basic services to the people in the shantytowns and to low-income persons in rural areas. The strategy of independent household solar systems, used successfully in other countries, could be one course to follow in order to make progress with improved access to a fundamental infrastructural service.

95 There are multiple actions, but the DSNCRP stresses the following ones:

- Increase in existing capacity through an equipment purchase strategy that minimizes the burden of the oil bill,

- Ongoing maintenance of the production park and transport and distribution works;

- Expansion and rehabilitation of the HT/MT/LT grids

- Securing fuel supplies (heavy fuel oil, gas-oil, oil)

- Combating waste and losses in the distribution network

- Measures to improve the productivity of power plants.

\section{SCIENCE, TECHNOLOGY, AND INNOVATION}

\section{Objectives and lines of action}

96 The strategy in this sector is to carry out and continue a genuine national agenda for scientific and technological innovation. In the short term, emphasis will be placed on governance of the science, technology, and innovation sector, and on consolidating and building up the knowledge and know-how base. More specifically, the objectives are to: i/ introduce a systematic and suitably adapted coordination structure for activities in science and technology; ii/ establish a production support infrastructure.

97 The main lines of intervention are: i/ development of the industry and promotion of research/action initiatives or private investment programs in strategic areas; ii/ development of a legal framework for scientific development; iii/ promotion of scientific and technological development; and iv/ building the capacities of higher education and research institutions.

\section{REGIONAL ECONOMIC INTEGRATION AND NATIONAL ECONOMIC DEVELOPMENT}

98 The economic strategy underlying the national Growth and Poverty Reduction Strategy Paper (DSNCRP) is built upon increased domestic production and the development of trade. For Haiti, it is a question of tapping its potential while properly positioning itself in the context of the economic and commercial regionalization projects (APE, CSME, etc.), on the one hand, and in broader international dynamics, in particular with the WTO.

99 On the production side, the identified actions are: i/ investment promotion; ii/ development and promotion of national production of goods and services; iii/ complementary State interventions; iv/ use of the Integrated Framework.

100 With regard to trade and development, the priority actions are: i/ promotion of competitive national investment; ii/ seeking accelerated export growth. This entails, at one and the same time, favoring the emergence of multiple and diversified initiatives with respect to the production of agricultural and artisanal goods, manufactured products, and services. 


\section{CHAPTER 6 \\ Pillar 2: Human Development - Priority Accorded to Basic Social Services}

\section{EDUCATION AND TRAINING}

\section{POLICY TO REORGANIZE EDUCATIONAL SUPPLY IN FAVOR OF POOR STUDENTS}

101 The supply of education is inadequate at all instructional levels. The situation is particularly critical in rural areas. There are 23 communal sections that have no school at all, and 145 (in 2007) that have no public school. According to 2004 data from the IHSI, the number of children under the age of 5 is estimated at 935,000, of whom 339,800, or 36.34 percent, are not covered by the system in place. In primary school, the number of children ages 6 to 12 and not enrolled is roughly 558,163, or 37.7 percent of the school-age population, with a very high degree of concentration $(463,163)$ in rural areas.

102 Out of the 122,311 students admitted to secondary school in 2004, only 81,709 , or 66.8 percent of those accepted or 18 percent of the initial cohort, were able to receive secondary schooling owing to the limited capacity to accommodate students at this instructional level. Quite apart from the existing group of those who have already completed secondary school and been unable to find a space in the university, an additional 15,500 were admitted in 2004. In the final year of secondary school, the State university was able to take in 2,300 students from this class, while roughly double that number found spots in private institutions. Unmet demand is thus on the order of 8,600 students, or 55.5 percent of the total student count seeking higher and university education, and this just for the academic year beginning in 2004 alone.

103 More and more youths currently in school are asking for access to vocational training. The majority of the supply of such training is private and spaces are limited, particularly in urban areas where the network of agricultural training facilities, which are unequally distributed throughout the country, ceased to be operational a number of years ago owing to insufficient funding.

\section{Objectives}

104 The targeted objectives are the following:

- Reducing the existing disparities between geographical departments and between urban and rural areas as regards the distribution of available schooling at the preschool and basic education levels

- Ensuring that, by 2010, all 565 commune-level sections have at least one public school covering 6 grades

- Introducing a basic education school (1st and 2nd cycles) that better addresses learners' needs, in particular those of older students

- Making vocational education more accessible to a greater number of young people

- Reducing average tuition costs for these instructional levels.

Strategic lines

- Creation and outfitting of new seated spaces in preschool

- Creation and outfitting of new seated spaces in primary school

- Scholarship programs or poor children in all commune-level sections

- Resumed operation of the EMAs and CFPAs

- Transformation of four nonpublic vocational training centers into reference centers.

POLICY ON REQUALIFICATION OF INSTRUCTIONAL STAFF AND SCHOOL DIRECTORS

105 The output of the system is quite low. At the basic level (1st and 2nd cycles) it is on the order of 43 percent owing to the high grade repetition rates (29 percent in the first year) and dropout rates (6 percent) recorded for every year of studies. At the secondary school level, output is even 
lower, on the order of 35 percent. This makes the financial loss even higher. The academic and professional qualifications of the majority of instructional personnel are low as are their average monthly wages. The instructional programs are no longer meeting student needs.

\section{Objectives}

106 The targeted objectives are the following:

- Enhance the structures for training instructional staff and school directors

- Train new teachers with more appropriate academic and professional profiles

- Improve the skill sets of the instructional staff and school directors already in place

- Motivate the private education sector to increase the compensation levels of teachers and directors.

\section{Strategic lines}

- Establishment of a one-year accelerated initial training (FIA) mechanism for training 2,625 student teachers and 450 school directors

- Strengthening of the existing initial teacher training mechanism by creating three new CFEFs in Artibonite, Nord, and Sud

- Transformation of the 51 teacher training institutions (ENIs) into EFISs (Specialized Initial Training Institutions) and CFCMs (Centers for Continuing Teacher Training)

- Continuation of the process of introducing EFACAPs, increasing their number by 116 by 2010: 35 in 2008, 41 in 2009, and 40 in 2010

- Continuing training for 14,000 instructional staff and 2,500 school directors in 2008/2010: 4,000 teachers and 700 school directors in 2008/2009 (Cohort I) and all 14,000 teachers and 2,500 school directors in 2009/2010

- Transformation of the BDSs into structures for the coordination and management of education and training at the school district level

- Setting the minimum salary to be paid to teachers and trained school directors according to their level of training

- Design and introduction of an initial and continuing training mechanism for trainers in the education and technical and vocational training sector.

\section{POLICY ON ADEQUATE SUPERVISION OF SCHOOLS, STUDENTS, AND PARENTS}

107 The pupil/teacher ratios (78 on average) and grades taught per teacher (1.87) are clearly far too high. The same is true as regards the ratio of teachers per inspector (each inspector covers about 200 schools on average) or per teaching advisor. The degree of literacy of parents is too low overall, as 62.5 percent of parents between the ages of 31 and 55 are illiterate and 87.4 percent of those ages 56 or more are as well. Furthermore, the school system has no mechanism for steering students towards instructional or training areas other than those regarded as conventional. This is one of the decisive factors behind the system's low retention capacity

\section{Objectives}

108 The objectives of these guidelines are as follows:

- Bringing the pupil/teacher ratio from 93 down to 50

- Offering students a broader range of educational paths than the basic one

- Strengthening the structures whereby parents participate in school management

- Improving the literacy level of parents. 


\section{Strategic lines}

- Recruitment and placement of 428 new teaching advisors in the various school departments with identified needs: 180 in 2008, 180 in 2009, and 68 in 2010

- Introduction of the vocational $3^{\text {rd }}$ cycle in the 116 EFACAPs

- Establishment of a mechanism for steering those who have completed the $6^{\text {th }}$ and $9^{\text {th }}$ year toward the basic $3^{\text {rd }}$ cycle and toward secondary education or vocational training

- Making the conventional secondary level program available at all lycées and secondary schools in the country, and the technical program available at 30 lycées and 60 private secondary schools

- Design and introduction of pathways for transitioning between the education system, particularly at the secondary level, and the vocational training system

- Establishment of a scholarship program targeting the children of poor families, especially in rural areas, oriented toward vocational training and the technical program at the secondary level

- Launching of a literacy training program for the 19-30 age group and the 31-55 age group, respectively, so as to increase literacy (i) among men to 8.5 percent and 24.5 percent; (ii) among women to 11.2 percent and 31.5 percent; and (iii) among rural women to 17 percent and 37 percent.

\section{POLICY TO IMPROVE THE COORDINATION OF OPERATORS IN THE EDUCATION SECTOR}

109 The operation of the educational system is quite poorly regulated. More than 70 percent of schools are not controlled by the State. The functioning of the system is for the most part ensured through private financing. Over a hundred NGOs are involved in the education sector. The resources mobilized through this network of organizations fail to achieve the desired effects owing to the lack of integration into a comprehensive policy in which intervention roles and strategies would be more clearly defined and articulated.

\section{Objectives}

110 The objectives of this coordination are the following:

- Create greater synergy between the State and the other stakeholders operating in the sector

- Regulate the operation of the educational system.

\section{Strategic lines}

- Establishment of the National Office for Partnership in Education (ONAPE)

- Development and regular updating of a database covering all the activities carried out in the education sector

- Creation and introduction of an accreditation and certification system for private educational and vocational training institutions

- Establishment of a computerized management information system at the National Vocational Training Institute (INFP)

- Preparation and implementation of a national qualification framework (CNQ).

\section{POLICY TO INCREASE PUBLIC FUNDING OF THE SECTOR}

111 The public resources allocated to the education sector are clearly insufficient, including for the public schools. The education sector receives but 4 percent of the amount of financing under the 
PIP for 2006-2007 and scarcely 3.6 percent of external aid. Operating expenses absorb the majority of this financing.

\section{Objectives}

112 The objectives are:

- Restore, beginning with the second year of the DSNCRP, the highest level of budget support received by the education sector in the past

- Maintain public spending on education above 20 percent for the duration of the fiveyear presidential term

- Significantly increase the level of public financing of basic education in order to achieve the MDGs.

\section{Lines of action}

- Passage of a law on education financing that guarantees achievement of the three objectives identified

- Preparation of a financing plan for the public education sector in order to support the strategic lines of the DSNCRP

- Introduction, through the ONAPE, of programs to subsidize the public and private schools on the basis of projects to improve the quality of primary education.

\section{HEALTH}

\section{PROMOTION OF A MODERN HEALTH SYSTEM READILY ACCESSIBLE BY VULNERABLE GROUPS}

\section{CHALLENGE OF THE MDGS FOR HAITI}

113 The MDGs for the health sector constitute a major challenge for the DSNCRP. The public policies selected are aimed at achieving the MDGs in question, namely MDGs 4, 5, and 6, which target infant/child health, maternal health, and the major pandemics (HIV/AIDS, malaria, and tuberculosis), respectively. Comprehensive improvement of the health system is a fundamental requirement for ensuring that there is sustainable movement toward achieving these MDGs. 
Table 9

Progress Toward Achieving the MDGs in Haiti (June 2007)

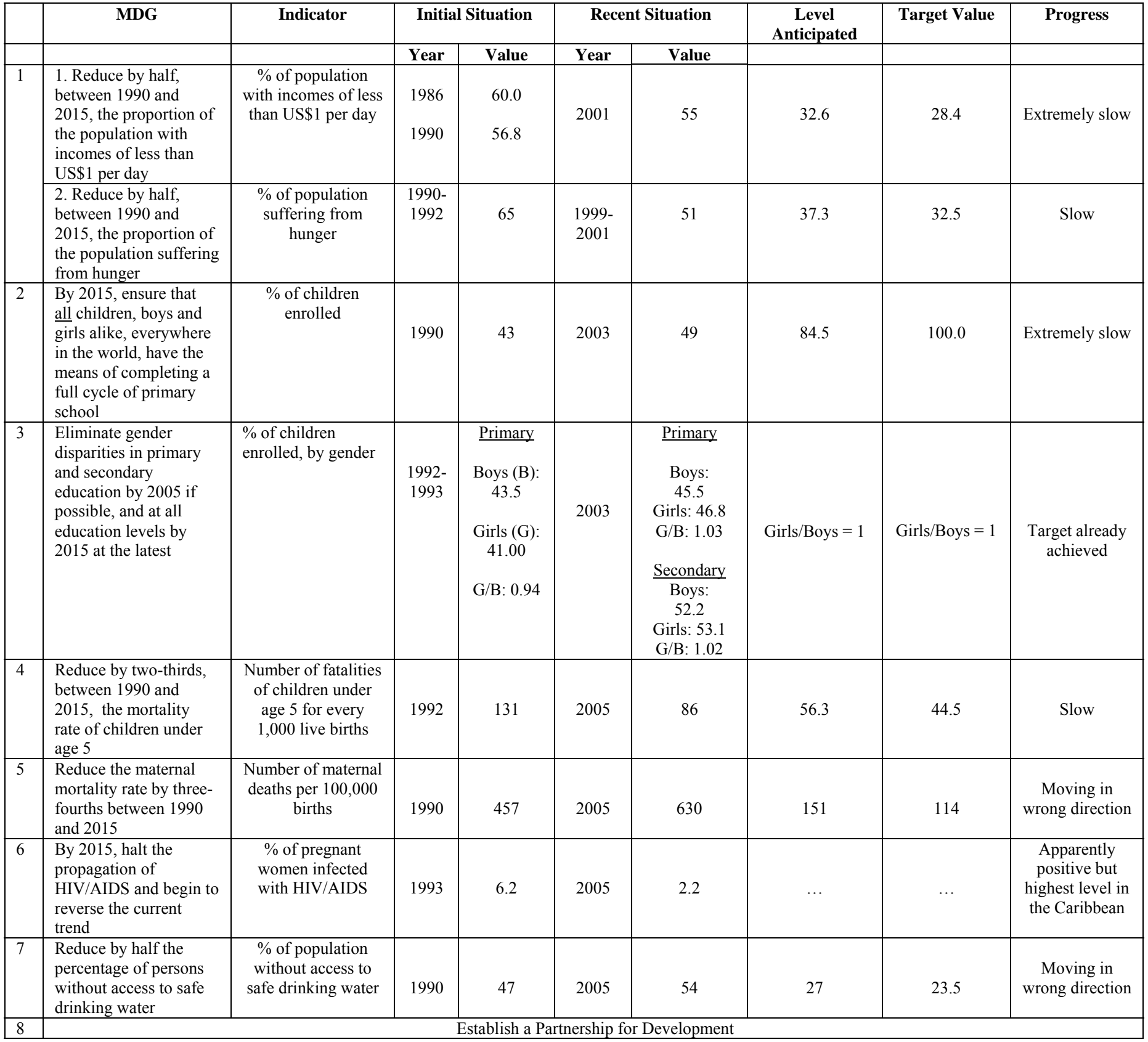

Source: *2010: End of terms of office of elected official. The level achieved (in 2010) is estimated on the basis of the average annual rate of growth toward the target value (for 2015) of each MDG.

* 2015: Time horizon for the MDGs. 
114 Infant/child mortality has shown a declining trend over the past two decades, but the rate (57 per 1,000) remains the highest in the Americas. Maternal health has deteriorated with the recent increase in the maternal mortality rate (MMR) (630 per 100,000), despite the fact that the prevalence of medically assisted childbirth held steady at 24 percent between 2000 and 20052006. The impact of the major endemics remains significant, as shown by the examples of HIV/AIDS (prevalence of 3.5 percent in 2005) and tuberculosis (detection rate of 70 percent). Also noteworthy is the poor relationship between investment levels and impacts, as illustrated by the high level of maternal mortality. Indeed, the maternal mortality rate has increased significantly despite sizable investments in maternal healthcare, on the order of US\$20 million a year for the past five years. This makes it all the more essential to redefine intervention strategies in the context of a unified, integrating plan under the leadership of the MSPP.

115 The national strategic plan for health sector reform 2005/2010 is aimed at improving the state of health of the people while taking the MDGs into account, in particular through the following objectives, programs and strategic lines of action:

0 Reduce the maternal mortality rate by at least 50 percent

o Reduce the infant mortality rate and infant/child mortality rate by at least 50 percent

0 Reduce the incidence of HIV/AIDS infection by 30 percent

o Reduce mortality from HIV/AIDS by 30 percent

o Reduce mother-to-child transmission of HIV/AIDS by 10 percent

0 Reduce the incidence of tuberculosis by 30 percent

o Reduce the mortality associated with malaria by 50 percent

o Control the incidence of certain diseases, such as filariasis, tetanus, poliomyelitis, and measles.

\section{REVITALIAZATION AND EXPANSION OF THE HOSPITAL NETWORK}

\section{Objectives}

o Increase access to reference care services on the part of the entire population in rural and urban areas

o Improve the quality of the medical care supply

o Improve the administrative and financial management of hospitals.

\section{Strategic lines of action}

o Restoring the condition of the reference departmental hospitals

0 Rehabilitation and construction of health centers with beds

o Rehabilitation of specialized hospitals

o Construction of a radiotherapy center

o Continued establishment of integrated diagnostic centers

\section{STRENGTHENING OF COMMUNE-LEVEL HEALTH UNITS (UCSS)}

116 The UCSs are the cornerstone of the strategy to transform the Haitian healthcare system. In accordance with the National Strategic Plan, a "Commune-Level Health Unit" (UCS) is a networked organization which covers an area with a population of 150,000 to 250,000 in which the healthcare stakeholders and institutions interact with community-level participation organizations. The people participate actively not only in preventive and promotional health activities, but also in the decisions relating to the health policy of the UCS and its operation and development.

117 The UCSs are entities in the national system which bring together the following:

- A geographical space known as the "health area"

- A potential user population for services

- Networked health organizations (reference system/counter-reference) 
- A minimum package of available services, in accordance with a complementary approach between the various echelons

- Organization and redefinition of the service personnel.

118 The introduction of UCSs represents a genuine challenge for the Ministry. Despite the investments made to date, only six of these entities are functional out of the 11 programmed for end-2007, and there are plans to cover the national territory with a total of 56 by 2012. The problems experienced with implementing this model are both structural and conjunctural, as the operation of the model is heavily dependent on the pooling of the resources available locally, but also on intensive participation of the people through their natural leaders and established authorities.

\section{Objectives}

119 The process of definitively setting up the UCSs should enable this local echelon of the health system to exercise its various functions by giving them the legal authority to do so as well as resources and means needed to plan, manage, implement, and evaluate their activities. To this end, the following objectives have been set:

- Revise the legal and institutional framework

- Ensure that the system of health coverage is broadened.

\section{Strategic lines of action}

- Drafting of a new framework law on UCSs and a new organic law on the Ministry of Health

- Preparation of a reference framework for introducing UCSs

- Definition of mechanisms for contracting with partners involved in the process

- Introduction of functional, high-performance UCSs.

\section{STRENGTHENED ASSUMPTION OF CARE FOR PRIORITY DISEASES}

120 Owing to their frequency or seriousness, these diseases have a major impact on the state of health of the people and also have considerable economic consequences, a situation that is all the more unacceptable in that it can be considerably improved by taking adequate measures. These priority diseases share the following traits:

- A prevention/information shortfall: prevention requires suitably tailored and timeextensive measures. In any event, the prevention programs focused on individual diseases that are currently in place suffer from highly inadequate coverage and should be strengthened.

- Inadequate assumption of care: despite the support of vertical problems that are more amply financed (HIV), the assumption of care for such diseases has inadequacies in terms of screening, access to appropriate care, and sometimes the quality of the care provided.

- A shortfall in terms of intersectoral collaboration: the prevention of and screening for these diseases could be significantly improved through sound collaboration with other sectors, such as the environment, urban planning, or education. Some sectors are concerned with the assumption of care for particularly vulnerable populations (prisoners, orphans, prostitutes, etc.). 


\section{Objectives}

121 The systems in place will be improved by remedying these shortfalls. To this end, the objectives sought are to:

- Strengthen the Prevention and Information aspects

- Improve the assumption of care for endemic diseases

- Develop intersectoral collaboration.

\section{Strategic lines of action}

The actions to be undertaken for STIs/HIV, Tuberculosis, Malaria/Filariasis, and Zoonosis concern:

o Prevention/Information

0 Assumption of care

o Intersectoral collaboration.

\section{POLICY ON ACCESS TO ESSENTIAL DRUGS}

122 This policy is based primarily on the following objectives: i/ develop a new supply and distribution system, ii/ bringing about qualitative and economic improvement in the access to medications.

\section{Strategic lines of action}

o Preparation of a national paper on the pharmaceutical policy as it applies to essential drugs

o Introduction of a system of supplying public health facilities with supplies of essential drugs

o Strengthened pharmaceutical inspection and control services

o Improved accessibility to essential drugs at all levels at an affordable, standard cost.

\section{POLICY TO STRENGTHEN GOVERNANCE OF THE HEALTH SYSTEM}

123 In accordance with the National Strategic Plan for Health Sector Reform, the State has a key role to play in sector governance. In this sense, the DSNCRP has set the following strategic objectives and actions:

\section{Objectives}

- Developing steering tools

- Strengthening State leadership

- Strengthening its standard-setting function.

\section{Strategic lines of action}

- Strengthen the legal and regulatory framework for regulation by devising a National Health Policy on a consensual basis

- Ensure the inspection and appraisal of health activities at all levels

- Strengthen partnerships by devising a Partnership Charter

- Modernize the health information system. 


\section{HUMAN RESOURCE DEVELOPMENT POLICY}

124 There are limited human resources in the health sector and they are poorly distributed throughout national territory. Coverage by health personnel is 2.5 physicians, 1 nurse, and 2.5 health aides for every 10,000 inhabitants, with 7 per 10,000 in Port-au-Prince and scarcely 0.2 per 10,000 in Grande Anse. The WHO norm is 25 human resource persons per 10,000 in habitants. $\mathrm{PAHO} / \mathrm{WHO}$ estimates indicate that if the current pace of migration of Haitian health professionals, combined with the rate of training new professionals in the country's schools and universities, were to be maintained at present levels, it would take 40 years of creating 740 new jobs a year to achieve this WHO standard.

125 It is advisable to address not only the shortage of human resources, but also their uneven distribution throughout the country. Of the 1,850 physicians who provide healthcare coverage, 90 percent are in the Ouest health department area. It is also important to redefine the type of human resources required by the Haitian healthcare system and to remedy the lag between the needs in the field and the training curricula of the medical, dental, and nursing schools.

\section{Objectives}

126 The human resources policy must be consistent with the objectives of the public health system reform. This requirement mandates that this policy pursue the following objectives:

- Human resource planning

- Human resource training

- Human resource administration and management

- Human resource capacity building.

\section{Strategic lines of action}

- Adjustment of the institutional framework and HR management policies in keeping with the needs of the sector

- Enhancement of the skills of existing personnel

- Production of human resources in response to the needs of the sector

- Equitable HR distribution in accordance with healthcare requirements

- Enhanced attractiveness of the sector.

\section{HOSPITAL WASTE MANAGEMENT POLICY}

127 Household waste and garbage in Haiti are not treated by reliable and technologically approved systems. Indeed, there are no organized landfills at the national level. Waste collection is generally the responsibility of the town halls, and is carried out in vastly different ways from one municipal health unit to the next. When they are collected, household waste and garbage are deposited in open dumps which lack supervision. Medical waste, in particular such waste classified as "Waste from Medical Care requiring special attention" and "Infectious and highly infectious waste" (14) represents a genuine danger to persons likely to visit the dumps. Moreover, depositing medical waste in unsupervised areas may have a direct environmental effect through contamination of the soil and groundwater bodies.

128 The removal of medical waste from the hospital site within 24 hours is a clearly delineated requirement (according to accepted standards, the maximum medical waste storage time must not exceed 24 hours) (15). Moreover, the incineration of waste as practiced by some health facilities is carried out without any filtering system, thus raising the problem of air pollution and the exposure to risks of disease on the part of the people living near such a pollution source. 


\section{Objectives}

129 In this context, the management of hospital waste constitutes a problem area that is particularly difficult to address. For this reason, the policy identified revolves around two key objectives:

- Examine the waste management problem globally, focusing actions on the commune level

- In this perspective, develop and introduce a program for hospital waste management.

\section{Strategic lines of action}

- With regard to the transporting of waste within and outside the institution, it is necessary to: i/ Package the waste in accordance with standards prior to transport, ii/Handle waste in keeping with the standards, iii/ Collect waste within the institution at a regular pace, iv/ Transport the waste in keeping with the established protocols applied.

- As regards waste storage at the institution, care must be taken to ensure that: $i$ / Between collection periods, waste is retained as close as possible to the location where it is produced, ii/ Containers with pedal-operated lids are available at all waste production points.

- Finally, as regards waste treatment within the institution, compliance with standards as to their disposal is essential.

\section{DRINKING WATER AND SANITATION}

130 Analysis of the situation reveals multiple causes behind the many dysfunctional situations identified, especially problems of an institutional nature, a gross shortage of investment in comparison with needs, deterioration in the responsible entities' capacity to manage services and manage water resources, and even the lack of civic spirit on the part of the population. The fundamental approach of the DSNCRP is to promote a public/private partnership that is as broad as possible. The objective of the public service put in place should not be profit-seeking, but rather to satisfy user requirements at the lowest cost to the community. These basic principles will be implemented through a strategy with the objectives and lines of action set forth below.

\section{Major objectives}

131 Four levels of objectives have been identified:

- Institutional objectives: (i) Replace the entities currently in charge (SNEP, CAMEP, POCHEP) with Regional Water and Sanitation Offices (OREPAs); and (ii) in tandem, restructure the MTPTC to enable it to assume the functions of regulating the sector.

- Economic objectives: Establish a balanced pricing system that is consistent with the investments made, allowing it to generate sufficient revenue to be able to cover the costs and contribute to a portion of the social costs which the community decides to spend in order to benefit low-income users.

- Technical objectives: Include two types of basic obligations in the partnership system linking the regulatory authority and operators: (a) public service obligations; and (b) supplementary obligations with respect to the establishment of new channels and new works, water capturing works, and other civil engineering works.

- Social objectives: Reflect in tangible achievements the DSNCRP vision of a more just society with greater solidarity, by furnishing basic water supply and sanitation services to the residents of shantytowns and low-income rural populations, while applying the principles of neutrality and transparency. 


\section{Strategic lines of action}

o Action Plan on "Institutional Development"

This plan is the concrete reflection of the strategy for implementing the new institutional framework planned to regulate the sector as a whole. It will introduce two major actions:

- The creation within the MTPTC of the Drinking Water and Sanitation Directorate which will ensure: i/definition of a tariff policy; ii/ establishment of the criteria to be met by the municipal health units or inter-communal structures in order to work for their systems; iii/ establishment of criteria and conditions to be met by operators in order to be accepted for providing the management of the systems.

- The determination of the number and spatial coverage of the OREPAs on the basis of technical and administrative criteria and economies of scale.

o Action Plan on " Operational Capacity”

This plan is aimed at building the operational capacities of CAMEP and SNEP in order to put the OREPAs in the best possible situation when they first become operational.

O Action Plan on "Investment"

i/ reassignment to the OREPAs of investment projects and budgets, ii/ acquisition of the equipment necessary to bring about rapid improvement in the management capacities and performance of CAMEP and SNEP, iii/ updating of the master plan on the water supply and feasibility of a priority development project. 


\section{CHAPTER 7 \\ Pillar 3: Democratic Governance - Priority Accorded to Justice and Security}

132 The National Growth and Poverty Reduction Strategy encompasses several forms of governance, namely political, economic, social, cultural, and environmental governance. In view of the prevailing circumstances in the country, in respect of governance the DSNCRP accords priority to the establishment of the rule of law, and to Justice and Security in particular. The establishment of an equitable legal order, a functional judicial system, and a general climate of security are essential conditions for growth and poverty reduction.

\section{JUSTICE}

133 The problems profoundly affecting justice in Haiti are institutional and logistical in nature. Noteworthy among the institutional problems are: (i) executive branch interference in the exercise of judicial authority; (ii) the corruption throttling the system in all its dimensions: police, courts, penitentiary system; (iii) impunity which contributes to reprisals, summary enforcement activities, and the settling of personal accounts; (iv) organized crime, drug and arms trafficking, kidnappings, and the violence of armed gangs; (v) the sizable gap between positive law and the practices and customs prevailing among the rural and peri-urban populations; (vi) the people's lack of understanding of their rights, duties, and obligations; (vii) lack of access on the part of the poorest and vulnerable groups to justice and the absence of legal or judicial assistance; (viii) the less than full understanding of the official language of the courts (French) enjoyed by those before them; (ix) the slow pace of police and judicial investigations, giving rise to unjustified delays that stymie the functioning of the penal system; (x) a climate of generalized mistrust toward the judicial and police structures, with neither institution appearing to be credible or reliable in the eyes of the public; and (xi) the nonexistence of a modern criminal records making it impossible to take court backgrounds into account in court rulings and decisions.

134 With regard to resources, noteworthy problems include: (i) the poor condition of infrastructure; (ii) the lack of organization and coordination of the stakeholders in the system; (iii) the excessively small budget for justice; (iv) the precarious working and living conditions of judges; (v) the uneven distribution of justice structures throughout the national territory in comparison with population distribution; and (vi) the lack of training and skills on the part of judicial personal, making the application of law and punishments random and arbitrary.

135 With regard to the corrections system, it is suffering not only from the exogenous effects resulting from the shortcomings and dysfunctions of the judicial system, but also from endogenous problems owing to the fact that: i/ The prisons are overcrowded and for the most part filled with individuals in preventive detention status who have yet to go before the courts, ii/ Detentions are often arbitrary and abusive, and preventive detentions unlawfully prolonged, iii/ Prison overcrowding compounded by the detention of individuals in abusive conditions at police stations, not only engenders serious incidents in terms of security but also flagrant violations of human rights; iv/ Confinement conditions, especially as regards sanitation and security, are not up to international standards.

136 With regard to civil status, there are many dysfunctional areas at present: i/ Absence of a cohesive and functional structure responsible for managing civil status and national identification, ii/ Poor coverage of the national territory by Civil Status Bureaus, iii/ Shabbiness and dysfunctional operation of the existing bureaus, iv/ Insufficient budget for the sector, v/ Absence of State control over the Civil Status Bureaus, vi/ Failure of the officers in charge of the service to apply the legislation rigorously, vii/ Problems experienced by citizens in obtaining the new National Identity Card (CIN).

137 The Justice Reform program will pursue a twofold objective: i/ Promote, in the long-term, eliminating the duality that characterizes the Haitian legal order, which at present is poorly adapted and inefficient, ii/ Facilitate the restructuring of the current legal system, a process that should lead to the introduction of a genuine public service in the area of Justice that includes the entire penal sequence: court administration, police, and penitentiary administration. 
138 In respect of this twofold objective, the DSNCRP will endeavor to lay the groundwork for a Haitian legal order by taking measures intended to have an impact in the short, medium, and long term. The aim is to meet the challenge of restructuring court administration while ensuring that all the population has access to justice. This new legal order, deeply imbedded in the Haitian social fabric, is the outcome of a social construct predicated on: i/ A new vision of Haiti's national history and social ties, which recognizes the serious consequences of past injustices and entertains the real possibilities that exist of leading to a renewal of social relations and exchanges throughout the country, ii/ Acceptance of the founding values of the Haitian nation, the only available and effective strengths that can justify belonging to one and the same environment and are capable of restoring social and political conviviality.

\section{ACCESSIBLE, CREDIBLE, AND INDEPENDENT JUSTICE}

139 The overall vision of justice for the next ten to twenty years is built on four hopes expressed by society: i/ Justice that is accessible, welcoming, and understandable by all, ii/ Justice that is credible, built upon the competence of stakeholders, invoking the conscience of all, resolving conflicts within a reasonable period of time, and seeking the best possible path for its decisions, iii/ Justice that is independent, respectful, and impartial, while protecting and guaranteeing the rights and dignity of the individual, iv/ Civil status services that are efficient and guarantee the rights of all to legal security and a personal identity.

140 To meet these expectations, five major priorities have been identified:

- Restructuring of the MJSP

- Strengthening of the judiciary branch

- Access to tribunals, and the efficiency thereof

- Rehabilitation and the cohesive development of the corrections system

- Modernization of legislation.

141 The restructuring of the MJSP is a critical stage for ensuring that the justice reform program is sustained, effective, and lasting. It calls for ownership of the process and MJSP leadership in implementing the strategic plan for the justice sector. Strengthening of the judiciary branch will be achieved through: i/ the independence of judges; and ii/ operationalization of the Magistrature School.

142 Access to the tribunals and the efficiency thereof will take concrete form through: $\mathrm{i} /$ gradual expansion of the number of tribunals throughout the national territory; ii/ the development of a functional "penal chain" and adequate interconnection of the justice and police components of it; iii/ combating prolonged preventive detention and the overcrowding of penal institutions; iv/ effectively and successfully combating corruption, drug trafficking, organized crime, gang activities, transnational criminality, and impunity; and (5) a justice system that is protective of minors in violation of the law.

143 Reform of the penitentiary system will target the following areas:

- rehabilitation of physical infrastructures

- training of personnel

- relations with the court system

- improved penitentiary practices

- prisoner education and rehabilitation.

144 The modernization of legislation through the adoption of specific and targeted changes in the Penal Code and the Criminal Procedures Code, as well as in other laws as necessary, will take concrete form through the following actions:

- Finalization and validation of the new framework for justice reform and the strategic plan

- Immediate reorganization of the MJSP with a view to promoting the justice reform process

- Restructuring and consolidation of the Judicial Inspectorate in the MJSP 
- Launching of the EMA, with the establishment of its Board of Directors and management

- Adoption of measures to resolve the problems of institutional relations between the courts and the police

- Reform and restructuring of civil status services.

\section{SECURITY}

145 In the joint country balance sheet published with the United Nations in October 2000, the Haitian State acknowledges that the lack of security is currently a global social phenomenon, simultaneously taking the form of physical, nutritional, sanitation, educational, land tenure, legal, economic, political, cultural, environmental, and psychological insecurity. This physical insecurity is a significant obstacle to the success of the growth and poverty reduction strategy. Moreover, it has a massive direct impact on disadvantaged population groups. It is the result simultaneously of pauperization, increasing inequality, uncontrolled urbanization, corruption, impunity at all levels, and, more fundamentally, the shortcomings of the justice and police systems. Combating insecurity through restoring policing as an institution is therefore at the core of the DSNCRP.

146 Combating insecurity requires intensification of the following activities on the ground:

- Developing a security synergy by establishing a partnership dynamic involving the people, the authorities, and the international community, in order to put an end to kidnappings for ransom and vehicle thefts in the capital city

- Preparing and implementing a plan to combat kidnappings and vehicle thefts in the metropolitan area

- Ensuring a greater police presence in the field

- Establishment of a security cordon around the zones sheltering criminals, hiding stolen vehicles, and holding kidnapped individuals

- Strengthening of security measures under way in the capital

- Imparting new dynamism to the "114" emergency line and introducing a rapid response system for emergency requests by the public

- Conduct of joint police operations with MINUSTAH

- Use of specialized units to reinforce the territorial units

- Use of new strategies against drug trafficking, with international cooperation, etc.

- Playing an active role in the national disarmament campaign implemented by the Government in coordination with MINUSTAH

- Develop near-at-hand policing through public relations activities by the units for intervention and the maintenance of order as well as through closer ties between the staff of other police units and the local populace.

\section{RESTORE CONFIDENCE IN POLICE PERSONNEL THROUGH IMPROVEMENTS IN STAFF REGULATIONS AND LIVING AND WORKING CONDITIONS}

147 This improvement requires that actions be taken at four levels:

o Recasting of the Personnel Regulations of the PNH

0 Improvements in compensation and remuneration of police officers

o Infrastructure improvements 


\section{ENHANCE THE SUPERVISION AND STRUCTURES IN THE INSTITUTION'S CHAIN OF COMMAND, MANAGEMENT, AND CONTROL}

148 To bring about this strengthening, a range of actions will need to be initiated:

- Obligation at all levels and command echelons within the National Police to improve the management of the resources made available to the institution

- Staff obligations as regards respect for the common wealth

- Reactivation of the records inventorying the materials and equipment supplied

- More frequent inspection of materials in order to determine their operational potential on an ongoing basis

- Obligation of senior staff to conduct surprise inspections on the rational use of the resources made available to their units

- Deduction from wages of the amount of expenses for the purchase or repair of materials lost or damaged through negligence

- Imposition of severe administrative sanctions against those guilty of misappropriation

- Monitoring of management indicators to identify changes in situations and the reasons for same

- Strengthening of the chain of command by training intermediate and senior supervisors after an internal and/or external recruitment competition aimed at candidates with university degrees

- Conduct of a study on the rank pyramid and on the staffing and resource tables in order to rapidly introduce a system for managing resources and the police career stream

- Appraisal of all supervisory personnel once a year

- Assignment of supervisory personnel to positions corresponding with their capabilities

- Reform of supervisors and officers with unsatisfactory performance

- Introduction and ongoing oversight of units and services by the Inspectorate General and the Office of the Director-General

- Programming of oversight and management training sessions for supervisory personnel.

\section{RESTRUCTURING OF THE PNH}

149 This restructuring requires the following actions:

- Submission to the Government of a proposal to organize a colloquium of eminent multidisciplinary national experts with a view to defining, once and for all, the type and nature of police force that can best be adapted to the country and should be established with technical support from the international community

- Implementation of a follow-up plan for restructuring the National Police

- Improvement of relations between the Police and the people, public and private institutions, and other units of government

- Development of an updated training curriculum for the officers, intermediate supervisors and higher supervisors of the National Police

- Personnel training on discipline

- Command restructuring through the adoption of a new structural organization chart. 
EXTENDING PNH COVERAGE TO THE ENTIRE NATIONAL TERRITORY, AND IMPROVING SERVICES

150 This deployment will be accomplished through the following actions:

- Rapprochement between the police and the populace

- Improved interlinkage of the territory through the creation of new units in localities that currently have none

- Deployment of the police in rural areas

- Improved outreach to the public at police stations

- Training of police officers in human rights and peaceful conflict resolution

- Improved procedures for lodging complaints against police officers

- Implementation of community policing

- Improved Police/Courts/Prisons relationships to contribute to the proper functioning of the penal sequence and combating impunity

- Organization of seminars at the national and local levels involving all government units involved in the penal sequence: judges, police officers, and penitentiary administrative personnel

- Development of PNH partnership with the other stakeholders in public safety, other ministerial departments, civil society, subnational governments, elected officials, and the populace

- Finalization of a national security plan currently being drafted. 


\section{CHAPTER 8 \\ Targeted and Cross-Cutting Policies and Strategies}

\section{FOOD SECURITY}

\section{Nutritional and sanitation situation}

151 This situation is a source of concern in all respects. The latest EMMUS IV survey revealed rates of 23.8 percent and 9.1 percent, respectively, for chronic malnutrition and acute malnutrition. The situation is two (2) times more serious in rural areas than in the metropolitan area of Port-auPrince. The status of micronutrient shortages contributes to aggravating the situation: 61 percent of those under age 5 and 46 percent of women suffer from anemia. A third of all children under age 5 (33 percent) have a Vitamin A deficiency, a rate significantly higher than the 15 percent threshold regarded as acceptable; 59 percent of children ages 6 to 12 suffer from an iodine deficiency, a rate that is also higher than the accepted ceiling of 50 percent (MSPP-WHOUNICEF 2005).

152 These problems of undernourishment and malnutrition, when uncorrected, very rapidly become irreversible and jeopardize the very future of the nation through deterioration in physical and mental faculties and the capacity for work of a sizable proportion of the population. The system for controlling food sanitation and healthfulness shows a number of weaknesses, particularly as regards the regulatory framework and appropriate inspection mechanisms. Responsibilities for the control system are shared by the Ministries of Agriculture, Commerce, and Health; the need for a mechanism for coordinating actions at this level is crucial, as is more rigorous control of environmental soundness.

\section{Overall food availability}

153 The overall food balance was positive at the end of 2006, but it was extremely fragile, characterized by: i/; national production accounting for only 45 percent, ii/ a doubling of the share of food imports between 2001 and 2004. If recovery measures are not taken rapidly, the situation runs the risk of deteriorating rapidly, as the national food supply is growing at an annual rate of 0.40 percent while national demand is increasing at a rate of 2 percent. The consequences of this are ever higher foreign exchange outflows in order to cover the costs of food imports and, as regards the food security of households, increased suffering in the countryside (poverty, food insecurity, and malnutrition are two times more prevalent in rural areas), and urban flight with its corollary, insecurity in the cities.

\section{Need for a comprehensive food policy}

154 The rather significant potential for increasing farm production for the local and export market is being tapped little or not at all. In fact:

o Productive investments in this sector are exceedingly small: from 2003 to 2005, scarcely US\$0.7 million was devoted to imports of agricultural machinery, tools, and inputsduring the same period, the Dominican Republic made US\$40 million in such investments.

o The budget choices made by the various Governments did not identify agriculture as a priority investment sector (the share of investment expenditure allocated to the MARNDR dropped from almost 10 percent in 2000-2001 to less than 3 percent in 2002-2003).

o Less than 1 percent of total outstanding credit goes to the agriculture sector.

o The necessary infrastructures (water, energy, transportation) remain woefully inadequate.

155 To concretely reflect the application in Haiti of the human right to food, as decreed in Article 22 of its Constitution, it is essential to apply an interconnected package of measures that are technical, organizational, and tax-related, to make sizable investments, and to maintain close coordination among the various ministries concerned (Agriculture, Planning, Health, Commerce, 
Education, Social Affairs, Environment, Finance, Condition of Women, Public Works, and Justice). The objectives and strategic lines of action in this area are as follows:

\section{Objective:}

Define a framework conducive to strengthening food security and monitoring its application.

\section{Strategic lines:}

- Orientation of development policies toward genuinely strengthening the food security of individuals and households.

- Institutionalization and legalization of measures making it possible to achieve in fact the human right to food.

- Definition of national strategic lines of action for strengthening food security.

- Preparation, in a participatory manner, of departmental and commune-level food security plans that define realistic objectives and properly targeted and interconnected interventions.

- Updating of the national food security and nutritional plan.

\section{Objective:}

Introduce cross-cutting mechanisms.

\section{Strategic lines:}

- Operationalization of the effective coordination of the major cross-cutting aspects of strengthening food security;

- Establishment of synergies in the interventions of the various entities involved in enhancing food security.

- Strengthening the partnerships between the State and civil society in this area.

- Strengthened management of food aid and promotion of complementarity between social safety net types of programs.

- Support for cross-cutting programs to enhance food security in their efforts to achieve intersectoral and interinstitutional integration.

\section{Objective:}

Strengthen the departmental capacities for intersectoral and interinstitutional integration.

\section{Strategic lines:}

- Strengthening local capacities for concerted planning, operationalization, and the evaluation of food security and local development projects and programs

- Promotion of partnerships between civil society, the State, and subnational governments

- Structuring of mechanisms at the local level for engaging in immediate and coordinated interventions in the event of crises

- Establishment of a database on stakeholders and interventions in the area of enhancing food security.

\section{Objective:}

Ensure the monitoring of food security and poverty.

\section{Strategic lines:}

- Organization and implementation of participatory monitoring of the status of food insecurity and poverty at the national and infranational levels. 
- Impact evaluation of food security and poverty reduction programs and projects through the gathering and analysis of relevant indicators.

- Dissemination of information on the basis of the data gathered and analyzed.

\section{Objectives:}

- Promote access to financial resources on the part of the microenterprises.

- Promote the provision of funding to the informal sector.

- Promote the integration of excluded and marginalized groups in the financial system.

\section{Strategic lines:}

- Structuring, professionalization, and consolidation of the sectors

- Diversification and decentralization of the supply of financial services, orienting them toward productive sectors in rural areas

- Establishment of an adequate legal environment and supervision matched to needs

- Access to productive financing, by producers, to offset the lack or weaknesses of guarantees.

\section{PERSONS WITH DISABILITIES}

156 According to the available statistics, out of Haiti's total population of 9 million inhabitants, some 800,000 are disabled, or 10 percent of the most vulnerable population groups in Haitian society. Analysis of the situation of the disabled should focus on social indicators so as to take stock of the scope of the problem and strive to devise viable and sustainable solutions. The objectives and actions in this area revolve are:

\section{Objective:}

Facilitate the process of integrating the disabled into socioeconomic life through the introduction of appropriate structures for improving their living conditions.

\section{Strategic lines:}

- Strengthening of the Secretariat devoted to the disabled;

- Revamping of the labor code to take account of the situation and rights of workers with special needs;

- Prevention of disability through vaccination, nutrition, early detection, and intervention;

- Creation of medical rehabilitation units in the main hospitals of the country;

- Subsidies for the purchase of prosthetic devices, medications, and other specific forms of assistance;

- Development of literacy programs for persons with special disabilities.

\section{YOUTH AND SPORTS}

157 One of the categories most affected by the ongoing multidimensional crisis is Youth, which accounts for over 50 percent of the overall population. Learning and experimentation tend to be forgone owing, among other factors, to the disastrous socioeconomic conditions prevailing in Haiti. This being so, our young people lack both the time and the resources to fully experience their youth, as indicated by the fact that 17 percent of those under age 30 are heads of household. They engage in all manner of activities (car washing, small-scale retail trade, prostitution, theft, 
etc.) to be able to bring something back to the household at the end of the day or evening. This kind of fragility can be readily identified on the basis of selected data:

- 5.2 percent of those ages 15 to 19 were infected by STIs/HIV-AIDS in 2003 (World Bank report)

- 59 percent of first childbirths occurred among those ages 15 to 30 in 2001

- Over 40 percent of those ages 15-24 fall outside the Haitian education system (ECVH-2001)

- 40.6 of young males and 54.8 percent of young females are unemployed.

\section{Objective:}

Improving the living conditions of youths, in particular through their socioeconomic and sociocultural integration and through the promotion of physical and sports-related activities.

\section{Strategic lines:}

- Development of an institution building program

- Development of a program for the socioeconomic and sociocultural insertion of Youth

- Establishment of a sports development program

- Establishment of a program to develop civic spirit

\section{GENDER EQUITY}

\section{School enrollment and level of education}

158 Illiteracy and insufficient schooling are phenomena characterizing all population groups in Haiti, and as regards gender-based social comparisons the following may be observed: i/ Belated entry into the education sector, ii/A higher school dropout rate, iii/ Discriminatory treatment of the consequences of early pregnancy: Girls who become pregnant are sanctioned by and often dismissed from the education system, while boys are not held accountable for their acts and not subjected to sanctions, iv/ An increasing and significant gap at the secondary level, v/ At the university level, there are no reliable and recent comparative data that can be used in analyzing the situation of female students, vi/ Pedagogical content that perpetuates social preconceptions as to gender. The content of curricula only reinforces stereotypes, vi/ Discriminatory technical training., vii/ A higher rate of illiteracy.

\section{Strategic lines of action}

o Formulation of a public education policy aimed at eliminating sexism, language problems, and all forms of discrimination in the national education system.

0 Introduction of sex education into the new training programs as a means of preventing early pregnancy and violence.

o Promotion of general laws on all aspects of education, with particular attention to gender issues so as to promote the education of girls and their retention within the school system.

o Appeals to the Directorate of Higher and University Education to incorporate the analysis of gender issues in the social science programs.

159 With a view to addressing this shortcoming, the DSNCRP has identified the following actions:

o Devise a policy on the subject and develop information, education, and communications programs aimed at ensuring that girls and women are in a position to properly address their sexuality. 
o Promotion of a national plan for reducing maternal mortality and providing highquality reproductive healthcare services.

o Development of an information, education, and communications strategy, as well as partnership services, in favor of sexual and reproductive health, in particular for young adolescents of both sexes and women of child-bearing age.

o Adoption of a policy on free medical and paramedical services in all hospitals and public health centers to prevent breast cancer and uterine cancer among poorer women.

o Advocate the opening of a mental health program in the regional, communelevel, and rural health centers.

o Encouragement of general measures in favor of the right to health information and information on types of treatment for women.

o Application of the Convention on HIV-AIDS to protect seropositive women in respect of their access to healthcare services, their right to work, and the exercise of their rights as citizens.

160 Women are underrepresented in the political sphere, both as regards political party membership and as regards the holding of positions of responsibility. As a result, the following actions have been identified with a view to improving women's access in the political sphere:

- Establishment, in accordance with the aspirations of the women's movement, of a quota for female participation on the order of at least 30 percent within the political parties, general government, in the various decision-making bodies, and in the executive branch.

- Availability of an adequate budget for implementing its policy in favor of women and its cross-cutting strategy in the various ministries, administrative divisions, and all departments and municipal health units.

- Application of the existing laws in favor of women.

- Advocacy of amending election law to ensure that women occupy at least 30 percent of elective offices.

161 Despite the existence of a number of legal tools, conventions, and international treaties confirming the equality of women, the Haitian legal framework includes laws which are discriminatory against women and keep them in an unfavorable legal position vis-à-vis men. Women are unable to exercise the rights conferred upon them by the codes currently in force. Frequently, conventional practices hold sway over the laws. Generally speaking, societal practices perpetuate discriminatory behaviors against women. Indeed:

- The Civil Code includes articles that are harmful to women, such as those defining marriage, which fail to reflect the reality of unions in Haiti, divorces, the situation of children born out of wedlock, etc.

- The Penal Code, which defines differential treatment of women and men for similar infractions, as well as in respect of women's right to reproductive health and abortion.

- The Labor Code codifies unequal treatment for those working within the home, the majority of which are women. Its articles on children working in the home, the majority of whom are girls, reproduce the same discriminatory approach.

- Despite the advances made by the 2005 decree decriminalizing adultery and criminalizing rape as a crime against persons, it bears noting that there is a general insufficiency as regards the definition of sexual assaults. 
162 Peace and security mandate justice for all of both sexes. The strategy includes actions to prevent, punish, and eliminate specific forms of violence against women such as:

o Enhancing the awareness of women and men, youths, and those even younger about all forms of violence against women.

0 Elimination of the trafficking in and sale of persons, especially of women.

o Introduction of a reform in judicial and legal proceedings to fill the legal void as regards the rights of women, in particular as regards: (i) consensual unions or plaçage; (ii) responsible parenthood; (iii) sexual assault and sexual harassment; (iv) the working conditions of workers in the home; (v) the working conditions of female laborers; (vi) declarations of births; (vii) the law on sexual equality; (viii) the 30 percent quota in appointed positions; and (ix) the partial decriminalization of abortion.

o The inclusion of women in legal and judicial entities, including as judges, police officers, clerk personnel, notaries, surveyors, etc.

163 As regards judicial matters, the actions identified are as follows:

o Harmonization of legal provisions to bring them into line with constitutional requirements and international conventions;

o Promulgation of new legal provisions to ensure that the country has legal instruments likely to promote the enforcement of international conventions, including in particular those against violence, discrimination, and in favor of reproductive rights;

o Reform of the court mechanism itself, making it more likely to provide impartial justice for all men and women while respecting the laws and conventions on women's rights.

\section{THE ENVIRONMENT AND SUSTAINABLE DEVELOPMENT}

164 The environmental dimension of development is of vital importance for the future of Haiti and its people. Environmental issues, considered overall from the standpoint of sustainable development, are not only crucial but cut across all components of the Growth and Poverty Reduction Strategy. Moreover, this finding is consistent with the framework defined by the Millennium Development Goals.

165 Haiti is experiencing accelerated environmental degradation. The social and political disruptions marking the country's history are being compounded by an environmental disruption that for many years, in an ever more accentuated way, has been reflected in spectacular losses in human lives. The state of the environment in Haiti is such that it is ludicrous to pursue a growth and poverty reduction strategy if environmental problems are not addressed comprehensively and reflected in the Haitian State's genuine political will to resolve them.

\section{The environment and the natural resources used by the Haitian poor}

166 Annual harvesting of firewood is producing a shortfall manifested in a gradual decrease in plant cover, which has declined from 60 percent of the territory in 1923 to 18 percent in 1952 and 1.44 percent in 1989 (Source ECMU/UNDP 1996). At present, plant cover is estimated at between 1 percent and 2 percent. The Haitian rural environment is in accelerated decline; the most direct factors behind this deterioration are deforestation and erosion. As a mountainous country in which two-thirds of rural areas include slopes of greater than 20 percent, Haiti suffers from extremely severe erosion. As a result of the removal of trees and brush clearing on marginal lands by the people, 25 of the 30 main watersheds in Haiti are now stripped bare (MDE 1999) and their 
soils severely impacted by erosion. ${ }^{3}$ The areas under cultivation on lands poorly suited to agriculture are estimated to cover between 20 percent and 30 percent of the country's surface area (World Bank/ BDPA/SCETAGRI 1990). While it is difficult to assess the scope of erosion with precision, it is estimated that each year roughly $1,600 \mathrm{MT} / \mathrm{ha} /$ year are lost to erosion. In consequence, over the past ten years agricultural productivity has declined by 0.5 percent to 1.2 percent a year.

167 Fishing provides sustenance to the poorest and most marginalized population groups. Maritime fishery directly employs about 30,000 persons; it is characterized by overexploitation of surface fishery resources owing to the substandard equipment of fishermen. The catch volume is estimated at between 4,000 and 5,000 metric tons a year, despite the fact that the FAO evaluated the potential at $14,000 \mathrm{MT}$ in the 1990s. The coastal topography and bathymetry result in an extremely narrow continental shelf measuring roughly 5,000 square kilometers, which contributes to limiting the productivity of non-industrial fishing. Haiti annually imports US\$16 million in fish (frozen horse mackerel, cured herring, and other preserved fish) and exports some US\$6 million to US\$7 million worth (principally shrimp and rock lobsters).

168 Water scarcity is a harsh reality for Haitians, particularly for the poorest population groups. The United Nations estimates that Haiti is among the nine countries whose people will experience a water shortage by 2025 (less than $1,000 \mathrm{~m}^{3} /$ inhabitant/year). The water sector is beset by serious problems. Most of Haiti's large cities are subject to flooding with the slightest downpour. A sharp decline has been observed in the flows from the major springs providing drinking water to the urban centers. Access to safe drinking water supplies throughout the country is extremely low, at roughly 43 percent, and the rate of coverage in Haiti is the lowest in the Western Hemisphere. This said, however, an assessment of the water resources balance in Haiti prepared by the MDE/IADB in 1997 indicated that less than 10 percent of available water resources were used. For the same period, needs represented 17 percent of the available resources.

169 The majority of the Haitian population continues to depend on wood for meeting its energy needs. Haiti annually covers about 72 percent of its energy requirements using local resources, consisting largely of firewood and charcoal (66 percent), but also bagasse and hydropower (4 percent and 2 percent, respectively). Petroleum products account for the remaining 25 percent of annual demand for fuel, and pose a heavy burden on the country's trade budget. Gas consumption has significantly increased in recent years, from 900 metric tons per year in 1991 to over 12,000 metric tons per year in 2004. The household sector is by far the most important in terms of overall energy consumption. According to a recent study (MDE/BME/ESMAP 2005), it accounts for 70 percent of the total on average, largely from biomass (firewood, charcoal, and agricultural waste). To meet the needs for ligneous fuels, rural residents annual chop down some 30 million trees to meet consumption needs for about 3.4 to 3.7 million tons of firewood (1,600-1,750 ktoe in 1995). All of these actions have repercussions in terms of emissions of greenhouse gases such as $\mathrm{CO} 2$, $\mathrm{CH} 4$, and $\mathrm{N} 2 \mathrm{O}$.

\section{The environment and the health conditions of the Haitian poor}

170 Poor Haitians are particularly exposed to a number of diseases (diarrhea, dysentery, malaria, etc.) that may be associated with environmental risk factors. Maritime pollution, pollution of the water provided in drinking water systems (fecal matter, effluents, waste oil from industry, solid waste, suspended particles resulting from the erosion of watersheds, and the spread of shantytowns) are causative factors in an extremely troublesome health problem. The rate of coverage of sewerage services is only 26.5 percent at the national level (WHO/PAHO 1997).

171 Deficiencies in the garbage collection and waste management systems are among the primary causes of urban pollution and the source of serious risks to public health. Waste management is

${ }^{3}$. World Bank, Rural Sector Study: Rural Development and Management of Watersheds 
also an issue in rural areas, though less acutely: organic waste is reintroduced into a natural setting in the form of fertilizer; however, the lack of access to basic hygiene services exposes the rural population, especially children, to considerable health risks.

\section{The poor and uncontrolled urbanization in Haiti}

172 Rural flight, the consequence of poverty and the agricultural crisis besetting rural areas, is at the origin of uncontrolled urbanization that has a significant impact on the living standard of Haitians and on the environment, in the form of the consumption of natural resources and overflowing waste. The large and medium-sized cities of Haiti are almost all excessively overgrown, and the consequences of such hypertrophy include unemployment and poverty, the inadequacy of urban services, overburdened infrastructure, difficult access to adequate housing, and environmental degradation. Rational management of the urban environment thus represents a serious environmental problem in Haiti.

\section{Vulnerability and environmental threats in Haiti, aggravated by climate change}

173 Haiti is extremely vulnerable as a country to natural disasters, and is exposed to growing and complex threats resulting from the interaction between natural threats aggravated by environmental degradation, high levels of poverty and social vulnerability among the people, and problems of governance and lack of control over urban and rural space. The country is subject to a broad range of natural threats of a hydrometeorological (hurricanes, droughts) or seismic (earthquakes, tsunamis) origin, and owing to the steepness of its topography, suffers from particularly intense geodynamics which induce frequent flooding, landslides, and rock slides.

\section{Environmental policies}

174 Efforts will focus on the following policies:

- Stressing economic security, the food security of Haitian communities, and the security of the ecosystems, as well as the introduction of sound and effective interinstitutional coordination mechanisms to ensure the harmonious management and cohabitation of the relations between the people and environmental resources.

- Managing the environment on a partnership basis, forging alliances with civil society for the responsible and sustainable management of resources without, in so doing, neglecting the issues of regulation, oversight, monitoring, and control.

\section{THE NINE FOCAL AREAS FOR INTERVENTION}

175 The "Strategic Thrusts" paper advocates 9 inseparable focal areas for intervention for combating poverty and improving the environment with a view to achieving the MDGs:

- Improved environmental governance

- Reduced environmental vulnerability of the poor and adaptation to climate change

- Improved environmental management of the cities

- Integrated management of water resources in the watersheds and coastal areas

- Reforestation: restore equilibrium between the supply of and demand for wood/charcoal energy

- Combating soil degradation and seeking sustainable management of biodiversity

- Combating pollution in its various forms

- Environmental monitoring and oversight

- The environment as a focal area for attracting investment and providing business opportunities to the poor

176 Territorial development, the gender issue (in particular as regards risk prevention in the rehabilitation of degraded land parcels), cultural issues (taking local customs, taboos, popular 
beliefs, and cultural values into account), job creation, and food security are among the crosscutting themes to be addressed in relation to the nine focal areas for intervention.

\section{RISK REDUCTION AND DISASTER MITIGATION}

177 As are many of its neighboring countries in the Caribbean, Haiti is situated in an area that is particularly exposed to the threat of tropical cyclones and is also in an active seismic zone which has historically triggered major earthquakes such as the one in Cap-Haïtien in 1842. Prevention and risk management are thus of capital importance for Haiti, a high-risk country. The global report on Reducing Disaster Risk: A Challenge for Development, published by the UNDP in 2004, provides a disaster risk index summary table, which ranks Haiti as among the highest in the world. The disasters that have occurred in the past five years confirm this extreme vulnerability.

178 During the 20th century, Haiti was struck by 34 intense tropical storms, windstorms, or hurricanes. Some 80 percent of these occurred after 1954, and 44 percent were recorded during the 1990s. A major disaster affects the country every 5-7 years ${ }^{4}$ and an internationally recognized disaster every two years. Owing to these repeated impacts and to environmental degradation, a major disaster is no longer necessary in order for significant damage to be incurred. The situation is expected to deteriorate even more in the future because of the increase in and concentration of property at risk, climate change, the advance of desertification, the reactivation of seismic faults, etc.

179 Taken together, the major natural disasters of the past century took more than 20,000 lives and caused damages to more than 6 million. Of late, the catastrophic events resulting from the floods in May 2004 and from tropical storm Jeanne in September 2004 led to the deaths of over 5,400 persons. Overall, the effects of the tropical storm affected 4 percent of the people of Haiti (298,000 persons). Damages were estimated at over G 10 billion (US\$265 million), or 7 percent of GDP. The direct losses to improved property ( 70 percent of the total) were considerable: urban infrastructure and housing, agricultural losses in terms of production, soil, and tools, and the road and communications infrastructures. To reduce the impact of hazards and disasters, the following actions were identified:

\section{Objective:}

Position risk management among the priority strategic focal areas for development.

\section{Strategic lines}

- Orient actions toward the management of causes rather than the management of effects

- Investment in risk reduction makes it possible to generate savings on the costs of rehabilitation and reconstruction

- Significant reduction in poverty in areas highly susceptible to events

- Enhanced decentralization, in particular through: (1) the introduction of local structures (departmental, commune-level, and commune districts) that can support the territorial governments; (2) development of the local risk management approach; and (3) positioning Haiti on the path of sustainable and equitable development.

\footnotetext{
${ }^{4}$ Some 20 major disasters were recorded between 1900 and 2004.

${ }^{5}$ Seismic risks are probably the least known unpredictable factors, particularly in light of the conditions of increasing physical vulnerability in densely populated urban areas.
} 


\section{MULTISECTORAL EFFORT TO COMBAT HIV/AIDS}

180 In 2005, UNAIDS estimated that Haiti had the highest rate of persons living with HIV/AIDS in the Caribbean. The findings of EMMUS-IV revealed a noteworthy reduction in prevalence, which it determined to be 2.2 percent nationally among adults between the ages of 15 and 49 . Nevertheless, the rate remains extremely high in some health departments, bordering on 4 percent. At end-2005, the number of seropositive persons living in Haiti was estimated at 103,669. The infection has spread to all age groups. The rate is slightly higher among women (2.3 percent) than among men of the same age group, while when the epidemic began the proportion was higher among men, suggesting a trend toward the feminization of the epidemic. It is also noteworthy that prevalence is estimated at 3.1 percent among men in the 50-59 age group. The proportion of the population (41 percent) with a genuine understanding of AIDS varies by level of education and level of housing quality. Twenty-nine percent of women and 22 percent of men reported that they had had unsafe sex. Fifty-five percent of young women and 95 percent of young men reported that they had had high-risk sex. Only 29 percent of young women and 43 percent of young men indicated that they had used condoms during sexual relations.

181 The AIDS pandemic is more prevalent among the poorest population groups and contributes to the pauperization of households by reducing their labor force, increasing their healthcare expenditure, and boosting the number of orphan dependents. The Republic of Haiti has been combating AIDS since 1986; so far, many activities have been carried out in the areas of prevention and the provision of care, as well as the reduction of discrimination against persons living with HIV/AIDS (PLWHAs). Major efforts have been made by the health sector to control the epidemic; however, there is room for the other sectors to mobilize and become further involved in providing the most suitable responses to this plague.

\section{Multisectoral Strategic Plan for 2006-2012}

182 The recent multisectoral strategic plan for combating AIDS 2006-2012 is more advanced in strategic terms and devoted more attention to researching the contribution of the other sectors. It defined six avenues of approach: (i) risk reduction, calling for communications efforts and clinical interventions; (ii) vulnerability reduction, which identified intervention efforts using basic factors relating to poverty; (iii) reduction of the impact of the epidemic on persons infected with and affected by HIV; (iv) promotion and defense of human rights, aimed at protecting the rights of healthy individuals, the protection of families, women, youth, and persons infected and affected by HIV; (v) ensuring the sustainability of interventions; and (vi) monitoring the epidemic and research.

183 In the context of the DSNCRP, this Plan for 2006-2012 incorporates the following actions:

- Consideration of all non-medical risk factors, which are better known by other sectors that are more concerned with them and have the credibility to do so;

- Mobilization of financial resources in addition to those requested from the Global Fund to support interventions aimed at reducing vulnerability;

- Implementation of targeted actions aimed at youths and at workers of both sexes, seeking to reduce poverty in these target groups;

- Incorporation of additional focal areas aimed at: (i) institution building in the other sectors, including efforts to identify needs for human, material, and financial resources, and the transfer of skills from the health sector through training, information sharing, and the assignment of resource persons; (ii) the development of resource persons; (iii) the development of local review and action structures focused on combating AIDS through poverty reduction, targeting women and youths on a priority basis. 


\section{STATE CAPACITY-BUILDING STRATEGY}

184 The DSNCRP will base its efforts on the GEF's Strategic Approach to Enhance Capacity Building, which defines capacity building as "the actions needed to enhance the ability of individuals, institutions, and systems to make and implement decisions, and perform functions in an effective, efficient, and sustainable manner."

\section{Reform and Modernization of the State}

185 Ten years after completing the latest global assessment of the public administrative apparatus, the State is still faced with the same major flaws identified earlier, so that the recommendations made by the National Commission for Administrative Reform (CNRA) remain valid in broad terms. In view of the gravity of the socioeconomic circumstances of the people and the opportunities represented by the vigorous resumption of international cooperation, it has become essential to rapidly restore the capacity to act of the State and the public sector in general.

186 In these circumstances, the strategic approach to modernization of the State is a comprehensive or systemic process articulated as follows:

- A primary role played by development and the enhancement of human resources, as these resources are the primary means of re-establishing the public sector's capacity to act

- A parallel process of managerial reform so as to impart dynamism to the operation of all essential public services at both the central and local levels

- To consolidate the new Public Administration thus established, other steps forward can be taken through the modernization of administrative technology and the physical work environment of public employees.

187 This strategy will take the specific form of six major reform programs, namely:

- Introduction of the new civil service system

- Accelerated modernization of the Central Administration's management systems

- In-depth reform of the decentralization of public services

- Effective launching of the decentralization process

- Modernization of the physical work environment of public services

- Technological modernization of the Public Administration

\section{Civil Service Reform Program}

\section{Objectives}

188 The DSNCRP seeks civil service reform in accordance with the following order of priorities:

- Introduction of a new strategic management framework, in particular at the Management and Human Resources Office (OMRH), so as to have an appropriate intervention instrument

- Preparation of the recruitment policy for new public employees

- Imparting new dynamism to the training and refresher training program for public employees

- Institutionalization of the management of civil servants' career paths

- Modernization of the regulatory framework of the civil service

- Application of an equal opportunities policy within the civil service

- Normalization of the status of contractual staff.

\section{Strategic lines}

o Institutionalization of the strategic management structures of the civil service

o Normalization of the status of contractual staff. 


\section{Management Reform Program}

189 This reform is based on the 2005 decree organizing the Central Administration of the State. In response to the major weaknesses identified previously following a diagnostic appraisal, this new legal framework lays down the new strategic management modalities by considerably strengthening the strategic coordination system, and does the same for the operational management of public service institutions by modernizing structures and providing mechanisms aimed at renovating management methods and procedures.

\section{Objectives}

Four major objectives are being pursued: (i) launch a vast movement to renovate the organizational frameworks, management methods, and procedures of the Central Administration; (ii) initiate a greater effort to renovate the cross-cutting functions of the Central Administration; (iii) continue the process of modernizing strategic coordination; and (iv) promote a new public management culture.

\section{Strategic lines}

o Organizational renovation of the management system

o Modernization of the planning system.

\section{Program to Reform the Decentralization of Public Services}

190 Two levels of territorial decentralization are defined: (i) the Delegation/Vice Delegation pairing, which provides coordination of governmental policy at the levels of the departments and arrondissements, respectively; and (ii) the deconcentrated units of the ministries and autonomous agencies.

\section{Objectives}

191 Starting from this change, the major lines of which are taking shape firmly, the DSNCRP intends to take advantage of the overall dynamic of reform to achieve the following major objectives:

- Formulate a comprehensive policy on territorial decentralization for the five-year period

- Develop the existing legal framework on territorial decentralization in general

- Strengthen the Delegations and Vice Delegations

- Promote the rapid development of decentralization in those institutions that have made progress with their plans for implementing this policy or have already entered the implementation phase

- Ensure that the renovation of the organizational frameworks of the ministries and autonomous agencies is consistent with the general principles relating to territorial decentralization.

\section{Strategic lines}

- Formulation of a national decentralization policy

- Development of the legal framework for territorial decentralization

- Strengthened territorial coordination of decentralization. 


\section{Territorial Decentralization Program}

192 Decentralization is enshrined in the Constitution of 1987, which makes it one of the primary objectives of the reform of the State. It even defines an original vision of decentralization by calling for three levels of Territorial Governments (Collectivités Territoriales-CTs) and making it possible for them to influence the functioning of the Executive, the Judiciary, and the Electoral System. Roughly twenty years after promulgation of the Constitution, the institutional reforms called for in its provisions have been carried out only to an extremely partial extent, as a result of which the framework for the CT management system is totally deficient.

\section{Objectives}

The DSNCRP will pursue the following objectives and actions:

- Preparation of a comprehensive decentralization policy

- Recast the legal framework for decentralization in the form of a Charter for Territorial Governments

- Introduce an institutional framework for steering and managing the decentralization policy

- Initiate a subprogram for capacity building in the Territorial Governments

- Launch a public awareness and decentralization promotion campaign.

\section{Strategic lines}

- Formulation of the national decentralization policy

- Strengthening of the legal framework for decentralization

- Development of a capacity building policy for Territorial Governments

- Strengthening the framework for steering and implementing the decentralization policy

- Launching a public awareness and advocacy campaign

\section{Program to Modernize the Physical Infrastructure for the Provision of Public Services}

194 The Haitian State has never undertaken either a renovation program or a construction program for public buildings to house its services, as a result of which it often houses its employees in rental properties which are quite poorly suited to the needs for which they are intended. However, the prospect of a comprehensive reform of the administration and civil service calls for a sizable investment effort focused on physical infrastructures and equipment, inasmuch as this reform process assumes and implies a work environment and tools that provide greater incentives for productivity and efficiency.

\section{Objectives}

195 The following objectives have been set:

- Construct two buildings to house the staffs of the General Secretariat of the Office of the Prime Minister (SGP), the Management and Human Resources Office (OMRH), and the National Public Policy School (ENAPP)

- Purchase equipment for the staffs of the SGP, OMRH, and ENAPP.

\section{Strategic lines}

- Improvement in the physical condition of administrative buildings

- Priority construction of two buildings

- Purchase of equipment for the new public services created 


\section{Program for the Technological Modernization of General Government}

196 The 2005 report on the degree of country readiness for e-government, recently published by the United Nations, ranks Haiti 166th out of the 191 member countries, with an overall index of 0.1786 as compared to the Caribbean average of 0.4282 . The recent study on the status of using ICTs in public administration paints the following picture:

- Many instances of overlapping between State institutions

- Still a low degree of ICT utilization

- Widely varied equipment from one institution to another

- Utilization and management of equipment that is not always efficient

- Very weak interactions between institutions and the general public

- Lack of skills in the ICT field

197 The DSNCRP identifies e-governance as one of the major focal areas of State reform with the following objectives and actions:

\section{Objectives}

- Coordinate the mobilization of all resources oriented toward carrying out activities relating to ICTs

- Develop convergence between the various actions carried out, either by public institutions or by the international community, by establishing intersectoral communications channels

- Strongly promote the State's initiatives to establish a genuine e-governance system.

\section{Strategic lines}

- Mobilization of resources

- $\quad$ Capacity building of public institutions

- Consideration of the environmental dimension

- Development of a differentiated intervention process

\section{URBAN DEVELOPMENT}

198 Over the past twenty years, the rate of growth of Haiti's largest cities picked up considerably. Indeed, the average annual rate of growth increased from 3.47 percent (1971-1982) to 4.42 percent (1982-2003) at the national level. While this situation bears witness to the vitality of the urbanization process, it also indicates the need to develop the territory and prepare urban planning policies. At present, a substantial proportion of the population living in Haiti's major cities reside in neighborhoods that lack basic community infrastructures, or their access to services (sanitation, safe drinking water, electricity, etc.) is substantially insufficient and/or of poor quality. The interventions taken at the initiative of nongovernmental organizations (NGOs) or international organizations have multiplied in a number of precarious neighborhoods in the Metropolitan Area between 1994 and 2006. However, the results are mixed, despite the funds allocated (nearly US\$33 million between 2004 and 2007) to improving living conditions and reducing poverty in the neighborhoods targeted. The capital city has unfortunately taken on the general ambiance of the major cities in the Caribbean and violence is becoming more prevalent. The State's loss of control is also reflected in criminal takeover of certain services (water points, markets) to the detriment of the general public. In order to bring this emerging violence under control an effort must be made to reconquer the city center in terms of urban planning, to restore its value by introducing the organs of power, expanding Parliament, building ministries, rehabilitating and building new premises to house the judiciary and for housing businesses. 
199 Making the cities the framework of choice for combating poverty will of necessity entail a voluntary and participatory effort to improve neighborhoods. The strategy proposed consists in emphasizing the interconnection between emergency and long-term needs in which the activities will express a broader development vision and framework oriented toward improving neighborhoods as a structuring element for the creation of jobs, poverty reduction, and the development of new relationships between socioeconomic and political stakeholders, and between public and private institutions. It is also the vision of a willing State that seeks to rehabilitate spaces which have been disregarded for too long by taking on its regulatory and normative role.

\section{General objective}

200 Contribute to sustainable urban development and poverty reduction through the preparation of, and support for the implementation of, plans for urban development and the rehabilitation of precarious neighborhoods in the cities of Haiti, controlling urban growth, developing adequate tools, and capacity building for the authorities and beneficiary communities.

\section{Specific objectives}

201 More specifically, this entails:

- Providing technical and methodological support to local stakeholders (municipalities, organized groups of beneficiaries, nongovernmental organizations, etc.) in respect of the preparation, execution, management, and monitoring/ evaluation of plans, programs, and projects aimed either at the rehabilitation of neighborhoods at risk or at the urban development of all municipal health units.

- Building the capacities of municipalities with a view to controlling the growth of at-risk neighborhoods, improving the management of urban services, and improving the living conditions of the local populations.

- Contributing to the emergence of networks between State and non-State stakeholders involved in the poor neighborhoods with a view to achieving rational and efficient use of funds in at-risk neighborhoods.

- Contributing to the emergency of a State entity focused on the rehabilitation of at-risk neighborhoods, with a view to achieving better coordination of the plans and projects under way now or in the future, and of the effective and sustainable financing of the priority needs of the people.

- Systematizing, validating, and disseminating the strategies and actions implemented with a view to their replication in other parts of the country, finding financing from donors, State institutions, and the private sector, and defining a national strategy in the area of urban development and the rehabilitation/ prevention of at-risk neighborhoods in Haiti's cities.

\section{Strategic lines of action}

- Public awareness, Structuring, and Strengthening of local populations to enable them to participate actively and dynamically in all stages (preparation, implementation, monitoring/evaluation) of the urban development and social, economic, and political rehabilitation process in their neighborhoods or municipal health units.

- Support with the consensual and participatory preparation of rehabilitation plans for at-risk neighborhoods in the urban areas of the country and urban development plans for all municipalities.

- Capacity building and institutional and governance development of State entities (ministries, subnational governments, etc.) and neighborhood organizations to enable them to control urban development, slow down out-of-control urbanization, and ensure that the standards and principles in respect of urban planning and environmental management/protection are observed, and ensure 
that project execution is monitored, in harmony with the rehabilitation plans for at-risk neighborhoods and the urban development plans.

- Seeking alliances among the various (State and non-State) stakeholders involved in at-risk neighborhoods to ensure the proper coordination of activities/projects under way in marginal urban areas, the effective and sustainable financing of the priority needs of the people, and a more rational and efficient use of funds.

- Systematization and publication of experiences, and validation of the approach and the results obtained, with a view to their replication in other areas of the country, and above all the definition of a national strategy on urban development and the rehabilitation/prevention of at-risk neighborhoods in Haiti: (1) Systematization of experiences by the universities (in a research/action and research/development dynamic); (2) Organization of workshops and forums in collaboration with the universities; (3) Sharing of experiences both with countries in Latin America and the Caribbean and with African countries, as well as with other municipalities at the national level; (4) Inventory and dissemination of the studies and papers already prepared on urban development.

- Seeking financing for the implementation of individual projects identified with local populations and of rehabilitation plans for at-risk neighborhoods: (1) Mobilization of domestic funds (taxes, NGOs, private sector, artist solidarity, taxes on remittances from the Haitian diaspora, etc.); and (2) Mobilization of external funding from international donors (World Bank, European Union, CIDA, etc.).

\section{TERRITORIAL DEVELOPMENT}

\section{Strategy as regards space}

202 In order to address poverty and growth problems, the DSNCRP is of the view that:

- Territorial development is the intelligent response to the problem raised by the need to reconcile economic growth and society's need for security.

- Territorial development entails decentralization and decentralization, as it is important that all subnational governments assume responsibility for their development dynamics in the context of balanced development of the regions.

- Strengthening collective facilities on the national and local levels is required in order to ensure that all households have access to basic services and to promote the development of productive activities. This will require a change in mentalities.

203 Improving the territory means that the Government will plan and manage the national and local territories through improved spatial programming of investments and the optimal management of resources. In this context, political decentralization and economic decentralization should work hand in hand so that territorial development ensures an appropriate spatial distribution of activities and guarantees a cohesive policy of rural renovation, namely:

- Improving the framework and living conditions of the people

- Halting the decline in agricultural employment

- Attracting new activities.

204 This effort will focus on integrated local development, starting from local master plans for territorial development and improvement at the level of the arrondissements, the framework for imparting cohesiveness and harmonization of local urban planning and commune-level development plans, and of the priority programs for structuring and development of the commune-level sections developed within same. Thus, to promote the sound and equitable development of the economy, integrated local development will use the approach of participatory, concerted, consensual, and partnership-based planning embodied in the various local 
development programs in existence throughout the country. This integrated local development will be based on strengthening or building up the "local productive system" (LPS).

\section{Objectives}

205 The basic objectives pursued are to:

1. Shed light on the future and present a clear and cohesive global vision of Haiti for the next twenty-five (25) years, through the 2032 horizon;

2. Provide a cohesive framework for all public policies and actions with respect to territorial improvement and development, thereby ensuring that the actions of the Haitian State are effective;

3. Serve as the anchor for the implementation of decentralization;

4. Guide and facilitate the spatial organization of investments so as to achieve balance among the regions and reduce territorial inequalities and major economic distortions;

5. Produce a full range of integrated actions whose interconnection should contribute to the structuring of the national territory through the utilization, exploitation, and optimal value enhancement of space and natural resources, on one hand, and the provision of major structuring equipment on a regional basis, on the other hand;

6. Structure and make optimal use of the national space, and organize urban and rural economic strengthening with a view to achieving the viable economic and social development of the country;

7. Facilitate improved utilization of public funds.

206 Specifically, this involves ultimately reconstructing the national territory on the basis of integrating the national space, solidarity between the rural and urban areas, and the competitiveness of the various territories where improvements in vast areas optimizes their productive potentials in a complementary manner so as to guarantee satisfactory living conditions to each Haitian citizen in the context of sustainable human development.

\section{Strategic lines of action:}

- Reorganization of the Ministry of Planning and External Cooperation

- Finalization of the law on territorial improvement and local development

- Decentralization of the MPCE to the arrondissement level

- Preparation of the new national master plan for territorial improvement and development

- Preparation of local master plans for territorial development and improvement in the arrondissements

- Revision of the way the national territory is subdivided

- Introduction of operational planning instruments

- Reorganization of the public investment program into a national component and local component

- Structuring of development stakeholders

- Supervision of territorial governments in the area of development planning

- Promotion of territorial development.

\section{CULTURE}

207 A number of positive factors, such as the existence of cultural wealth and a national historical legacy that have not been sufficiently tapped, are subject to various constraints that make it difficult to take advantage of them: the weakness of the cultural institutions; the deterioration of the tangible and intangible national patrimony; a pronounced tendency toward loss of the national identity, civic values, the spirit of mutual assistance, solidarity, and tolerance; the practice of 
exclusion and confrontation within the Haitian population; and the media's lack of capacity to educate, make aware, train, and inform the public.

208 It is specifically to reduce and eliminate these main obstacles that the Government's cultural policy revolves around the four (4) following focal areas:

i. Culture must be both a cement holding together the members of the Haitian community without regard to class, sex, age, and religion, the basis of solutions to the problems of the country, and one of the principal factors in national development;

ii. Culture must enable Haitians to win the battle for sustainable development, to safeguard their dignity as a people, and to hold sway over other nations;

iii. The primary cultural resources to be exploited are the arts and literature, archeological, historical, and natural sites, as well as popular and ancestral traditions;

iv. Cultural actions will be focused on a generalized and decentralized popular culture.

\section{Objectives}

209 The objectives to be pursued are to:

- Make culture and communications the main foundations of the country's economic and social development;

- Improve the intervention and dissemination capacities of the cultural and communications institutions;

- Safeguard, protect, and enhance the value of the cultural heritage, whether tangible or intangible, as well as popular traditions;

- Develop the arts, literature, and cultural industries.

\section{Strategic lines of action}

210 The strategic lines of action identified are:

- Institutional strengthening and decentralization through the rehabilitation, restructuring, and expansion of the cultural intervention and dissemination systems;

- Protection, enrichment, and enhancement of the value of the nation's tangible and intangible cultural heritage;

- Promotion of artistic, artisanal, and literary creation, and of a pluralistic and democratic society;

- Development of cultural cooperation ties with foreign countries. 


\section{CHAPTER 9 \\ Growth and Poverty Reduction Strategy Objectives}

211 Following a deep recession in 2004, the Haitian economy has gradually returned to the path of growth. The estimates currently available are such that the anticipated growth rate for 2007 will, while confirming the recovery beginning in 2005, nevertheless fall below the target of 4 percent set at the start of the year. Overall, the macroeconomic performance achieved during 2007 has been satisfactory, and generally in keeping with the objectives set at the start of the fiscal year, namely: (i) real GDP growth of 4 percent; (ii) an inflation rate in the 8-9 percent range; and (iii) gross foreign exchange reserves equivalent to somewhat more than 2 months' imports.

212 Thanks to the quality of macroeconomic management in recent years, economic growth is resuming in a context characterized by the consolidation of the economic fundamentals. Since February 2007 the inflation rate has been hovering around 8.0 percent; the fiscal deficit should be very near GDP; and the current balance of payments is expected to register a surplus. All this has helped make it possible to accumulate exchange reserves over the past three years. Gross foreign exchange reserves currently represent almost 2.5 years of imports, as compared to 1.4 months in September 2004. Overall, a review of the changes in the major macroeconomic indicators suggests that the macroeconomic conditions regarded as prerequisites for a return to growth are now being met. In order to consolidate the foundations for sustainable growth in the context of implementing the growth strategy, it will be necessary to strengthen the macroeconomic performance achieved and, in particular, to continue the economic stabilization effort.

\section{Growth and poverty reduction strategy objectives}

213 To roll back poverty in Haiti, it will be essential to guarantee rapid and sustained growth of the Haitian economy in the years ahead as well as to dampen the structural inequalities. For the 20072009 period, the annual average growth rate is set at 3.5 percent. For fiscal $2006 / 2007$, estimates have shown a 3 percent rate, and projections for 2007/2008 indicate a 3.7 percent rate. For subsequent years, average annual growth of 4 percent is anticipated.

214 To make sustained growth possible, the first three years should be focused on consolidating the gains made in the area of macroeconomic stabilization and strengthening the objective conditions for economic revitalization. These necessary conditions pertain in particular to:

0 Further strengthening the results obtained as regards security,

o Improving the business climate,

o Building the institutional capacities of public administrations,

o Reforming economic governance,

0 Rehabilitating and developing infrastructure.

215 On average, the GDP growth rate from 2000 to 2006 was approximately -0.1 percent. However, transfers from the Haitian diaspora contributed significantly to the economic support of the population. With annual average real GDP growth of 4 percent, a population growth rate of 2.3 percent, and an elasticity of the incidence of poverty in relation to the rate of growth of real per capita incomes estimated at $-1.13,{ }^{6}$ it would take about 36 years to reduce poverty by half in the absence of other changes. Moreover, according to the poverty rate model (the one for US\$1 per day PPP), under these circumstances poverty would decline from 55.0 percent in 2007 to 47.1 percent in 2015. In order to achieve growth rates compatible with an objective of significantly reducing poverty, it will be necessary to implement an accelerated growth strategy.

216 To achieve growth rates likely to induce a notable decline in the incidence of poverty, it will be essential to provide adequate incentives to producers operating on the Haitian market as well as to

\footnotetext{
${ }^{6}$ This is the Ravallion elasticity determined, in the case of Haiti, by using a Gini coefficient of 50.5. The model was estimated on the basis of survey data collected for a sample of 62 countries (Ravallion, 2004). The elasticity is given by: $-9.33 *(1-\text { Gini })^{\wedge}$.
} 
workers to encourage them to improve their productivity. In a context of increased liberalization of international trade, increasing the productivity of stakeholders in the economy is imperative as a condition for enhancing the competitiveness of products manufactured in Haiti and services offered from Haiti.

217 Regarding the competitiveness of the Haitian economy, the trend line appreciation of the real exchange rate is of some concern in that it risks having a negative impact on the price competitiveness of Haitian exports. To address this development, which appears to be a deepseated trend in the Haitian economy, the Government will make the necessary efforts to ease the constraints on private initiative, in particular the inadequacy of basic infrastructures, the deficiencies of existing infrastructures, the low productivity of production factors, the shortage of skilled human resources, difficult access to credit, inefficiencies in public administration, and political instability.

218 Given the prospects for market diversification and increased export volumes, the entire growth strategy of countries such as our own calls for a significant increase in investment, in particular in export-oriented branches of activity. An investment promotion and incentive campaign will be aimed simultaneously at foreign investors, Haitians in the diaspora, and Haitians or foreigners already operating in Haiti. Taken together, the policies set forth in the DSNCRP will contribute to creating an environment conducive to investment. Specifically, the measures relating to political stability, strengthening of the legal and regulatory framework, improving economic governance, and the preservation of macroeconomic stability will play a primordial role in promoting foreign direct investment (FDI). In addition, public investment in basic infrastructures and in building the stock of human capital will contribute to the establishment of an environment conducive to private initiative and will thus serve as a catalyst for private sector investment.

219 Poverty reduction will arise not only from the mechanical effect of increasing per capita incomes, but also from the implementation of policies aimed at reducing inequalities. The efforts to combat income inequalities and social exclusion are an integral part of the strategy. By favoring an increase in the share of national income held by the poor, it will make it possible to guarantee "pro-poor" growth. Because, despite the recent changes in favor of urbanization, the Haitian economy remains largely rural, the poverty reduction strategy must devote special attention to the promotion of agriculture, and beyond that, to the development of the activities of the rural economy. In order to have a lasting effect on poverty, economic policies will place employment at the heart of their concerns, and consequently the alignment of these policies will take place in the context of a job-creating growth strategy.

220 The success of the poverty reduction strategy will depend upon the combined effect of a group of public policies. The strategy adopted by the DSNCRP revolves around four fundamental focal areas:

o Promotion of rapid, sustained, and pro-poor economic growth;

o Increased investment in human capital and improved access to basic social services;

o Protection of vulnerable groups, preservation of the environment, and management of major risks;

o Strengthening of institutions, modernization of the State, and the promotion of good governance.

\section{Macroeconomic policies}

221 By extending the stabilization effort initiated in the third quarter of 2004, the policies followed made a contribution to the gradual restoration of macroeconomic equilibrium. The results obtained are, overall, satisfactory, and they make it reasonable to expect macroeconomic changes in line with the objectives set at the start of the fiscal year. The Government is determined, during the 2007-2011 period, to restore macroeconomic conditions conducive to the resumption of growth, and to pursue macroeconomic stability. This being so, the inflation target has been lowered from 8 percent in 2007 to 7 percent in 2009, and for 2011 it is projected that inflation will be even lower. 
For the 2007-2009 period, the economic and financial program of the Haitian Government has been negotiated with the International Monetary Fund (IMF). Following approval by the IMF Executive Board in November 2006, the program has benefited from support under the Poverty Reduction and Growth Facility (PRGF). The macroeconomic framework of the DSNCRP was designed on the basis of the main guidelines of the interim Poverty Reduction Strategy Paper (IPRSP), and is fully in keeping with the economic and financial policy memorandum for the PRGF.

\section{Chart 10.1: Growth and Inflation (in percent)}

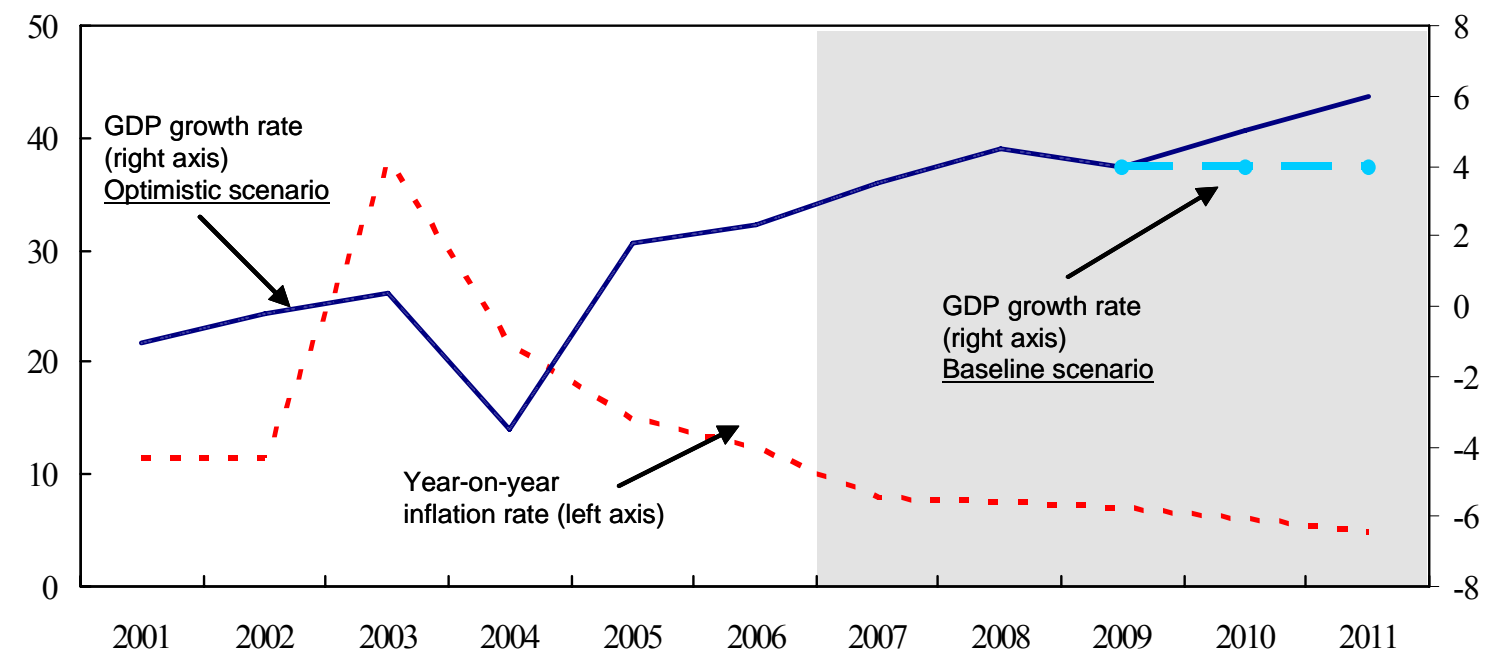

\section{Fiscal and tax policies}

223 In view of the demands posed by the poverty reduction objectives, the revenue of the Haitian State would appear to be sufficiently modest to justify taking action. At present, the ratio of tax receipts to GDP is only slightly above 10 percent. The tax policy will be aimed on a priority basis to increasing the tax ratio from 10 percent in 2006 to 14 percent by 2011 . The main categories of the tax reform measures contemplated will be aimed at strengthening the institutional capacities of the tax administrations and improving the efficiency of their actions, streamlining the system of tax exemptions, improving the coverage of rural activities, integrating operators in the informal system into the tax system, revising and updating the tax legislation, strengthening customs control throughout the national territory, and particularly at the provincial ports, adjusting the tax schedules, in particular in order to take account of the erosion brought about by inflation, correcting the distortions induced by certain taxes (taxes on petroleum products, for example), and readjusting certain rates that are deemed to be relatively low (the turnover tax rates, for example) or too high (those for registering mortgages, for example).

224 In tandem with the tax revenue mobilization efforts, the State will ensure improvement in the allocation of public expenditure by regularly increasing the relative weight of the expenditure allocated to public investment and by improving the targeting and execution of expenditure in the priority sectors. For the 2007-2011 period, the Government plans to hold current expenditure to about 56 percent of all public expenditure, thereby contributing to the determination of the budgetary space necessary for pursuing the objectives set under the growth and poverty reduction strategy.

225 The total expenditure of the public administration will increase regularly to reach approximately 21 percent by 2011 . For the 2007-2011 period, such expenditure will increase from an average of 19 percent of GDP. Investment expenditure, representing slightly over 8 percent of GDP on average, will be 65 percent financed by external resources. All current expenditure as well as a portion of investment expenditure will be covered by domestic resources equivalent to 
approximately 14 percent of GDP. The Haitian State will endeavor to guarantee the effectiveness of public expenditure during the period by orienting the allocation of such spending in light of the priorities established by the poverty reduction strategy. The Public Expenditure Management and Financial Accountability Review (PEMFAR) conducted jointly by the World Bank, the InterAmerican Development Bank (IADB), and the Haitian Government provides detailed information on the public expenditure management systems, the institutional capacities of the administrations, and the allocation of expenditure in the priority sectors.

\section{Chart 10.2: Tax Revenue and Public Expenditure}

(as percent of GDP)

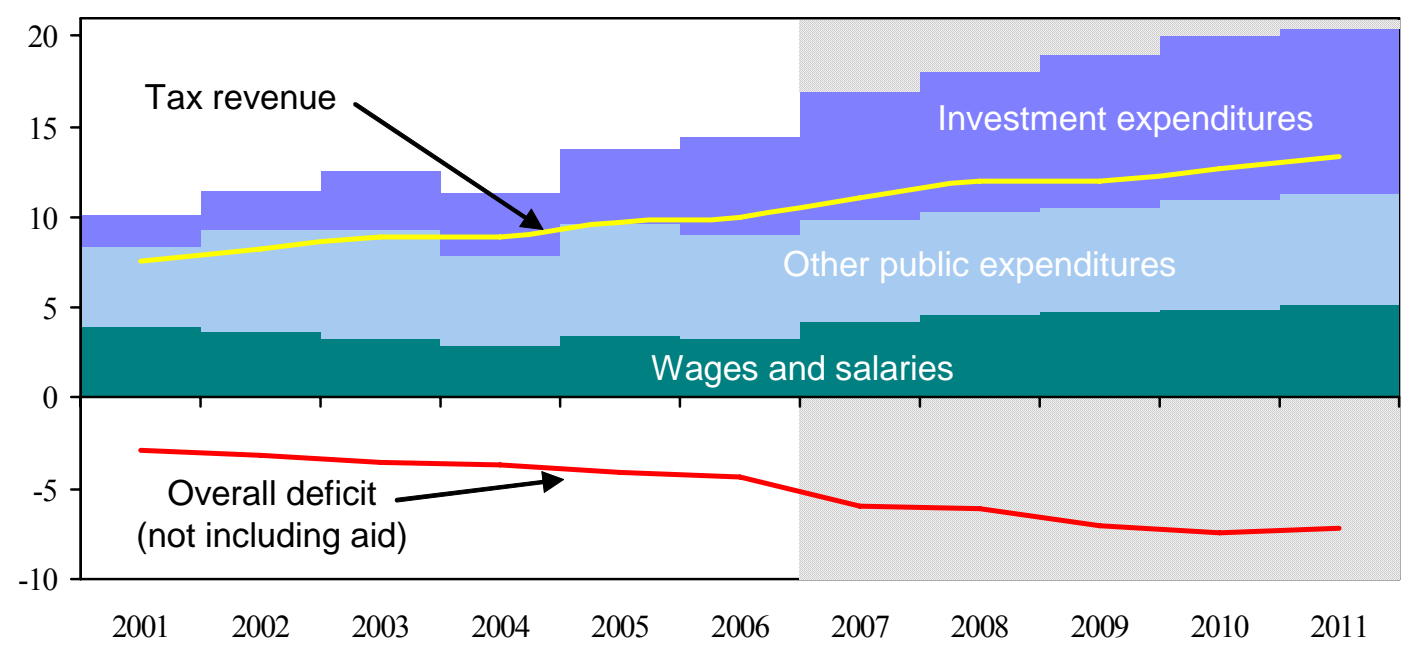

226 Over the past three years, the Haitian Government has made a considerable effort to improve the allocation of budgetary resources in favor of education and health, and has also favored expenditures in the priority sectors of agriculture and infrastructure. Expressed in terms of a percentage of GDP, education and health expenditure for the 2005-2007 period represented on average 2.4 percent and 1.4 percent, respectively, as compared to 1.6 percent and 0.7 percent for 2002-2004. The 2007/2008 budget confirms the impetus imparted to benefit the priorities of the DSNCRP.

227 Despite the significant increase in the share of public resources allocated to the priority sectors between 2004 and 2007, the corresponding budgets are still small. In order to improve the management of public expenditure at the central level, the Haitian Government plans to revise the budget preparation and execution procedures while, at the same time, it consolidates the internal control mechanisms and strengthens the institutional mechanisms of the Supreme Court of Accounts and Administrative Disputes (CSCCA). These reforms have already been initiated, and must be continued at a more sustained pace. The reform measures relate to the legal framework for public finance management, budget preparation methods, the budgetary information system, budget execution modalities, the monitoring and control mechanisms, and the public procurement system. To improve both the effectiveness and the quality of public expenditure, the Government intends to prepare and implement a Medium-Term Expenditure Framework (MTEF). This instrument will facilitate making the macroeconomic and sectoral policies more consistent with the public expenditures programmed and the expenditure effectively carried out. It will make it possible to take macroeconomic constraints into account in the programming of public expenditure and will facilitate intersectoral arbitrage. The Medium-Term Expenditure Framework will contribute to improving the predictability of the budget ceilings assigned to the various sectors.

228 The fiscal policy will be aimed at containing the deficit on State financial operations at a sustainable level that is compatible with the financing anticipated. The Government will take care 
to ensure this sustainability while ensuring the adequate coverage of the needs identified in the priority sectors. To contain the overall deficit of the public administration within reasonable limits compatible with the macroeconomic stability objectives, it will be necessary to increase tax receipts significantly, in addition to which the supplementary resources obtained in grant form will need to be maintained at a relatively high level. The overall deficit will be financed exclusively by external resources, as no recourse to Central Bank financing is contemplated for the 2007-2011 period. The available information makes it possible to anticipate that the overall deficit for 2007 should amount to -0.3 percent of GDP; however for the subsequent years and until 2011, it is projected that this deficit will widen to about -3 percent of GDP. As calculated, and excluding grants, the overall deficit of the public administration would amount to about -6 percent of GDP in 2007 and should gravitate around -7 percent of GDP between 2007 and 2011. These estimates of the overall deficit excluding grants highlight the critical importance of external grants in maintain the budgetary equilibrium of the Haitian public administration. In a context characterized by the low amount of tax receipts collected by the Haitian State, and given the gradual nature of the effort to increase the tax ratio between 2007 and 2011, it will consequently be essential to guarantee, to the greatest extent possible, the predictability of the flows of State budgetary resources stemming from external grants. The projections made for the 2007-2011 period and based upon historical trends indicate levels of external grants somewhere in the range of 4 to 5 percent of GDP. Such levels are appreciable, to be sure, but it would be desirable for Haiti to obtain additional resources in grant form in order to avoid financing gaps that could be engendered by the risks of macroeconomic imbalance. An increase in grants on the order of 2 percent of GDP over the average level would make it possible, for example, to cover the financing gaps projected for the last three years of the period.

229 The Haitian State is determined to conduct a prudent external borrowing policy in order to contain Haiti's debt at a sustainable level that is compatible with its repayment capacity. Moreover, in accordance with the commitments entered into in the context of the PRGR, the Government will not accumulate external debt arrears. To supplement the borrowing contracted on concessional terms, implementing debt relief initiatives will make it possible to release additional resources to finance a package of priority expenditures in support of the poverty reduction strategy.

\section{Monetary policy}

230 The monetary policy developed in the DSNCRP context will be aimed largely at establishing and maintaining a moderate inflation rate over the strategy implementation period. This will entail not only the achievement of low inflation rates, but especially of keeping the low in order to be able to have a positive impact on the expectations of economic agents. In the context of a growth and poverty reduction strategy, it is right and proper to guarantee low inflation, as inflation acts as a regressive tax on household incomes by eating away at the wages and assets held by the poor. Moreover, inflation may, depending on expectations, have undesirable effects on economic growth and income redistribution. High inflation generates uncertainty as to the general price level in the future, and consequently keeps prices high even if efforts are made to enhance efficiency. It also contributes to increasing the risk premium reflected in interest rates, thereby inhibiting investment. In addition, in a context of high inflation, relative prices tend to fluctuate considerably and therefore give of signals that can have a negative impact on resource allocation in the economy.

231 The disinflation policy will be continued between 2007 and 2011 . The fiscal discipline demonstrated over the past three years has, for the time being, eased the main constraint on the conduct of monetary policy. In deciding to maintain this discipline, that is, by continuing to avoid Central Bank financing of public deficits, the Haitian authorities hope to facilitate monetary management during the 2007-2011 period and promote the achievement of monetary conditions that favor economic growth. Among the many reforms to be undertaken, the Central Bank will need to clarify and adjust the framework for executing monetary policy in such a way as to 
strengthen the mechanisms for signaling monetary policy and increasing the effectiveness of the instruments used.

\section{Balance of payments}

232 When official transfers are excluded, the current balance of payments, expressed as a percentage of GDP, registered a deficit of slightly more than 6 percent of GDP in 2007. Between 2007 and 2011 , this deficit including official transfers is expected to average about 8 percent of GDP, with a slight upward trend owing to the continuing deterioration in the trade balance. However, if official transfers are included, the current account balance for 2007 would be reduced to slightly over 1 percent of GDP. Moreover, in recent decades the current account deficit has generally been less than 2 percent of GDP. The current account deficit estimates for the 2007-2011 period use the assumption that private flows from the Haitian diaspora constitute a permanent and generally stable component of Haiti's balance of payments. These private transfers are expected to represent over 20 percent of GDP in 2007 and do maintain more or less comparable levels over the period. The growing importance of current transfers, and especially the relative weight of transfers from emigrant workers, has the effect of significantly reducing the level of the current deficit while simultaneously contributing to ensuring the medium-term sustainability of the current account of the balance of payments.

233 On the assumption that flows of current transfers are satisfactorily predictable, and in the absence of major crises, the current transactions deficit is projected to change very little in terms of GDP between 2007 and 2011. Accordingly, the balance of payments should exert only small pressures on exchange reserves. In order to address external shocks, the target for gross exchange reserves is to accumulate the equivalent of three months' imports of goods and services. An increase in current transfer flows and the anticipated increase in flows of foreign direct investment (FDI) should facilitate this accumulation.

\section{Macroeconomic outlook for 2007-2011}

234 For purposes of briefly analyzing the outlook for 2007-2011, two different scenarios have been considered. The difference between the two is fundamentally based on an increase in economic activity in the last two years of the period resulting from higher investment levels, these owing to improved absorptive capacities of the Haitian economy and improvements in the level of resource mobilization. The projections are focused primarily on the 2007-2011 period, although for purposes of characterizing the scenarios the average growth rates have been maintained through 2015 at 6 percent and 4 percent, respectively, for the optimistic scenario and the baseline scenario. Using these assumptions, the respective rates of poverty reduction were calculated using, once again, the Ravallion model. They are shown in Table 10.1. A review of the available demographic indicators suggests that the Haitian population is currently in a demographic transition phase. Accordingly, instead of using the inter-census rate of 2.3 percent calculated by the IHSI, the population growth rates used correspond to a series estimated by the IHSI which reflects the demographic transition phenomenon. The population growth rate is now estimated at 2.1 percent, gradually declining to 1.9 percent by 2015 . Using these assumptions, in the baseline scenario the rate of poverty reduction by 2015 would be roughly 17 percent, whereas under the optimistic scenario the poverty rate would be reduced by almost 27 percent. 
Table 10.1: Delineation of the Various Scenarios

\begin{tabular}{|c|c|c|c|c|c|c|}
\hline Scenario & & 2007 & 2008 & 2009 & 2010 & 2011 \\
\hline \multirow{2}{*}{ 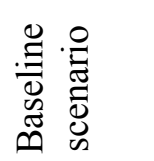 } & Per capita GDP growth rate & $1.4 \%$ & $2.4 \%$ & $1.9 \%$ & $1.9 \%$ & $1.9 \%$ \\
\hline & Poverty rate $^{1}$ & 55.0 & 53.5 & 52.4 & 51.2 & 50.2 \\
\hline \multirow{2}{*}{ 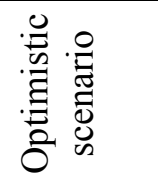 } & Per capita GDP growth rate & $1.4 \%$ & $2.4 \%$ & $1.9 \%$ & $2.8 \%$ & $3.8 \%$ \\
\hline & Poverty rate $^{1}$ & 55.0 & 53.5 & 52.4 & 50.7 & 48.5 \\
\hline
\end{tabular}

1/ Calculated using the Ravallion elasticity: $\varepsilon=-9.33^{*}(1-\text { Gini })^{\wedge 3}$, with the Gini coefficient estimated at 50.5 .

235 The growth targets under the two scenarios are based on similar assumptions with regard both to the external environment for the Haitian economy and to its internal dynamics. These targets take account of the structural impediments, and in particular the supply constraints with which the Haitian economy must deal. The targeted average rates are thus relatively modest, especially early in the period, in that it will be necessary to consolidate the bases for accelerated growth if it is to be sustainable. The main assumptions adopted are as follows: continuing improvement in the climate of security, implementation of measures to protect vulnerable groups, pursuit and maintenance of macroeconomic stability, efficient mobilization of external resources, significant increase in tax receipts, rehabilitation of basic infrastructure, increased investment in networked infrastructure, increased investment in human capital, strengthened institutional capacities, and the promotion of good governance. The difference between the two scenarios is attributable largely to differences in investment levels.

\section{Baseline scenario:}

i. Investment increases on average by 10.8 percent between 2007 and 2011, with a pronounced trend toward increased public investment. Private investment, the weight of which is three times higher, also is dynamic to some extent.

ii. Exports increase at a sustained pace, largely as a consequence of taking advantage of the opportunities afforded by the HOPE Act.

iii. The rehabilitation of rural infrastructures and the organization of rural entrepreneurs favor the production and export of leading agricultural products.

iv. A number of tourism enclaves become operational by the end of the period and, in the interim, increased efforts are made to promote tourist visits by foreign nationals of Haitian origin.

v. The renewed vigor of the tourism industry, the dynamism of agriculture, and the good health of the construction and public works subsector have positive effects on sustained employment and hence on household demand. End consumption increases at an average rate of 3.8 percent, sustained by increased incomes and the growth of current transfers.

\section{Optimistic scenario}

i. The same assumptions are used for the optimistic scenario. The difference between the two scenarios stems largely from the fact that, in the optimistic scenario, resource mobilization is more effective. On the one hand, the tax receipts collected in 2010 and 2011 are greater, and, on the other hand, external grants increase and make it possible to add resources to external budgetary support. 
ii. The bulk of the additional resources will be used to increase public investment expenditure over the last two years of the period. The financing gaps for 2010 and 2011 will be maintained at approximately the same level in terms of absolute value.

iii. The optimistic scenario also assumes a significant increase in the absorptive capacity of the public administration as well as higher budget execution rates, among other things.

iv. Moreover, the optimistic scenario projects an improvement in external demand, reflected in more rapid export growth.

236 In the optimistic scenario, end consumption grows in real terms at an average pace close to that observed over the period for the baseline scenario: 3.9 percent as against 3.7 percent. In both cases, the growth rate of end consumption is less than the GDP growth rate. Investment is more dynamic as regards both the public investment component and the private investment component: 21.0 percent as against 17.9 percent for the former, and 10.1 percent as against 8.9 percent for the latter. This relative increase in investment is explained, on one hand, by improved utilization of budgetary resources and, on the other hand, by the behavior of the private sector in response to the incentives introduced by more cohesive public policies. Businesses also take advantage of better conditions created through improved security and the completion of infrastructure works. While, at the start of the period, it is logical to conclude that investment growth will be driven primarily by public investment, at the end of the period, private investment should prove more dynamic. Finally, despite a vigorous rebound in exports, external demand continues to fall short of imports. These expand at a rate that is two times higher in the optimistic scenario.

Table 10.2: Anticipated Changes in Aggregate Demand Components

\begin{tabular}{|l|c|c|}
\cline { 2 - 3 } \multicolumn{1}{c|}{} & \multicolumn{2}{c|}{$\begin{array}{c}\text { Growth rate 2007 - 2011 } \\
\text { (at 1986/1987 prices) }\end{array}$} \\
\cline { 2 - 3 } \multicolumn{1}{c|}{} & Baseline scenario & Optimistic scenario \\
\hline GDP & $4.0 \%$ & $4.6 \%$ \\
\hline Imports & $7.9 \%$ & $13.8 \%$ \\
\hline Consumption & $3.7 \%$ & $3.9 \%$ \\
\hline Investment & $10.8 \%$ & $14.3 \%$ \\
\hline Exports & $13.1 \%$ & $30.0 \%$ \\
\hline
\end{tabular}

\section{Risk factors}

237 The macroeconomic framing of the DSNCRP is based on favorable assumptions as to changes in the international environment of the Haitian economy as well as to the determination of internal factors likely to have a negative impact on the results anticipated. The scenario presented above is consequently deliberately optimistic. It effectively takes the stance that the risks incurred on the macroeconomic side are, overall, controllable, and that consequently the growth and poverty reduction objectives could be achieved for the 2007-2011 period. However, to mitigate any problems that could arise during the implementation of macroeconomic policies, it is advisable to assess the various risks of the strategy and plan for measures to attenuate their undesirable effects. These risks stem from more than the possibility of shocks of various kinds that could affect macroeconomic equilibrium. In the text that follows, we will briefly review the principal risks of a political, institutional, economic, and natural order which could affect the macroeconomic framework of the DSNCRP and jeopardize meeting the objectives sought. 
238 Political stability can, as in the past, have multiple harmful effects on a great many economic variables. For example, it can lead to the drying-up of external resource flows and, for example, impede the execution of expenditure under the Public Investment Program, and thereby have a negative impact on growth and poverty reduction. The risks associated with institutional shortcomings and the quality of governance are a special category of risks which might arise from, among other things, inadequate implementation of the measures called for in the context of the DSNCRP, the adoption of inappropriate supplementary measures, and the weakness of institutional capacities on the part of the public administrations.

239 Examination of the time profile of external aid over the past two decades sheds light on the high degree of instability in the reactions of Haiti's international partners to the multiple political crises that broke out during that period. In order to control the risks engendered by the variability of the amounts of aid granted and to mitigate the potential insufficiency thereof, the Government intends to draw up the financing component of the Medium-Term Expenditure Framework (MTEF) in close collaboration with donors so as to ensure the solidity of their commitments at a sufficiently long time horizon.

240 As a small, open economy in the Caribbean, Haiti is particularly sensitive to changes in its external environment and especially to changes in the economic cycle of the U.S. economy. In particular, the likely slowdown in the U.S. economy, in response to the crisis in the subprime mortgage market, must be examined from the standpoint of its potential impact on the objectives set for the beginning of the period.

241 Haiti's poorly diversified exports currently are characterized by nearly 90 percent of the total being accounted for by a single product category: textile products assembled in Haiti, products which benefit from the preferential regimes granted to Haiti by the Caribbean Basin Initiative (CBI) and, more recently, by the "Haitian Hemispheric Opportunity through Partnership Encouragement Act" (HOPE). By absorbing about 85 percent of Haitian exports, the United States is clearly Haiti's main export market. This preponderance of the U.S. market and the intense concentration on a single product category entail inherent risks that need to be assessed.

242 Recent developments on the oil market are raising increasing concerns. Unfavorable changes in crude oil prices can have a serious impact on the extent to which growth objectives are achieved. An oil price increase is immediately reflected in the various activity parameters in the sectors, notably through increased energy and transport costs. It is therefore advisable to take into account the strong likelihood that high oil prices will stay high. In addition to the oil market, changes in the market prices of other products, such as wheat or rice, are of critical importance for Haiti's balance of payments. Food products and petroleum products represent about 30 percent and 25 percent, respectively, of total goods imported.

243 Finally, natural risks constitute a risk category that cannot be disregarded. Indeed, Haiti is highly exposed to natural disasters and its physical environment has deteriorated seriously in recent decades. 


\section{CHAPTER 10 \\ Strategy Financing, Implementation, and Monitoring}

\section{QUANTIFICATION AND FINANCING OF THE STRATEGY}

244 The operationalization of the National Growth and Poverty Reduction Strategy (SNCRP) requires considerable efforts in terms of mobilizing financial, material, and human resources. Accordingly, it depends upon the support of all national and international stakeholders for financing the target actions.

\section{Costs of operationalizing the National DSNCRP}

245 The National Growth and Poverty Reduction Strategy (SNCRP) will require, for its operationalization over the 2007-2010 period, an amount totaling One Hundred Fifty-Four Billion Five Hundred Sixty Million Gourdes (G 154,560,000,000), or Three Billion Eight Hundred Sixty-Four Million U.S. Dollars (US\$3,864,000,000). The implementation costs are a reflection of the resource requirements. The approach used was to prioritize the target actions with a view to creating conditions conducive to keeping Haiti on the economic growth path and reaching out to the most vulnerable groups affected by poverty. These requirements are organized by the major activity areas of the Government and reformulated as Pillars, namely: (i) growth vectors; (ii) human development; and (iii) democratic governance. The pillars are supported by specifically targeted strategies and by cross-cutting strategies for some areas.

246 The costs of DSNCRP implementation are rather crudely calculated at this stage. They will be further refined once the plans for carrying out the target actions have been specifically defined at the level of the various pillars. The breakdown of the financing requirements for the strategy by pillar and action area is as follows:

o Pillar 1 - Growth vectors: groups together the strategic sectors, namely: agriculture and rural development, tourism, trade, industry, and infrastructures. The estimated requirements are on the order of Seventy-Eight Billion Two Hundred Sixty Million Gourdes $(\mathbf{G} \mathbf{7 8 , 2 6 0 , 0 0 0 , 0 0 0 )}$, or $\mathbf{5 0 . 6}$ percent of the total.

o Pillar 2 - Human development: groups together the education and training, health, and water and sanitation sectors. The estimated requirements for this pillar are on the order of Thirty-Three Billion Gourdes (G 33,000,000,000), or 21.4 percent of the total.

o Pillar 3 - Democratic governance: covers justice, security, public finance reform, and the incentive framework for private initiatives. The estimated requirements are on the order of Twelve Billion Three Hundred Million Gourdes (G 12,300,000,000) or 8 percent of the total.

o The Specific and Cross-Cutting Policies and Strategies address, among other things, the environment, risks and disasters, gender equality, territorial development, urban development, food security, social protection, and building the capacities of the State. Their requirements are estimated at Thirty-One Billion Gourdes (G 31,000,000,000), or 20 percent of the total. The table which follows provides an estimate of the financing requirements of the strategy for the 2007/2008- 2009/2010 period. 
Table 12 - FINANCING REQUIREMENTS FOR THE 2008-2010 PERIOD

\begin{tabular}{|l|l|l|}
\hline \multicolumn{1}{|c|}{ Financing the DSNCRP } & 2007/08-2009/10 & $\%$ \\
\hline PILLAR 1 - Growth vectors & G 78,260,000,000 & 50.6 \\
\hline PILLAR 2 - Human development & G 33,000,000,000 & 21.4 \\
\hline PILLAR 3 - Democratic governance & $\mathbf{G ~ 1 2 , 3 0 0 , 0 0 0 , 0 0 0}$ & $\mathbf{8}$ \\
\hline Specific and Cross-Cutting Policies & $\mathbf{G ~ 3 1 , 0 0 0 , 0 0 0 , 0 0 0}$ & 20 \\
\hline TOTAL & $\begin{array}{l}\mathbf{G ~ 1 5 4 , 5 6 0 , 0 0 0 , 0 0 0} \\
\mathbf{U S} \$ 3, \mathbf{8 6 4 , 0 0 0 , 0 0 0}\end{array}$ & $\mathbf{1 0 0}$ \\
\hline
\end{tabular}

\section{Financing strategy for the National DSNCRP}

247 The basic principle of financing the National Growth and Poverty Reduction Strategy (SNCRP) is the preponderant role of the State in orienting and driving all development stakeholders. Efforts will be focused on mobilizing both domestic and external resources. The strategy will thus consist in exploring all possibilities for domestic financing while relying on the international community, which will participate significantly in the financing of actions oriented toward promoting growth and poverty reduction. In this regard, local resources, budgetary support, concessional borrowing, and foreign direct investment will make a major contribution toward driving economic and social development activities, especially those focused on poverty reduction.

248 The funds accruing from debt relief in the context of the Heavily Indebted Poor Countries (HIPC) Initiative should contribute significantly to financing the DSNCRP. Public finance reforms will also be introduced. In addition, it is hoped that resources will be mobilized from all our bilateral and multilateral partners to ensure the success of the strategy in terms of growth and poverty reduction. However, at the same time, considerable domestic efforts will be undertaken with a view to increasing tax yields so as to have further resources available, which should facilitate development financing.

\section{Risks associated with National DSNCRP financing}

249 The Haitian economy still has problems with deploying its productive resources with a view to ensuring the self-financing of its development, and remains highly vulnerable because of its significant dependence on the international community. Moreover, it is every bit as important to ensure reaching the completion point under the HIPC Initiative, in particular by observing the associated conditionalities. It is even more important to introduction strong and functional structures which can make optimal use of development assistance resources, and to strengthen institutional capacities to improve the absorption of aid.

250 Furthermore, increasing domestic resources is heavily dependent on the tax collection and political and economic stabilization efforts, which must play a preponderant role in improving Haiti's capacity to address DSNCRP financing requirements. Although the more specific costs of financing actions under the DSNCRP have not yet been determined, it is quite likely that the financing gap will be sizable and will not be able to be absorbed by the resources projected. 


\section{MONITORING AND IMPLEMENTATION}

\section{Institutional monitoring framework}

251 There are two levels to the implementation structure: the first is strategic, reporting to the President of the Republic; the second is operational, coordinated by the Prime Minister. These two levels bring together the main development partners, namely the private sector, territorial governments, and the cooperation sector, including the international agencies and NGOs. Overall, this implementation structure is under the ultimate control of the President of the Republic, who sponsors, for this purpose, the National Commission of Investments (NCI), which has the objective of promoting the competitiveness of Haitian resources as well as the performance of public investments, including those concerning the major work areas [Grands Chantiers] Within the commission, the Prime Minister (BPM) manages a Priority Arbitration Committee, whose central role is to give direction to public investments. The Secretariat of the National Commission of Investments (NCI) is confirmed by the Ministry of Planning and External Cooperation. The implementation structure takes the following form.

\section{At the strategy level:}

\section{National Investment Commission (CNI)}

252 The President of the Republic sponsors a National Investment Commission (CNI), the instrument whereby the Executive Branch can exercise its oversight over the fulfillment of its development vision as set forth in the DSNCRP, and along the lines defined by the Major Activity Areas. This commission will make it possible in particular for the Head of State to have a clear notion of the implementation of the development priorities and of the rate of return achieved, that is, what must be done in order to apply the development vision, and of its impacts on the competitiveness of human resources, changes in the major work areas, household living conditions, and growth. The President of the Republic would then take the corrective measures required.

\section{Priority Arbitration Committee (CAP)}

253 For his part, the Prime Minister chairs the work of a Priority Arbitration Committee (CAP) whose function is to properly steer public investment with a view to achieving the development goals set forth in the DSNCRP, which are aligned with the major work areas. The members of this Committee include the MPCE and the MEF. The Prime Minister acts within this committee through the Public Policy Coordination and Monitoring Unit (CCS) ${ }^{7}$ and the Budgetary Affairs Unit (CAB) of Office of the Prime Minister (BPM).

\section{At the operational level:}

\section{National Office for Implementation Coordination (CNM)}

254 The MPCE, in addition to carrying out its functions relating to the governance of development assistance and the national development priorities, determines, through its Technical Directorates supported by the National Poverty and Social Exclusion Observatory (ONPES) currently being set up, the steps required for applying the strategy so as to identify and provide the performance indicators for the actions agreed and the operating plans. It also works together with the Ministry of Economy and Finance and the sectoral ministries through the Research and Programming Units.

\footnotetext{
${ }^{7}$ See the Decree reorganizing the Central Administration.
} 


\section{Institutional framework for the DSNCRP}

255 The Ministry of Planning and External Cooperation is responsible for the coordination and monitoring of DSNCRP implementation. The various technical directorates of the MPCE distribute among themselves the responsibilities for coordinating, implementing, and monitoring and evaluating the DSNCRP. These directorates will be supported not only by the National Poverty and Social Exclusion Observatory (ONPES), but also by the Research and Programming Units (UEPs) of the sectoral ministries.

\section{Monitoring instruments}

256 The following instruments will make it possible to monitor the objectives pursued by the DSNCRP:

o The Macroeconomic Framework

o The Budget of the Republic

o The Public Investment Program (PIP)

o The Medium-Term Budgetary Framework (MTBF)

o The Medium-Term Expenditure Framework (MTEF)

0 The budget reconciliation laws for the various fiscal years

o The Sectoral Medium-Term Expenditure Frameworks (SMETFs).

o DSNCRP monitoring and evaluation mechanism

257 The monitoring and evaluation mechanism to be put in place has three components:

o Execution monitoring

o Impact monitoring

o Participatory monitoring.

\section{Monitoring of DSNCRP implementation}

258 Monitoring execution covers the physical and financial implementation of all the actions set forth in the National Growth and Poverty Reduction Strategy Paper (DSNCRP). It will be carried out in the context of a participatory approach involving the permanent structures of the Administration, the deconcentrated structures, local subnational governments, the private sector, donors, and the beneficiary populations. The structures of the Ministry of Planning and External Cooperation will be involved as set forth below:

o The Economic and Social Programming Directorate (DPES) of the MPCE, working in concert with the Economic Research Directorate of the MEF and the Poverty and Social Exclusion Observatory (ONPES) and with the support of the Research and Programming Units (UEPs) of the sectoral ministries, will be responsible for monitoring the implementation and the overall and specific policies set forth in the DSNCRP. It must: (i) monitor changes in the macroeconomic framework; (ii) ensure that the strategies and interventions of donors are consistent with those of the DSNCRP; (iii) produce and publish an annual monitoring report with a stocktaking and recommendations for the GPSRP; (iv) contribute to the development of evaluation capacity as a tool to help with decision making and an instrument for improving the efficiency of the public sector; and (v) strengthen the capacities for analyzing and formulating development and poverty reduction policies;

o The Public Investment Directorate (DIP), with support from the Research and Programming Units (UEPs) of the sectoral ministries, will be tasked with the coordination and preparation of the Public Investment Program and with monitoring implementation as regards the imputability of the operators concerned, with reporting on the above to the authorities on the basis of 
performance indicators, and with proposing any adjustments that may be required. It will also ensure that operating plans for these actions are drawn up and carried out;

o The External Cooperation Directorate (DCE) and the NGO Activities Coordination Unit (UCAONG) will be responsible for supporting the various structures involved in identifying, mobilizing, and monitoring the financing provided by development partners;

o The Monitoring and Evaluation Directorate (DSE), with support from the Research and Programming Units (UEPs) of the sectoral ministries, will be at the center of the physical and financial monitoring of the public investments implemented in the context of the DSNCRP. It will ensure that: (i) the monitoring and execution tools for all actions under the DSNCRP throughout the country are used and applied; and (ii) that status reports on the state of physical and financial progress with DSNCRP actions are drawn up by the executing bodies and analyzed;

o The Departmental Directorates of the MPCE, working in tandem with the Departmental Directorates of the sectoral ministries and territorially deconcentrated autonomous agencies, will participate in the implementation, monitoring, and evaluation of DSNCRP actions at the territorial level;

o The National Poverty and Social Exclusion Observatory (ONPES), in support of the foregoing structures, will be responsible for impact monitoring and participatory monitoring as well as for DSNCRP evaluation.

\section{Impact evaluation of DSNCRP actions}

259 Impact monitoring involves analysis of trends with respect to poverty and the living conditions of the people. It will be carried out by: (i) developing and implementing an information system including all surveys essential to the monitoring of indicators on the household living conditions and poverty objectives; and (ii) gathering information on the performance monitoring indicators of the actions included in the DSNCRP.

\section{Participatory monitoring}

260 Participatory monitoring will be carried out in accordance with the methods defined, and will enable the authorities to obtain information on grassroots assessments of the activities carried out in connection with poverty reduction. The civil society associations, especially those that participated in DSNCRP preparation in the regions, will be organized and receive adequate training to enable them to observe, monitor, and express opinions on the execution of poverty reduction actions in their areas of influence.

\section{DSNCRP evaluation}

261 Evaluation will occur in two stages, first with a midterm review and then with an ex post evaluation. The midterm review will make it possible to assess the progress made toward meeting the objectives set and determine how to contribute to the adaptation, improvement, or modification of programs and projects. The final ex post evaluation will be focused on assessing overall program and project impacts. It should be emphasized that an annual DSNCRP appraisal as well as regular monitoring of the sectoral and cross-cutting programs will be carried out in order to assess the changes brought about by their implementation. The specific identified objectives and performance indicators are presented in an annex to this paper. The impact and participatory indicators will be defined in light of the pillars, sectors, and areas selected. 


\section{ANNEX I}

English Translation of Official Original Document in French 


\section{CONTENTS}

1. Schema of Overall Planning Framework

2. Matrix of Objectives and Measures (2007-2010)

3. Matrix of Objectives of Public Finances Reforms

4. Economic Accounts Tables

Gross Domestic Product Account

Summary of Financial Operations of the Central Administration

Summary of Haiti's Balance of Payments (2002-2011)

Monetary Survey

5. Summary Table of DSNCRP Costs

6. Schema of Institutional Framework for Implementation

7. Table of DSNCRP Monitoring Indicators 


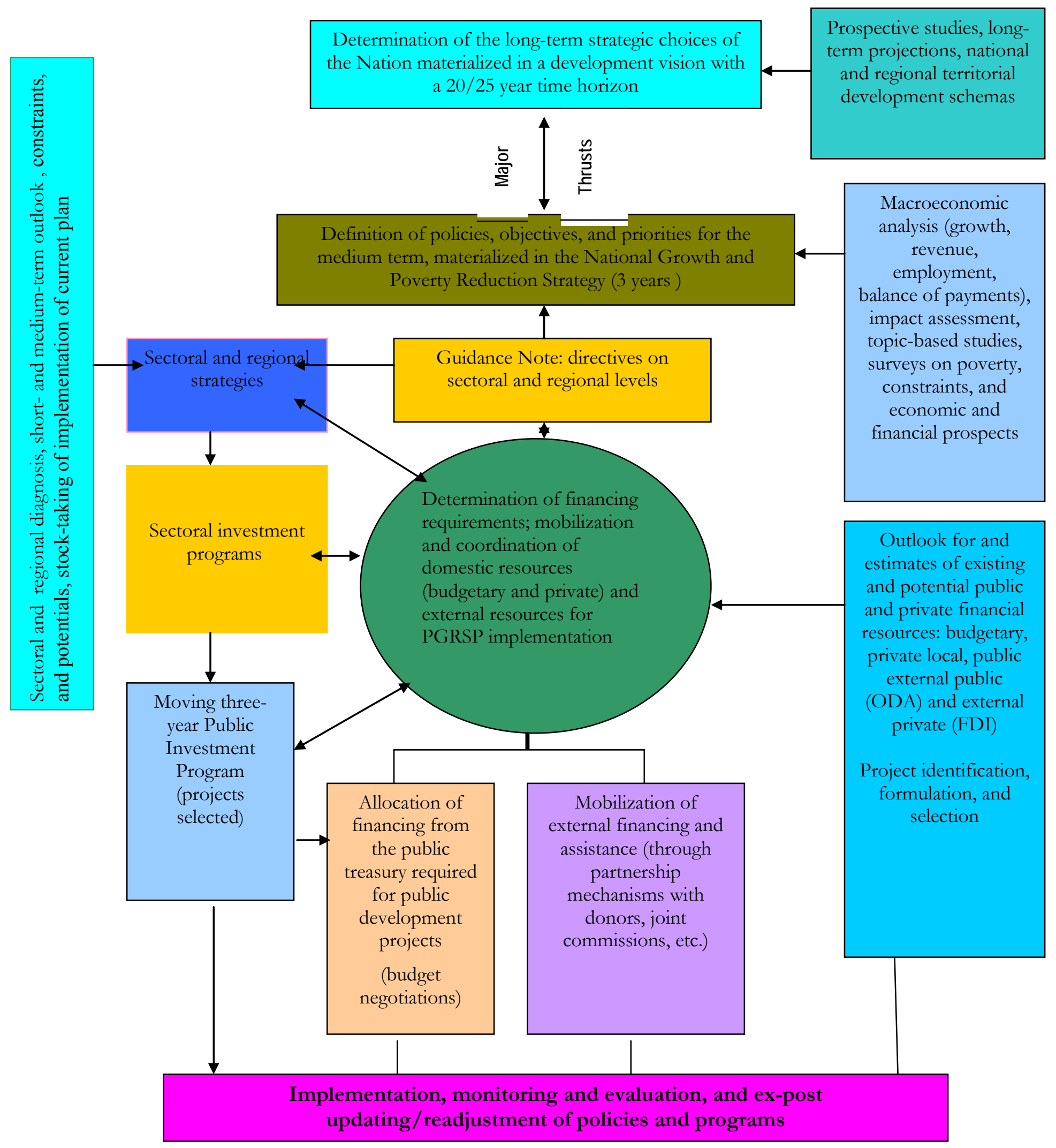


MATRIX OF OBJECTIVES/SUMMARY OF ACTIONS MATRICES 


\section{1.- AGRICULTURE AND RURAL DEVELOPMENT}

\begin{tabular}{|l|c|c|}
\hline \multicolumn{1}{|c|}{ OBJECTIVES } & $\mathbf{2 0 0 7 - 2 0 1 0}$ & PARTNERS \\
\hline $\begin{array}{l}\text { OVERALL OBJECTIVE: Promote modern, wealth-creating, and environmentally friendly agriculture, } \\
\text { making it possible to achieve food security for all and improve the living conditions of farmers }\end{array}$ & $\mathbf{1 7 , 8 8 0 , 0 0 0 , 0 0 0}$ \\
SPECIFIC OBJECTIVE 1: Build institutional capacities of the agricultural sector (See annexed PEMFAR) & $3,840,000,000$ \\
SPECIFIC OBJECTIVE 2: Promote sustainable agriculture and improved land tenure management & $3,280,000,000$ \\
SPECIFIC OBJECTIVE 3: Revitalize agricultural production & $4,150,000,000$ \\
SPECIFIC OBJECTIVE 4: Modernize basic agricultural infrastructures in rural areas & $195,000,000$ \\
SPECIFIC OBJECTIVE 5: Promote fisheries and aquaculture & $450,000,000$ \\
SPECIFIC OBJECTIVE 6: Promote the development of agroprocessing subsectors & $465,000,000$ \\
SPECIFIC OBJECTIVE 7: Promote a new marketing strategy & $200,000,000$ \\
SPECIFIC OBJECTIVE 8: Introduce agricultural production support infrastructures & & \\
\end{tabular}




\section{2.- TOURISM}

\section{OBJECTIVES}

OVERALL OBJECTIVE: Make tourism a sustainable development lever of direct benefit to the population

SPECIFIC OBJECTIVE 1: Ensure good governance in the sector

SPECIFIC OBJECTIVE 2: Develop tourism that is broadly based territorially

2007-2010

$344,940,000$

$1,057,650,000$

\section{3.- COMMERCE AND INDUSTRY}

\begin{tabular}{|c|c|c|}
\hline OBJECTIVES & 2007-2010 & PARTNERS \\
\hline $\begin{array}{l}\text { OVERALL OBJECTIVE: Make Commerce and Industry sustainable development levers of direct benefit } \\
\text { to the population }\end{array}$ & $416,373,000$ & \\
\hline $\begin{array}{l}\text { SPECIFIC OBJECTIVE 1: Impart new dynamism to the effort to provide incentives for } \\
\text { private investment }\end{array}$ & $95,000,000$ & \\
\hline SPECIFIC OBJECTIVE 2: Promote regional economic integration & $138,146,000$ & \\
\hline SPECIFIC OBJECTIVE 3: Regain lost market shares & $155,227,000$ & \\
\hline SPECIFIC OBJECTIVE 4: Revitalize light industry & 0 & \\
\hline SPECIFIC OBJECTIVE 5: Promote foreign and national direct investment & $28,000,000$ & \\
\hline
\end{tabular}




\begin{tabular}{|c|c|c|}
\hline OBJECTIVES & 2007-2010 & PARTNERS \\
\hline $\begin{array}{l}\text { OVERALL OBJECTIVE: Improve the people's access to services and structuring infrastructure as a } \\
\text { development vector }\end{array}$ & $58,559,763,800$ & \\
\hline TRANSPORT SUBSECTOR & $34,244,763,800$ & \\
\hline SPECIFIC OBJECTIVE 1: Build the institutional capacity of the sector (see annexed PEMFAR) & & \\
\hline SPECIFIC OBJECTIVE 2: Reconcile the trade-offs between regions and decentralization constraints & $8,000,000,000$ & \\
\hline $\begin{array}{l}\text { SPECIFIC OBJECTIVE 3: Bring services closer to citizens and make essential services available to users } \\
\text { threatened by exclusion }\end{array}$ & $20,003,763,800$ & \\
\hline SPECIFIC OBJECTIVE 4: Promote balanced and equitable development of the transport system & $51,000,000$ & \\
\hline $\begin{array}{l}\text { SPECIFIC OBJECTIVE 5: Promote Haiti's integration into the Caribbean area and into international } \\
\text { trade }\end{array}$ & $6,190,000,000$ & \\
\hline ELECTRICITY SUBSECTOR & $24,037,000,000$ & \\
\hline SPECIFIC OBJECTIVE 6: Improve oversight of investment and regulatory decisions & $12,000,000$ & \\
\hline SPECIFIC OBJECTIVE 7: Generate sufficient revenue to cover operating and investment expenditure & $24,014,200,000$ & \\
\hline SPECIFIC OBJECTIVE 8: Strengthen the partnership between the organizing authority and producers & $10,800,000$ & \\
\hline NATIONAL CONSTRUCTION AND PUBLIC WORKS LABORATORY (LNBTP) & & \\
\hline SUBSECTOR & $278,000,000$ & \\
\hline SPECIFIC OBJECTIVE 8: Strengthen the LNBTP (see annexed PEMFAR) & $100,000,000$ & \\
\hline SPECIFIC OBJECTIVE 9: Enhance research & $178,000,000$ & \\
\hline
\end{tabular}


PILLAR 2: HUMAN DEVELOPMENT - PRIORITY ACCORDED TO BASIC SOCIAL SERVICES

$33,037,555,925$

1.- EDUCATION AND TRAINING

\begin{tabular}{|c|c|c|}
\hline OBJECTIVES & $2007-2010$ & PARTNERS \\
\hline $\begin{array}{l}\text { OVERALL OBJECTIVE: Improve access to preschool and basic education and to vocational training } \\
\text { SPECIFIC OBJECTIVE 1: Build the institutional capacities of the sector (see annexed PEMFAR) } \\
\text { SPECIFIC OBJECTIVE 2: Reorganize the supply of schooling in favor of poor pupils } \\
\text { SPECIFIC OBJECTIVE 3: Improve the quality of education by recertifying instructional personnel and school } \\
\text { directors } \\
\text { SPECIFIC OBJECTIVE 4: Organize adequate oversight of schools, students, and parents } \\
\text { SPECIFIC OBJECTIVE 5: Improve the coordination of operators in the education sector } \\
\text { SPECIFIC OBJECTIVE 6: Increase the public resources allocated to the education sector }\end{array}$ & $\begin{array}{c}21,132,555,925 \\
16,051,950,790 \\
1,545,250,000 \\
2,775,000,000 \\
740,355,135 \\
20,000,000\end{array}$ & \\
\hline
\end{tabular}


2.- HEALTH

\begin{tabular}{|c|c|c|}
\hline OBJECTIVES & $2007-2010$ & PARTNERS \\
\hline $\begin{array}{l}\text { OVERALL OBJECTIVE: Promote a modern health system readily accessible by vulnerable groups } \\
\text { SPECIFIC OBJECTIVE 1: Build the institutional capacities of the health sector (see annexed PEMFAR) } \\
\text { SPECIFIC OBJECTIVE 2: Rehabilitate, construct, and upgrade health infrastructures } \\
\text { SPECIFIC OBJECTIVE 3: Strengthen the Commune-Level Health Units } \\
\text { SPECIFIC OBJECTIVE 4: Strengthen the assumption of care for priority diseases } \\
\text { SPECIFIC OBJECTIVE 5: Improve waste management in hospital facilities } \\
\text { SPECIFIC OBJECTIVE 6: Guarantee the public's access to essential drugs } \\
\text { SPECIFIC OBJECTIVE 7: Reduce the maternal mortality rate } \\
\text { SPECIFIC OBJECTIVE 8: Increase the prevalence of contraceptive use }\end{array}$ & $\begin{array}{c}7,641,000,000 \\
6,400,000,000 \\
12,000,000 \\
300,000,000 \\
135,000,000 \\
78,000,000 \\
628,000,000 \\
88,000,000\end{array}$ & \\
\hline
\end{tabular}

3.- DRINKING WATER AND SANITATION

\begin{tabular}{|l|c|c|}
\hline \multicolumn{1}{|c|}{ OBJECTIVES } & PARTNERS \\
\hline $\begin{array}{l}\text { OVERALL OBJECTIVE: Improve access to hygiene and sanitation services and the supply of quality } \\
\text { drinking water at the lowest cost to the community }\end{array}$ & $\mathbf{2 0 0 7 - 2 0 1 0}$ & \\
$\begin{array}{l}\text { SPECIFIC OBJECTIVE 1: Restructure the MTPTC to enable it to take on the functions of regulating the sector } \\
\text { (see annexed PEMFAR) }\end{array}$ & $136,000,000$ \\
$\begin{array}{l}\text { SPECIFIC OBJECTIVE 2: Generate sufficient resources to cover operating and investment expenditure } \\
\begin{array}{l}\text { SPECIFIC OBJECTIVE 3: Provide basic services to the residents of shantytowns and low-income rural } \\
\text { residents }\end{array}\end{array}$ & $60,000,000$ & \\
\hline
\end{tabular}


PILLAR 3: DEMOCRATIC GOVERNANCE - PRIORITY ACCORDED TO JUSTICE AND SECURITY

I.- JUSTICE

\begin{tabular}{|l|c|c|}
\hline \multicolumn{1}{|c|}{ OBJECTIVES } & 2007-2010 & PARTNERS \\
\hline $\begin{array}{l}\text { OVERALL OBJECTIVE: Ensure an environment conducive to rapid and sustainable development } \\
\text { through justice that is accessible, credible, efficient, and competent, and a civil status system enabling } \\
\text { every citizen to have his or her own personal identity guarantee a legal existence }\end{array}$ & $\mathbf{6 , 0 8 9 , 0 0 0 , 0 0 0}$ \\
$\begin{array}{l}\text { SPECIFIC OBJECTIVE 1: Restructure and reorganize the MJSP to enable it to assume leadership in } \\
\text { implementing the Strategic Plan for the Reform of Justice and to take on ownership of this reform process in } \\
\text { harmony with legal stakeholders and civil society as special partners }\end{array}$ & $750,000,000$ \\
SPECIFIC OBJECTIVE 2: Strengthen the Judiciary Branch & $880,000,000$ \\
SPECIFIC OBJECTIVE 3: Facilitate access to and the efficiency of the courts & $1,549,000,000$ \\
SPECIFIC OBJECTIVE 4: Improve incarceration conditions and penitentiary management mechanisms & $2,720,000,000$ \\
SPECIFIC OBJECTIVE 5: Modernize legislation & $190,000,000$ & \\
\hline
\end{tabular}

II.- SECURITY

\begin{tabular}{|l|r|r|}
\hline \multicolumn{1}{|c|}{ OBJECTIVES } & $\mathbf{2 0 0 7 - 2 0 1 0}$ & PARTNERS \\
\hline OVERALL OBJECTIVE: Ensure the security of persons, their property, and their production activities & & $\mathbf{5 , 0 2 7 , 0 0 0 , 0 0 0}$ \\
SPECIFIC OBJECTIVE 1: Combat rampant insecurity through bold actions & & $2,020,000,000$ \\
SPECIFIC OBJECTIVE 2: Improve the image of the National Police & $3,007,000,000$ & \\
\hline
\end{tabular}




\section{III.- NEAR-AT-HAND GOVERNANCE}

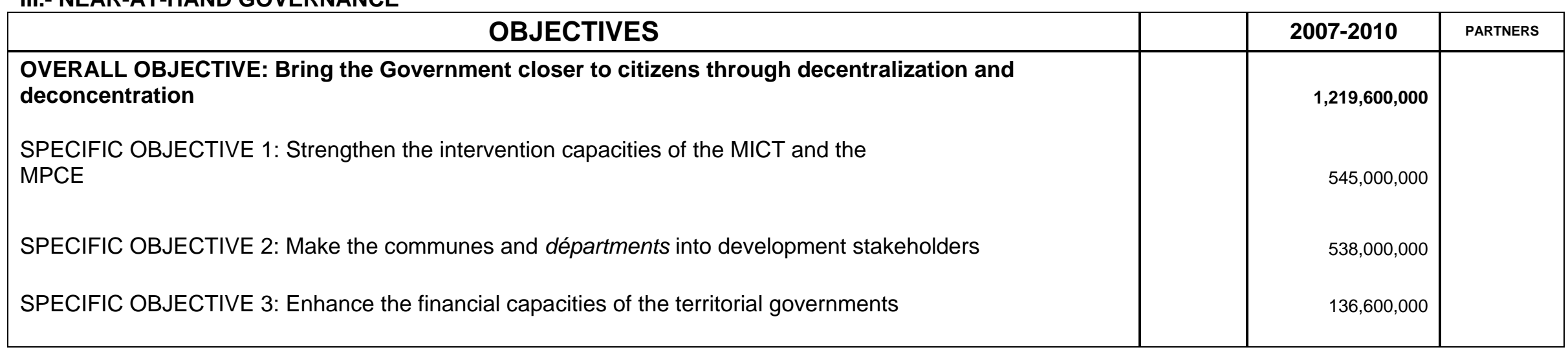




\section{TARGETED AND CROSS-CUTTING POLICIES AND STRATEGIES}

\section{1.- FOOD SECURITY}

\begin{tabular}{|c|c|c|}
\hline OBJECTIVES & 2007-2010 & PARTNERS \\
\hline $\begin{array}{l}\text { OVERALL OBJECTIVE: Improve the integration and coordination of food policies and strategies } \\
\text { making it possible to address the human right to food }\end{array}$ & $93,000,000$ & \\
\hline $\begin{array}{l}\text { SPECIFIC OBJECTIVE 1: Define a framework conducive to strengthening food security and controlling its } \\
\text { application }\end{array}$ & $39,000,000$ & \\
\hline SPECIFIC OBJECTIVE 2: Introduce cross-cutting mechanisms & $12,000,000$ & \\
\hline SPECIFIC OBJECTIVE 3: Build the départements' capacities for intersectoral and interinstitutional integration & $34,000,000$ & \\
\hline SPECIFIC OBJECTIVE 4: Monitor food security and poverty & $8,000,000$ & \\
\hline
\end{tabular}

\section{2.- GENDER EOUITY}

\begin{tabular}{|c|c|c|}
\hline OBJECTIVES & 2007-2010 & PARTNERS \\
\hline $\begin{array}{l}\text { OVERALL OBJECTIVE: Ensure the Observance of Women's Rights and the Application of Gender } \\
\text { Mainstreaming in Public Policies }\end{array}$ & $1,279,054,794.95$ & \\
\hline SPECIFIC OBJECTIVE 1: Conceptualize, develop, and introduce a policy on equality of the sexes & $7,088,484$ & \\
\hline SPECIFIC OBJECTIVE 2: Enhance institutional capacities as regards the Gender sector & $120,000,000$ & \\
\hline SPECIFIC OBJECTIVE 3: Improve the status of women & $647,196,577$ & \\
\hline SPECIFIC OBJECTIVE 4: Promote and strengthen women's rights & $143,699,696$ & \\
\hline SPECIFIC OBJECTIVE 5: Promote the education and right to health of women and girls & $286,549,276$ & \\
\hline $\begin{array}{l}\text { SPECIFIC OBJECTIVE 6: Reform judicial and legal procedures as regards the rights of women and equality } \\
\text { between the sexes }\end{array}$ & $28,300,199$ & \\
\hline $\begin{array}{l}\text { SPECIFIC OBJECTIVE 7: Educate and enhance the awareness of decision-makers and the public with a viev } \\
\text { to eliminating discrimination and sexism }\end{array}$ & $46,220,562.80$ & \\
\hline
\end{tabular}




\begin{tabular}{|c|c|c|}
\hline OBJECTIVES & 2007-2010 & PARTNERS \\
\hline $\begin{array}{l}\text { OVERALL OBJECTIVE: Improve environmental management with a view to contributing to sustainable } \\
\text { growth while ensuring the economic and social security of the poor and the security of the ecosystems } \\
\text { that support life }\end{array}$ & $5,582,000,000$ & \\
\hline SPECIFIC OBJECTIVE 1-: Improve environmental governance & $40,000,000$ & \\
\hline $\begin{array}{l}\text { SPECIFIC OBJECTIVE 2: Reduce the environmental vulnerability of the poor to natural disasters and risks, } \\
\text { and adapt to climate change }\end{array}$ & $744,000,000$ & \\
\hline SPECIFIC OBJECTIVE 3: Improve the environmental management of the cities & $40,000,000$ & \\
\hline SPECIFIC OBJECTIVE 4: Ensure integrated management of water resources & $120,000,000$ & \\
\hline SPECIFIC OBJECTIVE 5: Balance the supply of and demand for wood & $3,360,000,000$ & \\
\hline SPECIFIC OBJECTIVE 6: Combat soil degradation and sustainably manage biodiversity & $358,000,000$ & \\
\hline SPECIFIC OBJECTIVE 7: Combat pollution in all its forms & $280,000,000$ & \\
\hline SPECIFIC OBJECTIVE 8: Monitor and conduct oversight of the environment & $320,000,000$ & \\
\hline $\begin{array}{l}\text { SPECIFIC OBJECTIVE 9: Make the environment a center for attracting inve } \\
\text { opportunities }\end{array}$ & $320,000,000$ & \\
\hline
\end{tabular}

\section{4.- SOCIAL PROTECTION}

\begin{tabular}{|l|r|r|}
\hline \multicolumn{1}{|c|}{ OBJECTIVES } & \multicolumn{1}{|c|}{$\mathbf{2 0 0 7 - 2 0 1 0}$} & \multicolumn{1}{c|}{ PARTNERS } \\
\hline OVERALL OBJECTIVE: Reduce exclusion and enhance social protection & $\mathbf{1 , 5 1 8 , 0 0 0 , 0 0 0}$ \\
SPECIFIC OBJECTIVE 1: Build the institutional capacities of the MAST & $20,000,000$ \\
SPECIFIC OBJECTIVE 2: Socially and economically integrate the disabled & $430,000,000$ \\
SPECIFIC OBJECTIVE 3: Support and supervise services for the elderly & $285,000,000$ \\
SPECIFIC OBJECTIVE 4: Supervise adolescents, the deported, and young adults at risk & $783,000,000$ & \\
\hline
\end{tabular}




\section{OBJECTIVES}

OVERALL OBJECTIVE: Make culture and communication the backbone of Haiti's economic and social development

SPECIFIC OBJECTIVE 1: Build the institutional capacities of the culture and communication sector SPECIFIC OBJECTIVE 2: Protect and enhance the value of the national patrimony

SPECIFIC OBJECTIVE 3: Promote artistic, literary, and artisanal production

\begin{tabular}{|r|r|r|}
\hline & $\mathbf{2 0 0 7 - 2 0 1 0}$ & PARTNERS \\
\hline & $\mathbf{1 , 7 5 2 , 0 2 0 , 0 0 0}$ & \\
& $897,500,000$ & \\
$774,120,000$ & \\
& $80,400,000$ & \\
& & \\
\hline
\end{tabular}

\section{6.- URBAN DEVELOPMENT}

\begin{tabular}{|c|c|c|}
\hline OBJECTIVES & 2007-2010 & PARTNERS \\
\hline $\begin{array}{l}\text { OVERALL OBJECTIVE: Contribute to sustainable urban development and poverty reduction by: } \\
\text { (1) preparing and supporting the implementation of development and rehabilitation plans for at-risk } \\
\text { neighborhoods; (2) controlling urban growth and developing adequate tools; and (3) building the } \\
\text { capacities of the authorities and beneficiary communities }\end{array}$ & $1,596,000,000$ & \\
\hline SPECIFIC OBJECTIVE 1: Make local governance operational and effective & $648,000,000$ & \\
\hline SPECIFIC OBJECTIVE 2: Urbanize the cities by improving marginal housing areas & $624,000,000$ & \\
\hline SPECIFIC OBJECTIVE 3: Strengthen the participatory process in rehabilitating marginal housing & $204,000,000$ & \\
\hline SPECIFIC OBJECTIVE 4: Seek financing for grassroots projects & $120,000,000$ & \\
\hline
\end{tabular}

\section{7.- TERRITORIAL DEVELOPMENT}

\begin{tabular}{|l|c|c|}
\hline \multicolumn{1}{|c|}{ OBJECTIVES } & $\mathbf{2 0 0 7 - 2 0 1 0}$ & PARTNERS \\
\hline $\begin{array}{l}\text { OVERALL OBJECTIVE: Contribute to the reconstruction of the national territory as a means of } \\
\text { ultimately achieving Haiti's balanced and sustainable development }\end{array}$ & $\mathbf{1 5 , 7 6 5 , 0 0 0 , 0 0 0}$ \\
SPECIFIC OBJECTIVE 1: Introduce the strategic and normative national development framework & $1,565,000,000$ \\
SPECIFIC OBJECTIVE 2: Impart new dynamism to the regions & $14,200,000,000$ & \\
\hline
\end{tabular}




\begin{tabular}{|l|l|l|}
\hline \multicolumn{1}{|c|}{ OBJECTIVES } & \multicolumn{1}{|c|}{$\mathbf{2 0 0 7 - 2 0 1 0}$} & PARTNERS \\
\hline $\begin{array}{l}\text { OVERALL OBJECTIVE: Improve the intervention capacities of the SNGRD by strengthening the DPC, } \\
\text { the SPGRD, and the territorial civil protection structures }\end{array}$ & & \\
SPECIFIC OBJECTIVE 1: Strengthen the action capacities of the DPC and the SPGRD & & \\
SPECIFIC OBJECTIVE 2: Strengthen the intervention capacities of the civil protection structures on the ground & & $25,500,000$ \\
\end{tabular}

\section{9.- STATE CAPACITY BUILDING}

\begin{tabular}{|l|r|r|}
\hline \multicolumn{1}{|c|}{ OBJECTIVES } & $\mathbf{2 0 0 7 - 2 0 1 0}$ & PARTNERS \\
\hline OVERALL OBJECTIVE: Build institutional capacities & $\mathbf{3 , 1 2 9 , 2 0 0 , 0 0 0}$ \\
SPECIFIC OBJECTIVE 1: Continue the reform of the State's Central Administration & $129,200,000$ \\
SPECIFIC OBJECTIVE 2: Introduce the new civil service system & $328,300,000$ \\
SPECIFIC OBJECTIVE 3: Initiate the effective deconcentration of public services & $178,500,000$ \\
SPECIFIC OBJECTIVE 4: Launch the decentralization process & $274,200,000$ \\
SPECIFIC OBJECTIVE 5: Modernize the physical framework for public services & $2,219,000,000$ & \\
\hline
\end{tabular}

\section{0- GENERAL FRAMEWORK FOR SUPPORTING THE PRIVATE SECTOR}

\begin{tabular}{|l|c|c|}
\hline \multicolumn{1}{|c|}{ OBJECTIVES } & $\mathbf{2 0 0 7 - 2 0 1 0}$ & PARTNERS \\
\hline OVERALL OBJECTIVE: Improve the business climate & $\mathbf{1 1 0 , 3 0 0 , 0 0 0}$ \\
$\begin{array}{l}\text { SPECIFIC OBJECTIVE 1: Upgrade the legal framework for economic activity and the development of the } \\
\text { market economy }\end{array}$ & $23,000,000$ \\
$\begin{array}{l}\text { SPECIFIC OBJECTIVE 2: Strengthen the institutions guaranteeing private initiative, business freedom, the } \\
\text { market economy, and competitiveness }\end{array}$ & $87,300,000$ & \\
\hline
\end{tabular}




\section{SUMMARY}

\begin{tabular}{|c|c|c|}
\hline PILLAR 1: GROWTH VECTORS & $78,258,726,800$ & $51 \%$ \\
\hline $\begin{array}{l}\text { PILLAR 2: HUMAN DEVELOPMENT - PRIORITY ACCORDED TO BASIC SOCIAL } \\
\text { SERVICES }\end{array}$ & $33,037,555,925$ & $21 \%$ \\
\hline PILLAR 3: DEMOCRATIC GOVERNANCE - PRIORITY ACCORDED TO JUSTICE AND SECURITY & $12,335,600,000$ & $8 \%$ \\
\hline TARGETED AND CROSS-CUTTING POLICIES AND STRATEGIES & $30,894,374,795$ & $20 \%$ \\
\hline TOTAL & $\begin{array}{c}154,526,257,520 \\
\$ 3,863,156,438\end{array}$ & $100 \%$ \\
\hline
\end{tabular}


MATRIX OF OBJECTIVES OF PUBLIC FINANCES REFORMS

\begin{tabular}{|c|c|c|c|}
\hline GENERAL OBJECTIVE: REFORM THE HAITIAN PUBLIC FINANCES & & $2007-2010$ & PARTNERS \\
\hline $\begin{array}{l}\text { SPECIFIC OBJECTIVE 1: Strengthen links between resource allocations and } \\
\text { Government priorities identified in the DNSCRP and sectoral strategy }\end{array}$ & N.A. & N.A. & \\
\hline SPECIFIC OBJECTIVE 2: Improve budget execution & N.A. & N.A. & \\
\hline SPECIFIC OBJECTIVE 3: Improving transparency of budget information & N.A. & N.A. & \\
\hline $\begin{array}{l}\text { SPECIFIC OBJECTIVE 4: Gradually integrating gradually expenditure financed by external } \\
\text { resources in the sector budget }\end{array}$ & N.A. & N.A. & \\
\hline $\begin{array}{l}\text { SPECIFIC OBJECTIVE 5: Evaluate the impact of budgetary expenditure and monitor the } \\
\text { budget results }\end{array}$ & N.A. & N.A. & \\
\hline
\end{tabular}

N.A.: Information Not Available 
ECONOMIC ACCOUNTS TABLES 


\begin{tabular}{|c|c|c|c|c|c|c|c|c|c|c|}
\hline \multirow{2}{*}{$\begin{array}{l}\text { Gross Domestic Product Account } \\
\text { (in millions of Gourdes at constant } \\
\text { prices) }\end{array}$} & & \multicolumn{9}{|c|}{ Projections } \\
\hline & $\underline{2002}$ & $\underline{2003}$ & $\underline{2004}$ & $\underline{2005}$ & $\underline{2006}$ & $\underline{2007}$ & $\underline{2008}$ & $\underline{2009}$ & $\underline{2010}$ & $\underline{2011}$ \\
\hline GDP & 94028 & 119758 & 140387 & 168034 & 200456 & 225052 & 256096 & 286316 & 315634 & 345298 \\
\hline Imports & 33548 & 57326 & 61432 & 68610 & 86255 & 83227 & 92437 & 108040 & 125325 & 139110 \\
\hline Resources & 127576 & 177084 & 201819 & 236644 & 286711 & 308279 & 348533 & 394356 & 440959 & 484408 \\
\hline Consumption & 92140 & 121378 & 143162 & 167291 & 200186 & 224675 & 250658 & 280737 & 308250 & 334143 \\
\hline Investment & 23570 & 36758 & 38386 & 46072 & 57861 & 69896 & 81918 & 95189 & 111276 & 125853 \\
\hline Exports & 11866 & 18948 & 20271 & 23281 & 28664 & 13708 & 15956 & 18430 & 21434 & 24413 \\
\hline Uses & 127576 & 177084 & 201819 & 236644 & 286711 & 308279 & 348533 & 394356 & 440959 & 484408 \\
\hline
\end{tabular}

\begin{tabular}{|c|c|c|c|c|c|c|c|c|c|c|}
\hline \multirow{2}{*}{$\begin{array}{l}\text { Gross Domestic Product Account } \\
\text { (in millions of Gourdes at 1986-1987 } \\
\text { prices) }\end{array}$} & \multirow[b]{2}{*}{$\underline{2002}$} & \multirow[b]{2}{*}{$\underline{2003}$} & \multirow[b]{2}{*}{$\underline{2004}$} & \multirow[b]{2}{*}{$\underline{2005}$} & \multirow[b]{2}{*}{$\underline{2006}$} & \multicolumn{5}{|c|}{ Projections } \\
\hline & & & & & & 2007 & 2008 & 2009 & 2010 & 2011 \\
\hline GDP & 12968 & 13015 & 12557 & 12783 & 13079 & 13469 & 13967 & 14526 & 15107 & 15711 \\
\hline Imports & 14757 & 15225 & 15063 & 15449 & 16160 & 17219 & 17673 & 18727 & 19637 & 20051 \\
\hline Resources & 27725 & 28240 & 27620 & 28232 & 29239 & 30688 & 31640 & 33253 & 34744 & 35762 \\
\hline Consumption & 20514 & 20691 & 19921 & 20359 & 21162 & 21882 & 22253 & 23185 & 23792 & 24103 \\
\hline Investment & 4390 & 4526 & 4381 & 4443 & 4541 & 4922 & 5126 & 5262 & 5470 & 5538 \\
\hline Exports & 2821 & 3023 & 3318 & 3430 & 3536 & 3885 & 4261 & 4806 & 5482 & 6121 \\
\hline Uses & 27725 & 28240 & 27620 & 28232 & 29239 & 30688 & 31640 & 33253 & 34744 & 35762 \\
\hline
\end{tabular}

\begin{tabular}{|l|lllllll}
\hline Real GDP growth rate & $-0.3 \%$ & $0.4 \%$ & $-3.5 \%$ & $1.8 \%$ & $2.3 \%$ & $3.0 \%$ & $3.7 \%$ \\
\hline
\end{tabular}




\begin{tabular}{|c|c|c|c|c|c|c|c|c|c|c|}
\hline Summary of Central Administration & & & & & & jections & & & & \\
\hline (in millions of Gourdes) & & & & & & & & & & \\
\hline & $\underline{2002}$ & $\underline{2003}$ & $\underline{2004}$ & $\underline{2005}$ & $\underline{2006}$ & $\underline{2007}$ & $\underline{2008}$ & $\underline{2009}$ & $\underline{2010}$ & $\underline{2011}$ \\
\hline Total revenue & 7828 & 10748 & 12606 & 16255 & 20109 & 23196 & 29942 & 34339 & 39295 & 45453 \\
\hline Total revenue & 7828 & 10748 & 12606 & 16255 & 20109 & 23196 & 29942 & 34339 & 39295 & 45453 \\
\hline Current revenue & 7826 & 10748 & 12606 & 16255 & 20109 & 23196 & 29942 & 34339 & 39295 & 45453 \\
\hline Domestic revenue & 5757 & 7979 & 9095 & 11980 & 14010 & 16368 & 20682 & 23626 & 28329 & 32769 \\
\hline Customs receipts & 2069 & 2769 & 3511 & 4275 & 6099 & 6828 & 9260 & 10713 & 10966 & 12684 \\
\hline Other current revenue & 2 & 0 & 0 & 0 & 0 & 0 & 0 & 0 & 0 & 0 \\
\hline Total expenditure & 10978 & 14870 & 15644 & 16968 & 21283 & 21886 & 32788 & 39647 & 44876 & 52334 \\
\hline Current revenues & 9070 & 10843 & 11171 & 14854 & 18563 & 15845 & 26564 & 31651 & 34674 & 39386 \\
\hline Wages and salaries & 3480 & 3869 & 4131 & 5699 & 6471 & 8087 & 12617 & 14430 & 15564 & 17870 \\
\hline Current expenditure & 4270 & 4475 & 4582 & 4151 & 4862 & 1165 & 7515 & 9563 & 11372 & 13183 \\
\hline Subsidies and transfers & 768 & 1446 & 1166 & 3992 & 5552 & 5329 & 5607 & 6099 & 6002 & 6591 \\
\hline Interest payments & 552 & 1053 & 1292 & 1012 & 1678 & 1264 & 825 & 1559 & 1737 & 1741 \\
\hline Investment expenditure & 1908 & 4027 & 4473 & 2114 & 2720 & 6041 & 6224 & 7996 & 10201 & 12948 \\
\hline Current balance & -1244 & -95 & 1435 & 1401 & 1546 & 7351 & -2175 & 4175 & 6223 & 8032 \\
\hline Overall balance & -3150 & -4122 & -3038 & -713 & -1174 & 1310 & -2846 & -5308 & -5581 & -6881 \\
\hline Financing & 3150 & 4122 & 3038 & 713 & 1174 & -1310 & 2846 & 5308 & 5581 & 6881 \\
\hline Domestic financing & 3311 & 3384 & 3049 & -126 & -167 & -1758 & -410 & -910 & -910 & -910 \\
\hline Monetary authorities & 2897 & 3645 & 2903 & 6 & -334 & -1129 & 0 & 0 & 0 & 0 \\
\hline Commercial banks & -42 & 9 & 59 & -47 & 119 & -68 & -410 & -410 & -410 & -410 \\
\hline Other & 456 & -270 & 87 & -85 & 48 & -561 & 0 & -500 & -500 & -500 \\
\hline External financing & -161 & 738 & -11 & 839 & 1341 & 448 & 3256 & -1759 & -1759 & -1759 \\
\hline Of which: Budgetary support & & & & & & -950 & 1311 & 2053 & 4216 & 4579 \\
\hline Grants & & & & & & & 3607 & $\ldots$ & $\ldots$ & $\ldots$ \\
\hline Drawings & & & & & & & 720 & $\ldots$ & $\ldots$ & $\ldots$ \\
\hline Paris Club rescheduling & & & & & & & 129 & 0 & 0 & 0 \\
\hline HIPC Initiative & & & & & & & 531 & 864 & 0 & 0 \\
\hline Financing gap & & & & & & & & 7977 & 8250 & 9550 \\
\hline Financing gap (US\$) & & & & & & & & 222 & 229 & 265 \\
\hline
\end{tabular}




\begin{tabular}{|c|c|c|c|c|c|c|c|c|c|c|}
\hline \multirow{2}{*}{$\begin{array}{l}\text { Haiti: Summary Balance of Payments } \\
\text { (in millions of U.S. dollars) }\end{array}$} & \multirow[b]{2}{*}{$\underline{2002}$} & \multirow[b]{2}{*}{$\underline{2003}$} & \multirow[b]{2}{*}{$\underline{2004}$} & \multirow[b]{2}{*}{$\underline{2005}$} & \multirow[b]{2}{*}{$\underline{2006}$} & \multicolumn{5}{|c|}{ Projections } \\
\hline & & & & & & $\underline{2007}$ & $\underline{2008}$ & $\underline{2009}$ & $\underline{2010}$ & $\underline{2011}$ \\
\hline Current transactions account & -30 & -46 & -57 & 114 & -1 & 67 & -12 & -222 & -267 & -307 \\
\hline Current transactions account (excluding grants) & -165 & -183 & -157 & -214 & -381 & -361 & -460 & -572 & -755 & -823 \\
\hline Trade balance & -708 & -783 & -833 & -850 & -1054 & -1086 & -1231 & -1392 & -1516 & -1602 \\
\hline Exports of goods & 274 & 333 & 378 & 459 & 494 & 553 & 698 & 786 & 875 & 963 \\
\hline Of which: exports of assembly industry & 221 & 278 & 320 & 397 & 435 & 491 & 631 & 713 & 795 & 877 \\
\hline Imports of goods & -983 & -1116 & -1211 & -1308 & -1548 & -1640 & -1929 & -2178 & -2391 & -2564 \\
\hline Of which: petroleum products & -157 & -196 & -218 & -313 & -397 & -400 & -450 & -467 & -473 & -486 \\
\hline Net services & -93 & -166 & -204 & -313 & -336 & -357 & -400 & -414 & -561 & -632 \\
\hline Credit & 164 & 135 & 133 & 138 & 197 & 230 & 290 & 366 & 295 & 286 \\
\hline Debit & -256 & -301 & -337 & -452 & -533 & -587 & -690 & -780 & -856 & -918 \\
\hline Net revenue & -13 & -16 & -12 & -37 & 7 & 1 & -4 & 2 & 12 & 22 \\
\hline Current transfers, net & 784 & 918 & 993 & 1313 & 1382 & 1509 & 1623 & 1582 & 1797 & 1905 \\
\hline Official transfers, net & 135 & 137 & 100 & 328 & 380 & 428 & 448 & 350 & 488 & 516 \\
\hline Private transfers, net & 649 & 781 & 893 & 985 & 1002 & 1081 & 1175 & 1232 & 1309 & 1389 \\
\hline Capital account and financial operations account & -42 & 27 & 89 & -58 & 88 & 90 & 89 & 93 & 141 & 144 \\
\hline Foreign direct investment & 5 & 14 & 6 & 26 & 160 & 80 & 80 & 80 & 80 & 80 \\
\hline Net capital flows to public sector & -25 & -3 & -10 & 31 & 51 & 23 & 43 & 50 & 98 & 103 \\
\hline Net flows from banking sector & 3 & -47 & 29 & -76 & -83 & -13 & -34 & -37 & -38 & -39 \\
\hline Errors and omissions, net & -25 & 63 & 65 & -40 & -39 & 0 & 0 & 0 & 0 & 0 \\
\hline Overall balance & -72 & -19 & 33 & 56 & 88 & 157 & 77 & -129 & -127 & -163 \\
\hline Financing & 72 & 19 & -33 & -56 & -88 & -157 & -77 & -93 & -102 & -103 \\
\hline Change in reserve assets & 49 & 21 & -51 & -22 & -107 & -199 & -118 & -124 & -114 & -103 \\
\hline Change in liabilities & -8 & -11 & -2 & 9 & 10 & 21 & 23 & 23 & 12 & 0 \\
\hline Change in arrears & 31 & 9 & 20 & -43 & 9 & -45 & 0 & 0 & 0 & 0 \\
\hline Other (incl. debt rescheduling and HIPC Initiative) & 0 & 0 & 0 & 0 & 0 & 67 & 18 & 8 & 0 & 0 \\
\hline Financing gap & 0 & 0 & 0 & 0 & 0 & 0 & 0 & 222 & 229 & 265 \\
\hline
\end{tabular}




\begin{tabular}{|c|c|c|c|c|c|c|c|c|c|c|}
\hline \multirow{2}{*}{$\begin{array}{l}\text { Monetary Survey } \\
\text { (in millions of Gourdes) }\end{array}$} & \multirow[b]{2}{*}{$\underline{2002}$} & \multirow[b]{2}{*}{$\underline{2003}$} & \multirow[b]{2}{*}{$\underline{2004}$} & \multirow[b]{2}{*}{$\underline{2005}$} & \multirow[b]{2}{*}{$\underline{2006}$} & \multicolumn{5}{|c|}{ Projections } \\
\hline & & & & & & $\underline{2007}$ & $\underline{2008}$ & $\underline{2009}$ & $\underline{2010}$ & $\underline{2011}$ \\
\hline Net foreign assets & 8421 & 13475 & 12683 & 18630 & 24000 & 30493 & 35866 & 41660 & 47775 & 54147 \\
\hline Net domestic assets & 28808 & 38553 & 44078 & 49660 & 51091 & 51895 & 54737 & 59016 & 63503 & 67771 \\
\hline Credit to public sector (excl. special accounts) & 15229 & 18700 & 21097 & 21159 & 20118 & 20118 & 20118 & 20118 & 20118 & 20118 \\
\hline Credit to Central Administration & 15219 & 18611 & 21401 & 21322 & 20570 & 20124 & 20124 & 20124 & 20124 & 20124 \\
\hline Other credit to public sector & 10 & 89 & -303 & -163 & -452 & -6 & -6 & -6 & -6 & -6 \\
\hline Credit to private sector & 14512 & 19365 & 21142 & 25609 & 27019 & 28399 & 31241 & 35520 & 39778 & 43845 \\
\hline Other items, net (incl. special accounts) & -932 & 488 & 1839 & 2892 & 3955 & 3378 & 3378 & 3378 & 3607 & 3808 \\
\hline M3 Aggregate - Broad money & 37229 & 52028 & 56761 & 68290 & 75091 & 82388 & 90602 & 100677 & 111278 & 121918 \\
\hline Deposits & 30576 & 43585 & 48076 & 57743 & 63932 & 70370 & 77621 & 86391 & 95648 & 105013 \\
\hline Deposits in Gourdes & 16810 & 21903 & 25824 & 28292 & 31533 & 33962 & 36685 & 40369 & 44168 & 47773 \\
\hline Deposits in Dollars & 13766 & 21683 & 22252 & 29451 & 32399 & 36408 & 40936 & 46022 & 51480 & 57241 \\
\hline
\end{tabular}


COSTS TABLE BY PILLAR AND STRATEGY 
COSTS TABLE BY PILLAR AND STRATEGY

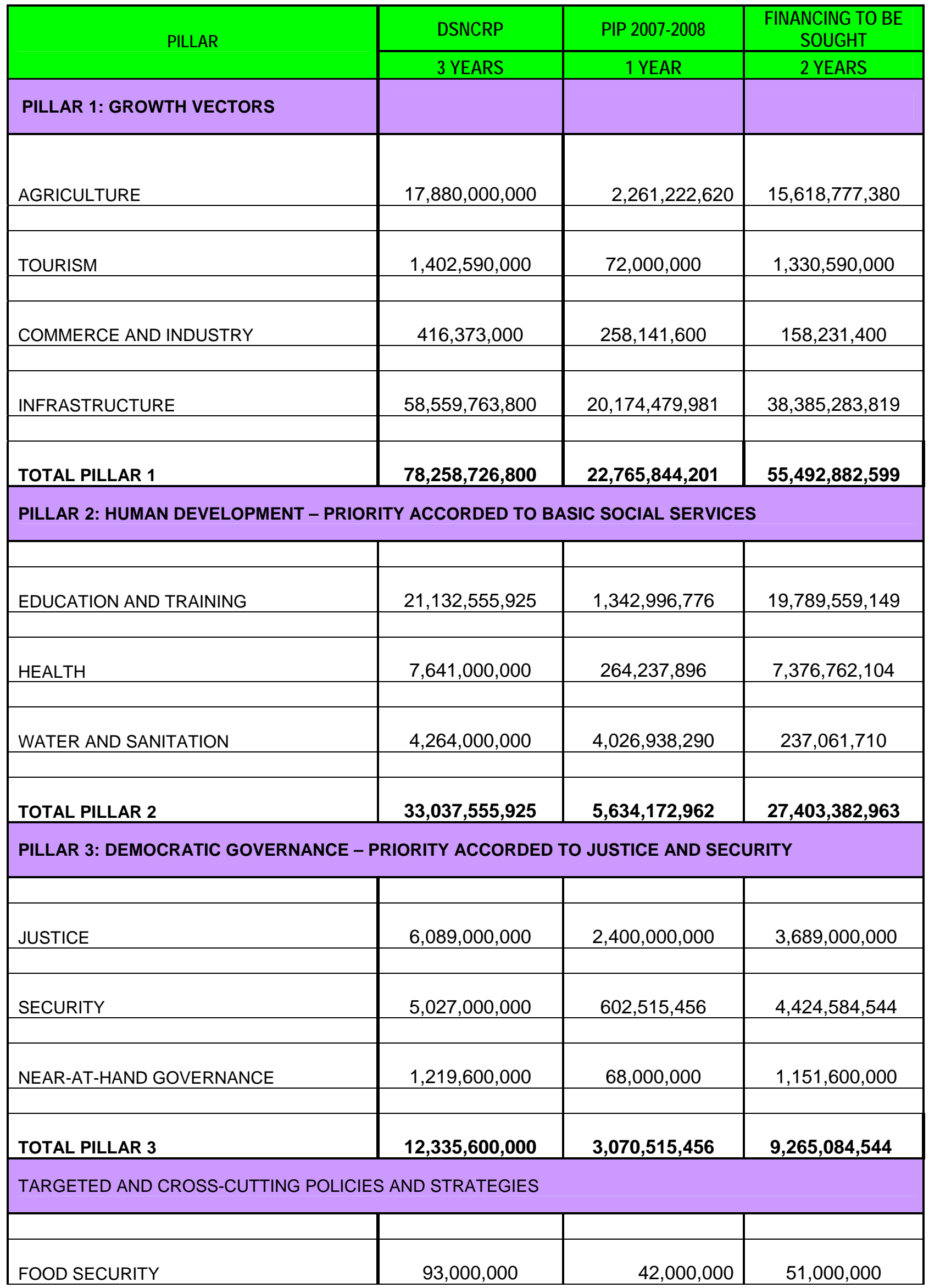




\begin{tabular}{|c|c|c|c|}
\hline GENDER EQUITY & $1,279,054,795$ & $41,000,000$ & $1,238,054,795$ \\
\hline ENVIRONMENT & $5,582,000,000$ & $1,367,889,304$ & $4,214,110,696$ \\
\hline SOCIAL PROTECTION & $1,518,000,000$ & $95,000,000$ & $1,423,000,000$ \\
\hline CULTURE AND COMMUNICATION & $1,752,020,000$ & $108,320,000$ & $1,643,700,000$ \\
\hline URBAN DEVELOPMENT & $1,596,000,000$ & N.A. & $1,596,000,000$ \\
\hline TERRITORIAL DEVELOPMENT & $15,765,000,000$ & $5,173,106,895$ & $10,591,893,105$ \\
\hline RISKS AND DISASTERS & $69,800,000$ & $329,750,134$ & $(259,950,134)$ \\
\hline STATE CAPACITY BUILDING & $3,129,200,000$ & N.A. & \\
\hline $\begin{array}{l}\text { INCENTIVE FRAMEWORK FOR SUPPORT } \\
\text { OF PRIVATE SECTOR }\end{array}$ & $110,300,000$ & N.A. & \\
\hline $\begin{array}{l}\text { TOTAL CROSS-CUTTING POLICIES AND } \\
\text { STRATEGIES }\end{array}$ & $30,894,374,795$ & $7,157,066,333$ & $20,497,808,462$ \\
\hline TOTAL & $154,526,257,520$ & $38,627,598,953$ & $115,889,658,567$ \\
\hline
\end{tabular}


SCHEMA OF INSTITUTIONAL FRAMEWORK FOR IMPLEMENTATION AND MONITORING 


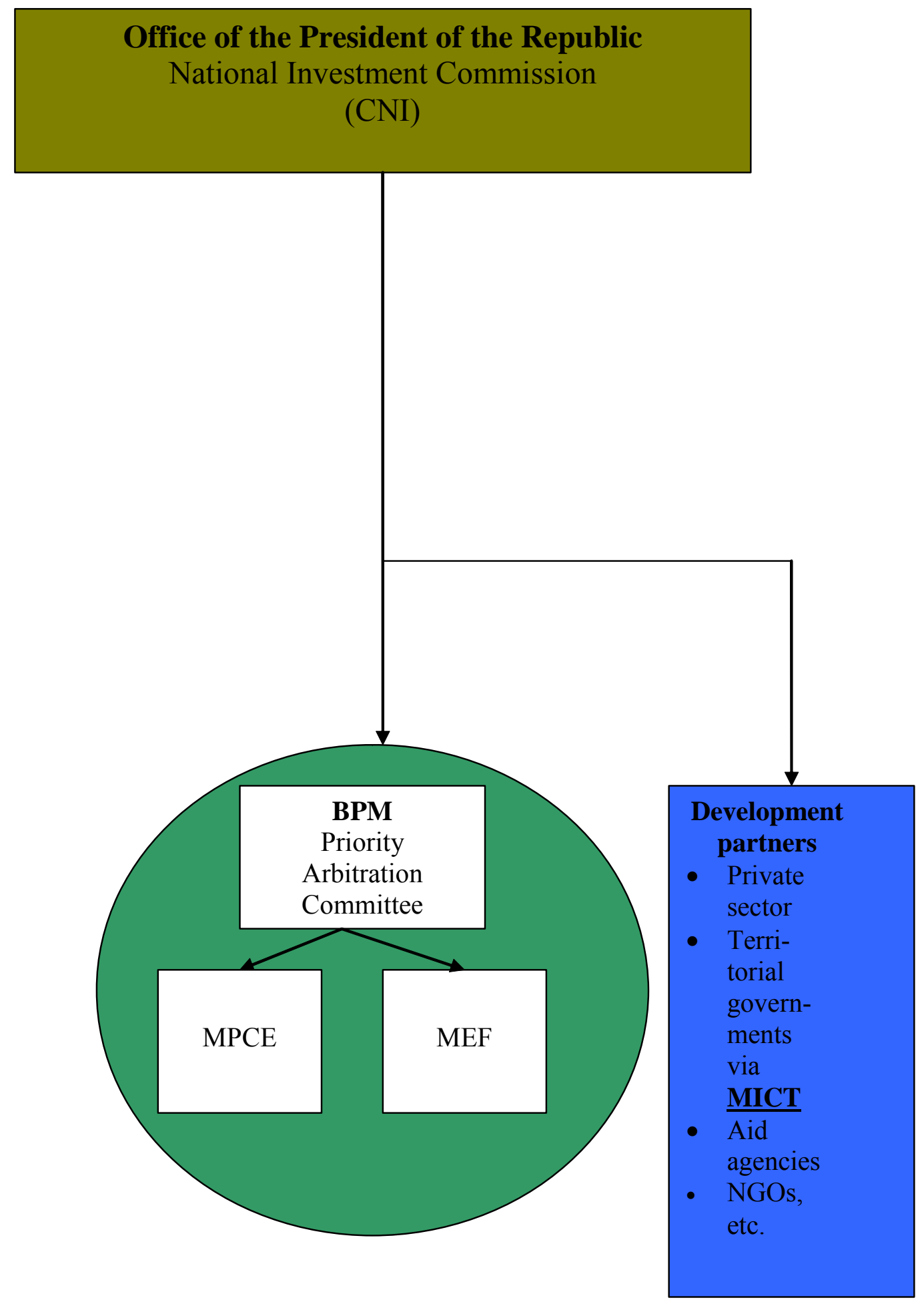


MONITORING INDICATORS TABLES 
Table 1: CORE INDICATORS BY OBJECTIVE

\begin{tabular}{|c|c|c|c|c|}
\hline OBJECTIVE & INDICATOR & Type of indicator & Frequency & Data source \\
\hline \multirow[t]{6}{*}{$\begin{array}{l}\text { Lay the groundwork for } \\
\text { good economic governance } \\
\text { and modernization of the } \\
\text { State }\end{array}$} & & & & \multirow[t]{6}{*}{$\begin{array}{l}\text { Specific breakdown; Survey of } \\
\text { users of public services; } \\
\text { CWIQ; Transparency } \\
\text { International }\end{array}$} \\
\hline & Rule of law indicator & Performance & Short-term & \\
\hline & Corruption perception index & Performance & Short-term & \\
\hline & $\begin{array}{l}\text { Representation of women at various levels (elective and } \\
\text { appointed offices) }\end{array}$ & Performance & Short-term & \\
\hline & $\begin{array}{l}\text { Proportion of official development assistance (ODA) } \\
\text { devoted to priority sectors }\end{array}$ & Performance & Short-term & \\
\hline & Public expenditure committed as $\%$ of GDP & Input & Short-term & \\
\hline \multirow[t]{5}{*}{$\begin{array}{l}\text { Introduce a decentralized } \\
\text { and participatory } \\
\text { partnership with a view to } \\
\text { facilitating territorial } \\
\text { governments' access to } \\
\text { investment resources while } \\
\text { building managerial } \\
\text { capacities at the local level }\end{array}$} & & & & \multirow[t]{5}{*}{$\begin{array}{l}\text { CWIQ; } \\
123 \text { Survey; } \\
\text { ECVH; } \\
\text { Environmental statistics }\end{array}$} \\
\hline & Public expenditure committed as $\%$ of GDP & Input & Short-term & \\
\hline & $\begin{array}{l}\text { Index ranking communes in respect of basic socio- } \\
\text { economic infrastructures }\end{array}$ & Impact & Long-term & \\
\hline & Proportion of managed forest zones & Impact & Long-term & \\
\hline & $\begin{array}{l}\text { Percentage of households using solid fuels (wood and } \\
\text { charcoal) }\end{array}$ & Performance & Short-term & \\
\hline \multirow[t]{5}{*}{ Renewed economic growth } & & & & \multirow[t]{5}{*}{ IHSI, BRH, and MEF } \\
\hline & Exports/GDP ratio & Performance & Short-term & \\
\hline & Foreign domestic investment growth rate & Performance & Short-term & \\
\hline & Ranking of investment climate & Performance & Short-term & \\
\hline & Average cost of creating a new business & Performance & Short-term & \\
\hline
\end{tabular}




\begin{tabular}{|c|c|c|c|c|}
\hline \multirow[t]{11}{*}{$\begin{array}{l}\text { Substantially rebuild the } \\
\text { human capital stock }\end{array}$} & & & & \multirow[t]{11}{*}{$\begin{array}{l}\text { Annual survey of basic } \\
\text { socioeconomic infrastructure; } \\
\text { CWIQ; } 123 \text { Survey; EMMU; } \\
\text { ECVH }\end{array}$} \\
\hline & Public expenditure committed as $\%$ of GDP & Input & Short-term & \\
\hline & Prevalence rate of modern contraceptive use & Performance & Short-term & \\
\hline & $\begin{array}{l}\text { Percentage of Commune-level Health Units (UCS) } \\
\text { offering a minimum package of services }\end{array}$ & Performance & Short-term & \\
\hline & Infant/child mortality rate & Impact & Long-term & \\
\hline & Proportion of women receiving a prenatal consultation & Performance & Short-term & \\
\hline & $\begin{array}{l}\text { Proportion of population with sustained access to basic } \\
\text { drugs at an affordable cost }\end{array}$ & Performance & Short-term & \\
\hline & Gross enrollment ratio, secondary school & Performance & Short-term & \\
\hline & Percentage of students passing official examinations & Performance & Short-term & \\
\hline & Index of access to running water & Outcome & Short-term & \\
\hline & Index of access to basic sanitation services & Outcome & Short-term & \\
\hline
\end{tabular}


Table 2: CORE PERFORMANCE INDICATORS

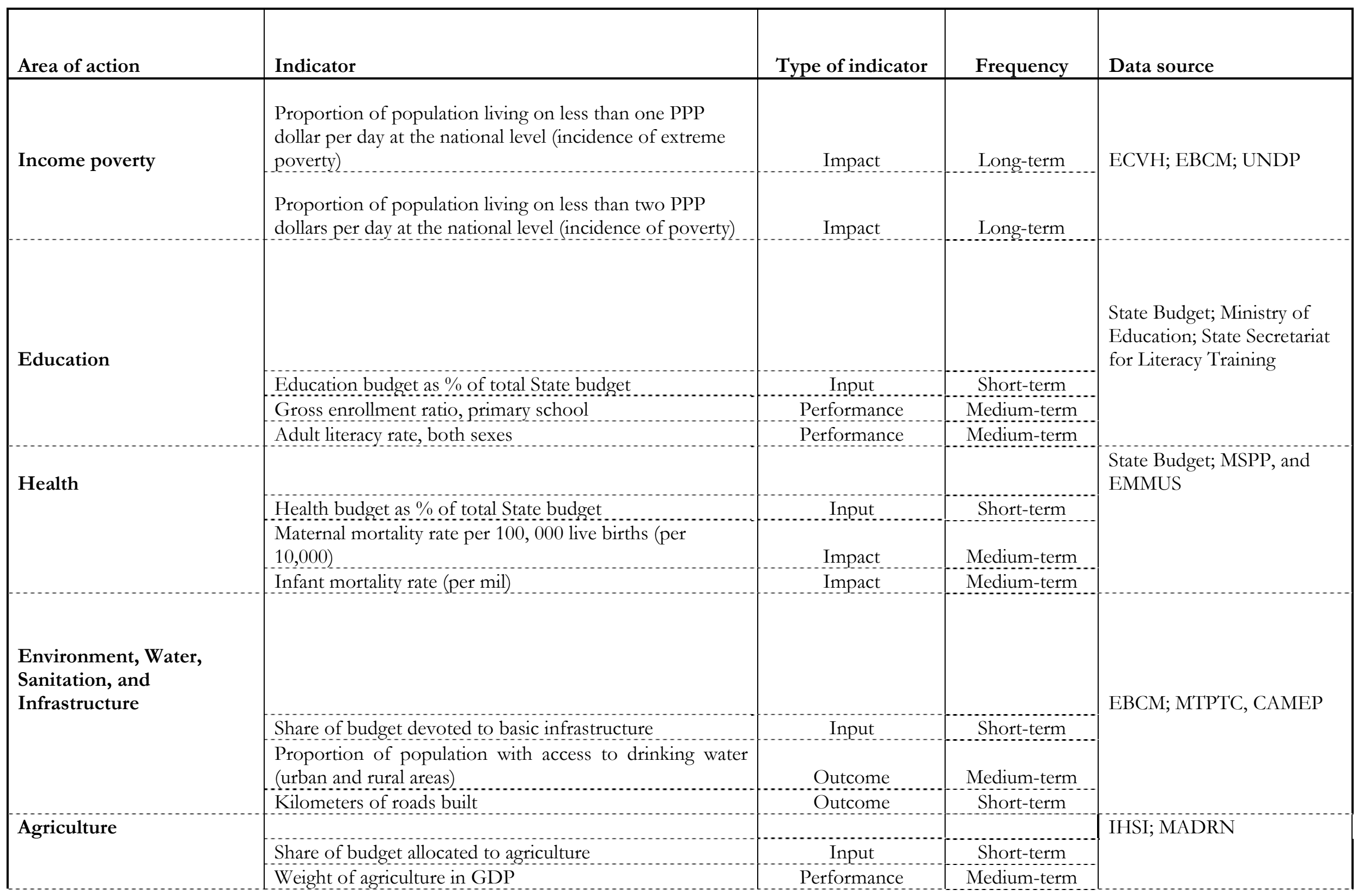




\begin{tabular}{|c|c|c|c|c|}
\hline \multirow[t]{3}{*}{ Decentralization } & & & & \multirow[t]{3}{*}{$\begin{array}{l}\text { Ministry of the Interior and } \\
\text { Territorial Government }\end{array}$} \\
\hline & $\%$ of public expenditure at subnational government level & Input & Short-term & \\
\hline & $\begin{array}{l}\text { Quantity of public services provided by subnational } \\
\text { governments }\end{array}$ & Outcome & Short-term & \\
\hline \multirow[t]{2}{*}{ Employment } & & & & \multirow[t]{2}{*}{123 Survey } \\
\hline & Number of permanent jobs created & Performance & Medium-term & \\
\hline \multirow[t]{3}{*}{ Participation of women } & & & & \multirow{3}{*}{ Ministry of Education } \\
\hline & $\begin{array}{l}\text { Girl/boy (female/male) ratio in primary, secondary, and } \\
\text { higher education }\end{array}$ & Performance & Medium-term & \\
\hline & $\%$ of women entrepreneurs & Performance & Medium-term & \\
\hline \multirow[t]{3}{*}{ Governance/ Corruption } & & & & \multirow[t]{3}{*}{$\begin{array}{l}\text { PNH; Transparency } \\
\text { International; } \\
\text { State Budgets; World Bank }\end{array}$} \\
\hline & $\begin{array}{l}\text { Share of annual budget for Justice by comparison with } \\
\text { State budget }\end{array}$ & Input & Short-term & \\
\hline & Number of corruption cases sanctioned by law & Performance & Short-term & \\
\hline \multirow[t]{5}{*}{ Macroeconomy } & & & & \multirow{5}{*}{ IHSI; MEF; BRH } \\
\hline & Annual GDP growth rate & Performance & Short-term & \\
\hline & Real interest rate & Climate & Short-term & \\
\hline & Private investment rate & Performance & Short-term & \\
\hline & Public investment rate & Performance & Short-term & \\
\hline
\end{tabular}




\section{ANNEX II \\ Detailed Matrix of Policy Actions of DSNCRP \\ English Translation of Official Original Document in French}





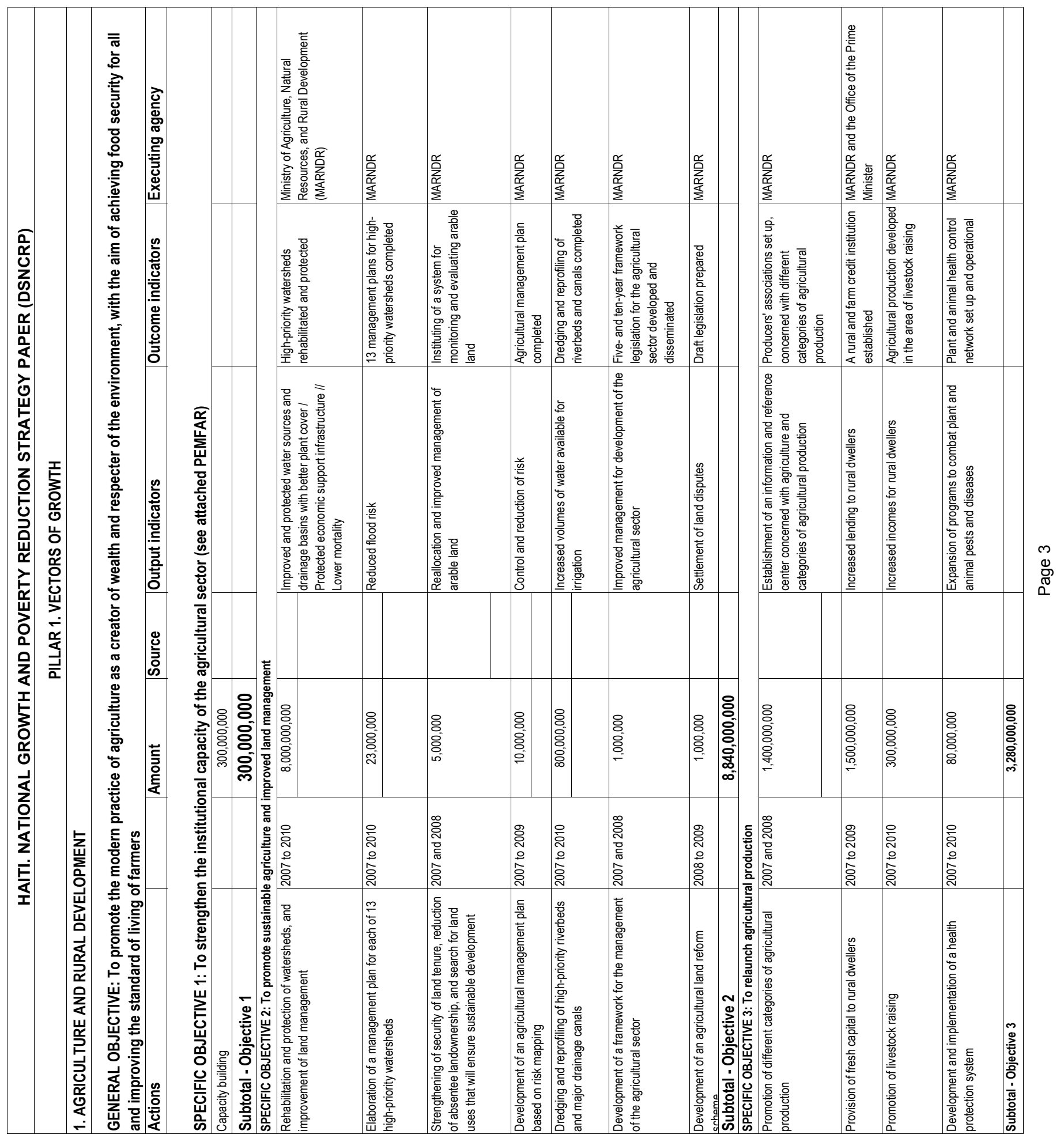




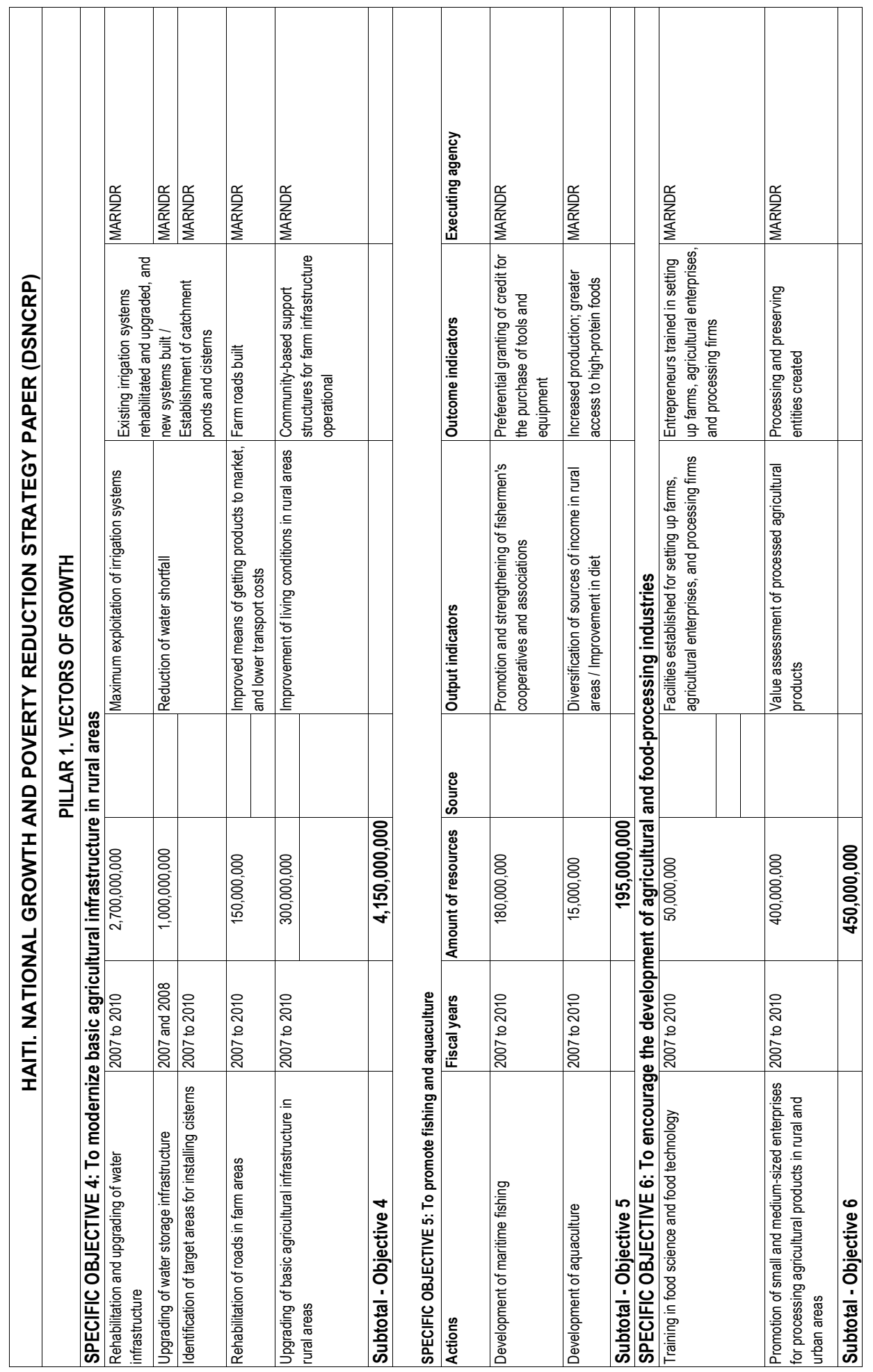




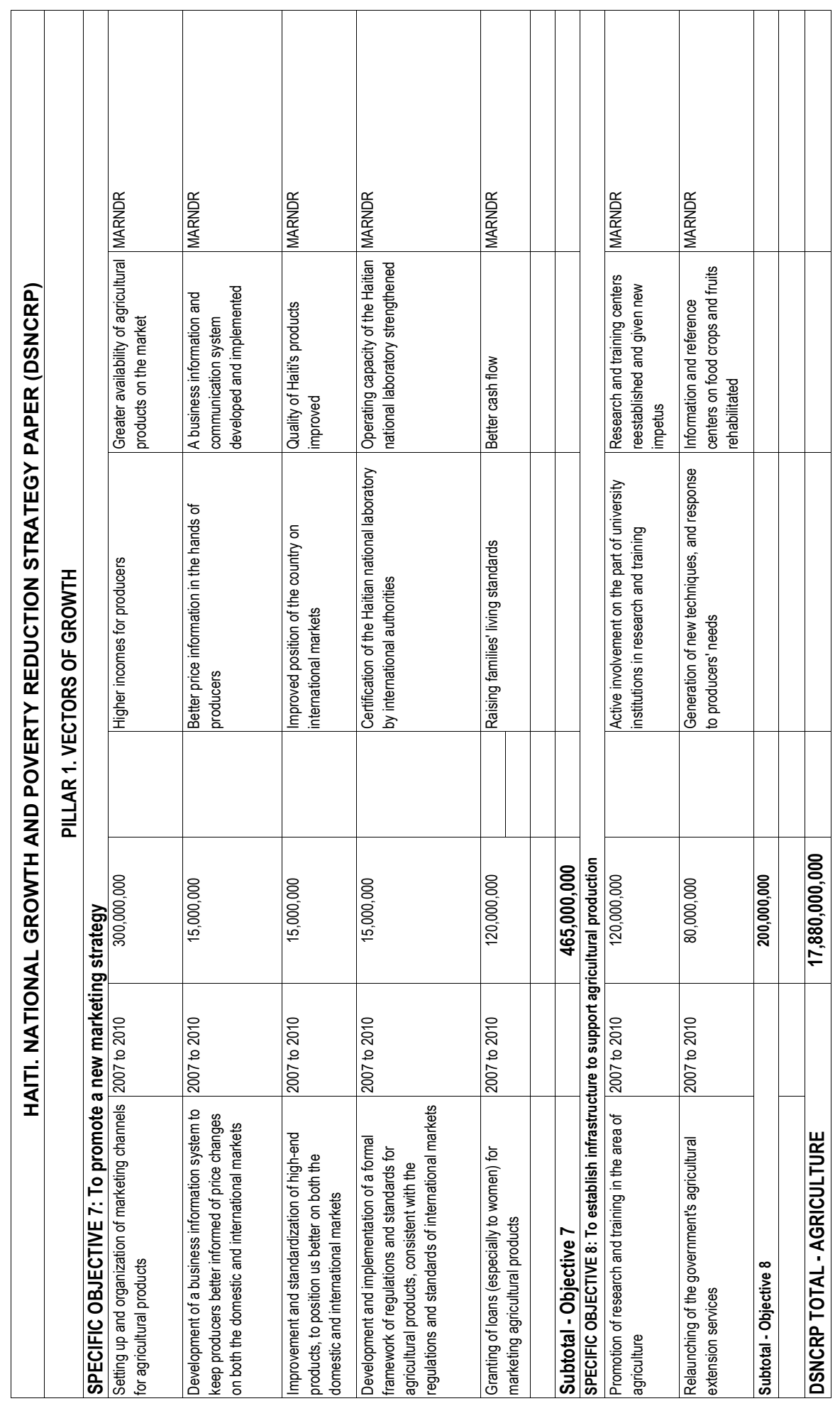

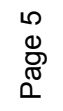




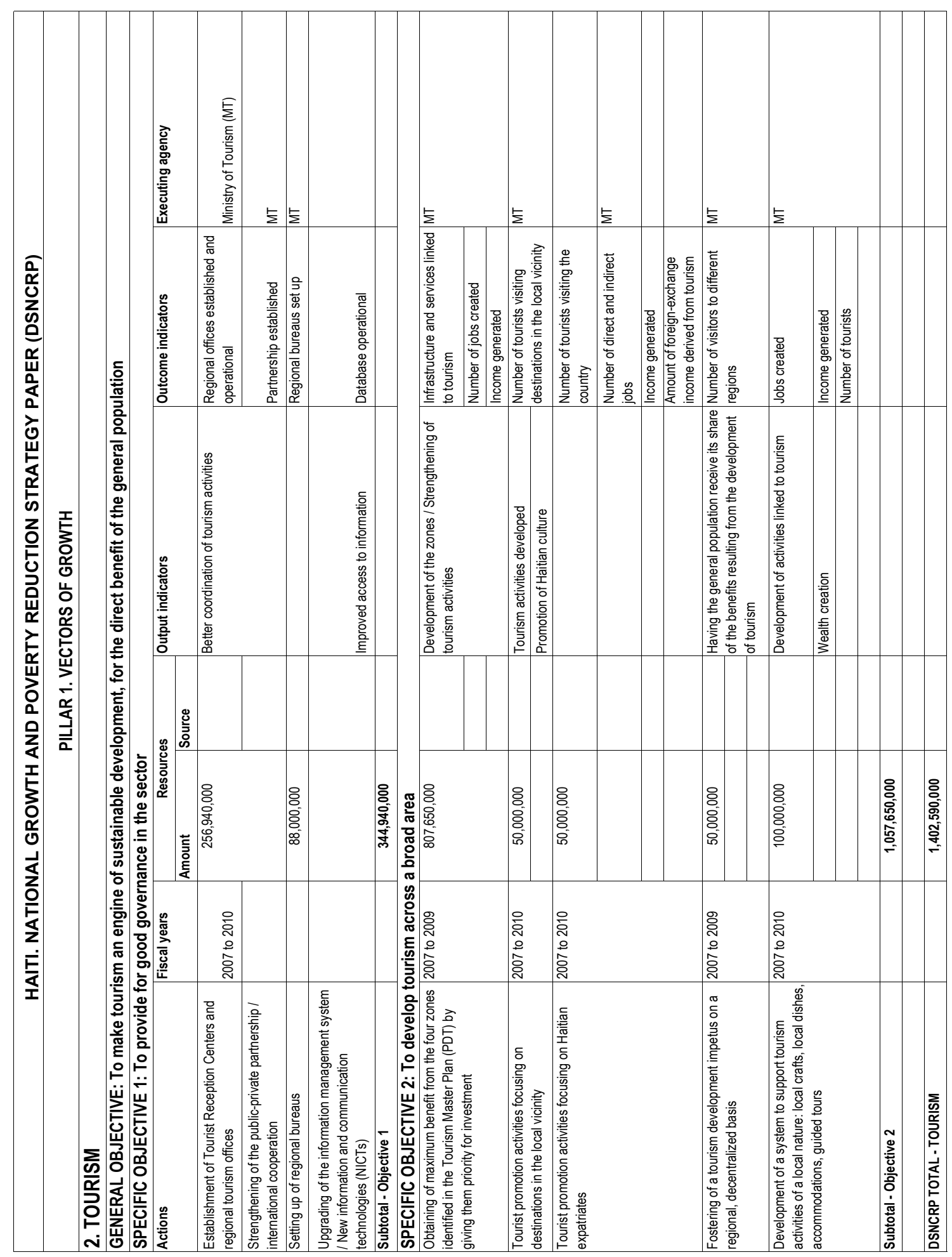

0
0
0
$\frac{1}{0}$ 


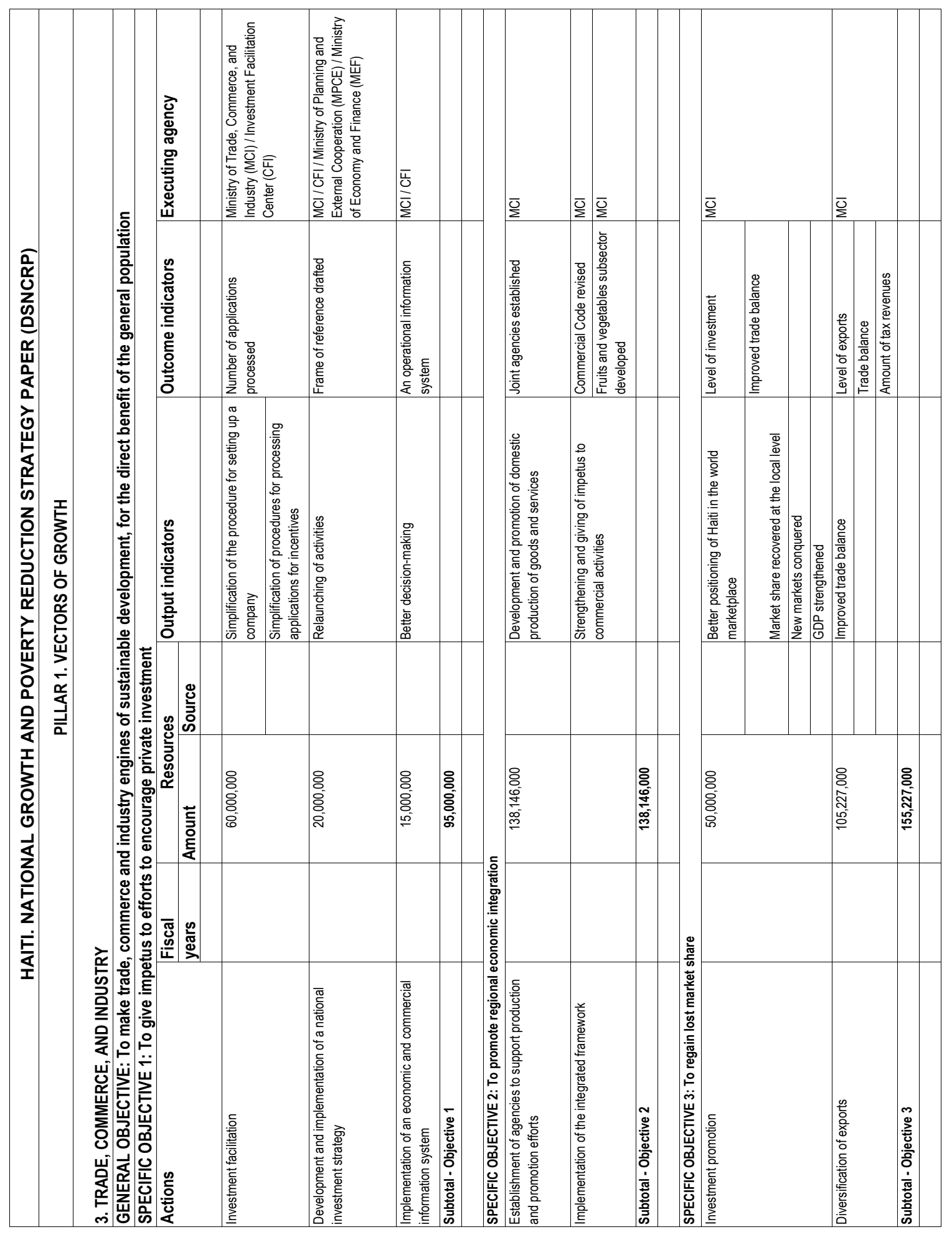

\begin{tabular}{l}
\multirow{0}{0}{} \\
$\stackrel{7}{\square}$ \\
0
\end{tabular} 


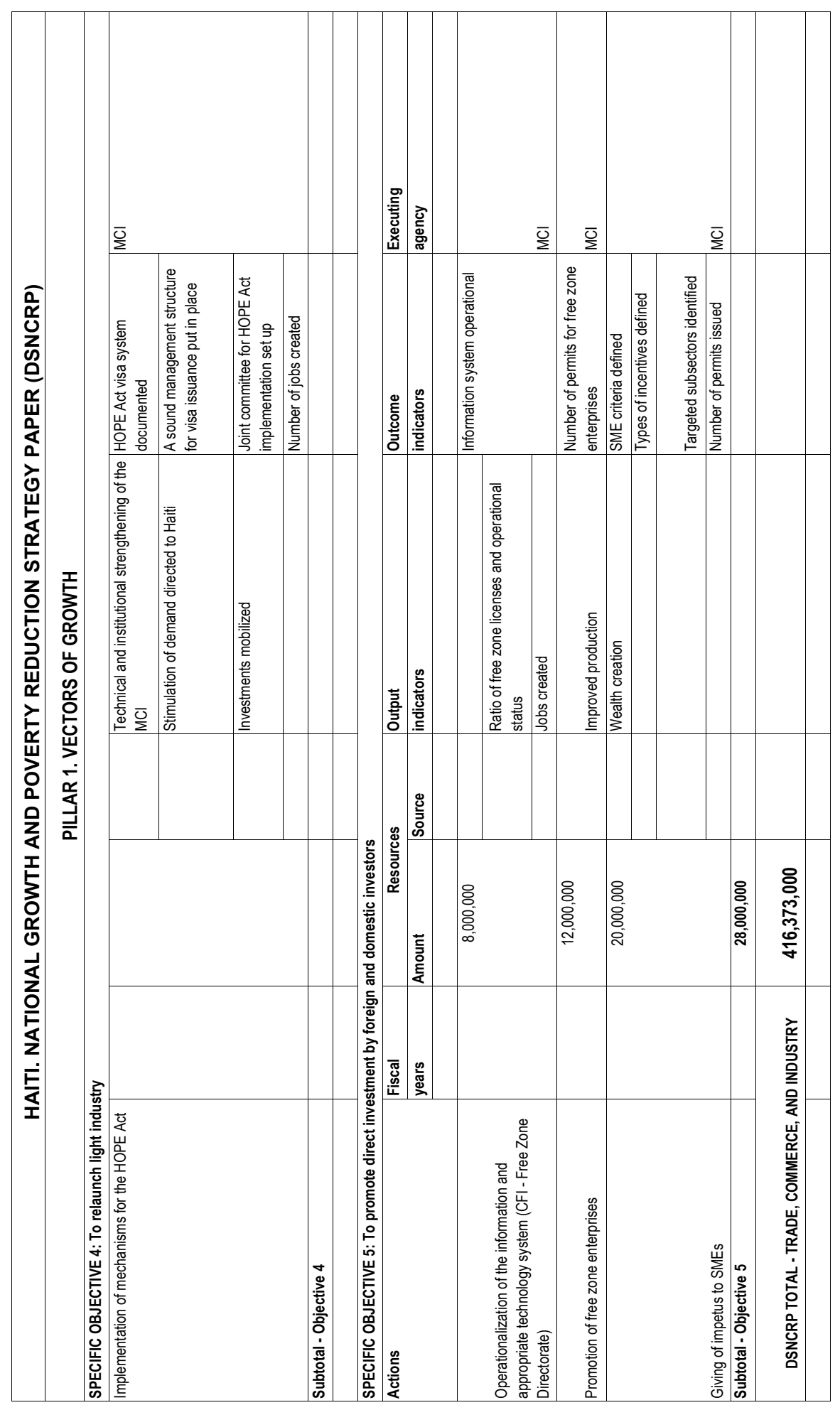

$\infty$
0
0
0
0 


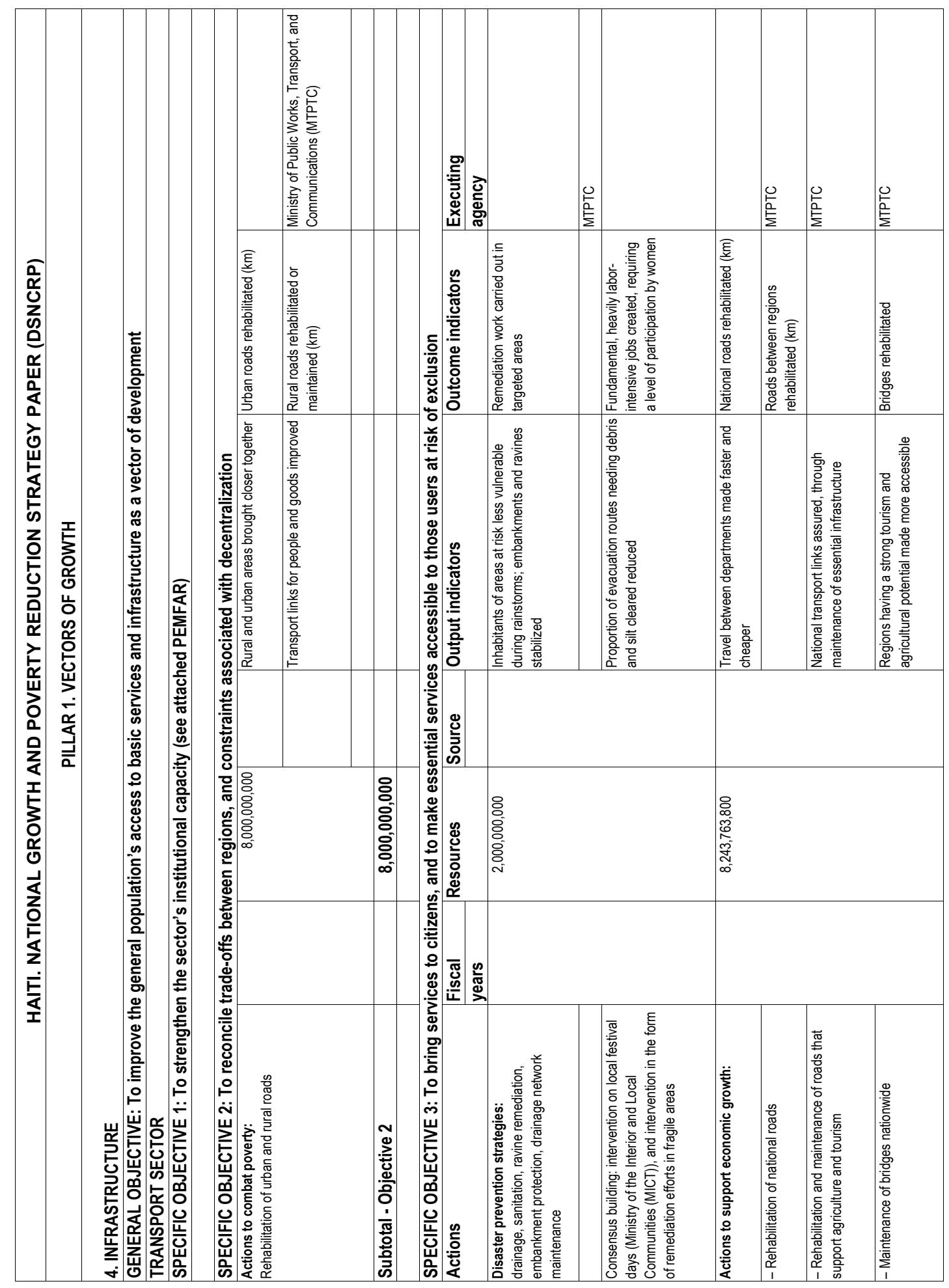

0
0
0
0
0 


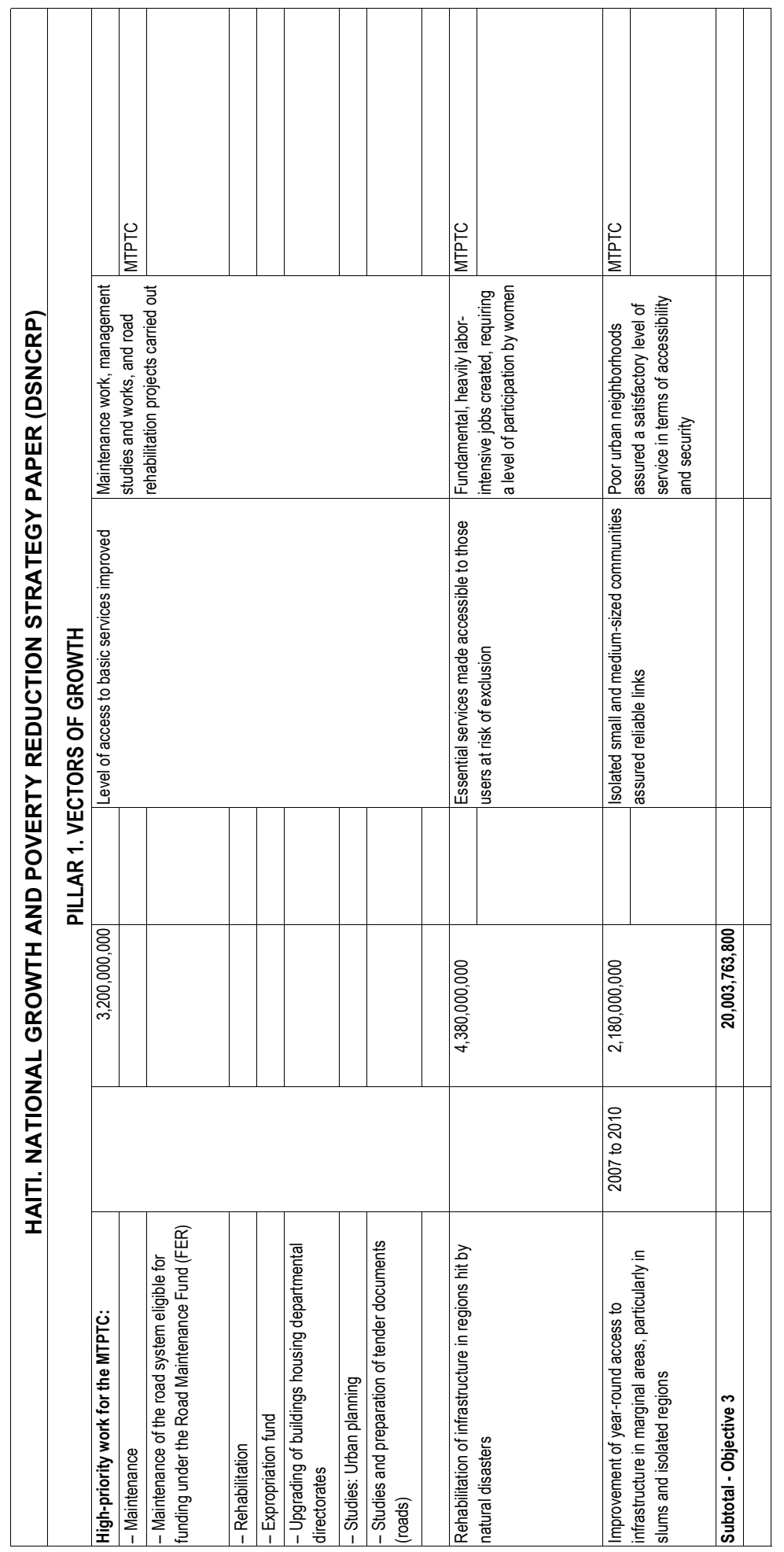

$\frac{0}{0}$
$\frac{0}{\pi}$
0 


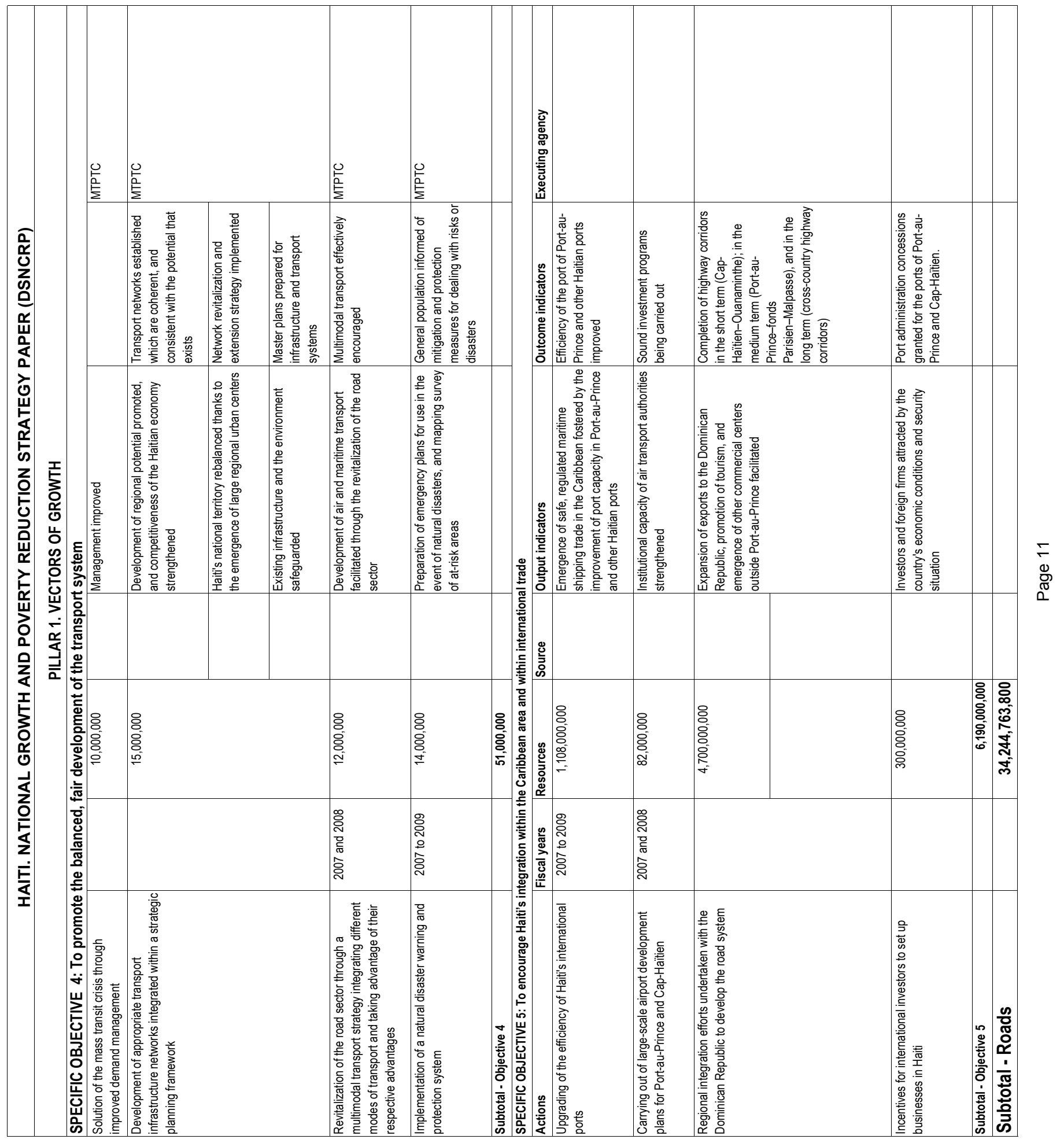




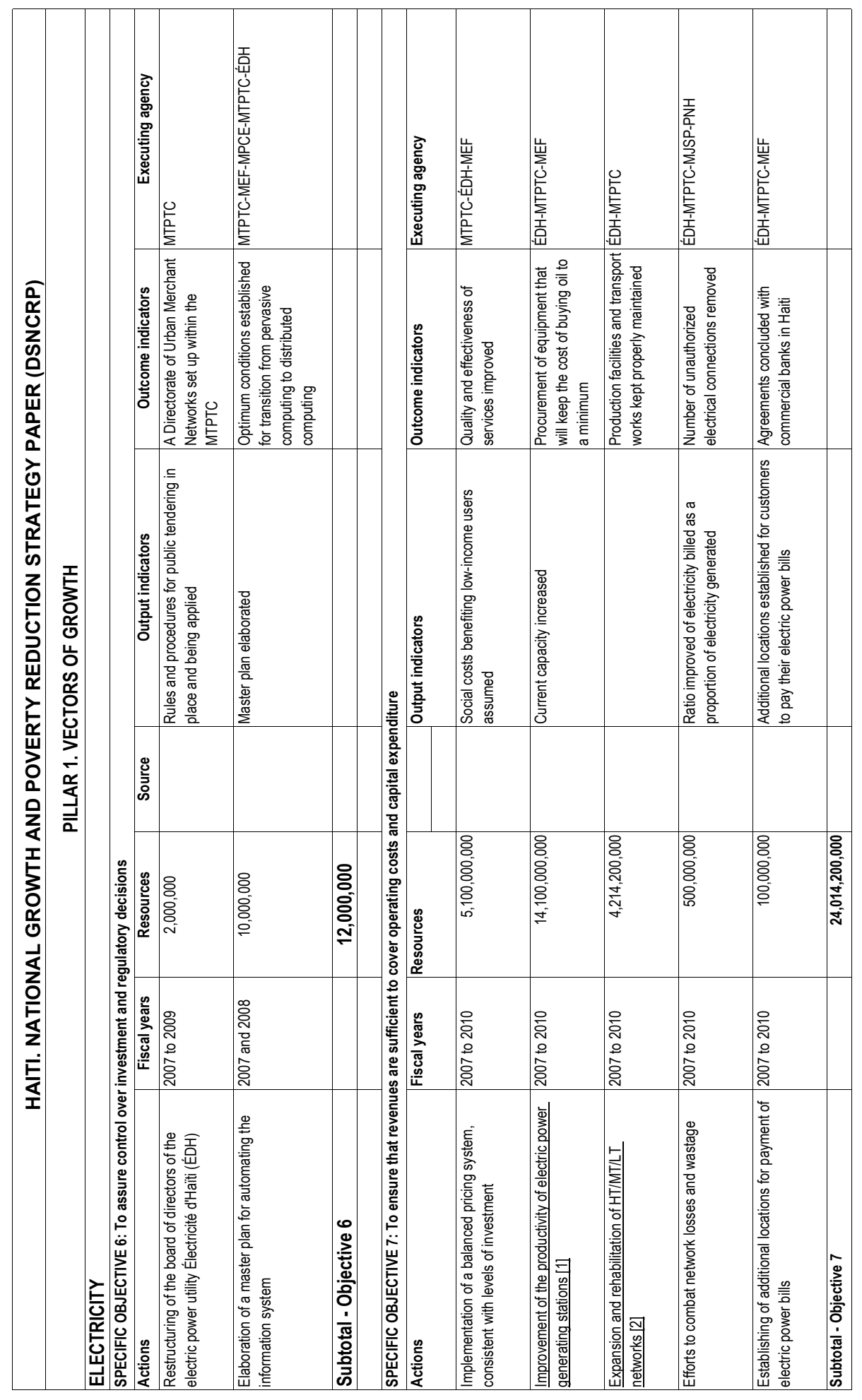

$\stackrel{1}{0}$
$\frac{\pi}{\pi}$
$\frac{\pi}{0}$ 


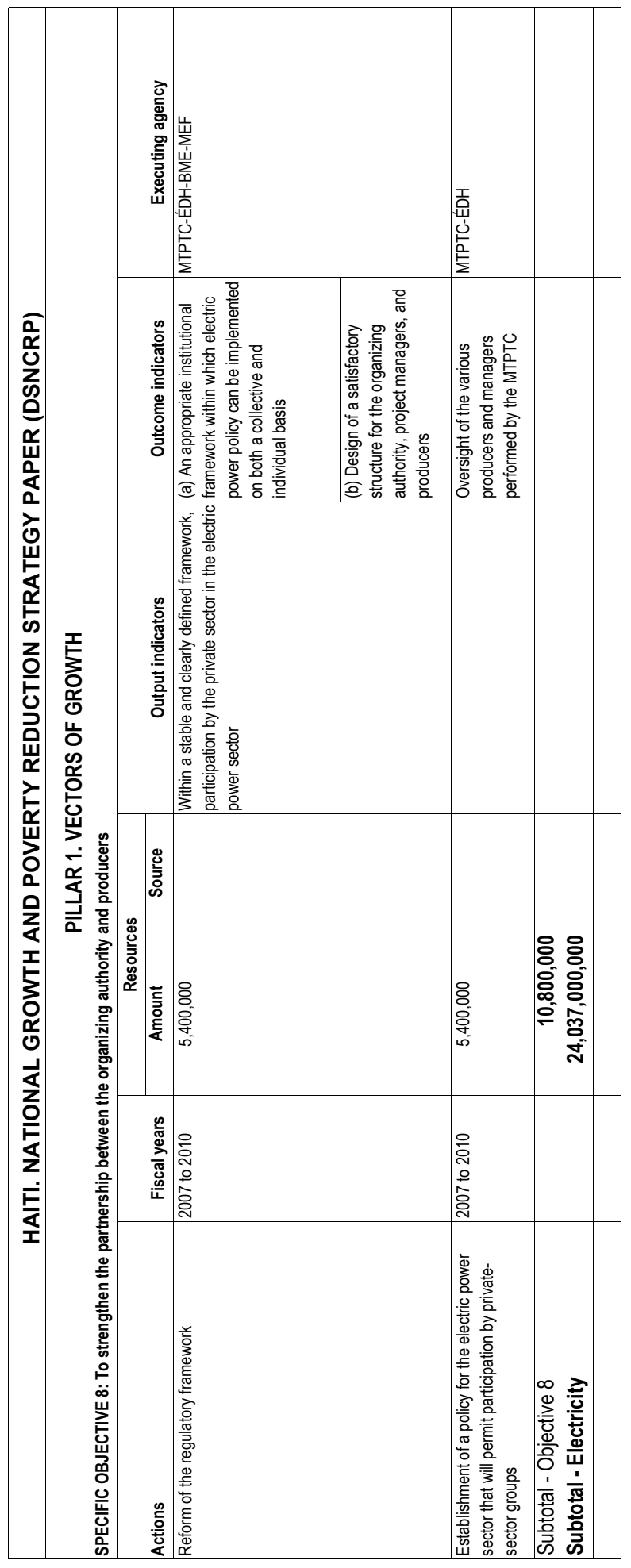

$\frac{m}{\sigma}$ 


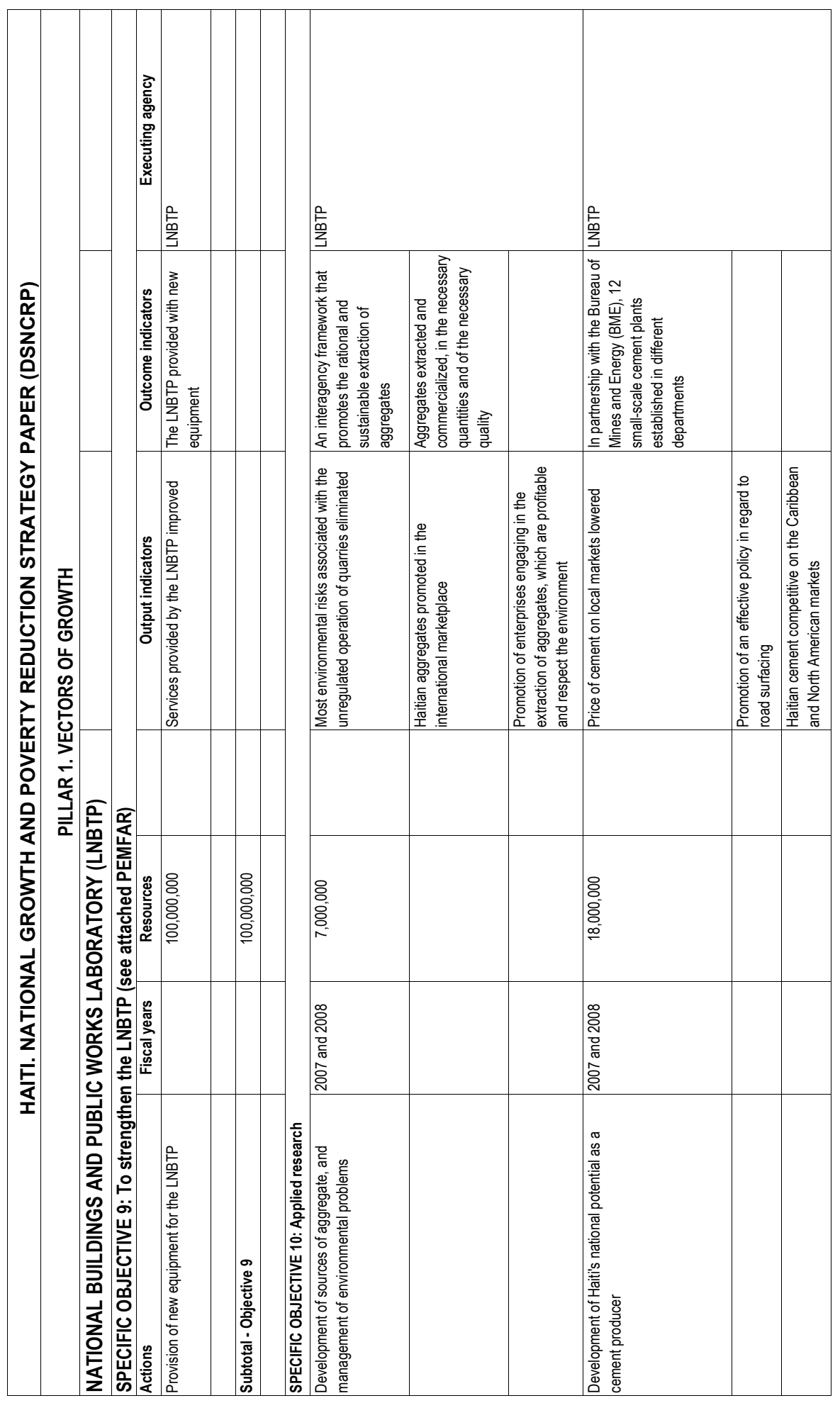

$\frac{\nabla}{0}$
$\frac{0}{0}$
0 


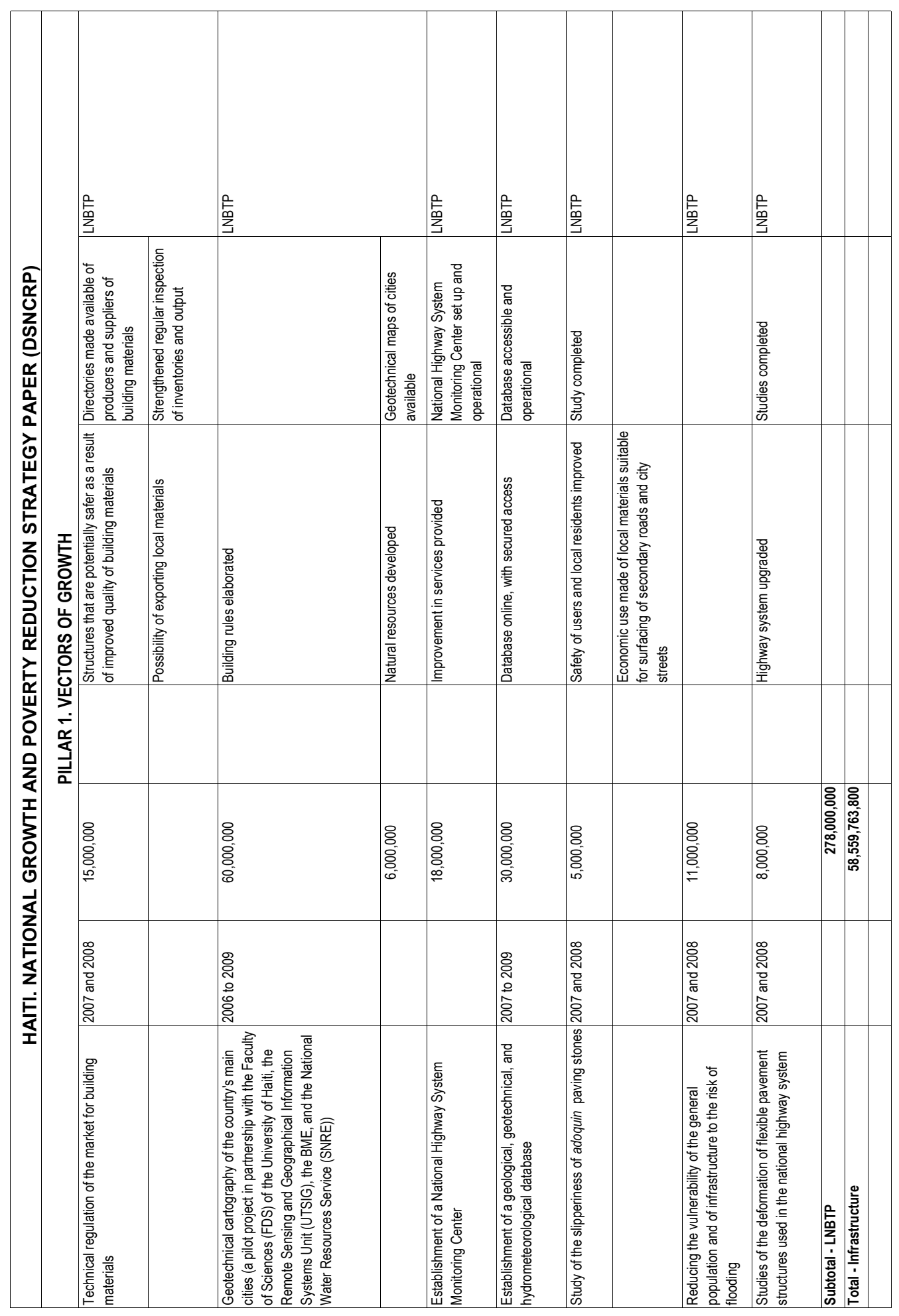

$\frac{10}{0}$
$\stackrel{0}{\pi}$
0 


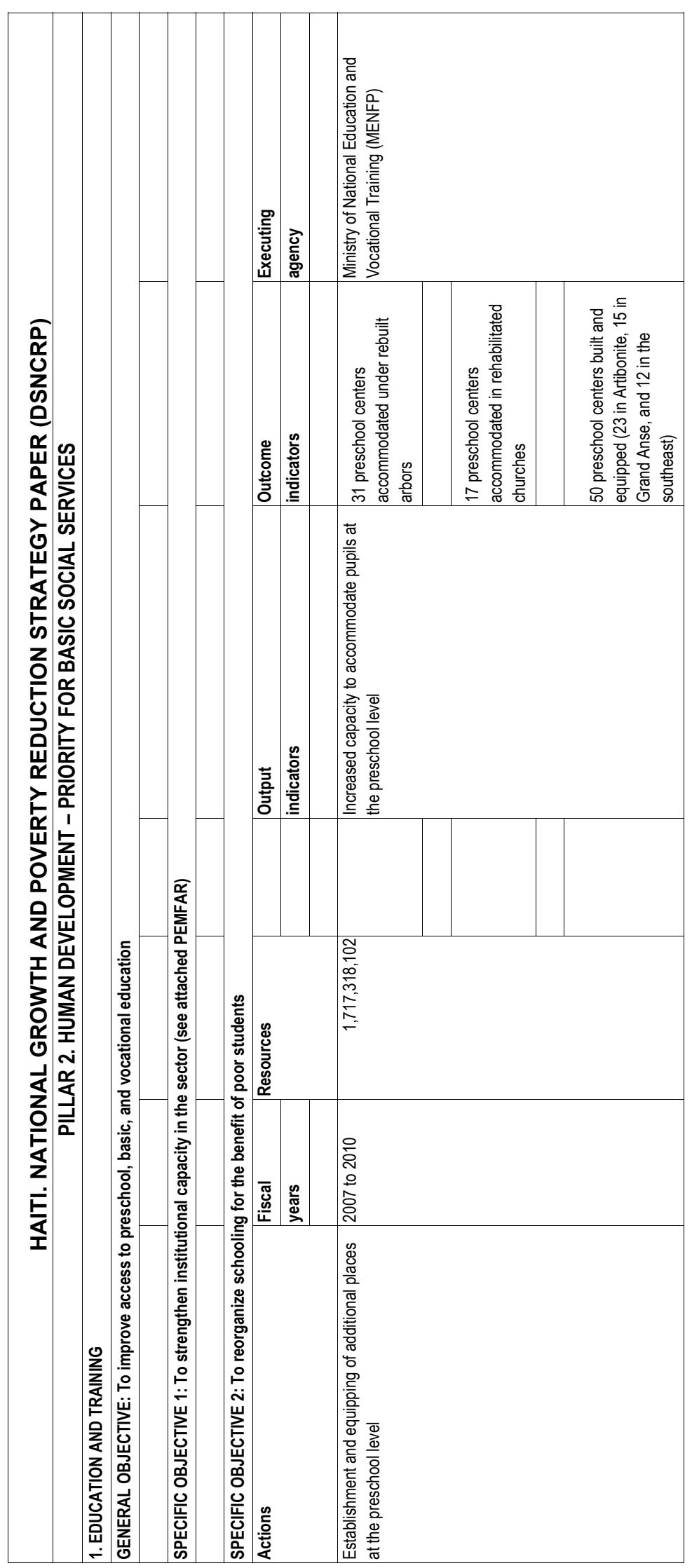

$\frac{0}{0}$ 


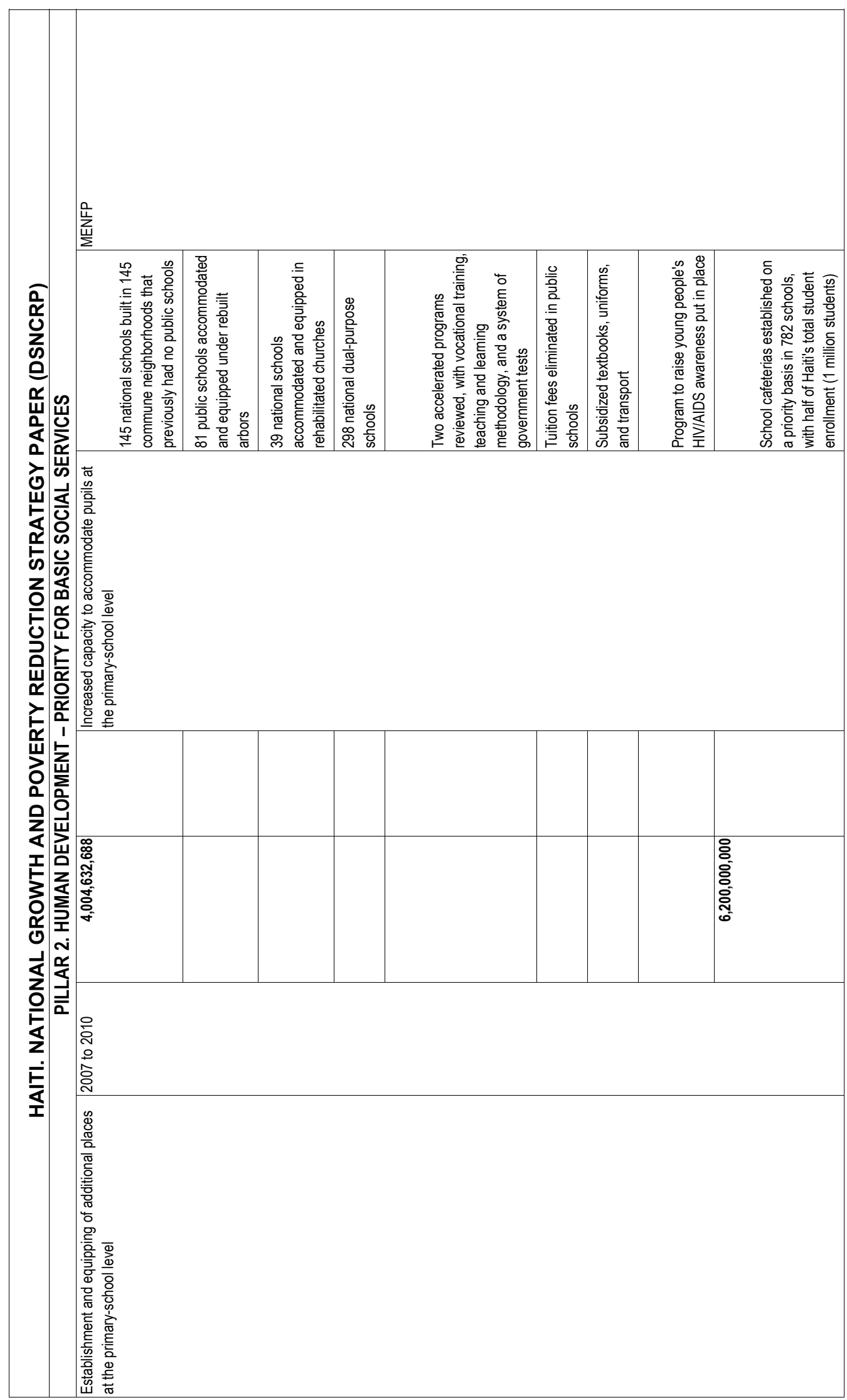

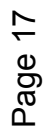




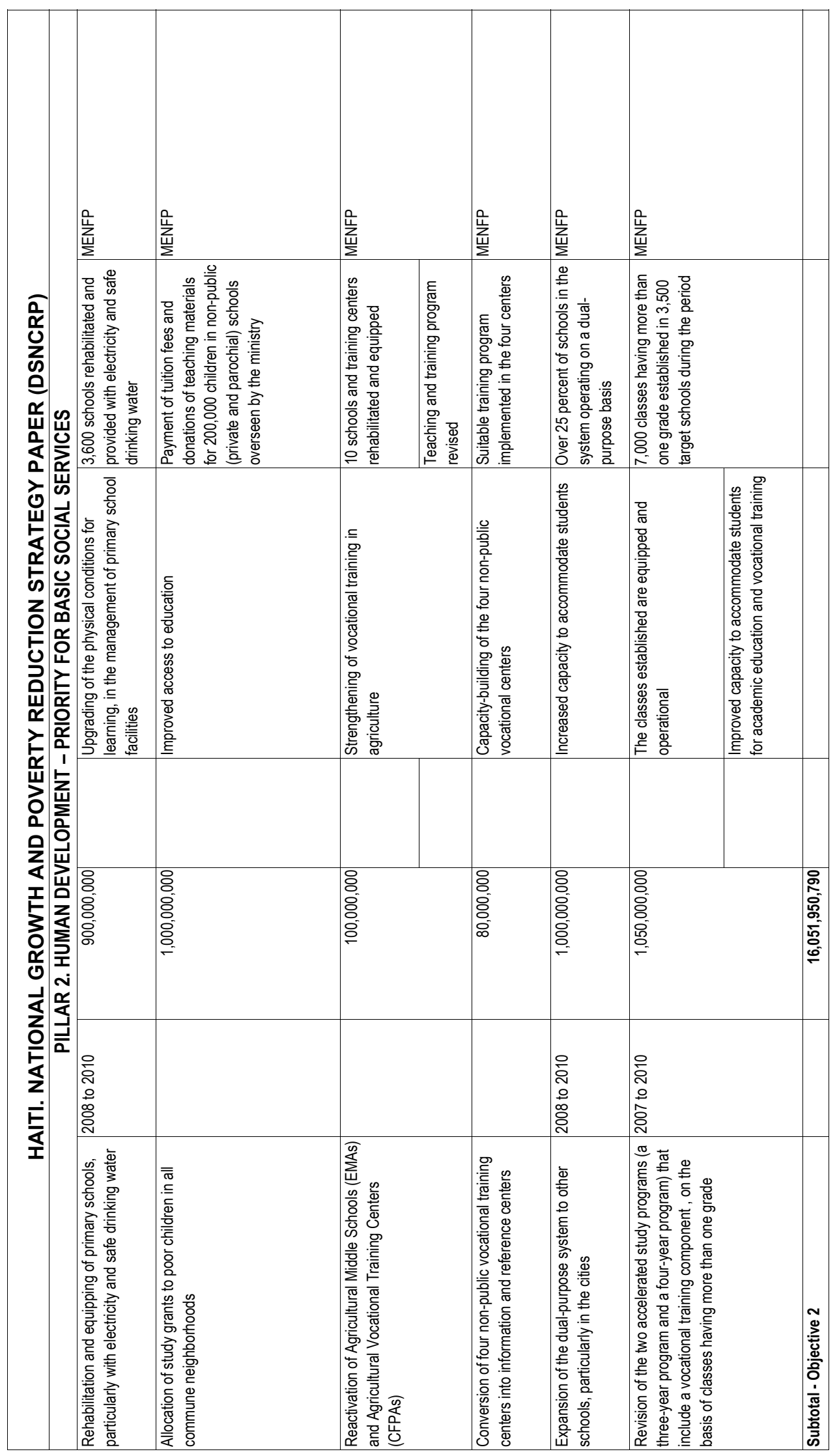

$\frac{\infty}{\infty}$ 


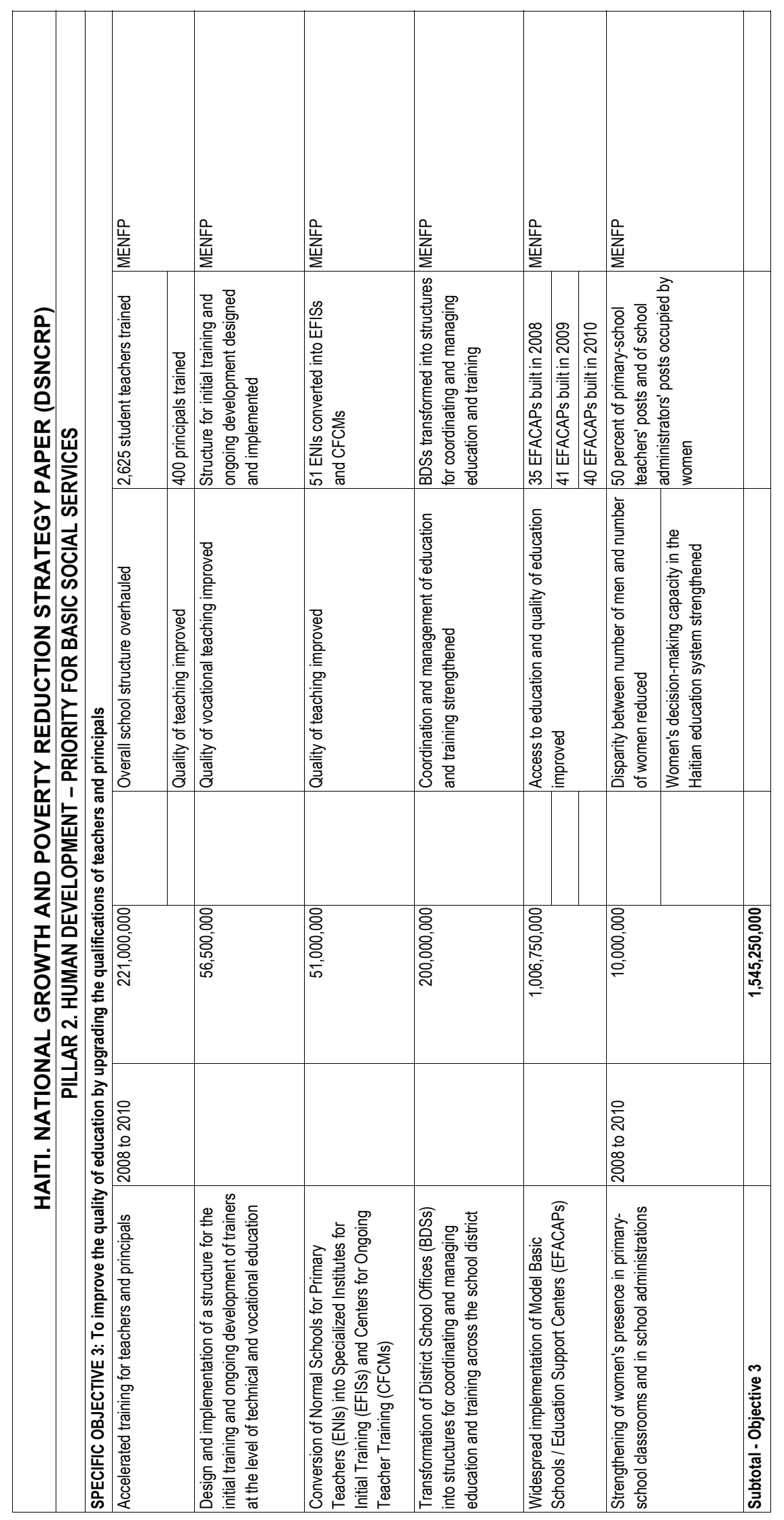




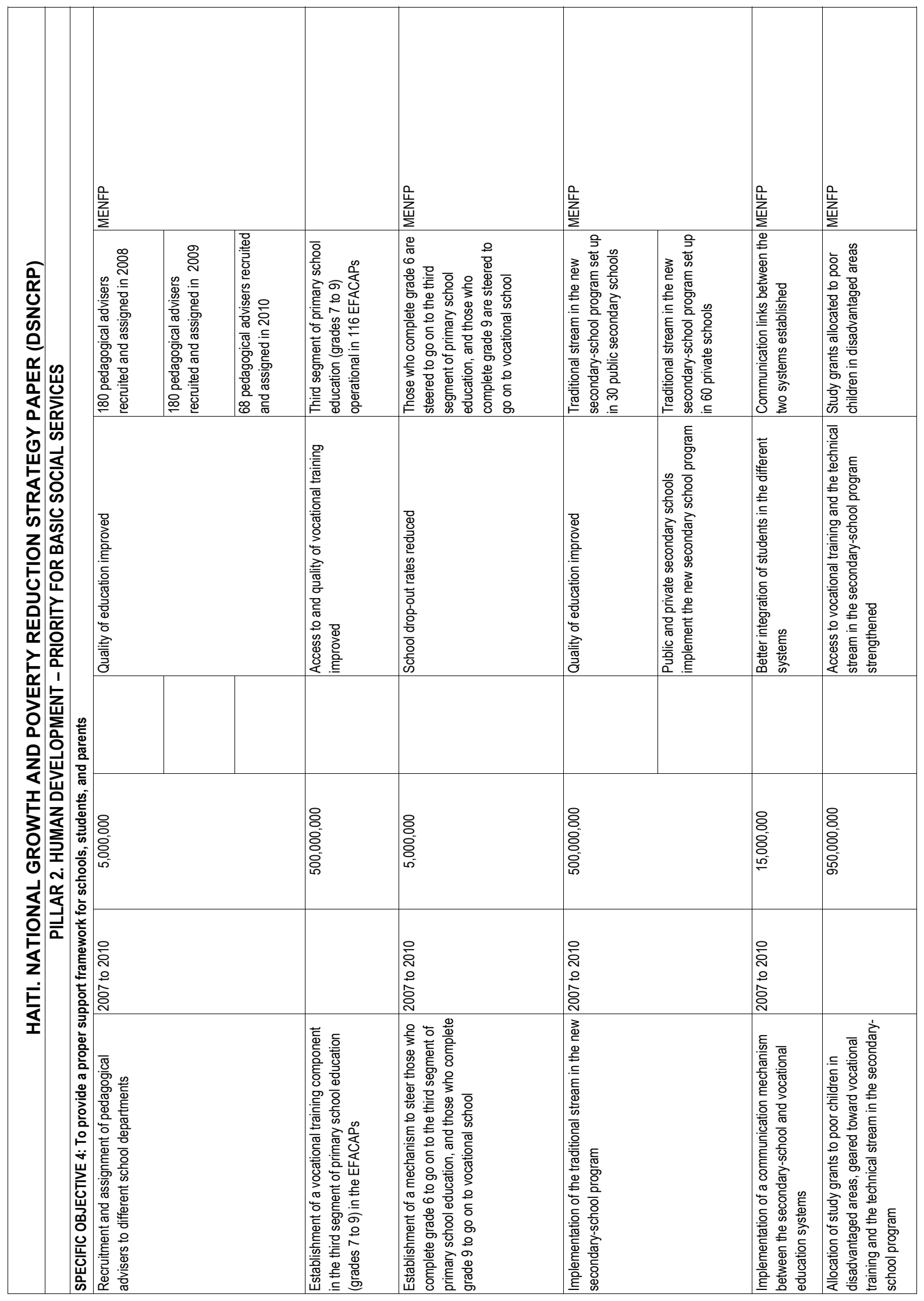

$\stackrel{2}{0}$
$\stackrel{0}{\pi}$
0 


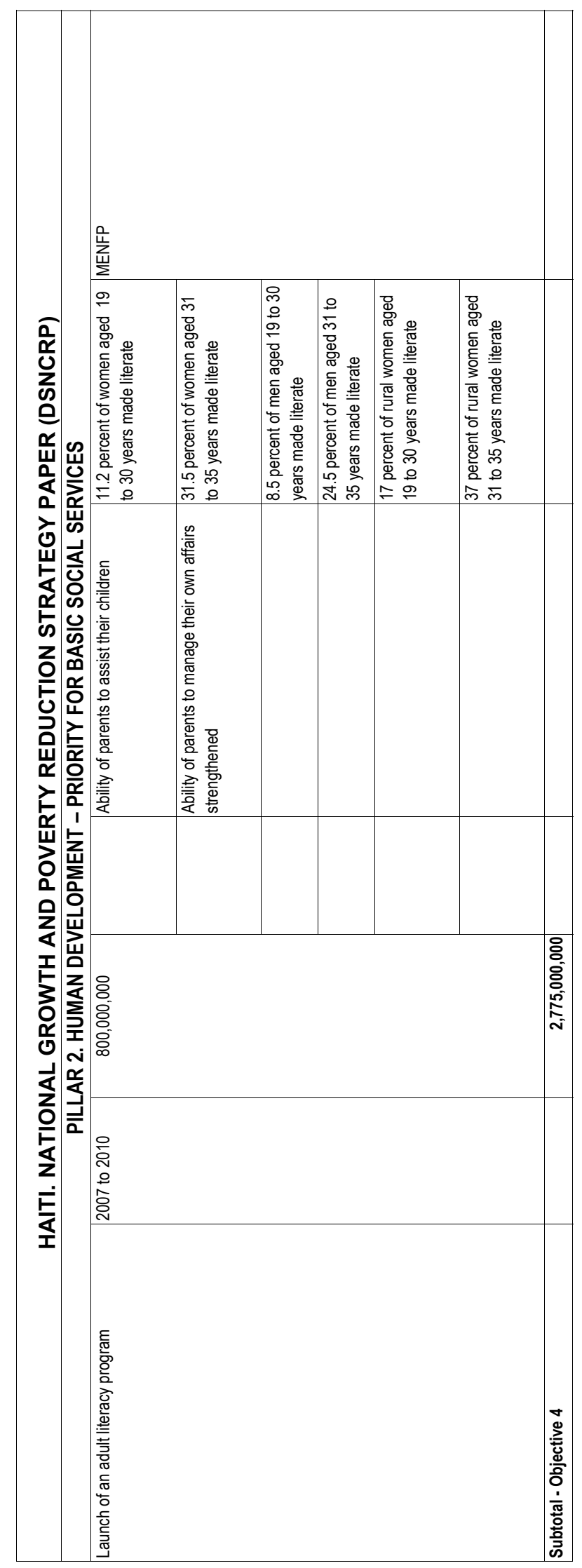

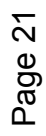




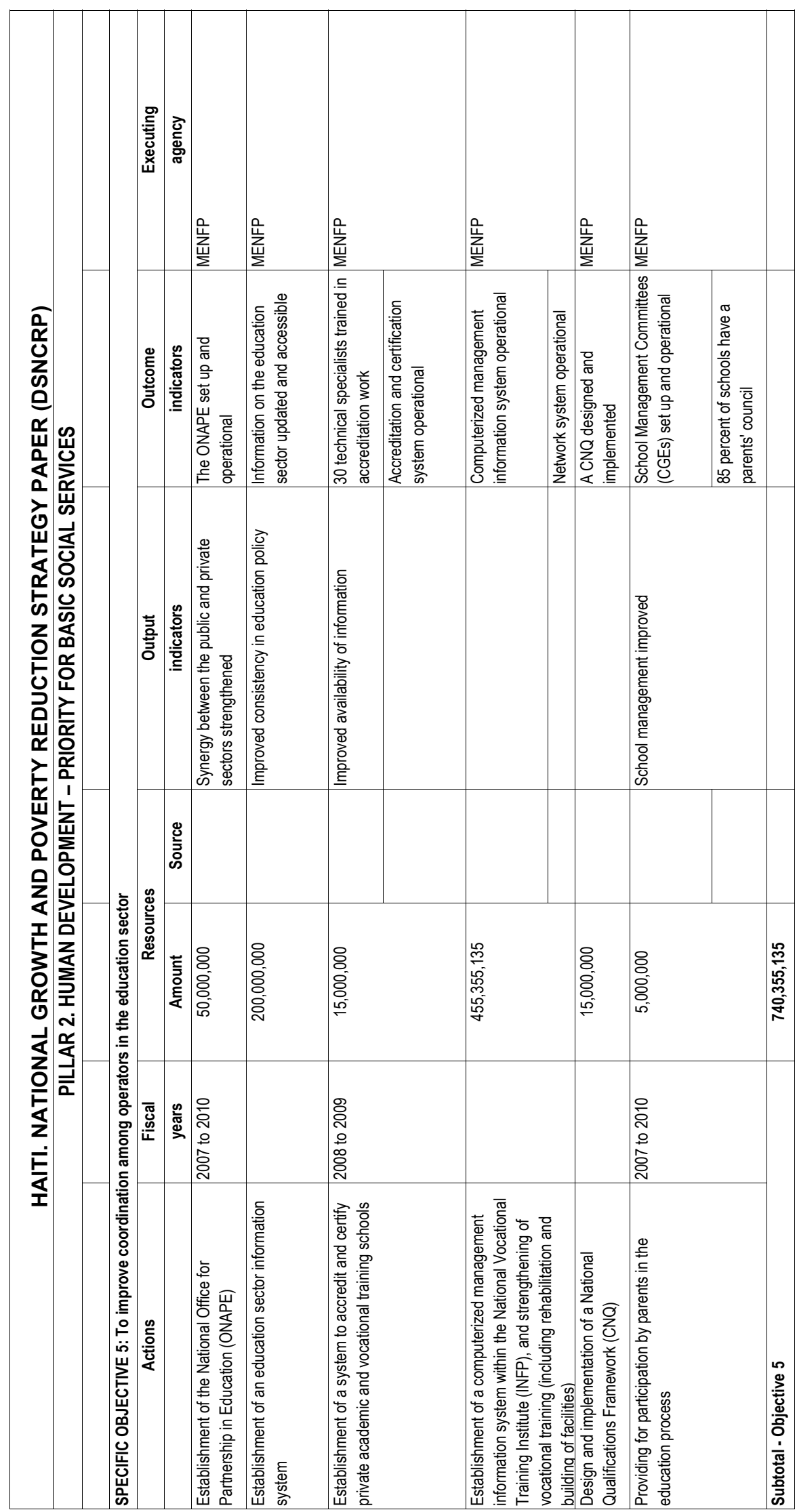




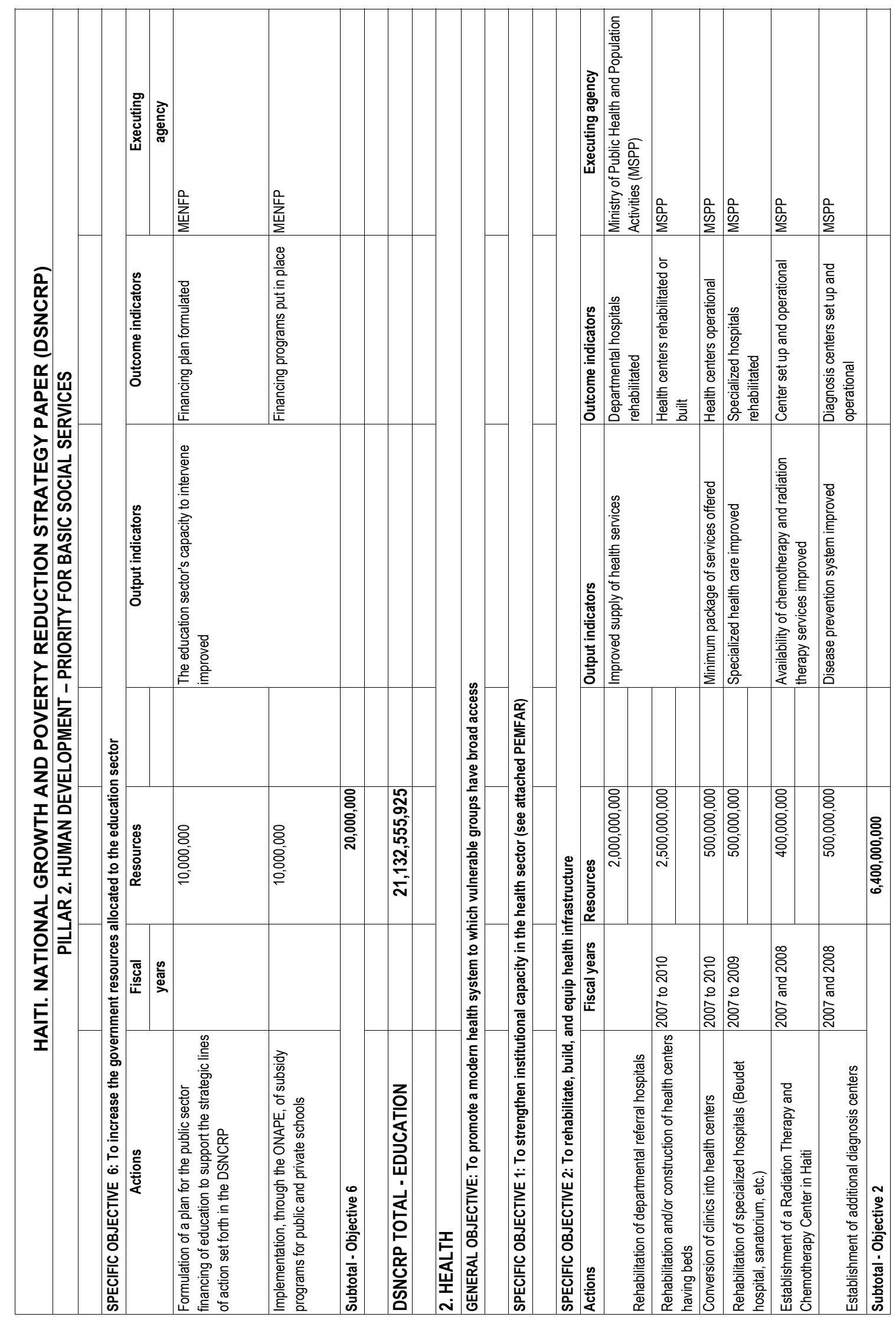




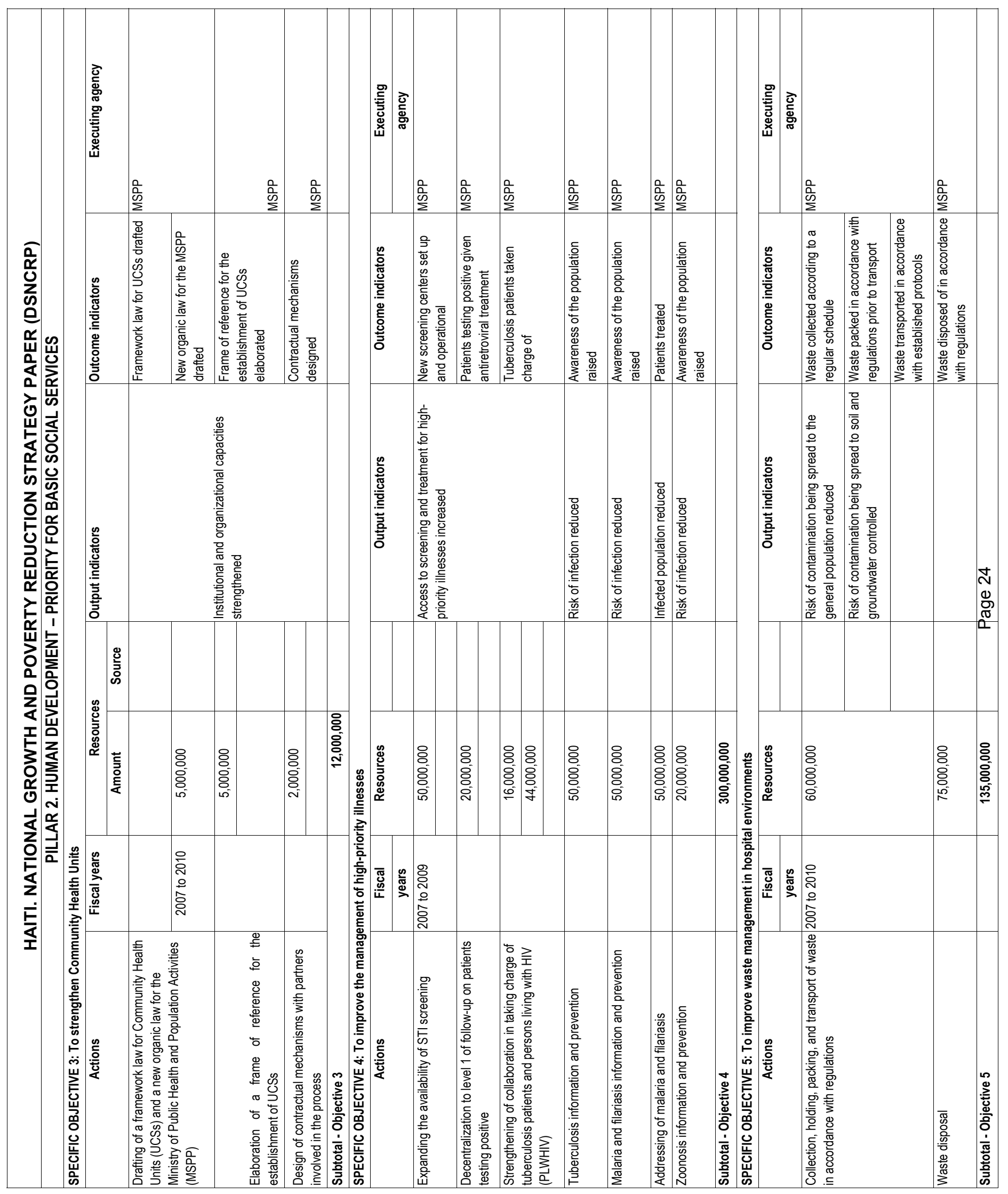




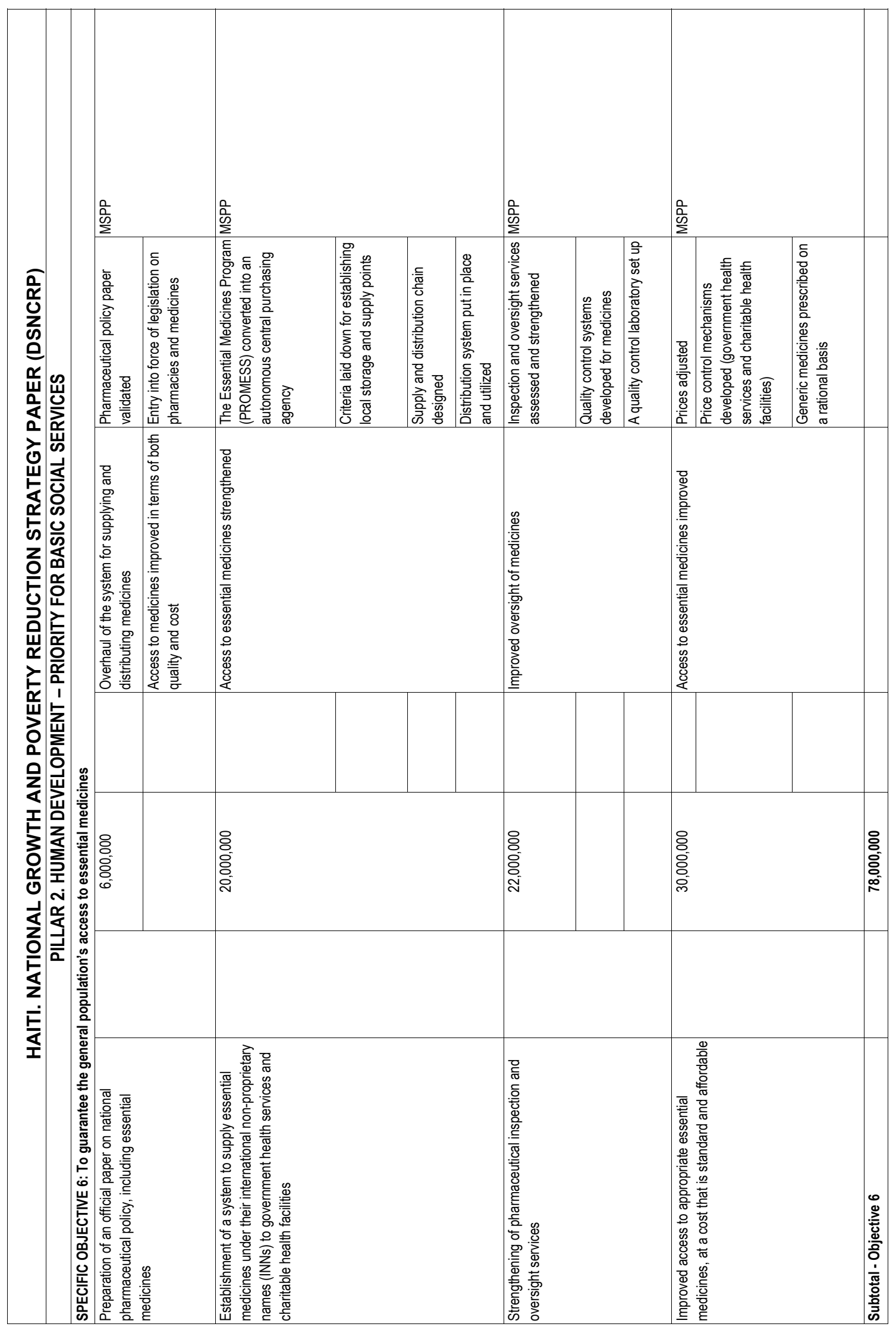

N
0
$\mathbb{8}$
0 


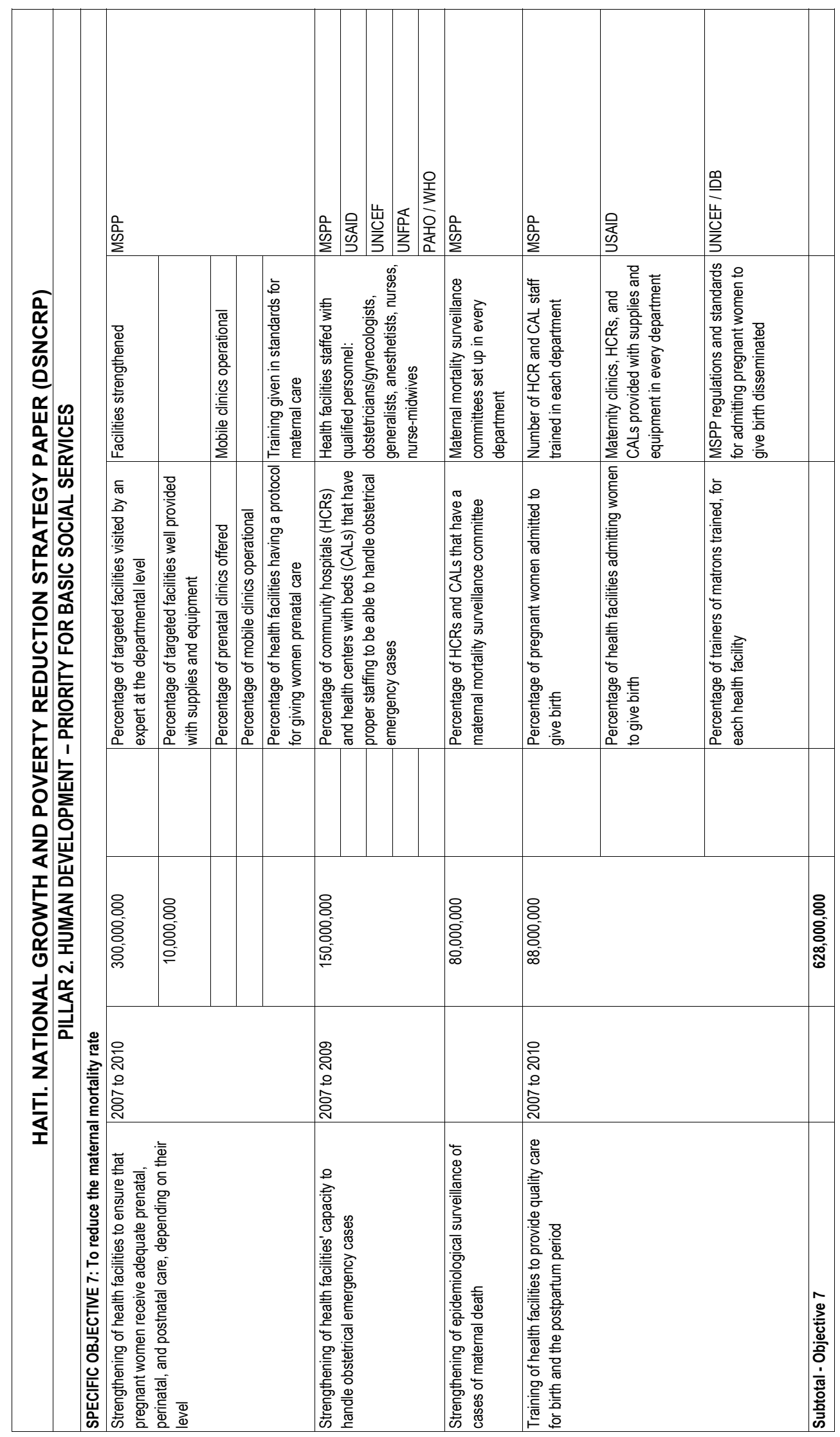

0
0
0
0
0 


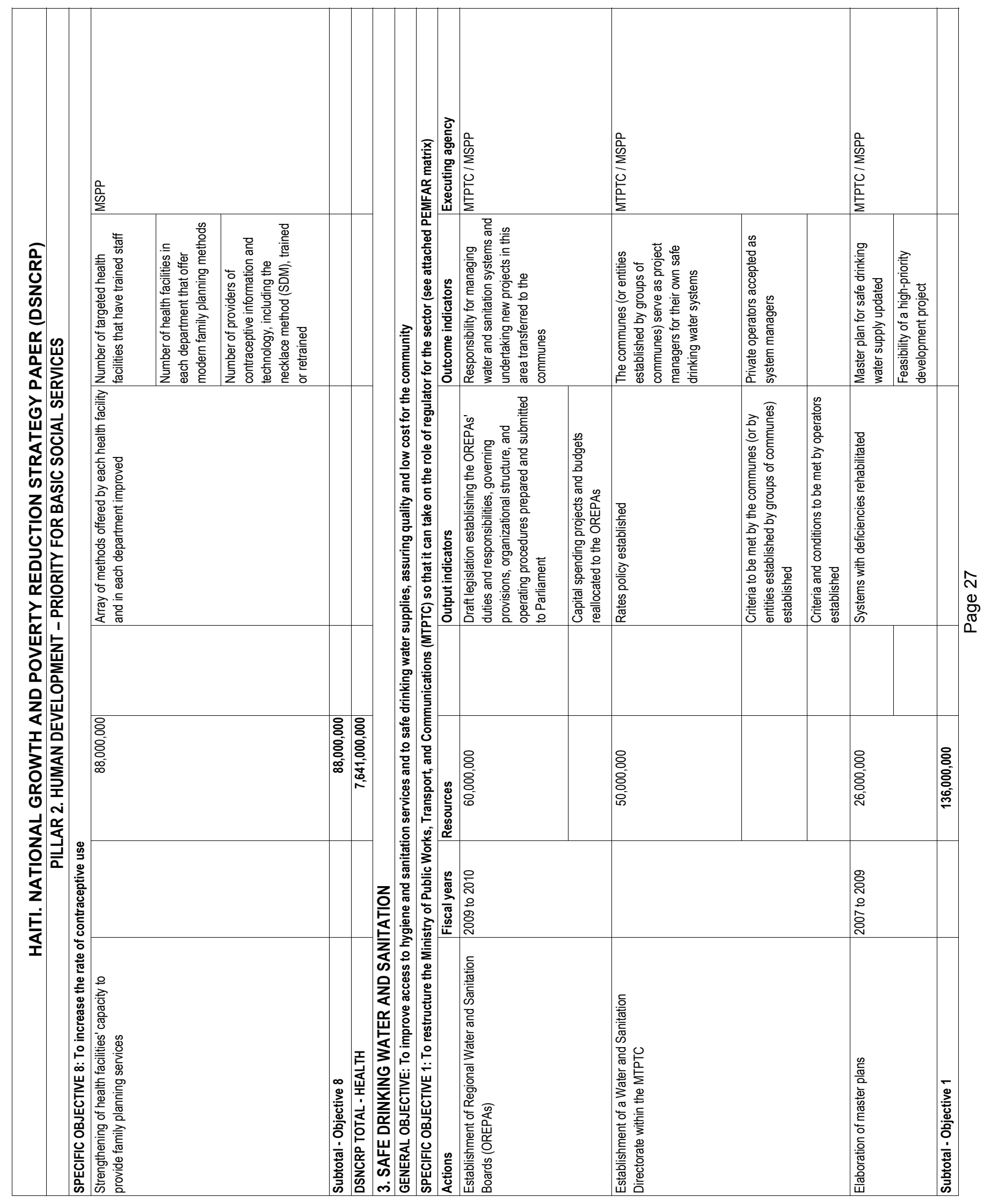




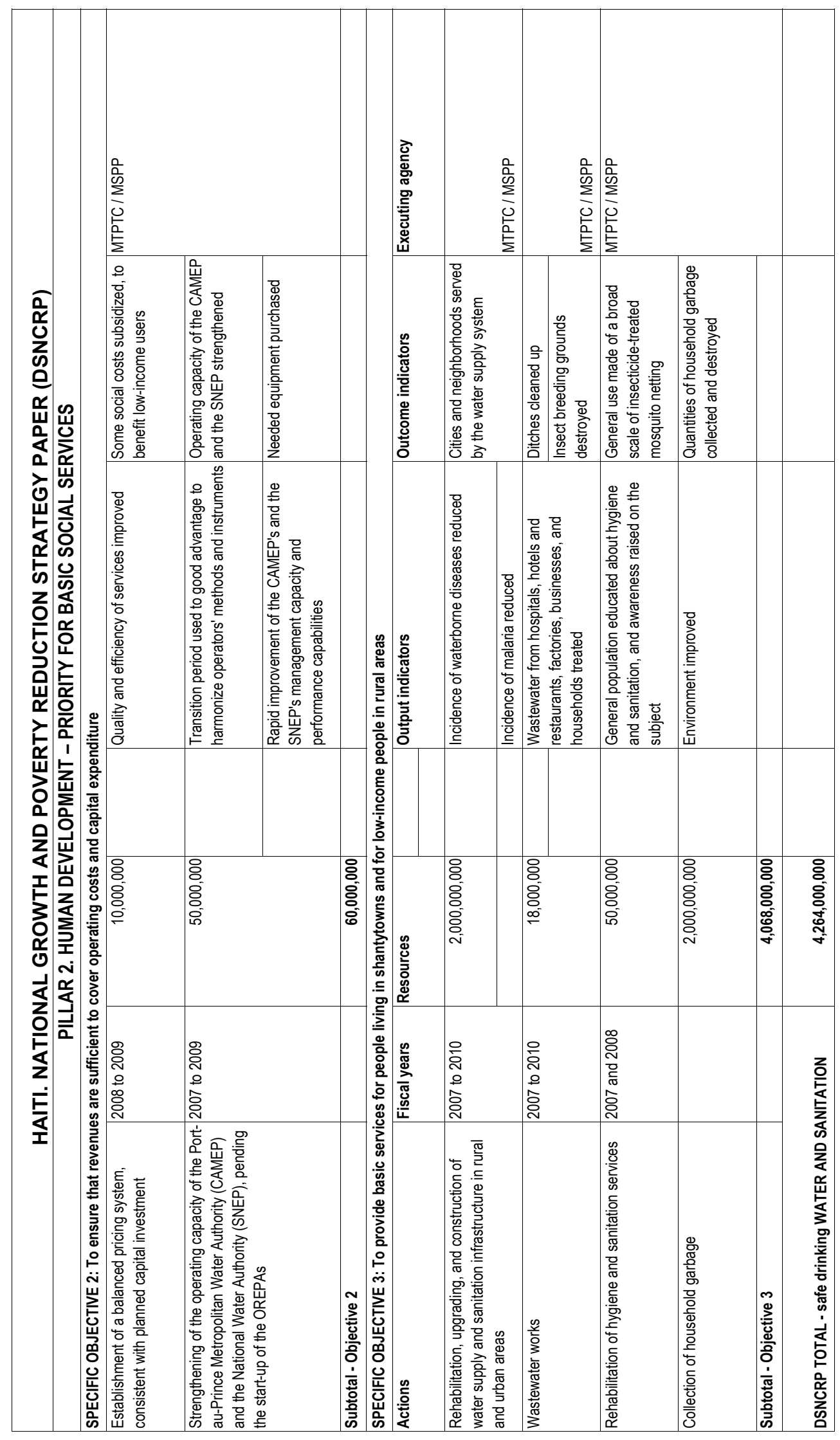

$\stackrel{\infty}{N}$
$\stackrel{0}{\sigma}$
0
0 


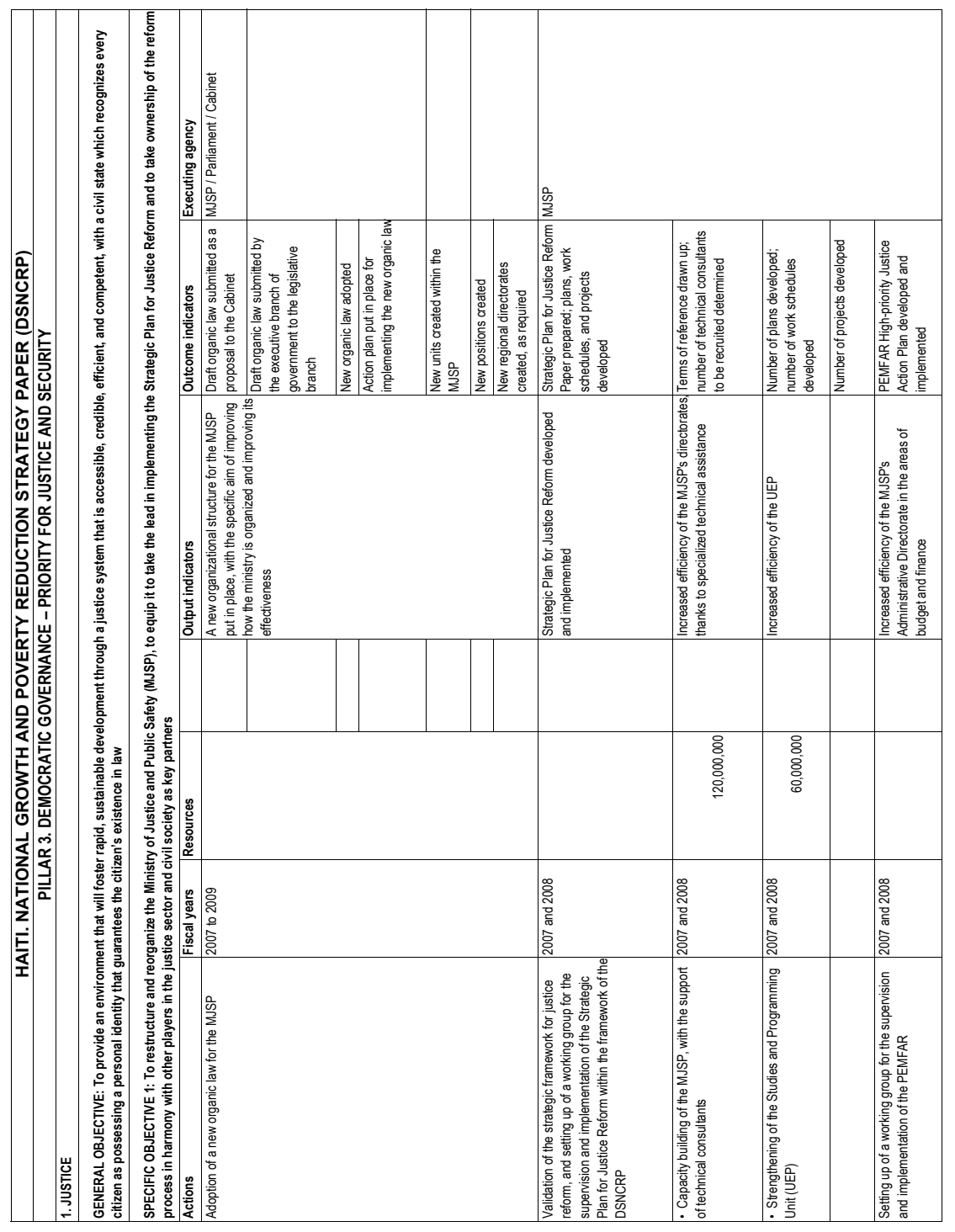

$\stackrel{ }{ }$
$\mathbb{0}$
$\mathbb{0}$
0 


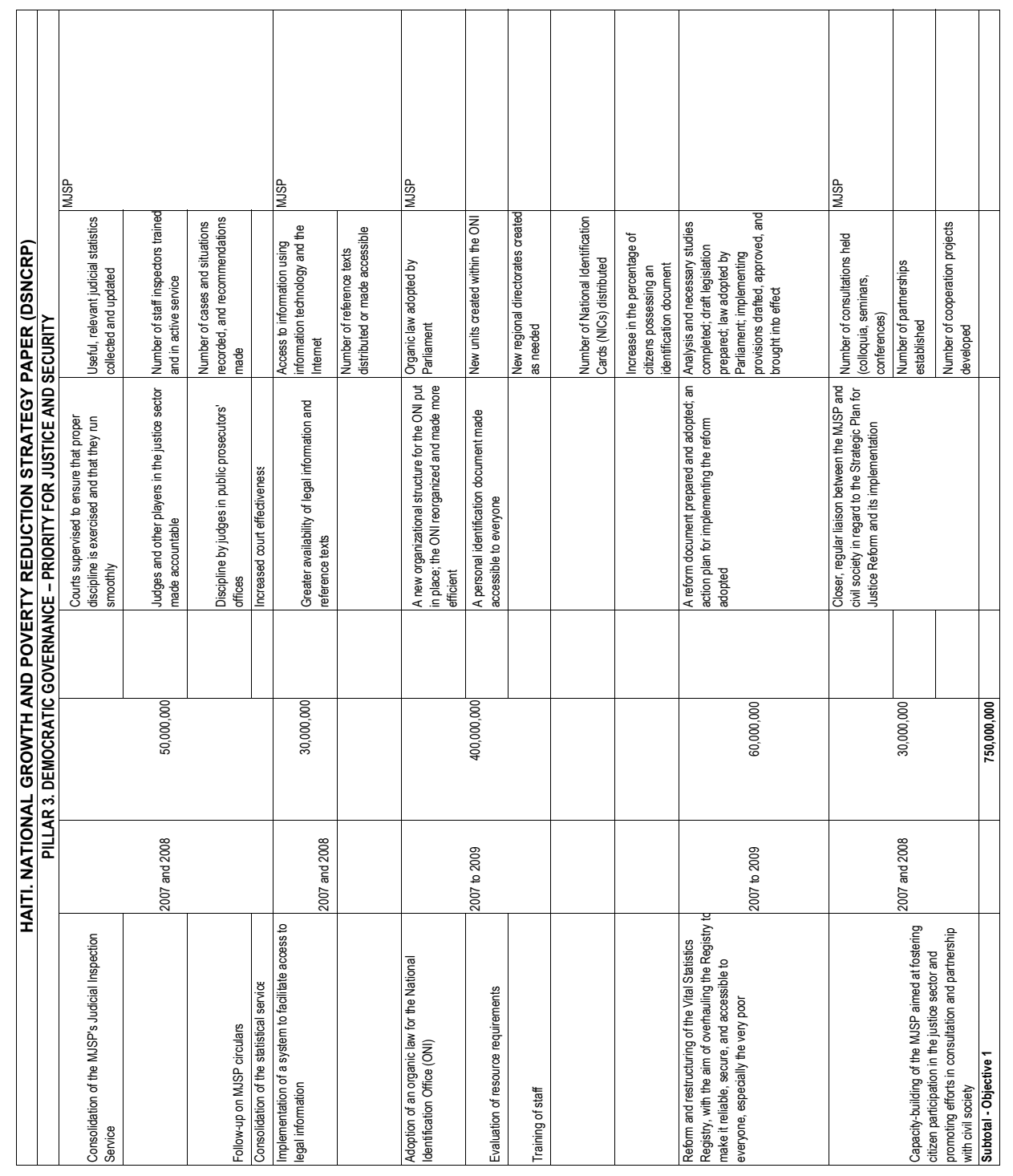




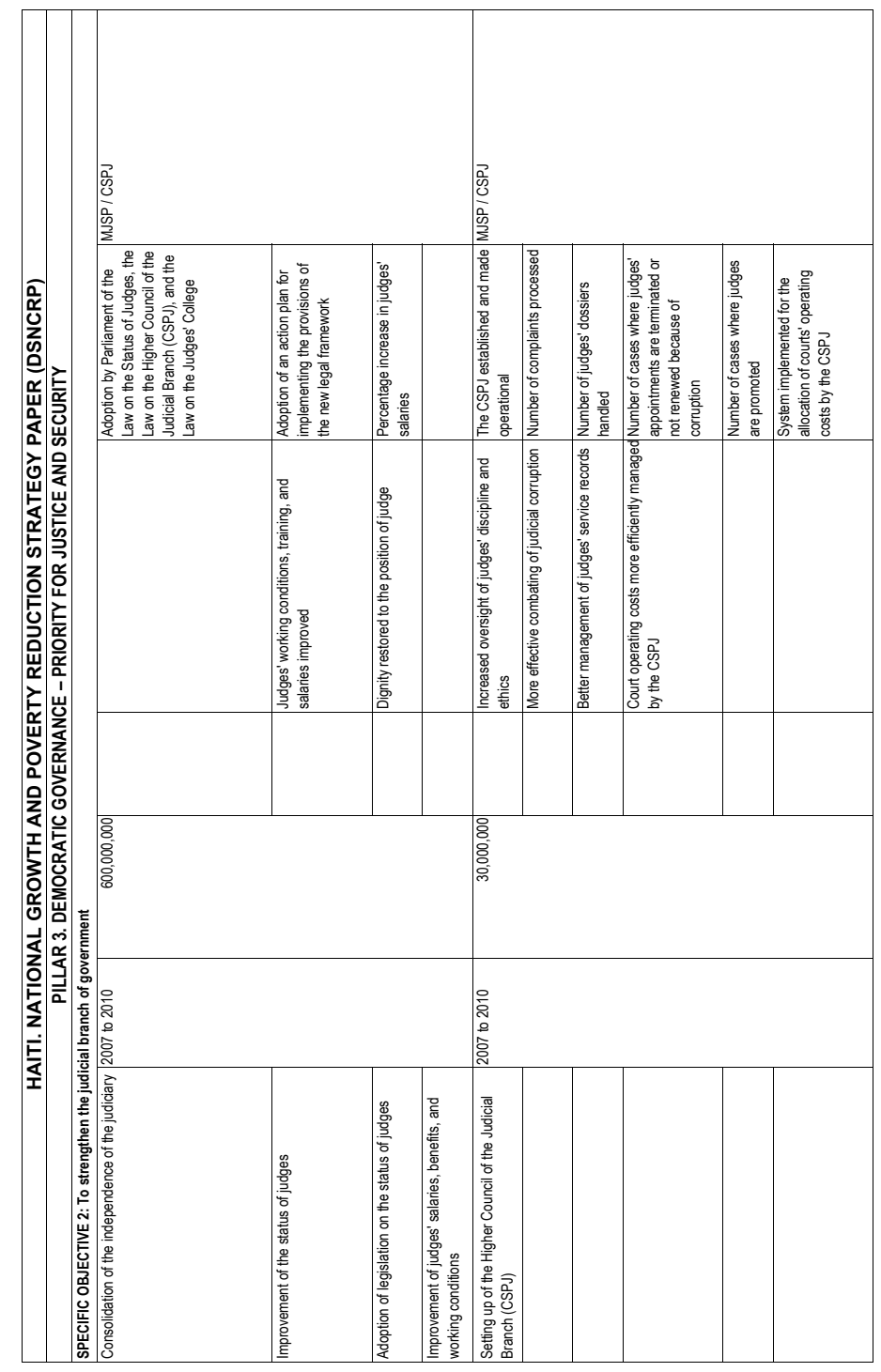




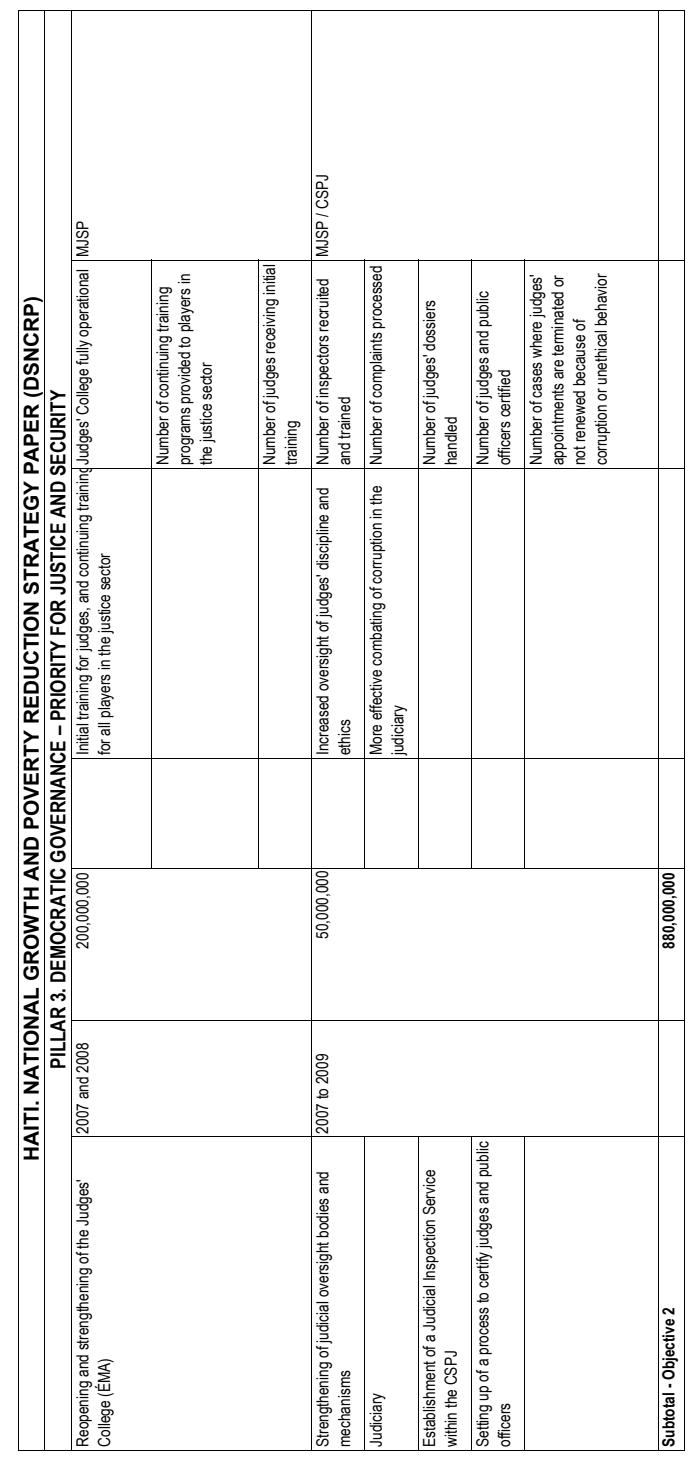

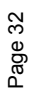




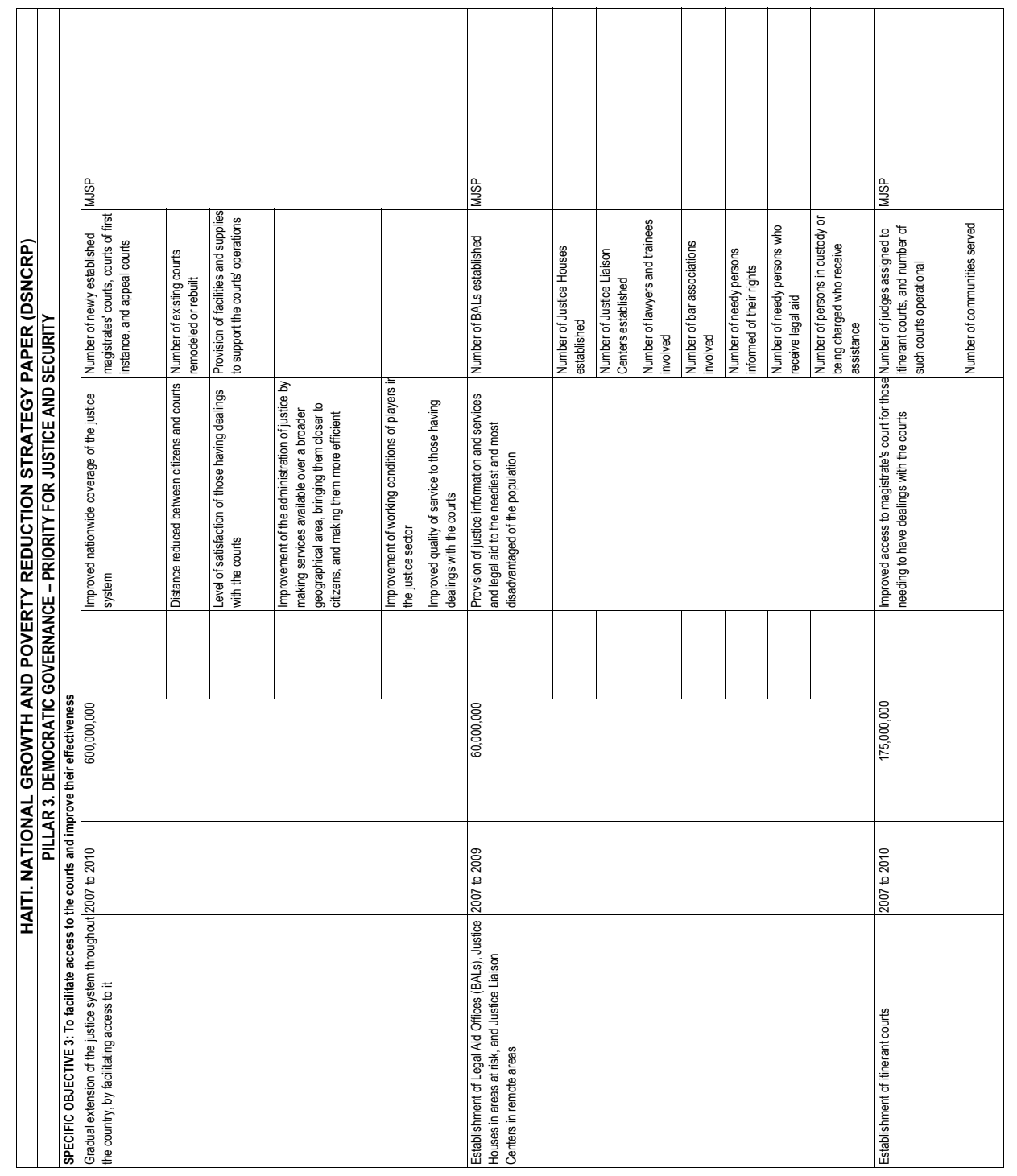

$\mathbb{P}$
$\mathbb{0}$
$\mathbb{D}$
$\mathbb{0}$ 


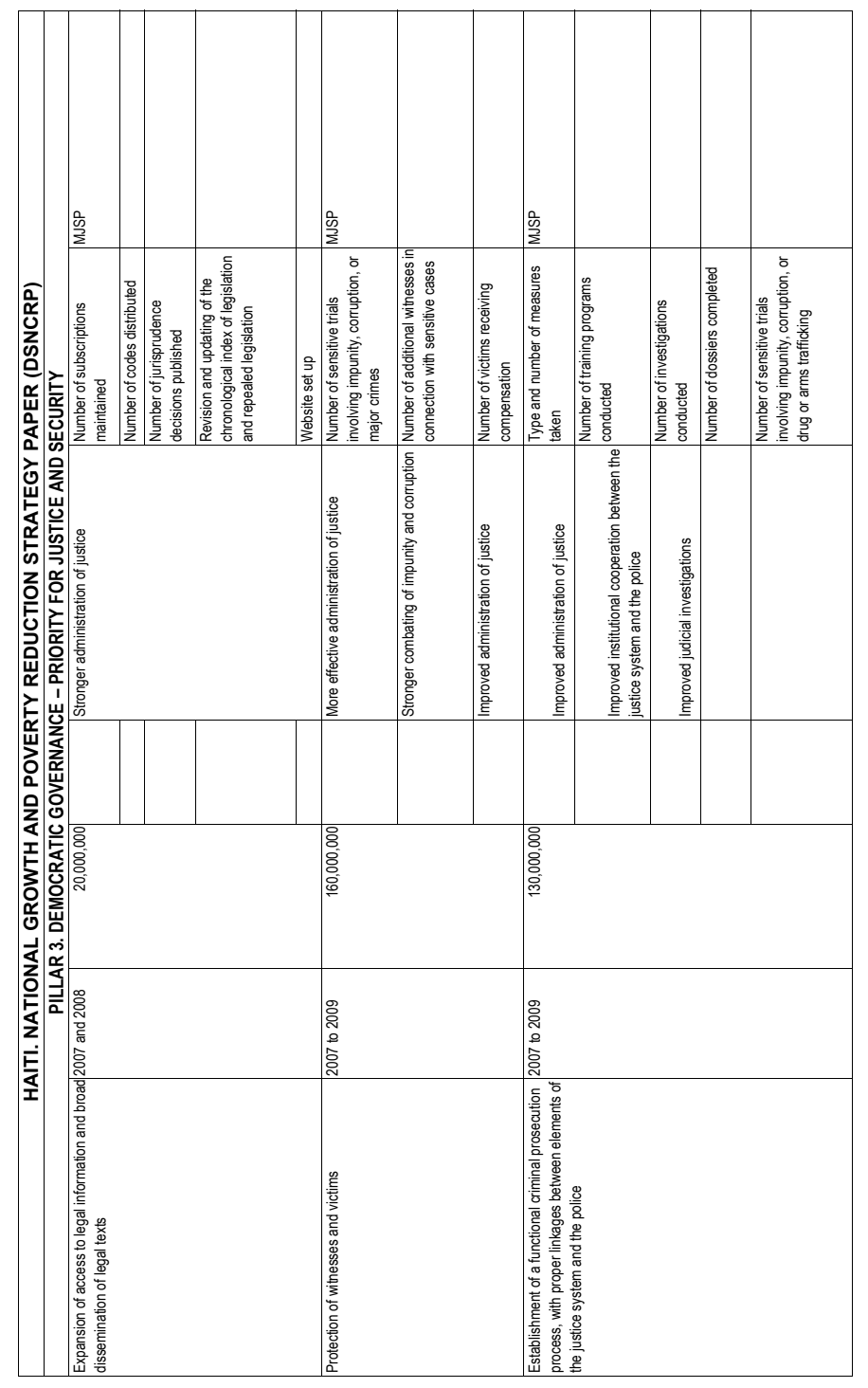

$\stackrel{5}{m}$
$\mathbb{D}$
$\mathbb{0}$
0 


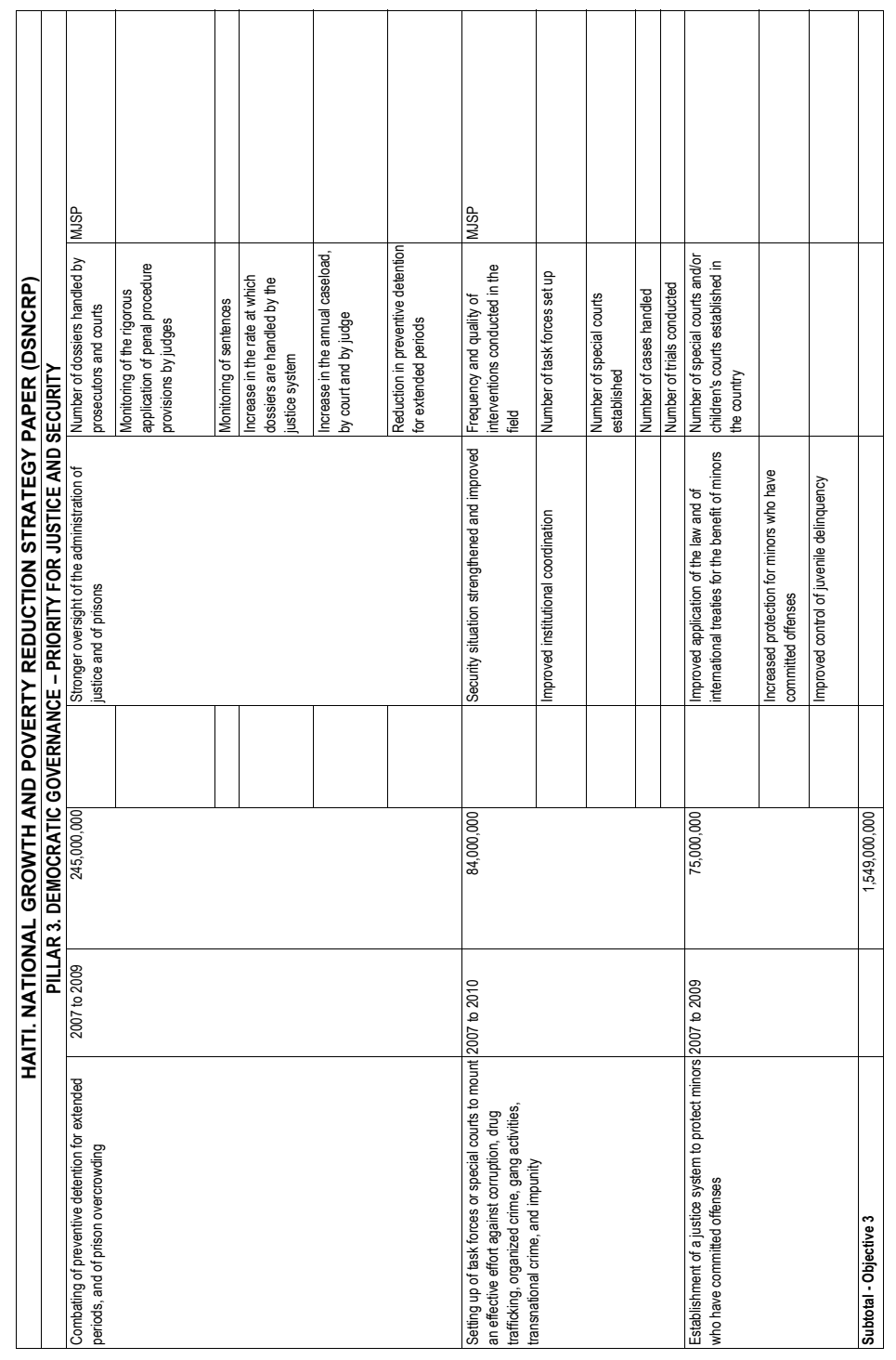




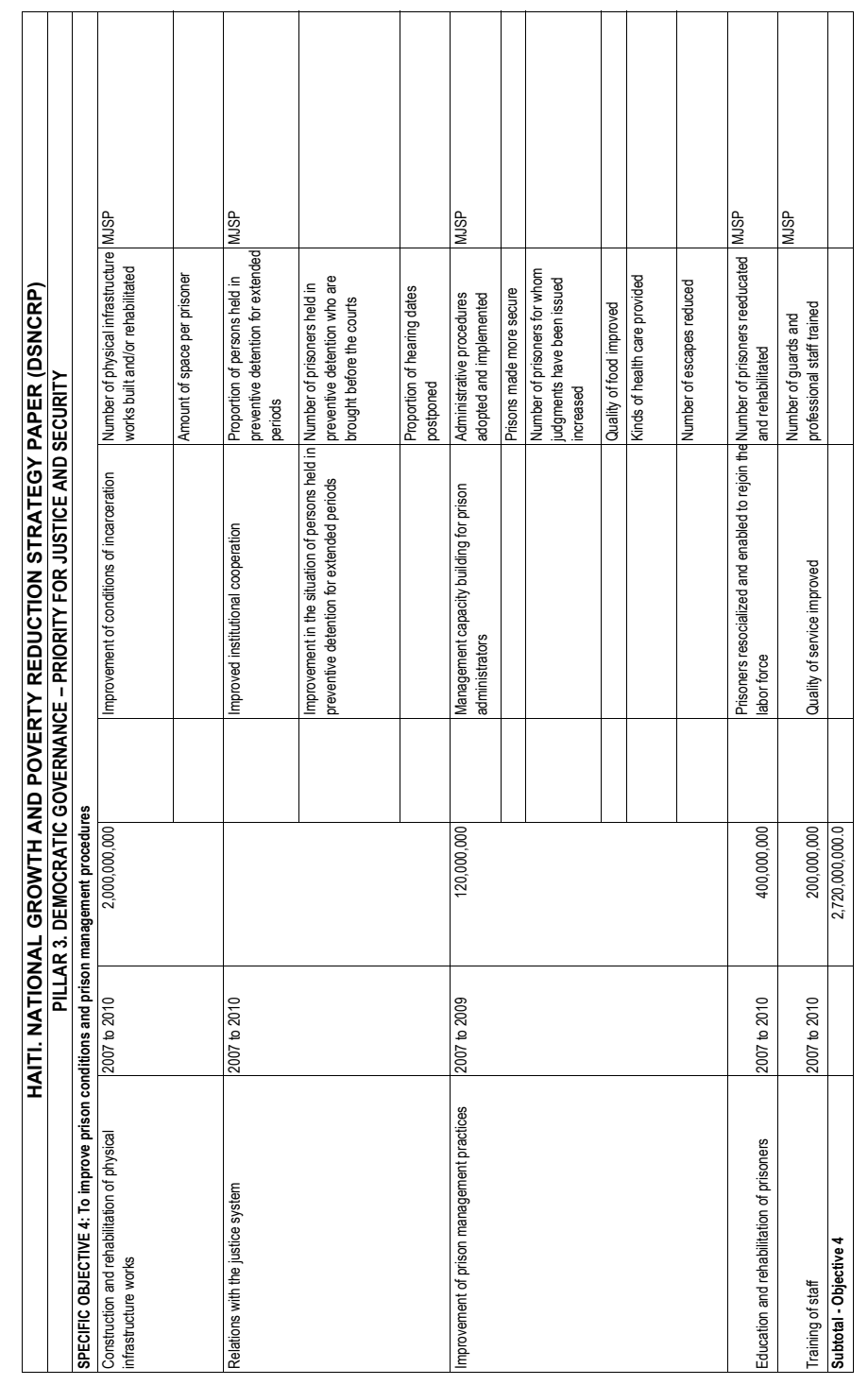

$\infty$
$\infty$
$\Phi$
$\mathbb{D}$
$\square$ 


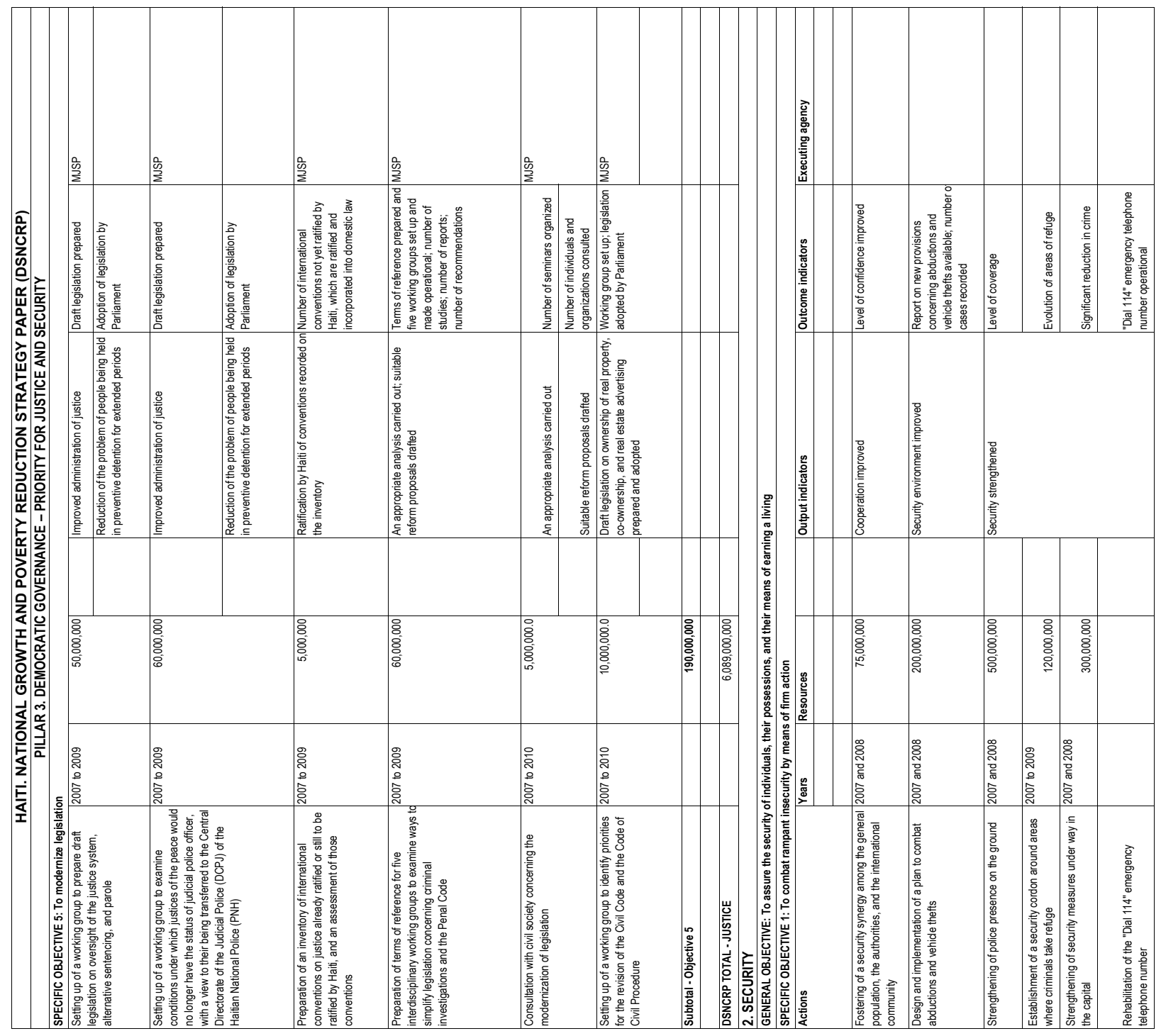

$\hat{m}$
0
$\stackrel{\sigma}{0}$
0 


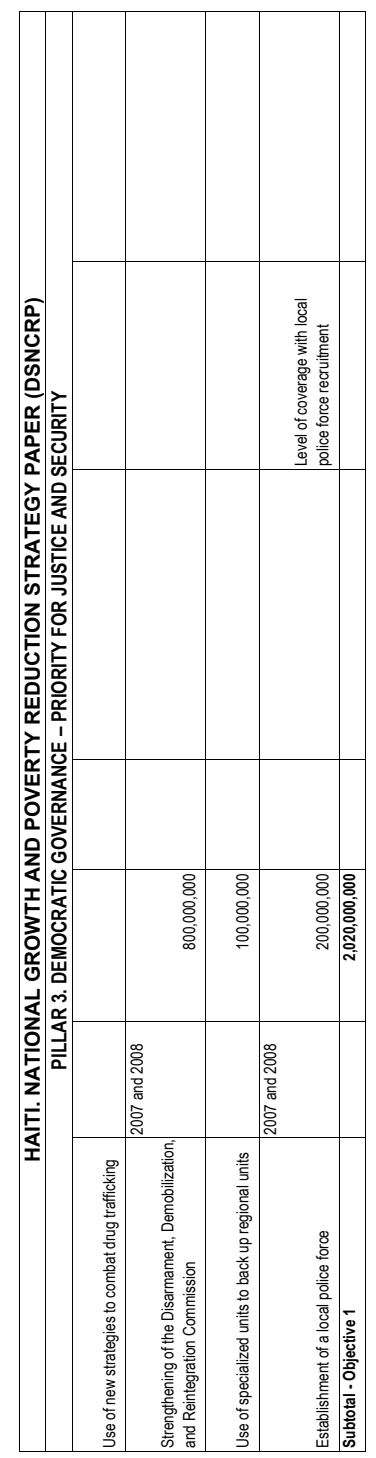

$\infty$
0
$\infty$
$\mathbb{D}$
$\mathbb{0}$
0 


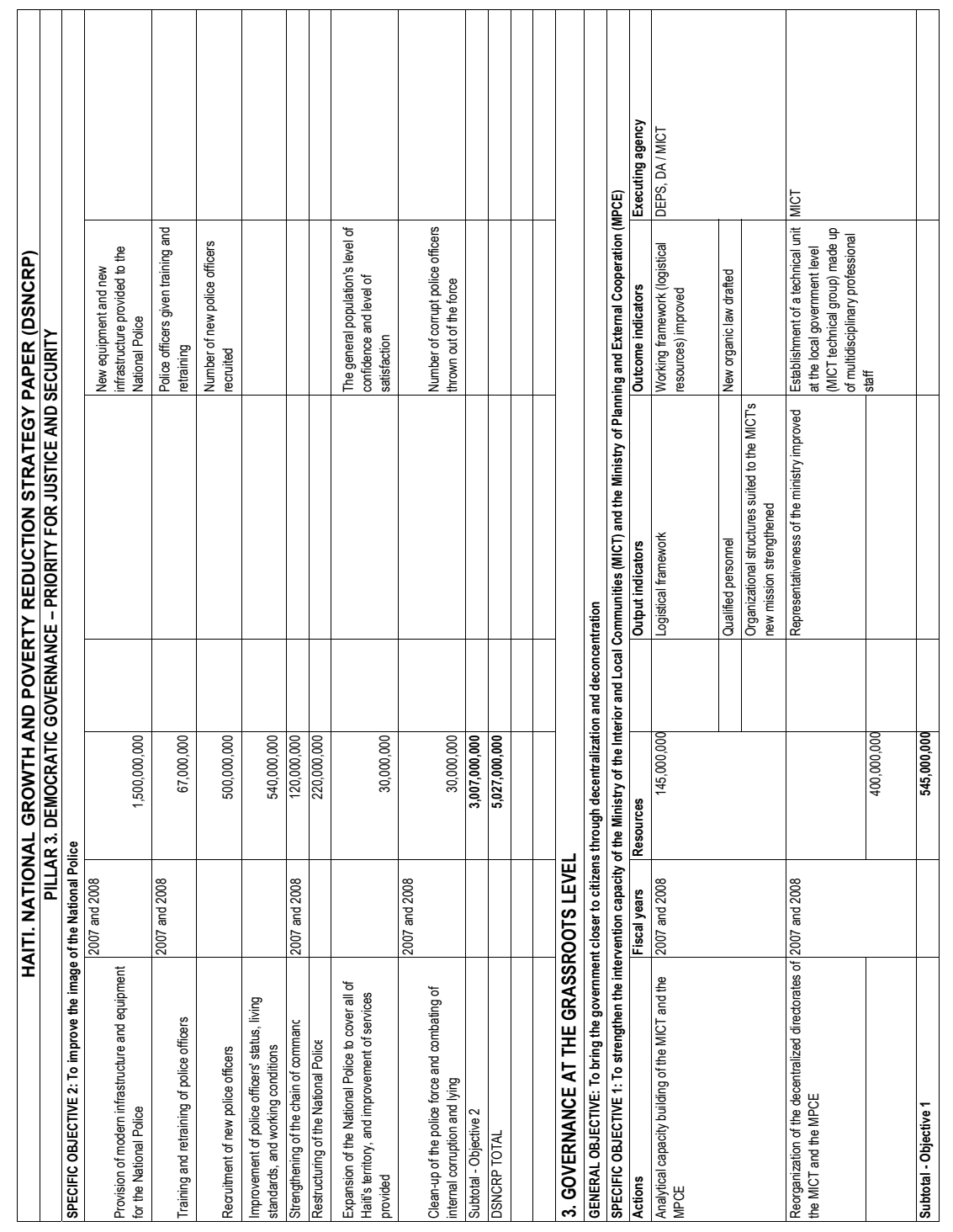

9
9
0
$\mathbb{8}$
0 


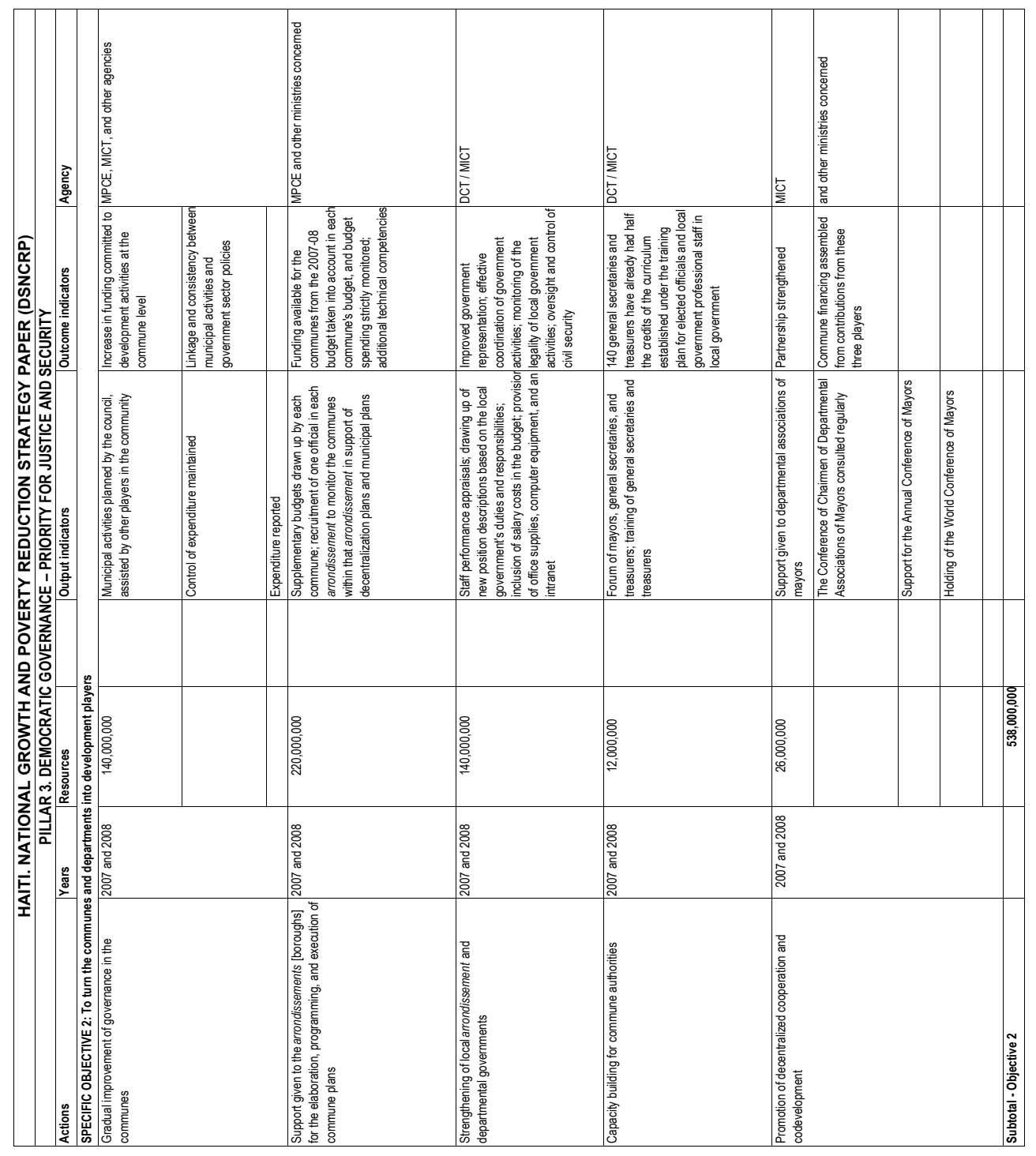

웅
$\stackrel{8}{\pi}$
0 


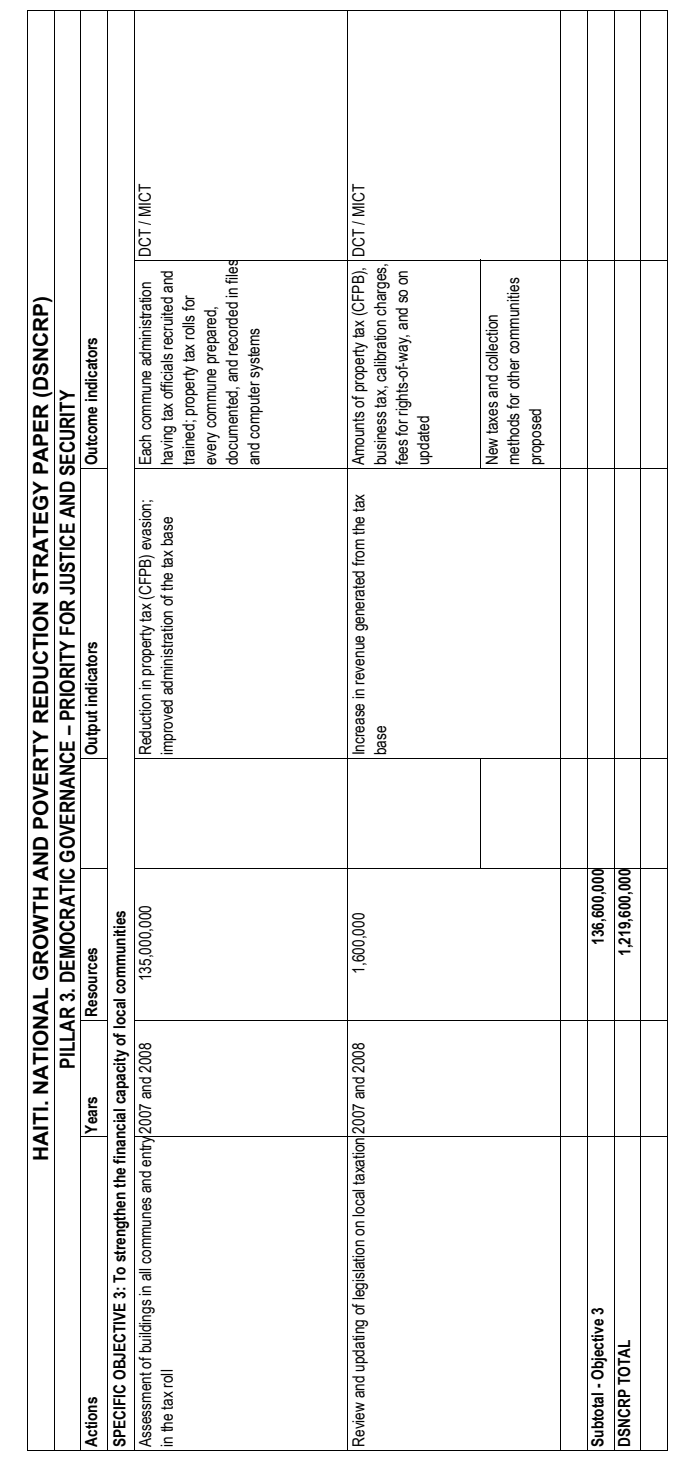




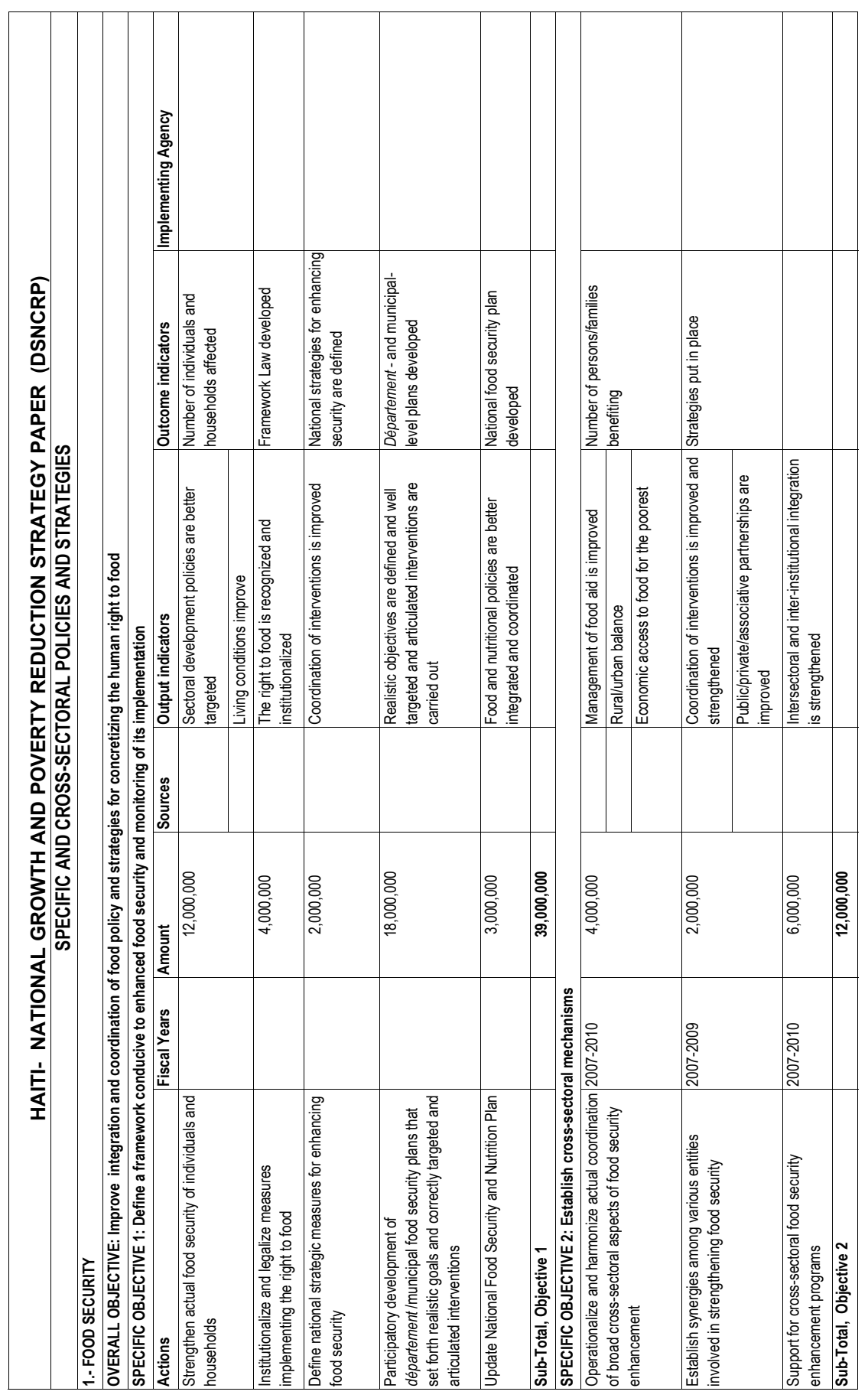

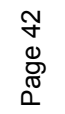




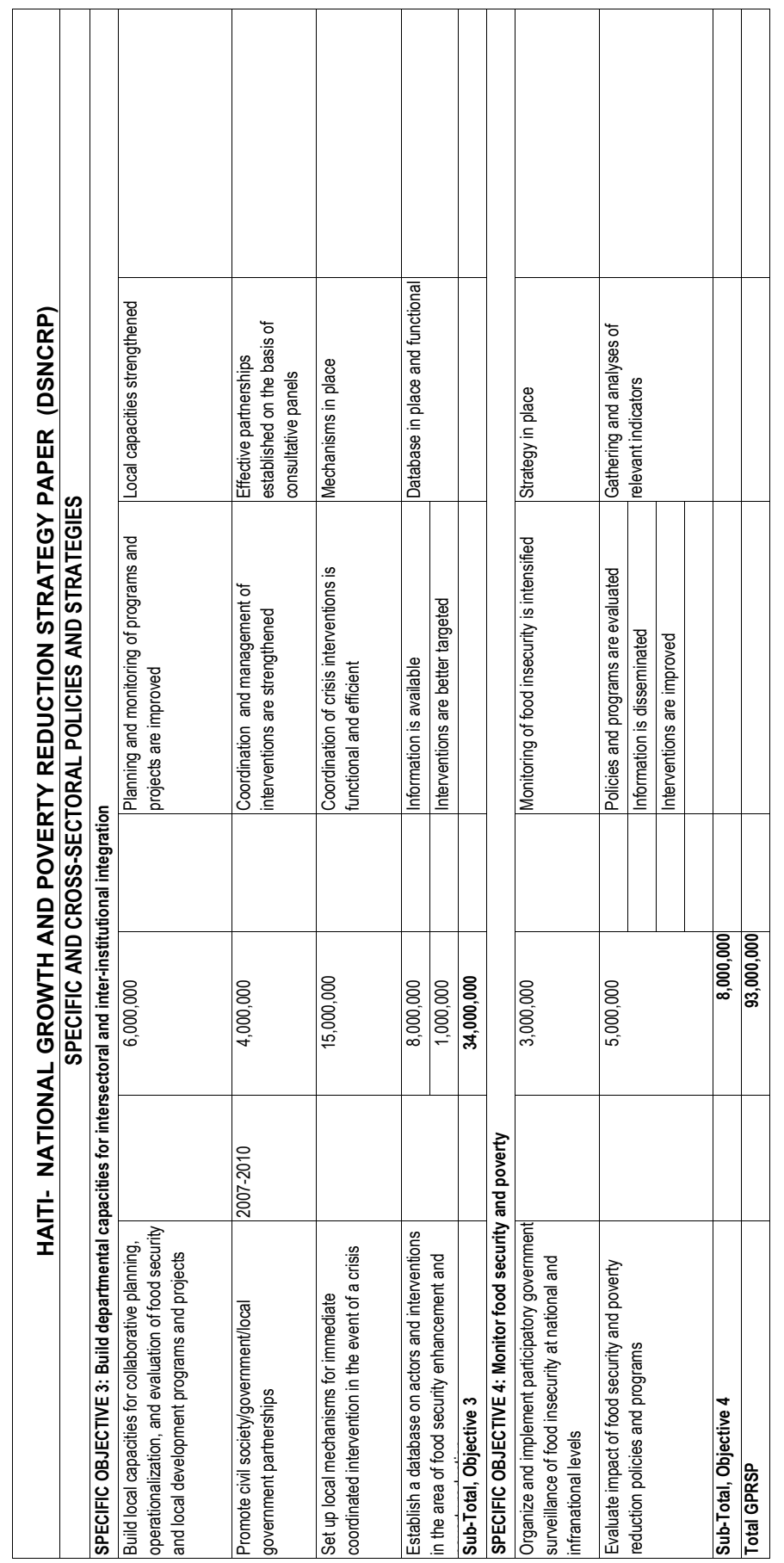




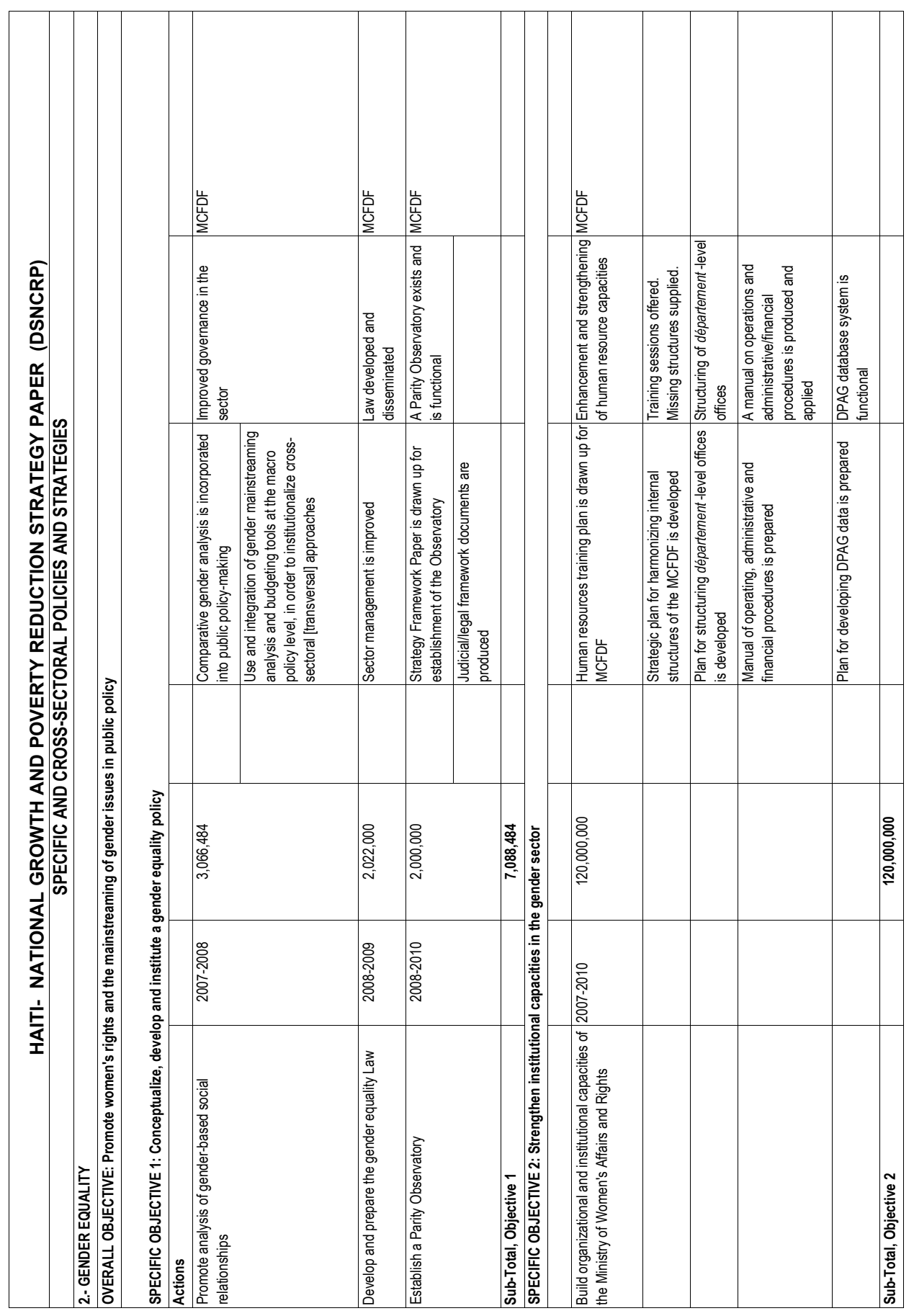

\begin{tabular}{l}
$\forall$ \\
\multirow{8}{0}{} \\
$\stackrel{0}{0}$
\end{tabular} 


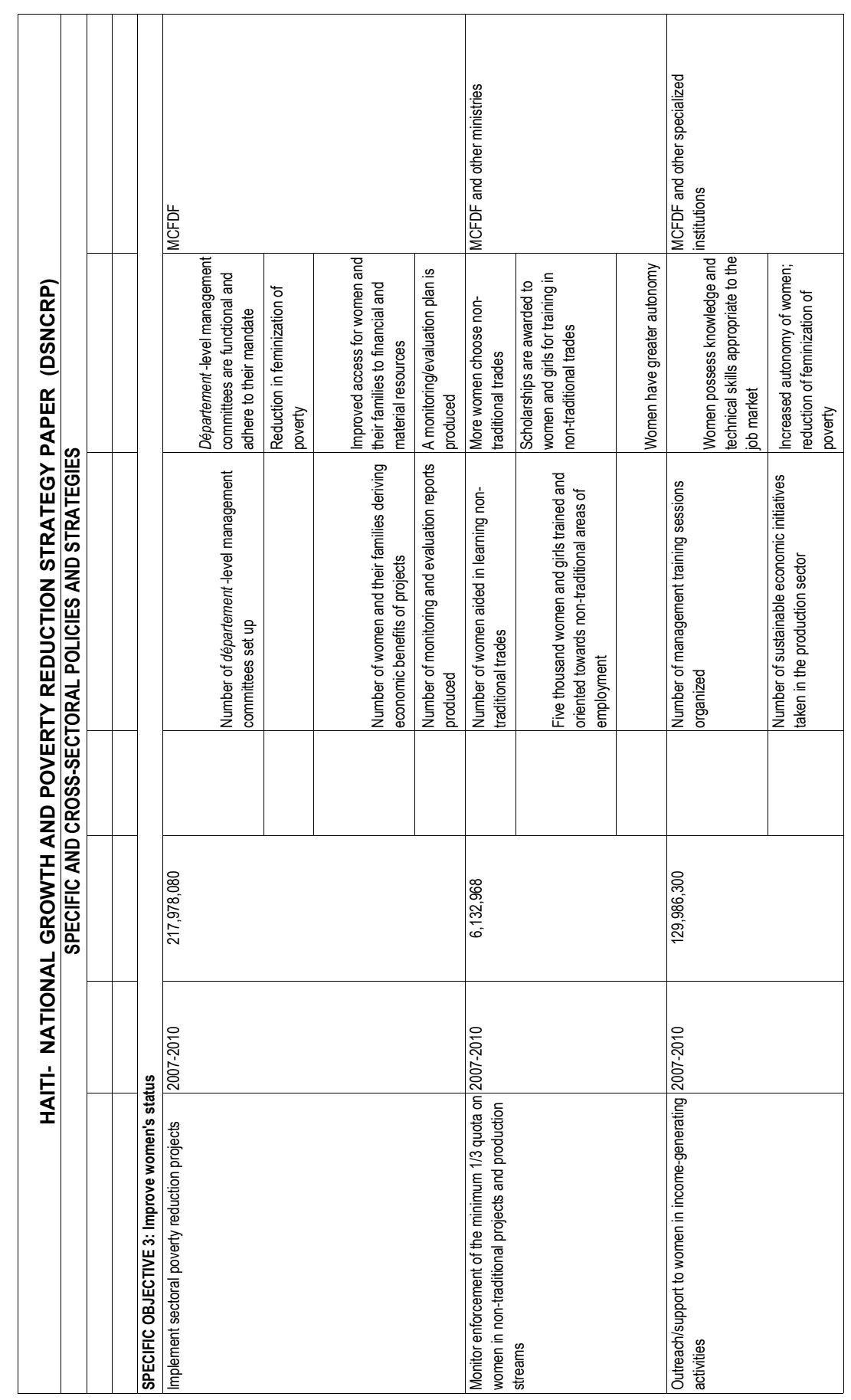

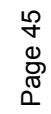




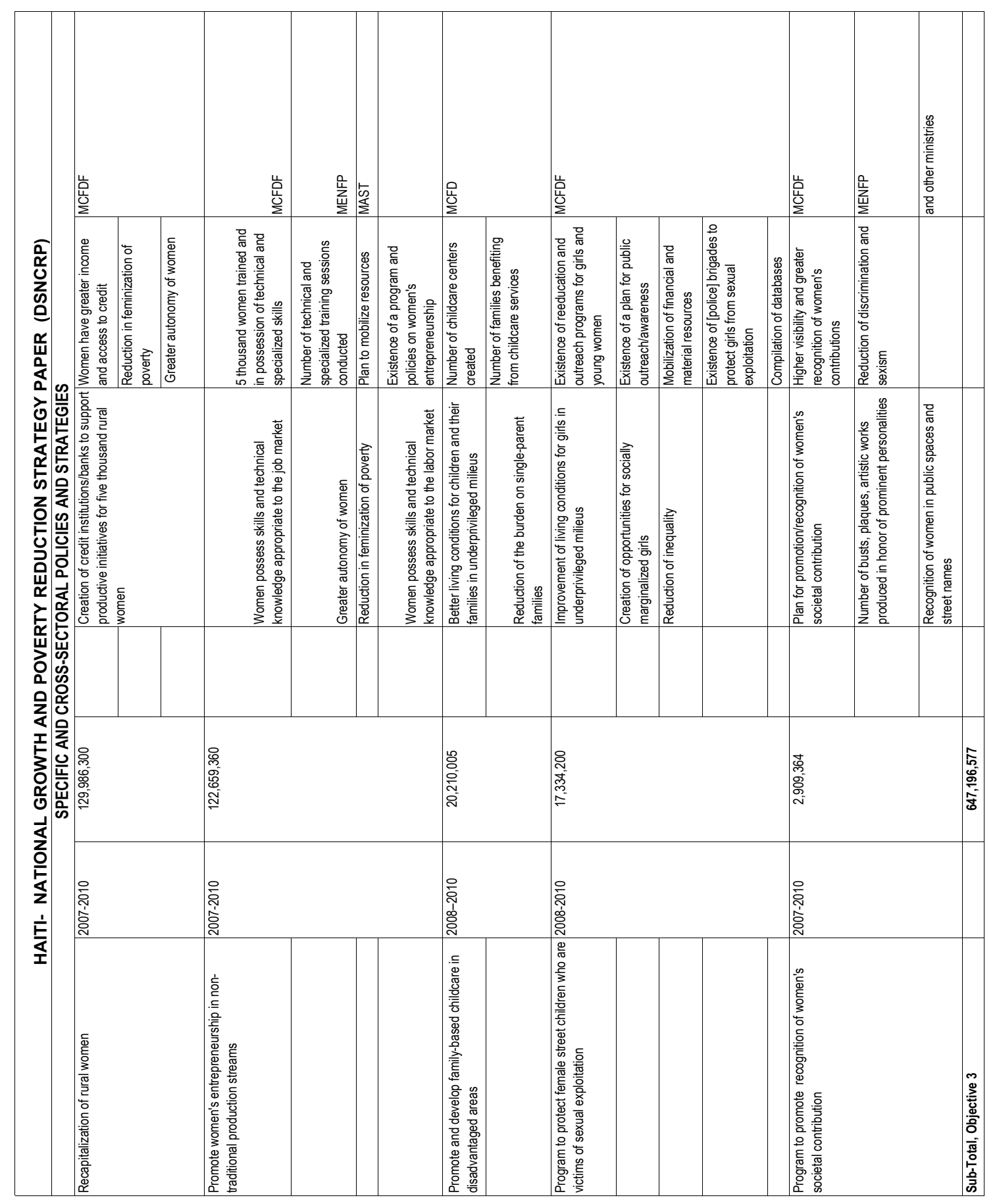




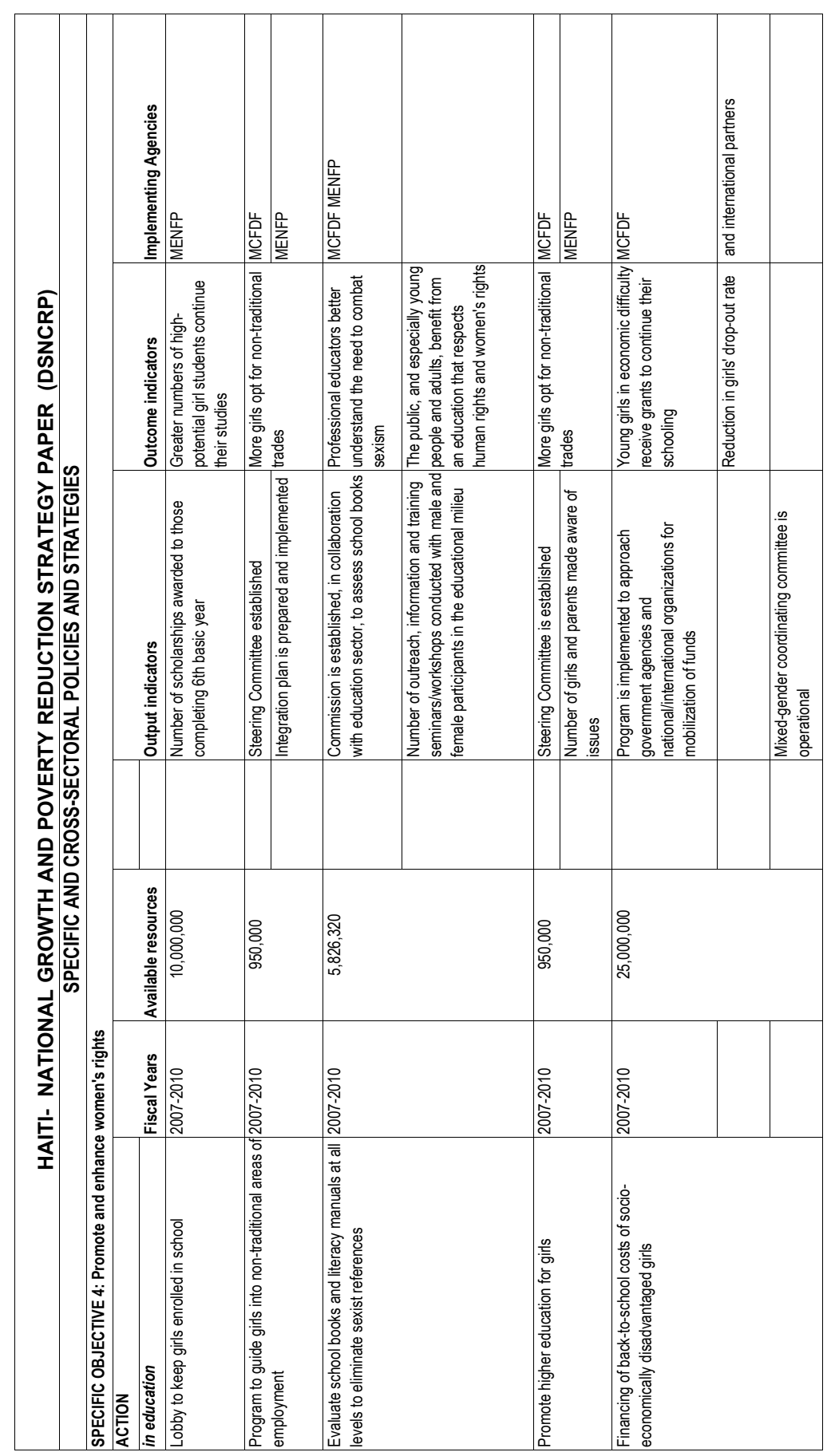

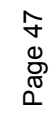




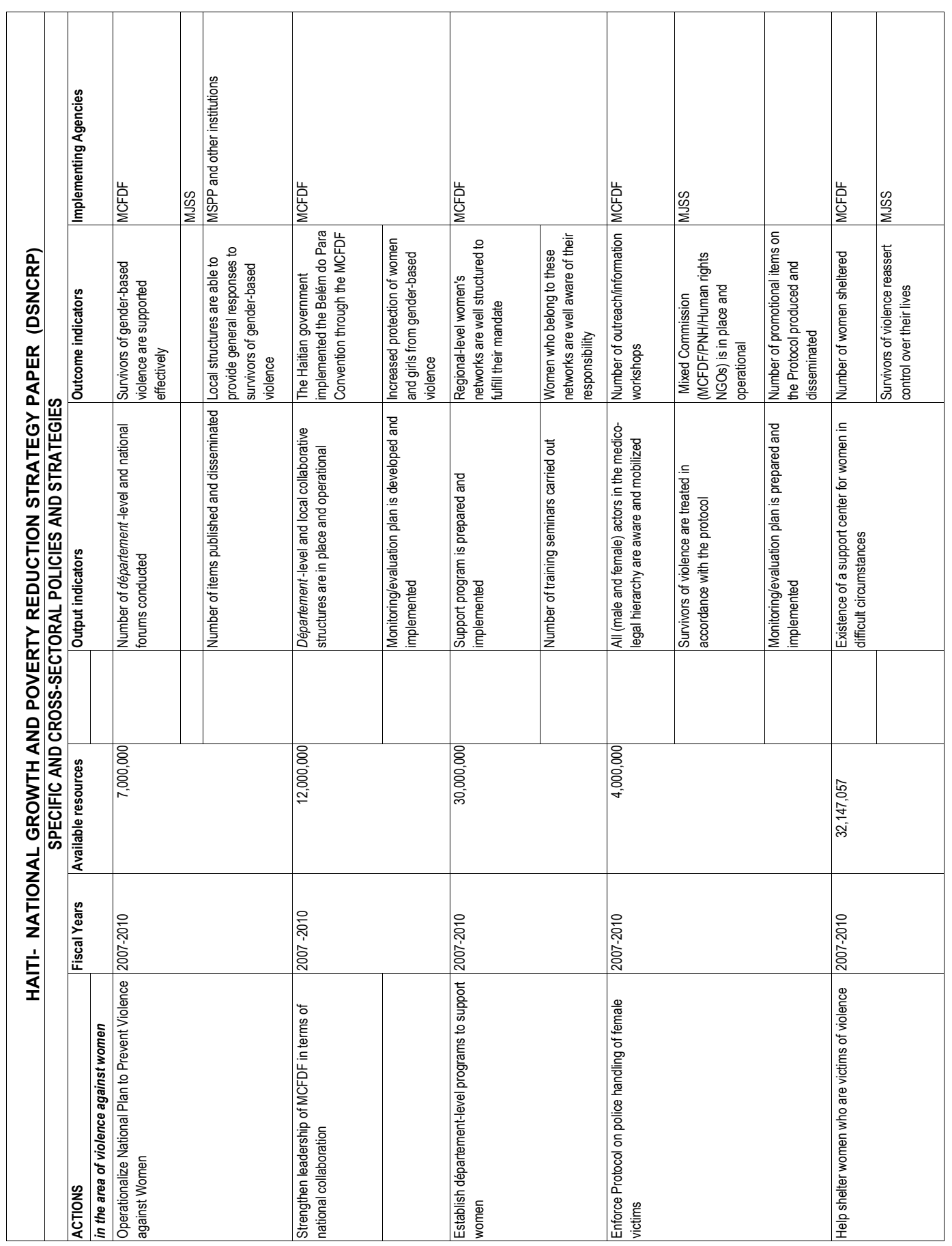




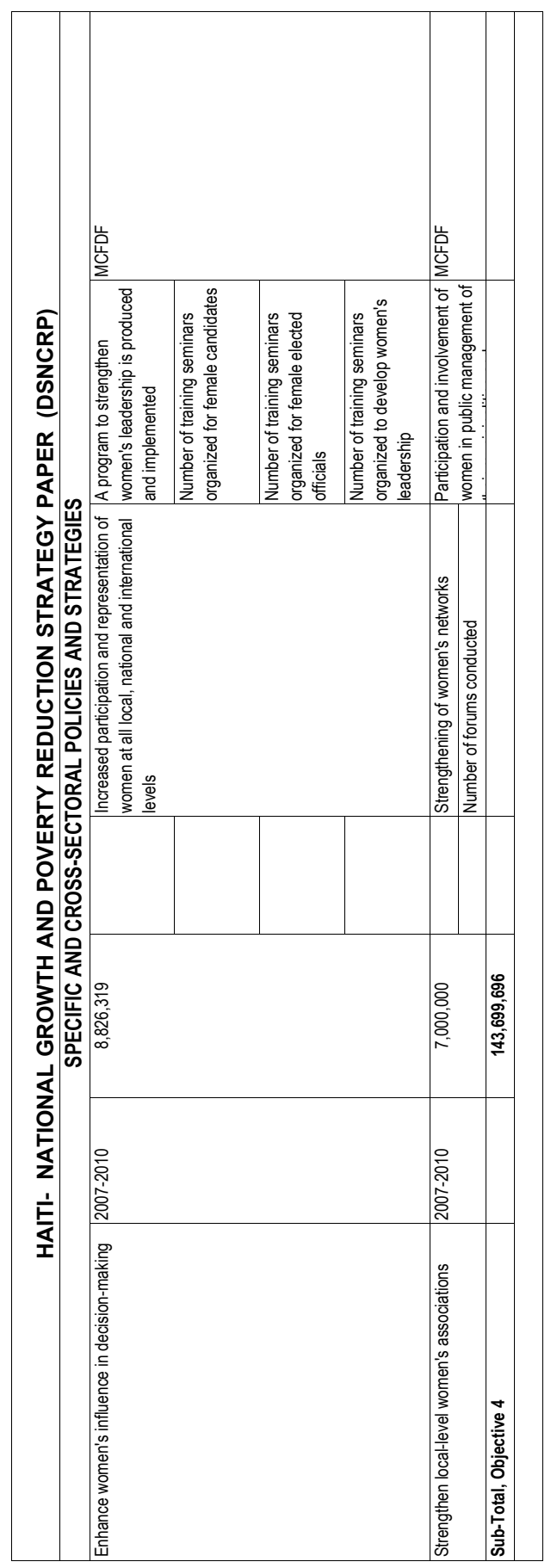

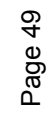




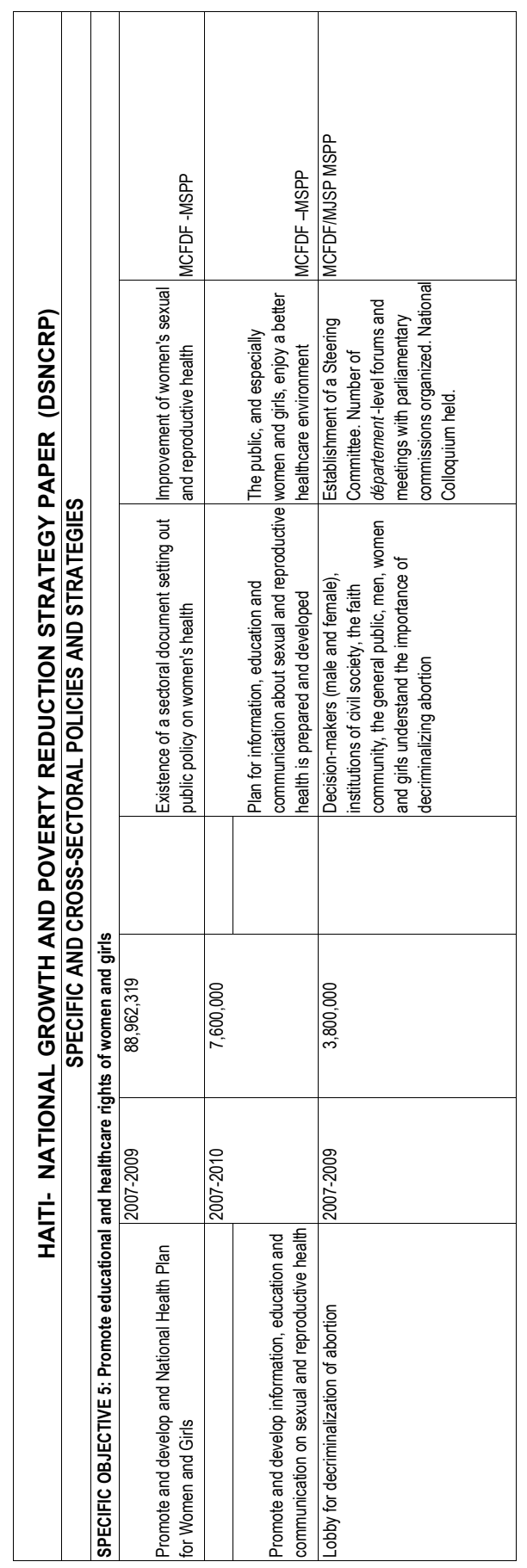




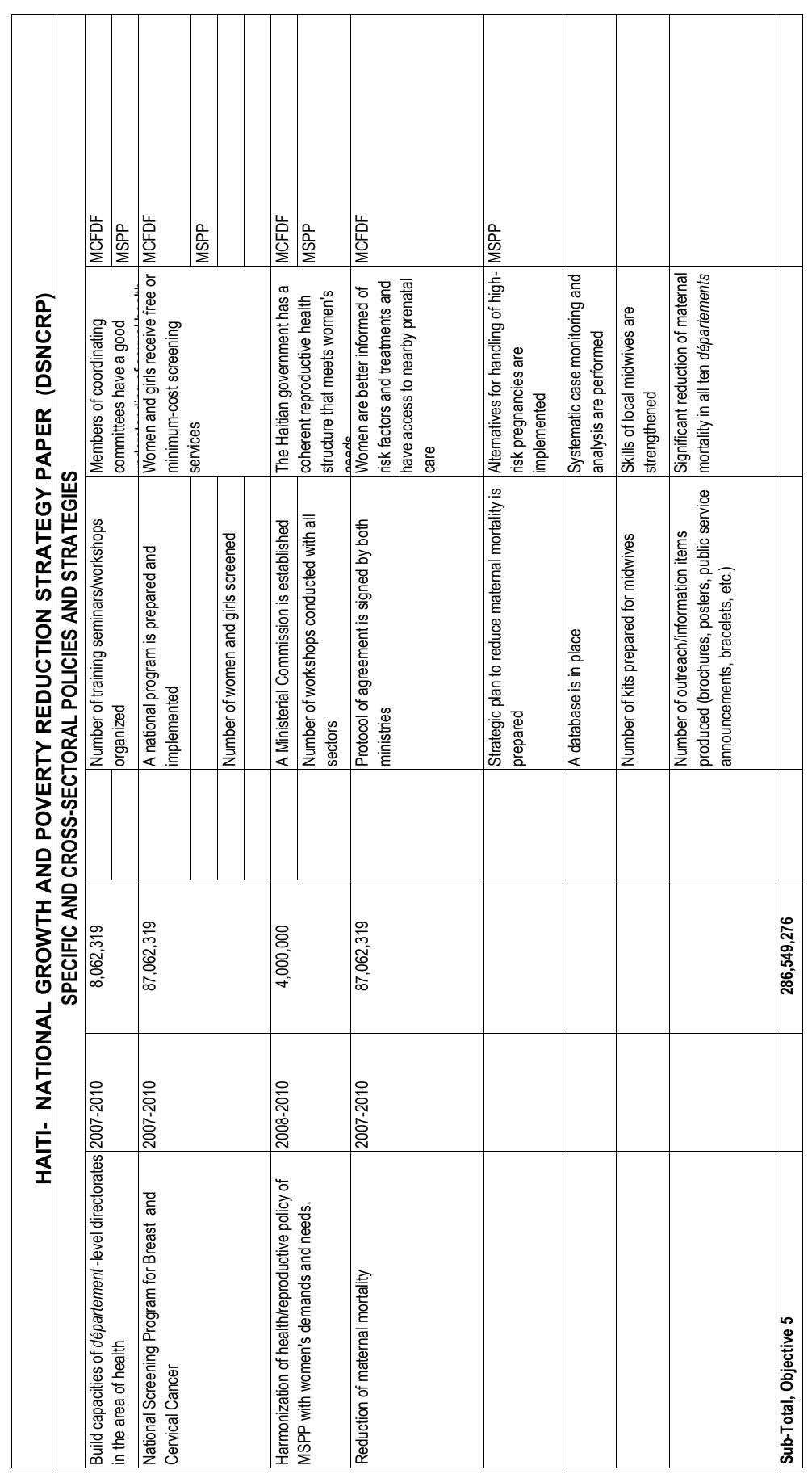

5
in
0
0
0 


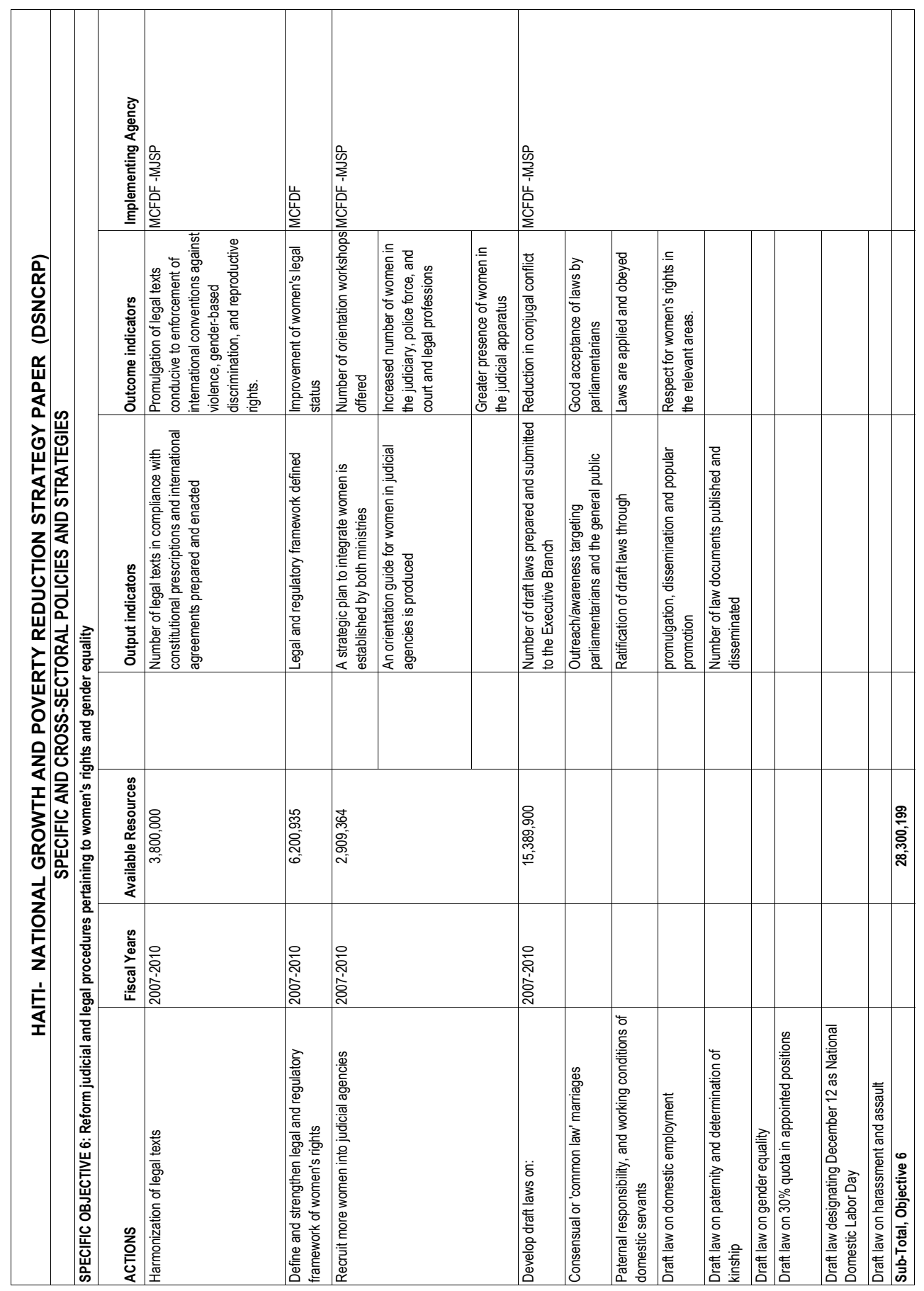

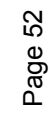




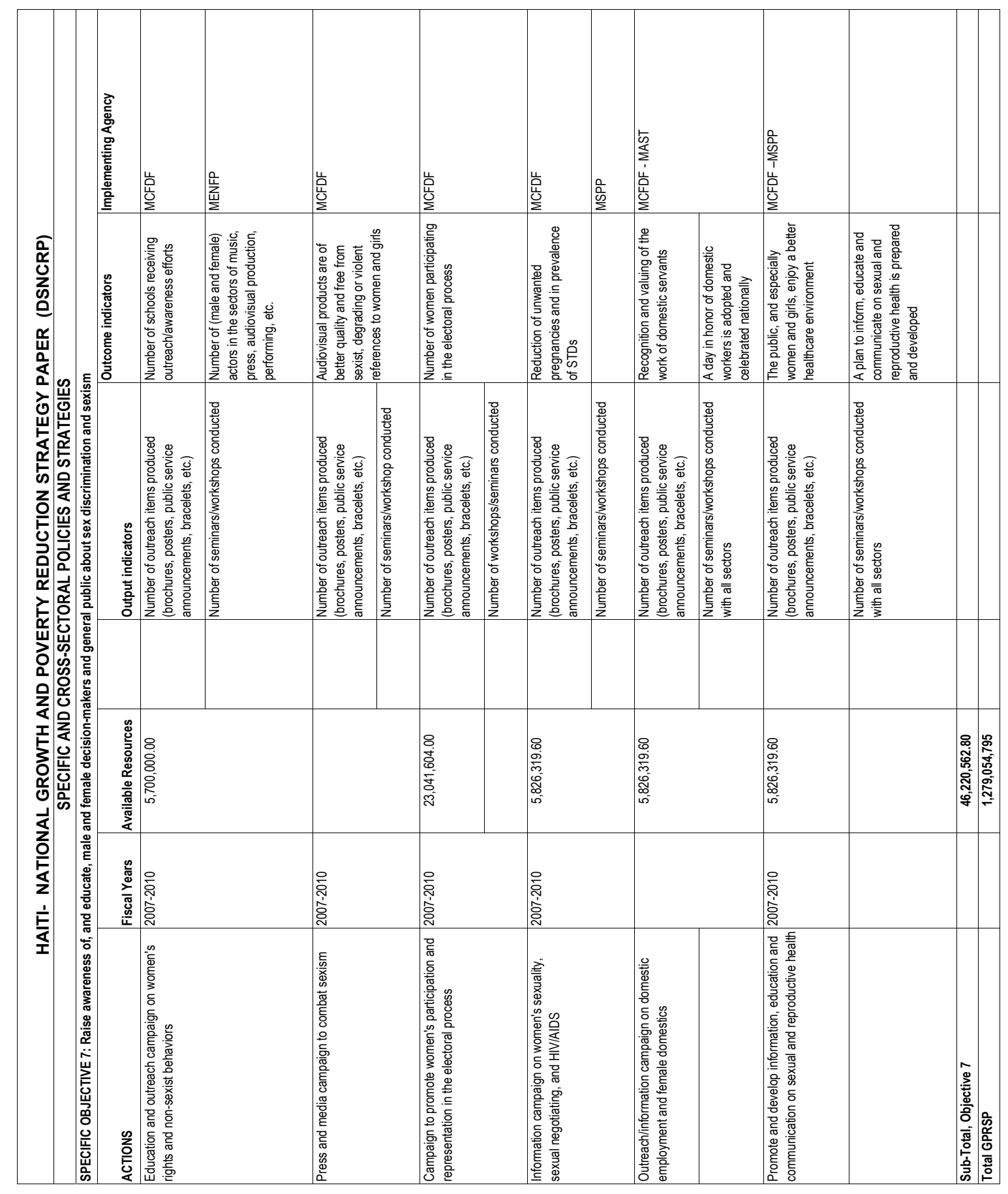

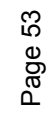




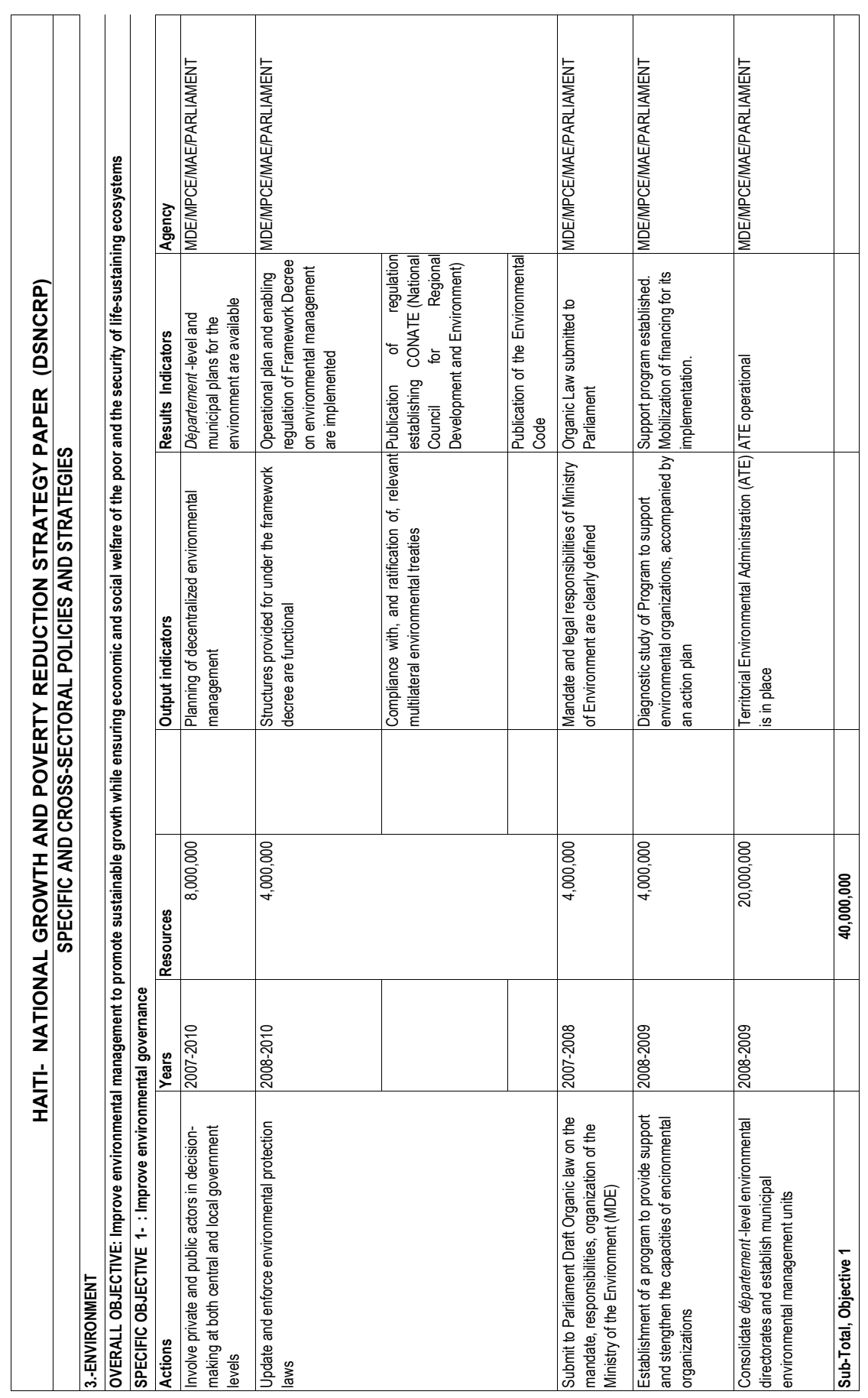

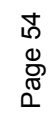




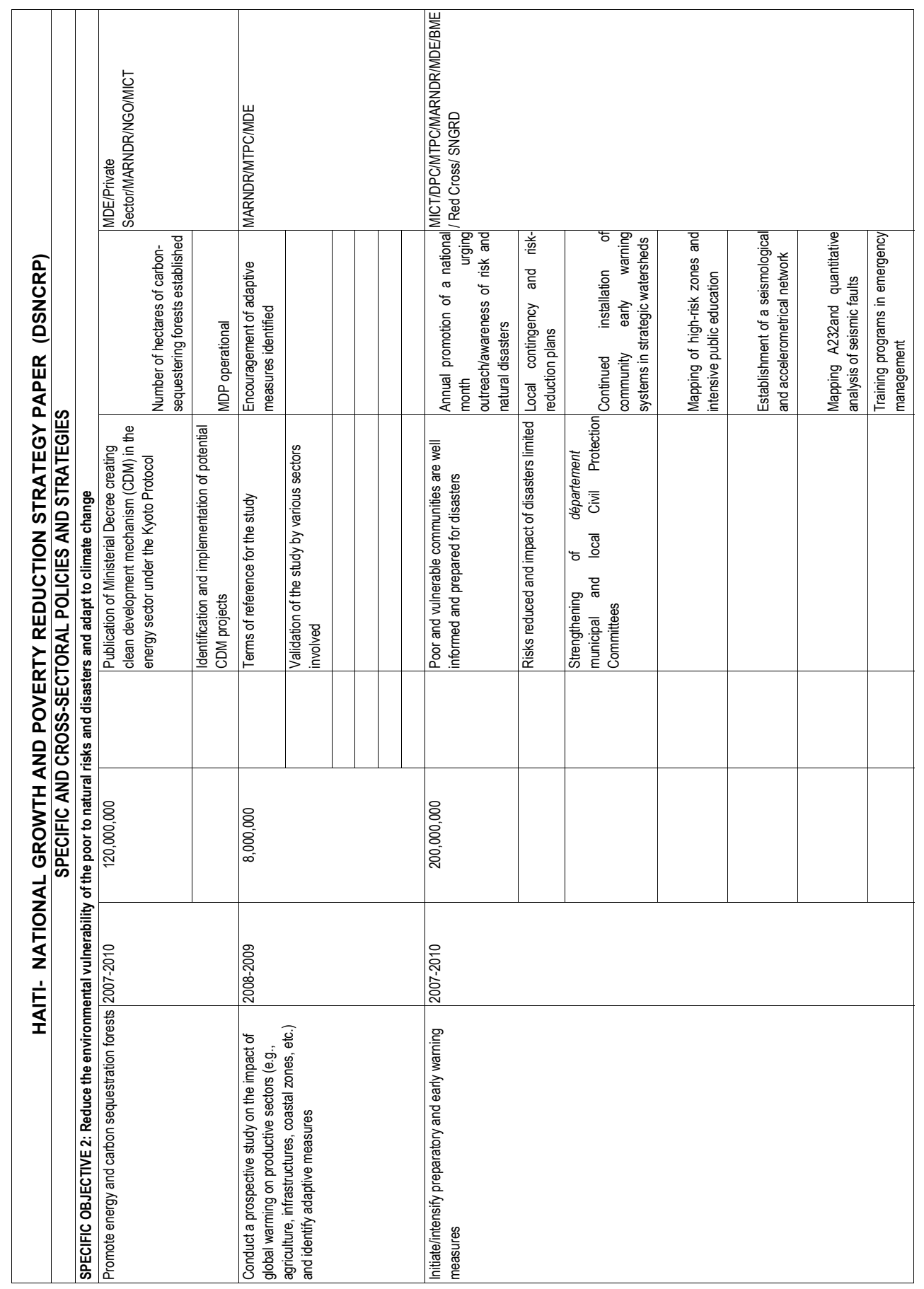




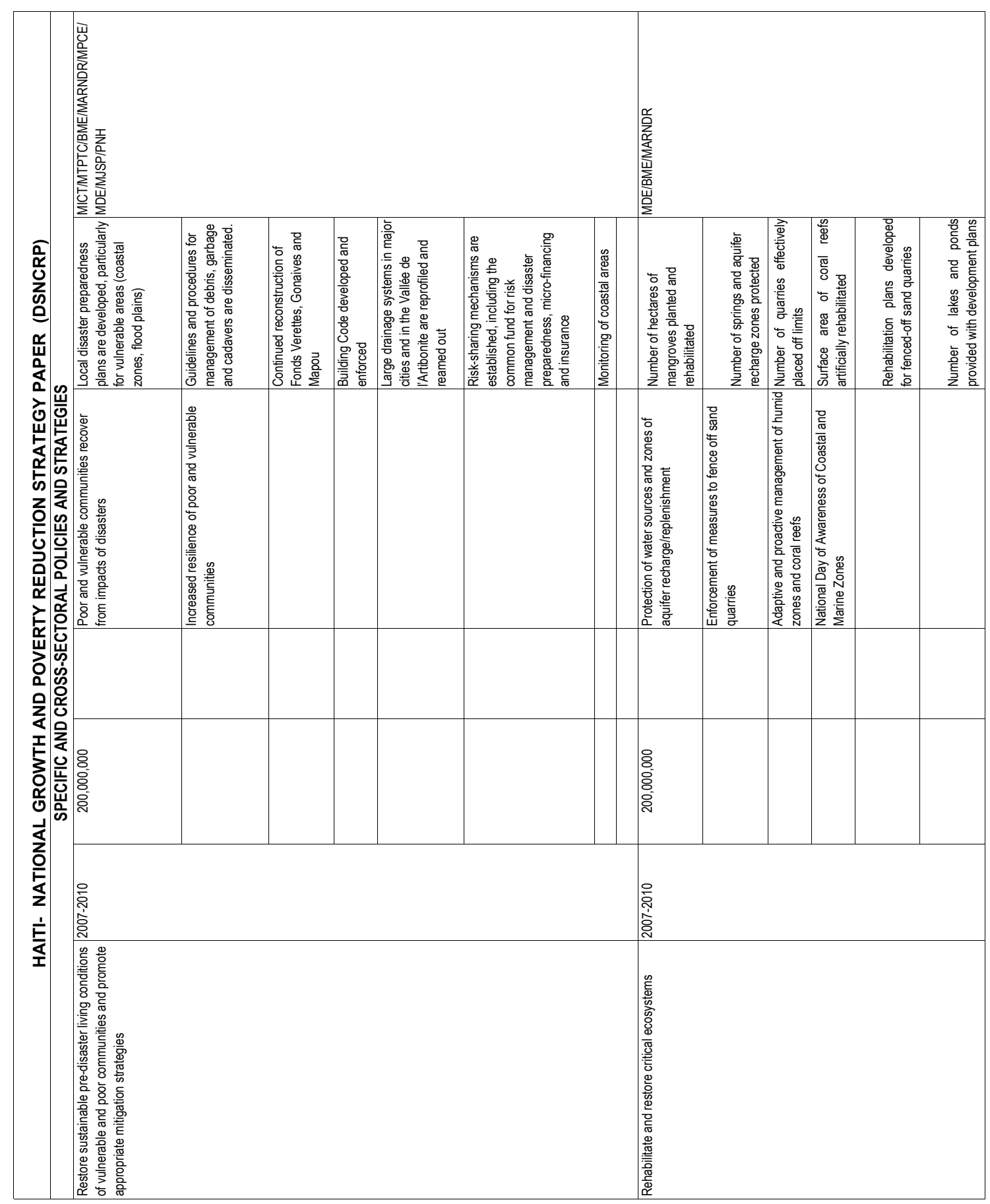

0
10
0
0
0
0 


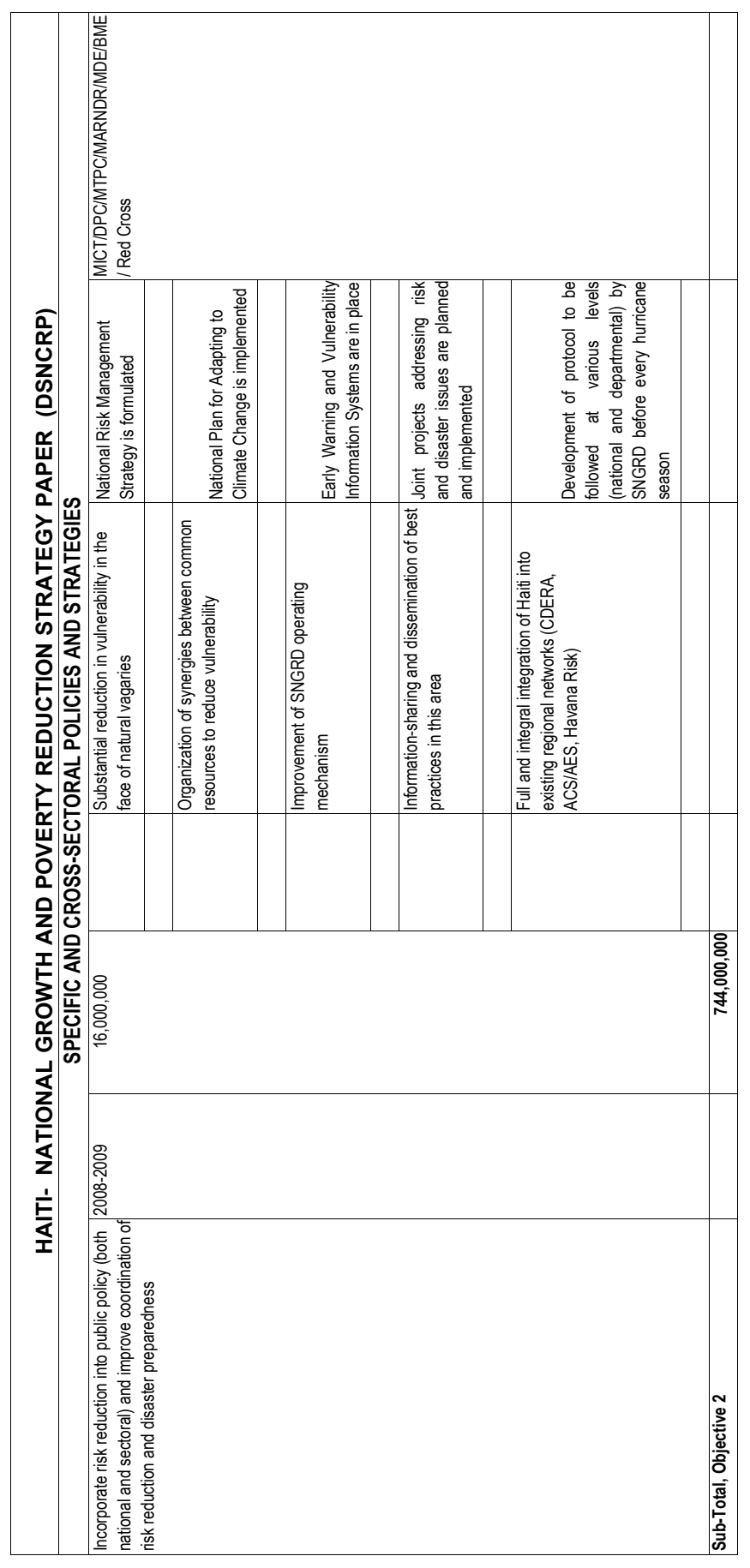

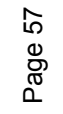




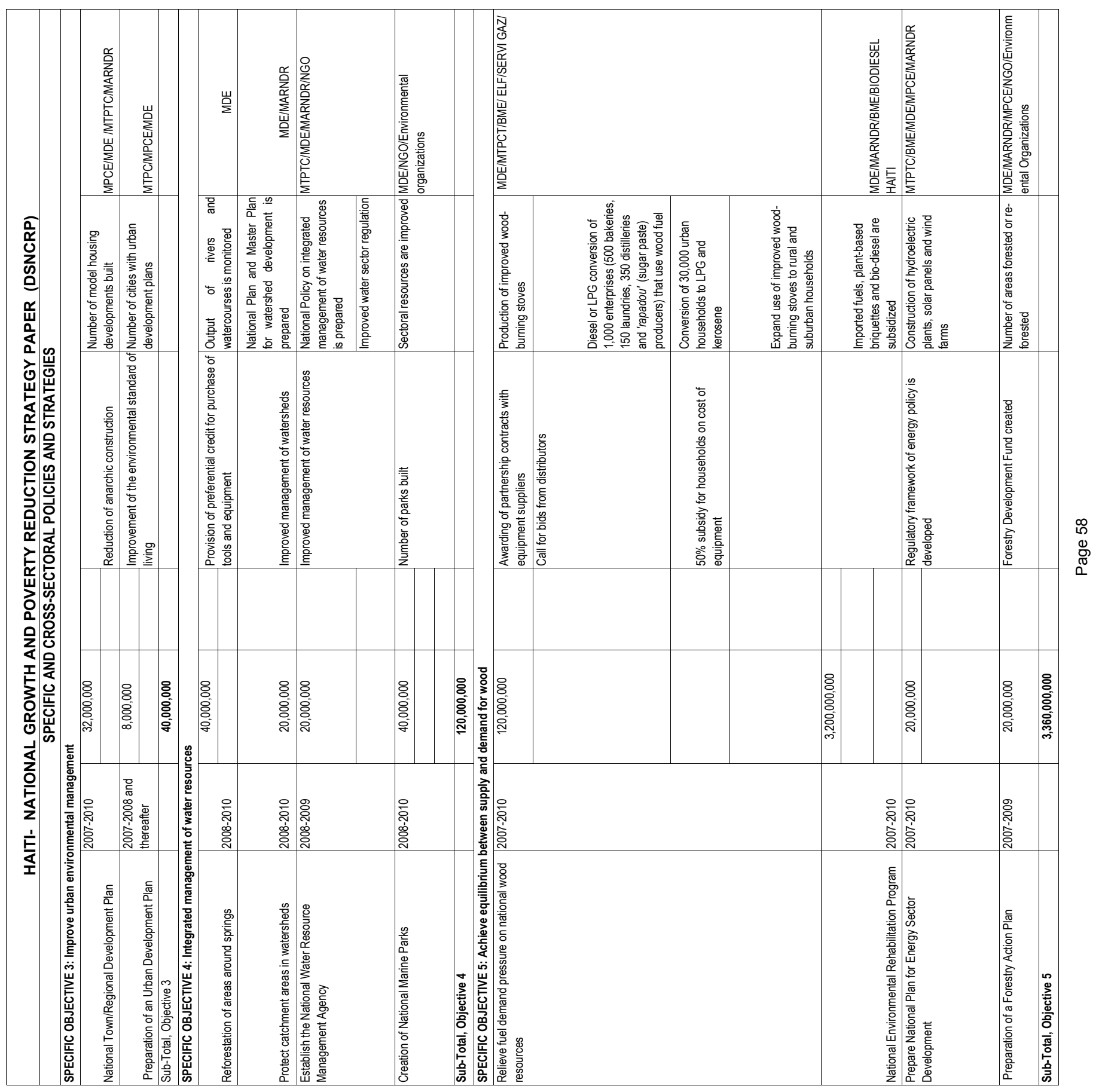




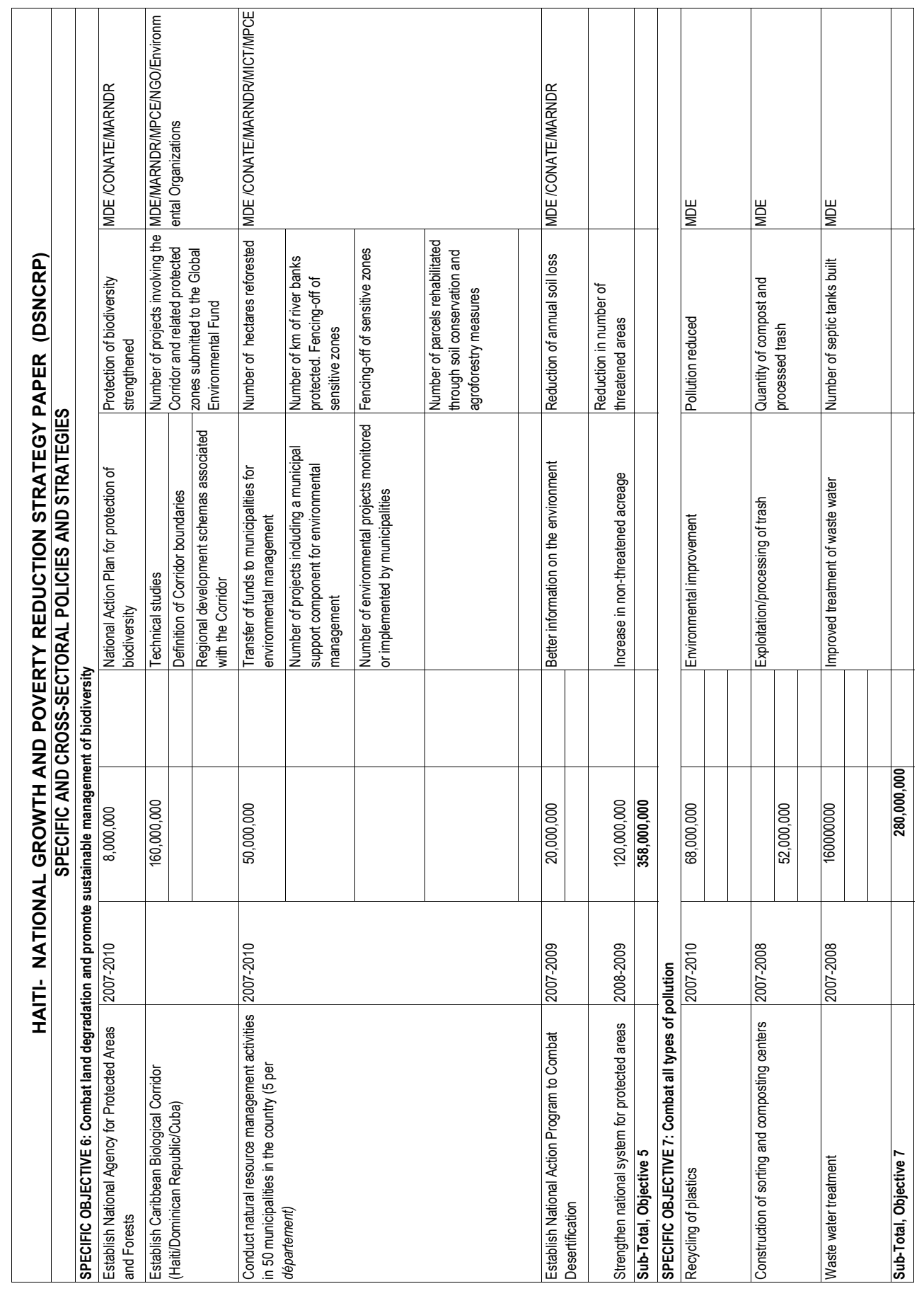

م)
0
0
0
0
0 


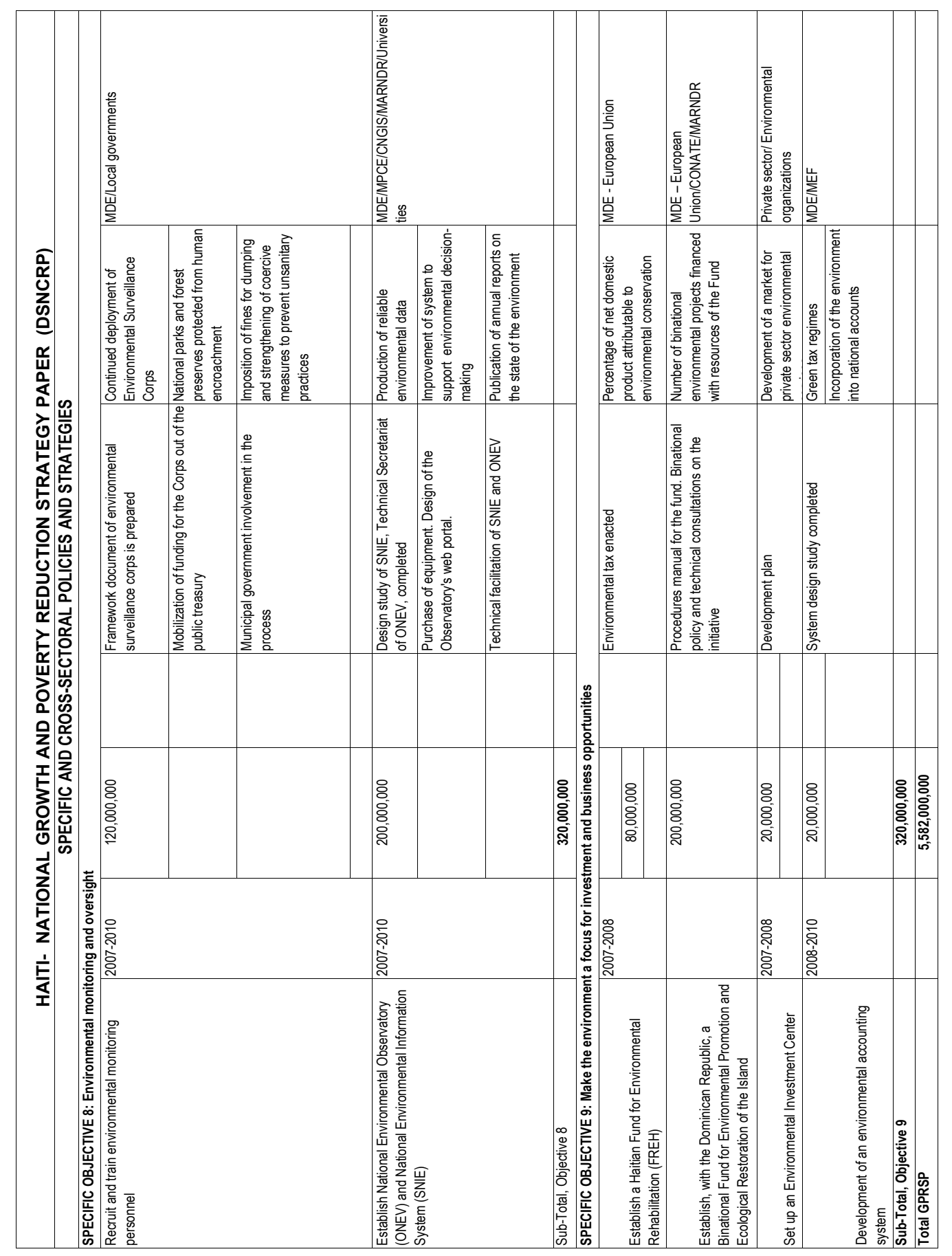




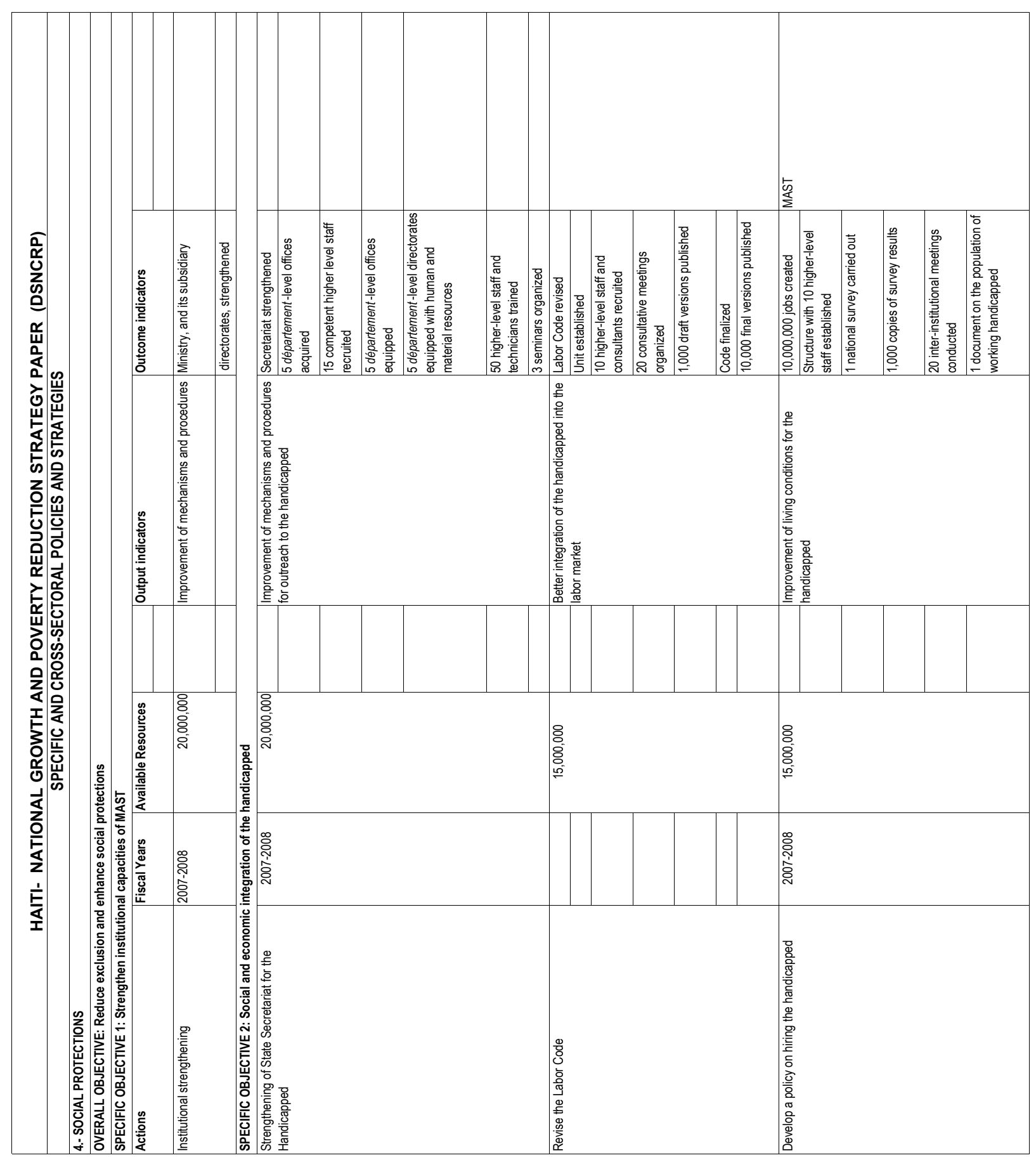

$\square$
0
0
0
0 


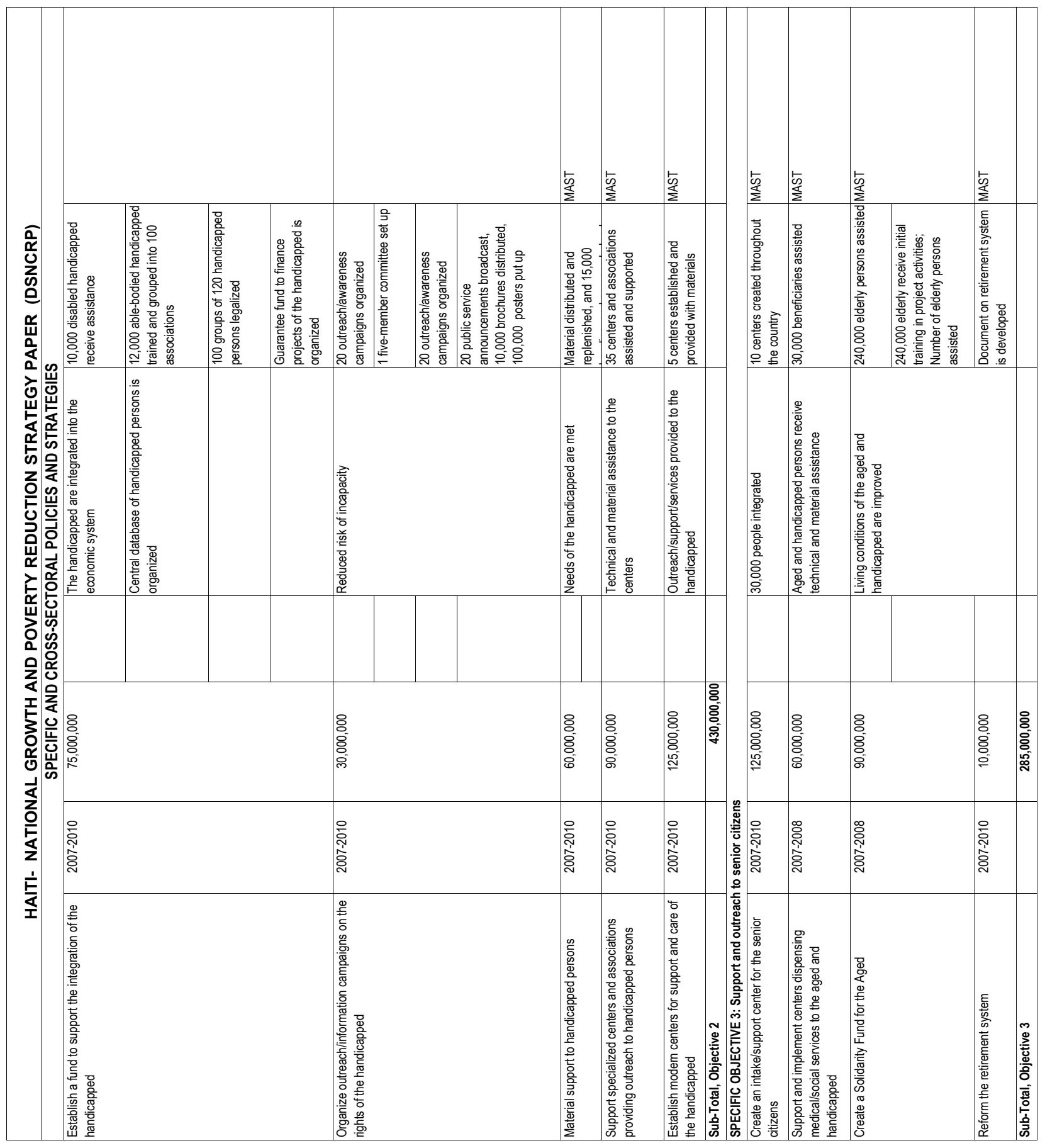

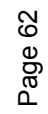




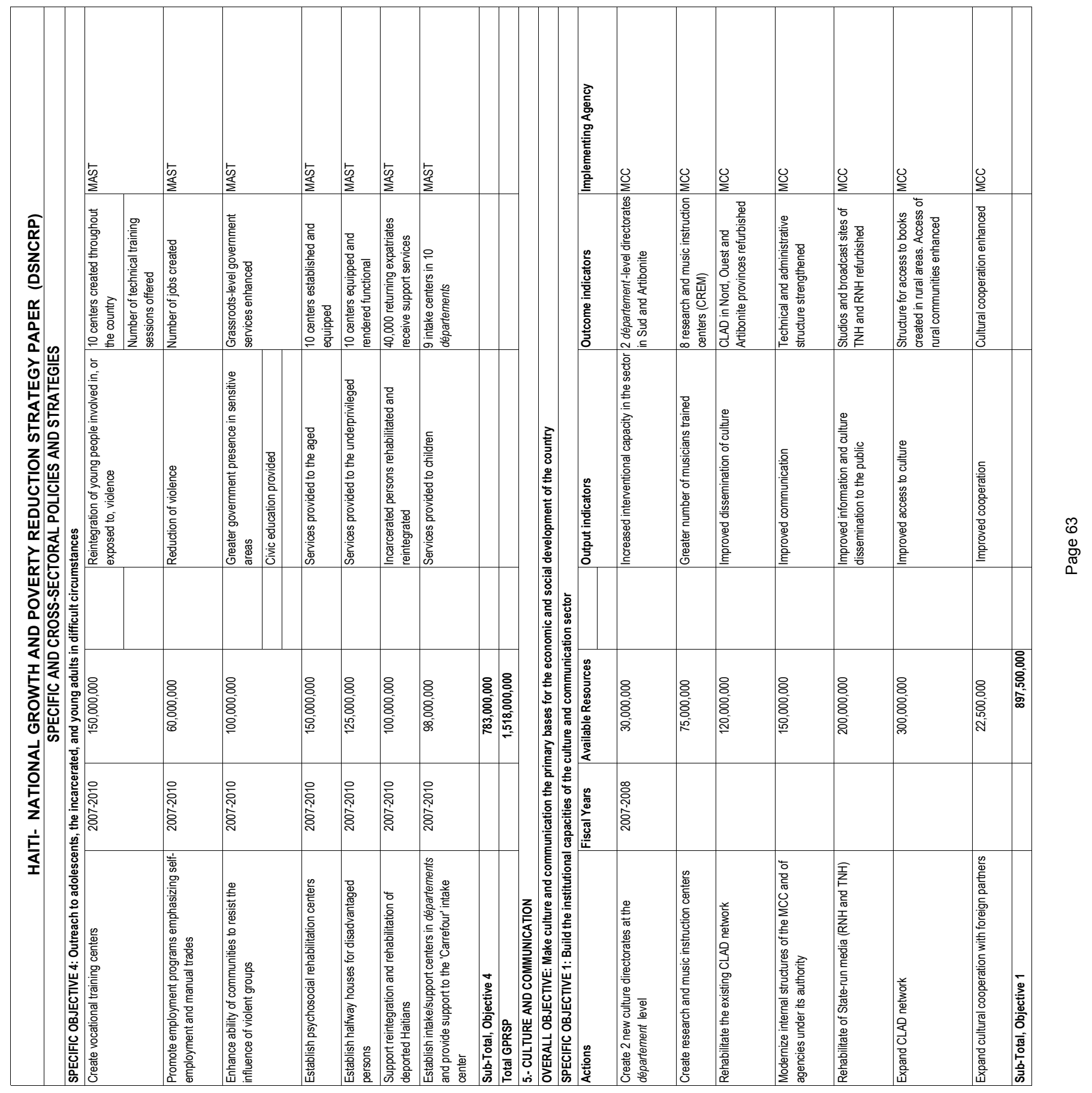




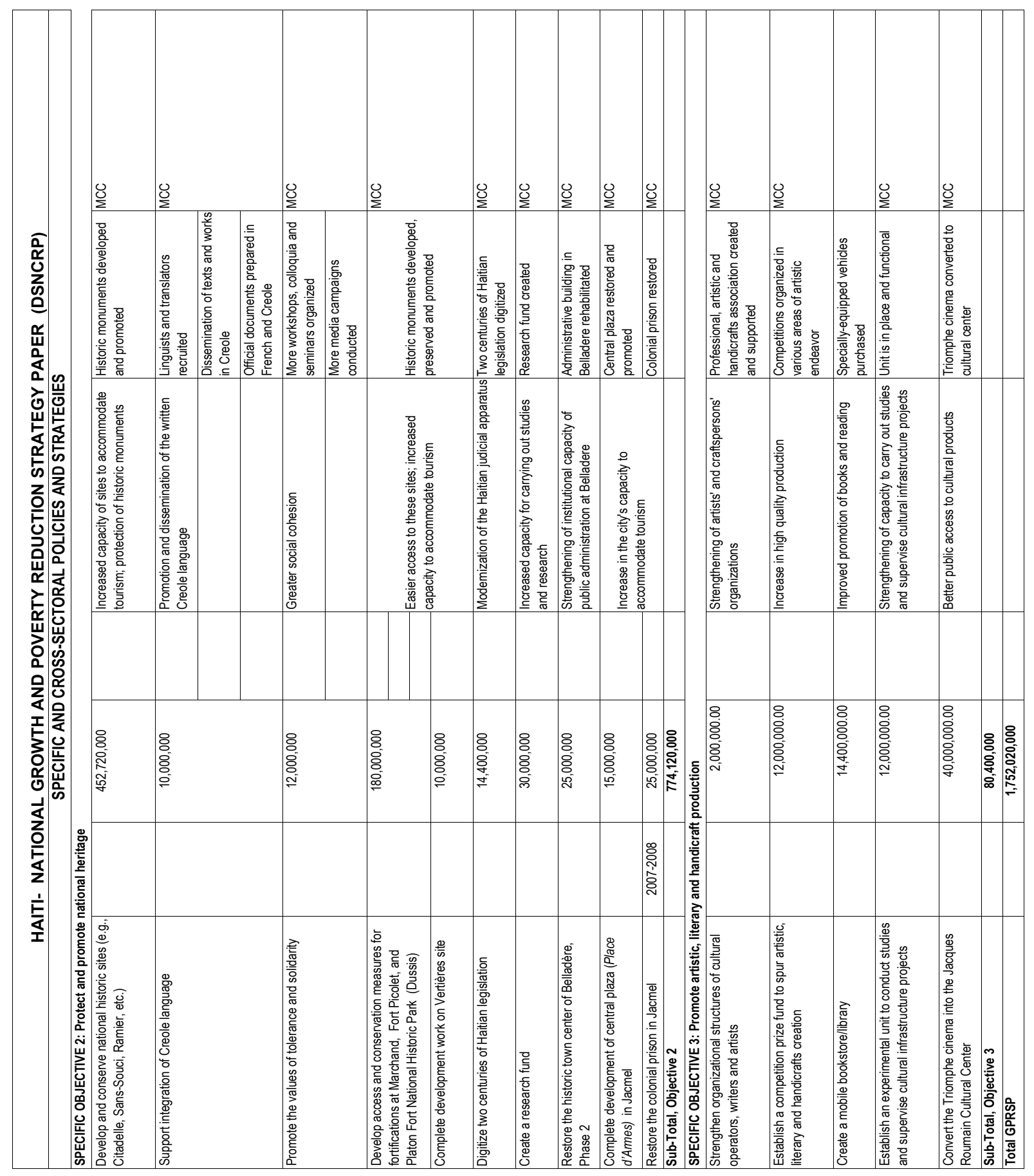

व
8
8
8
0 


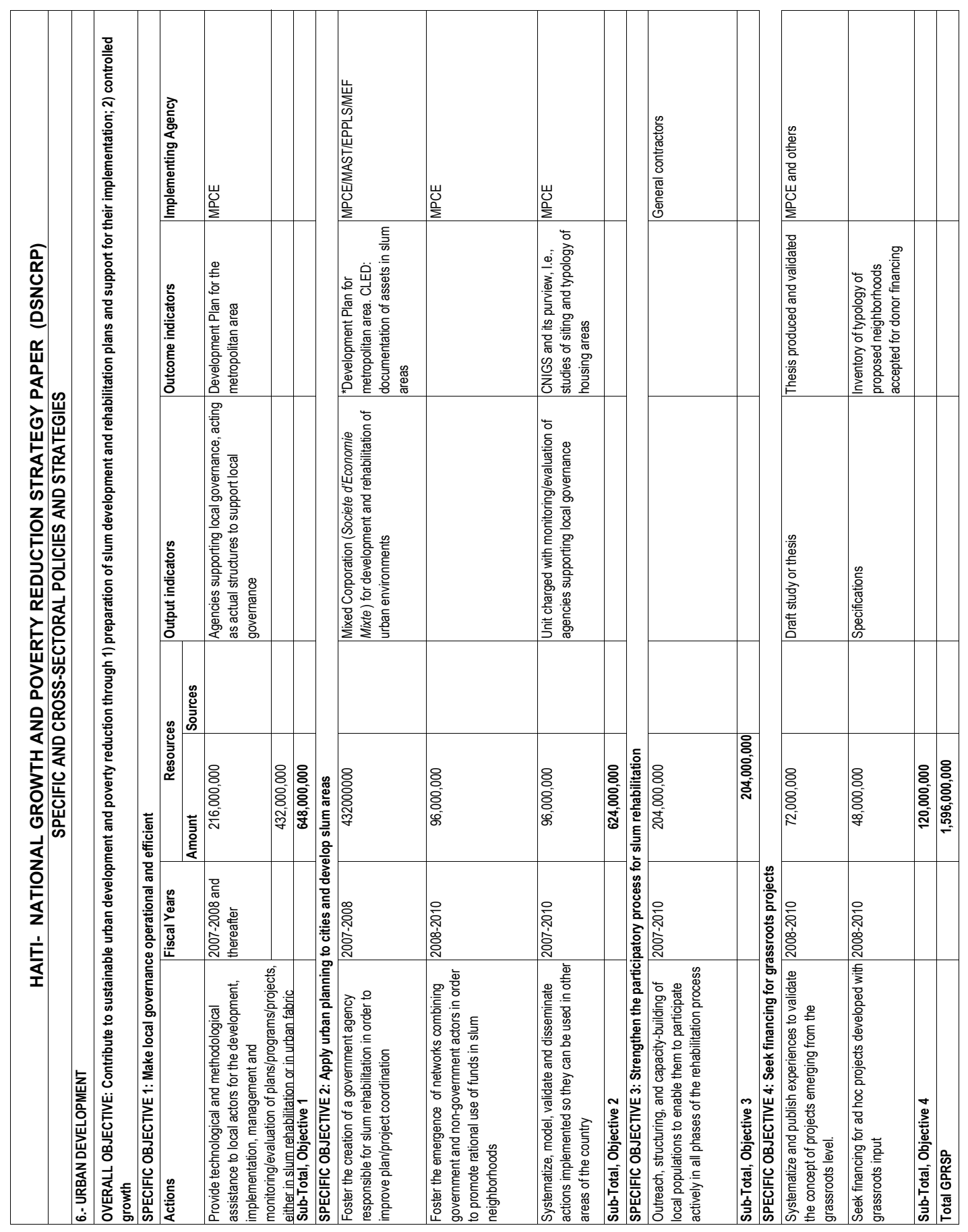




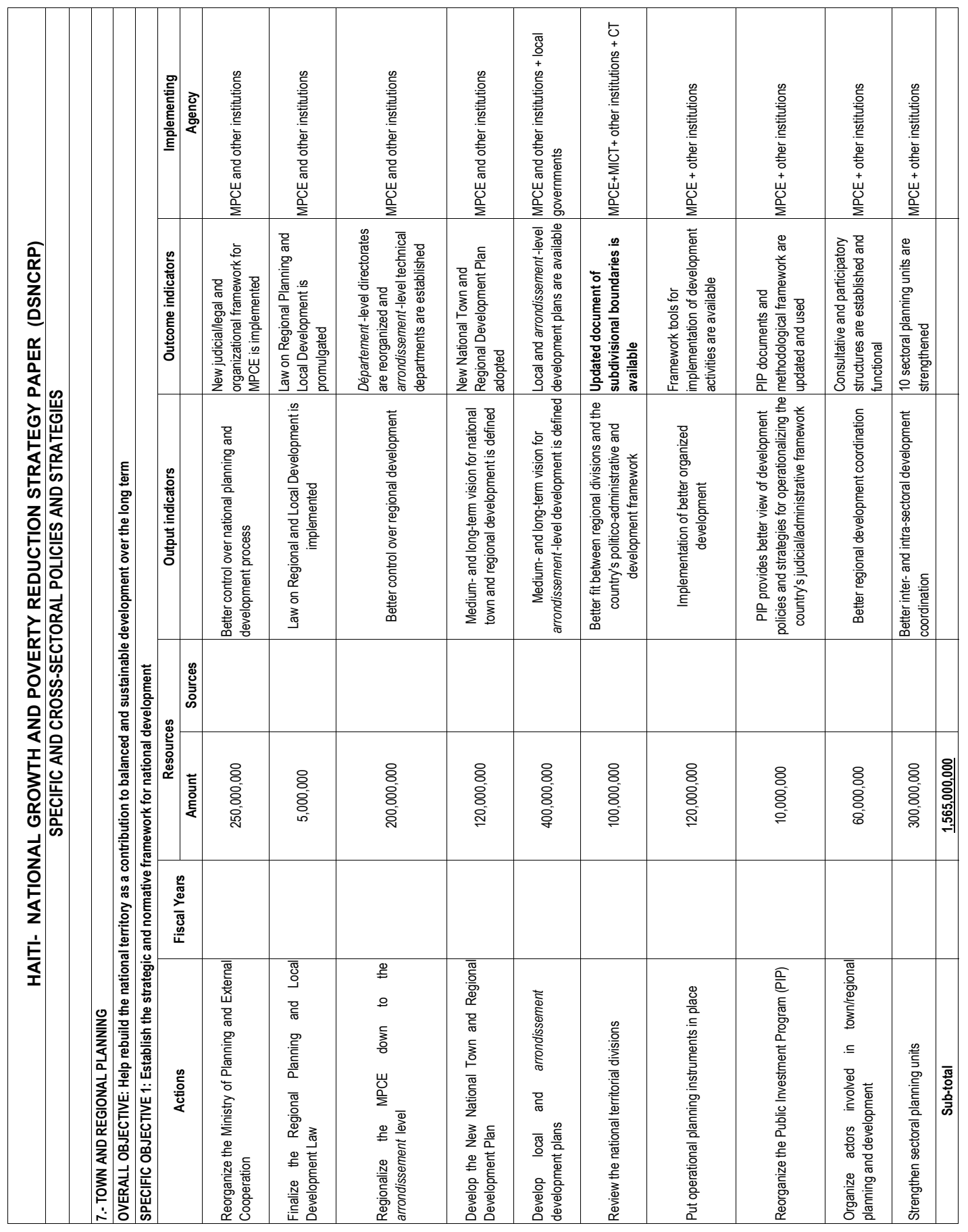




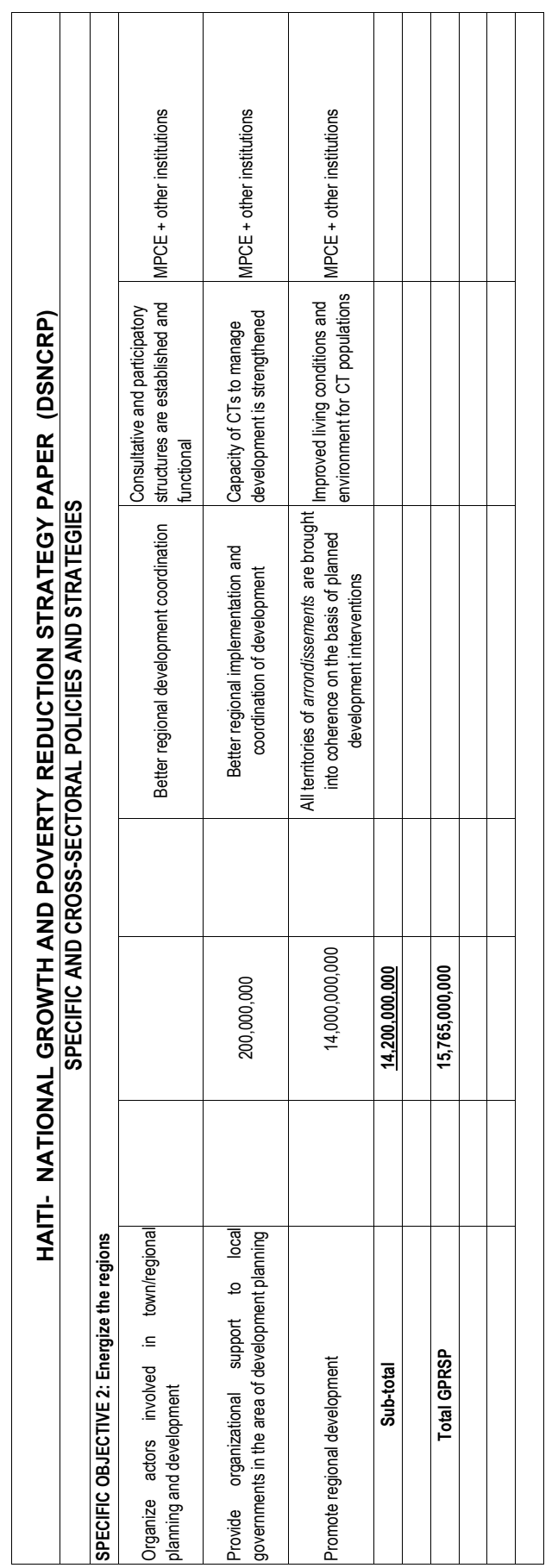

$\hat{\sigma}$
0
0
0
0 


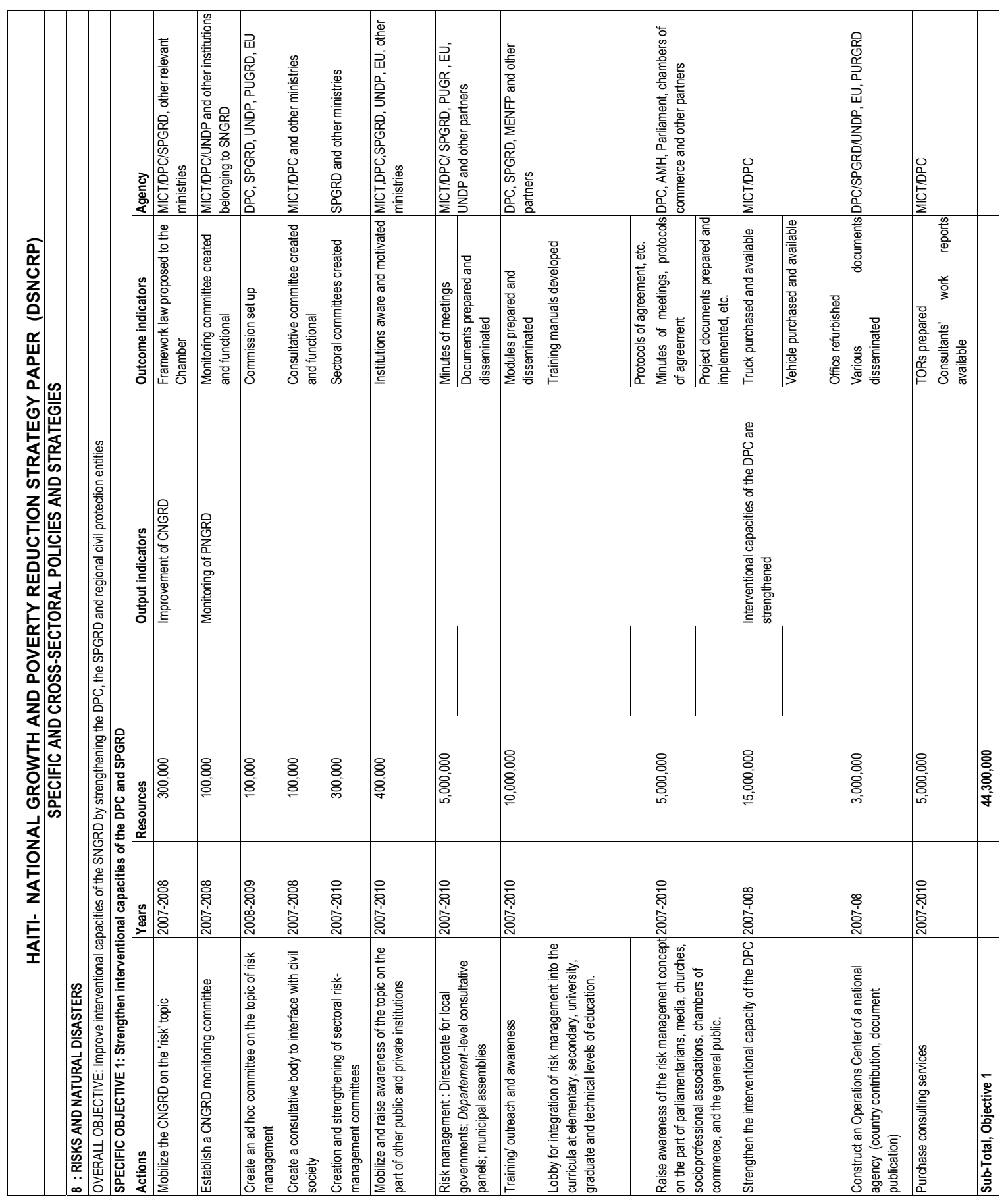

$\infty$
0
0
0
0
0 


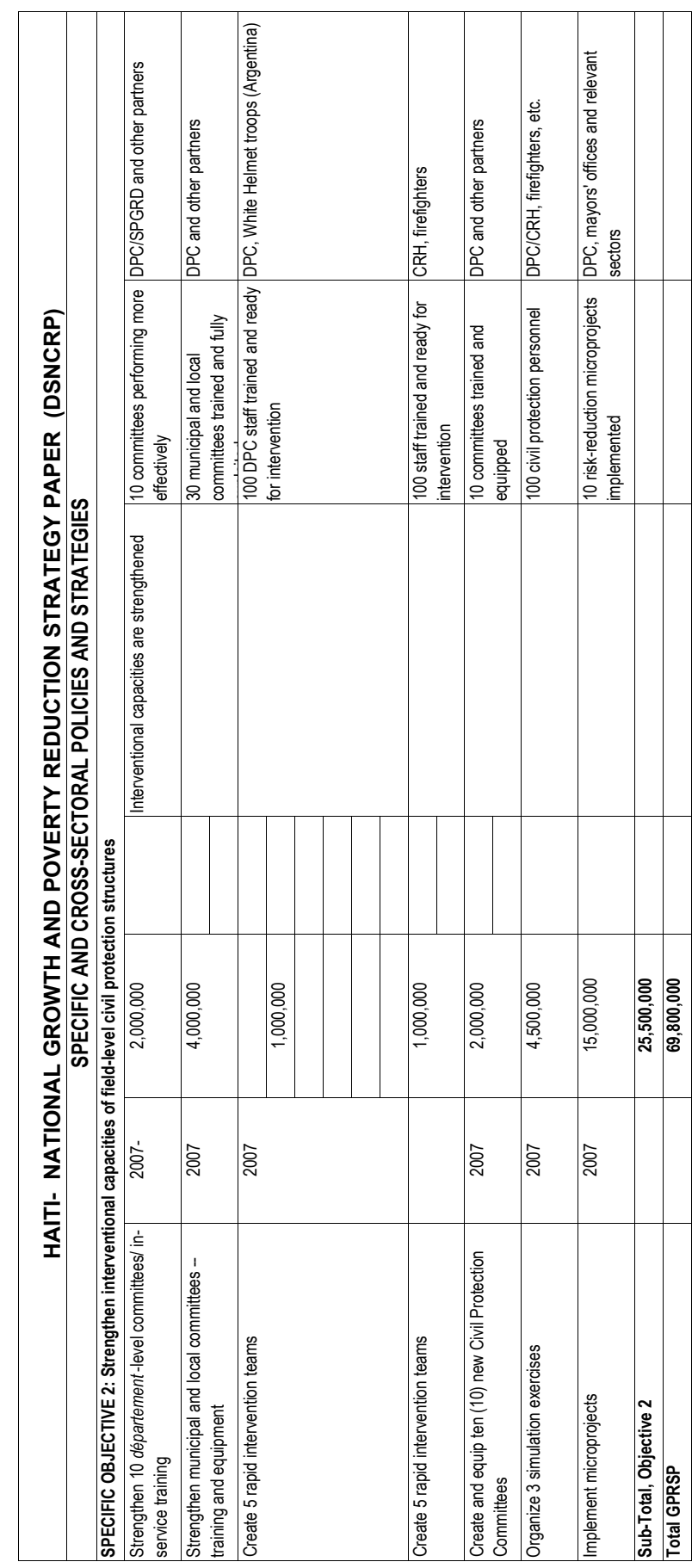

ஜ
8
8
ர 


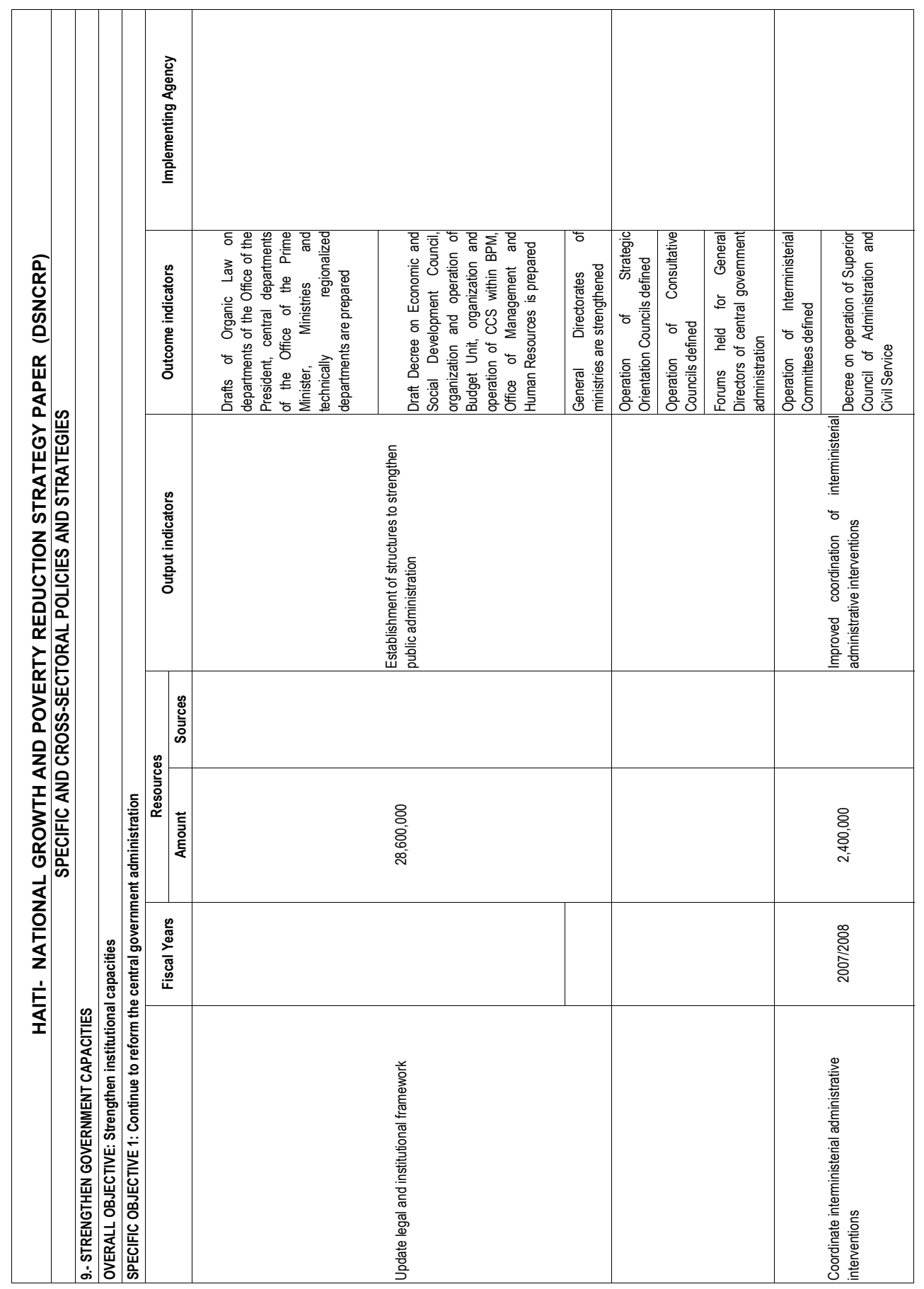

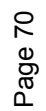




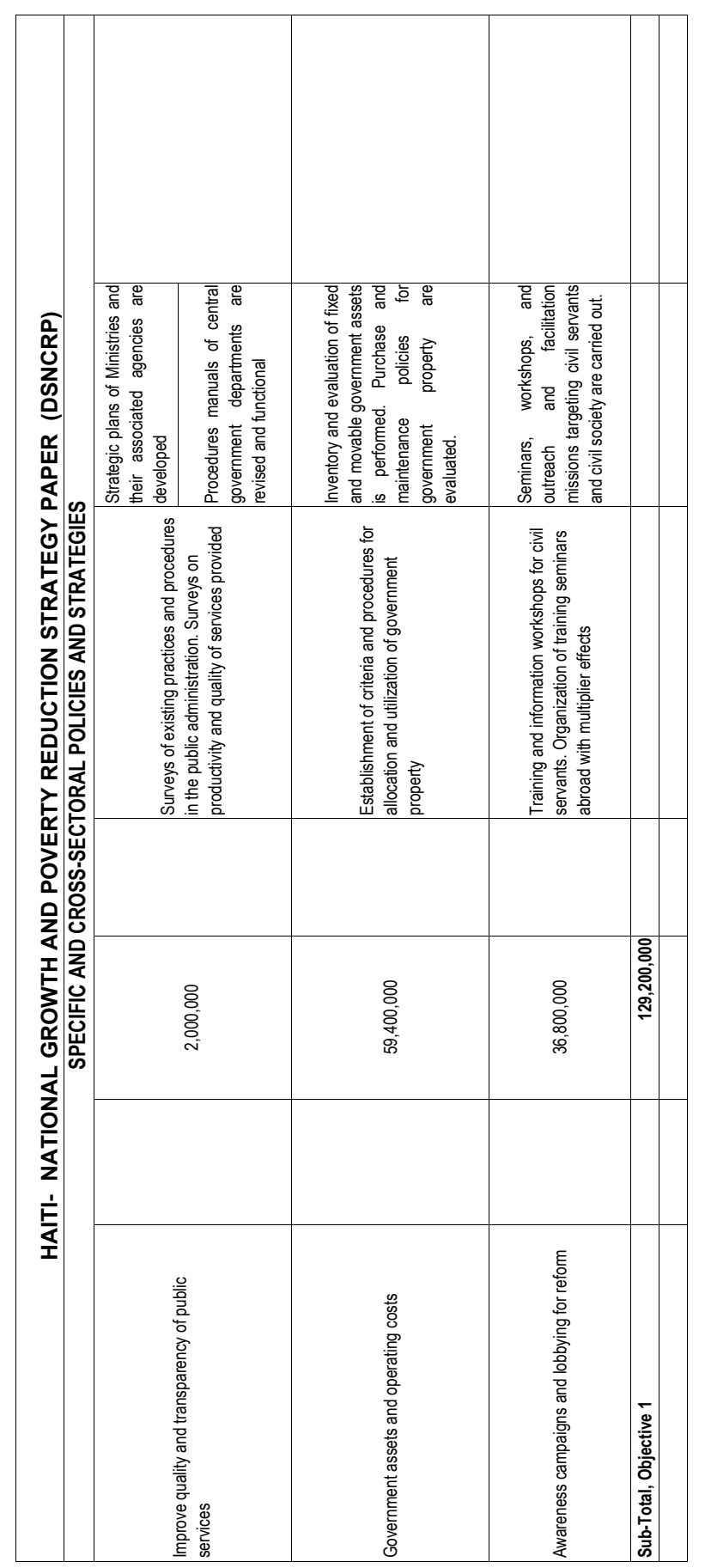

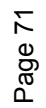




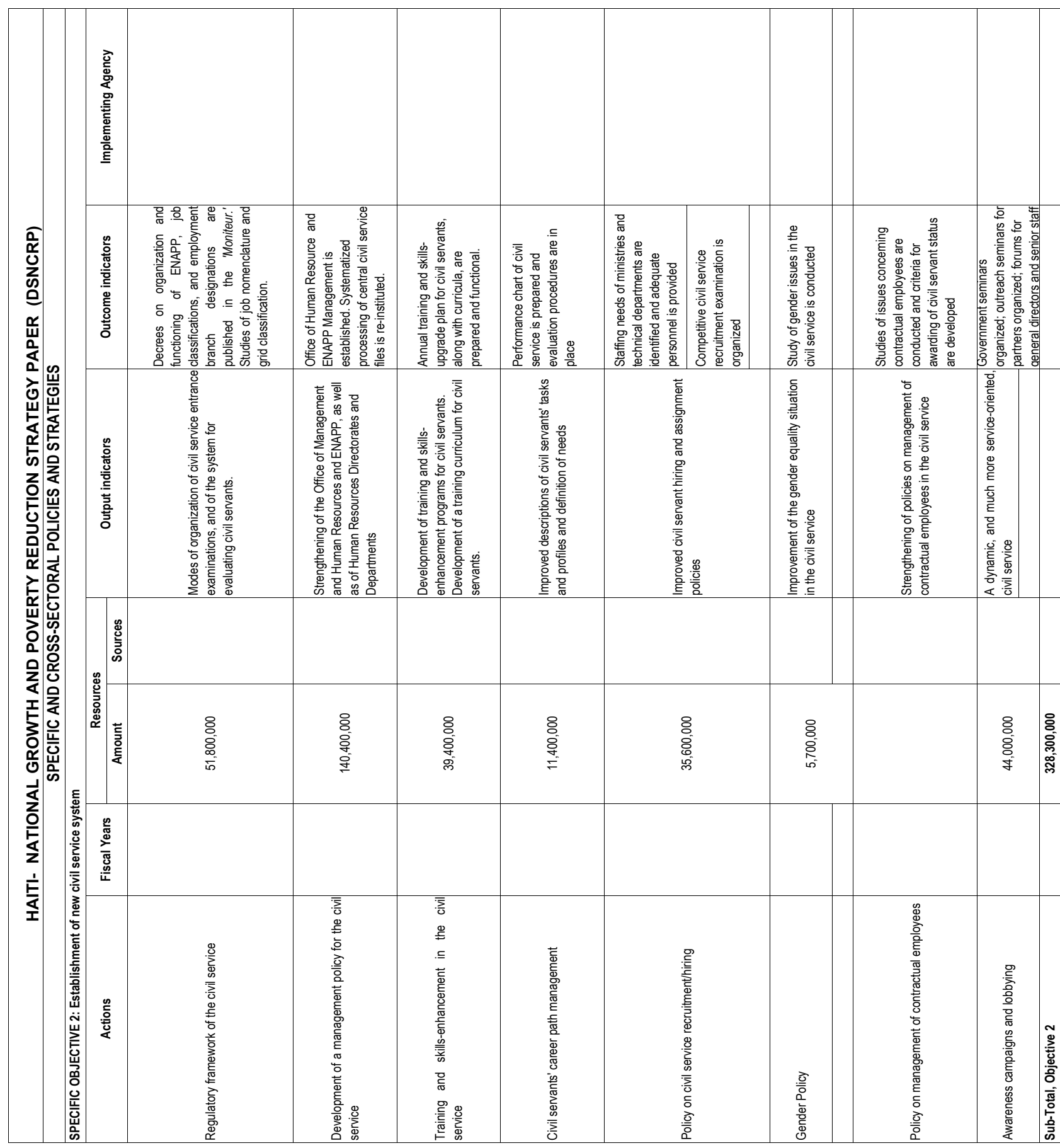

N
$\frac{0}{0}$
$\frac{0}{0}$ 


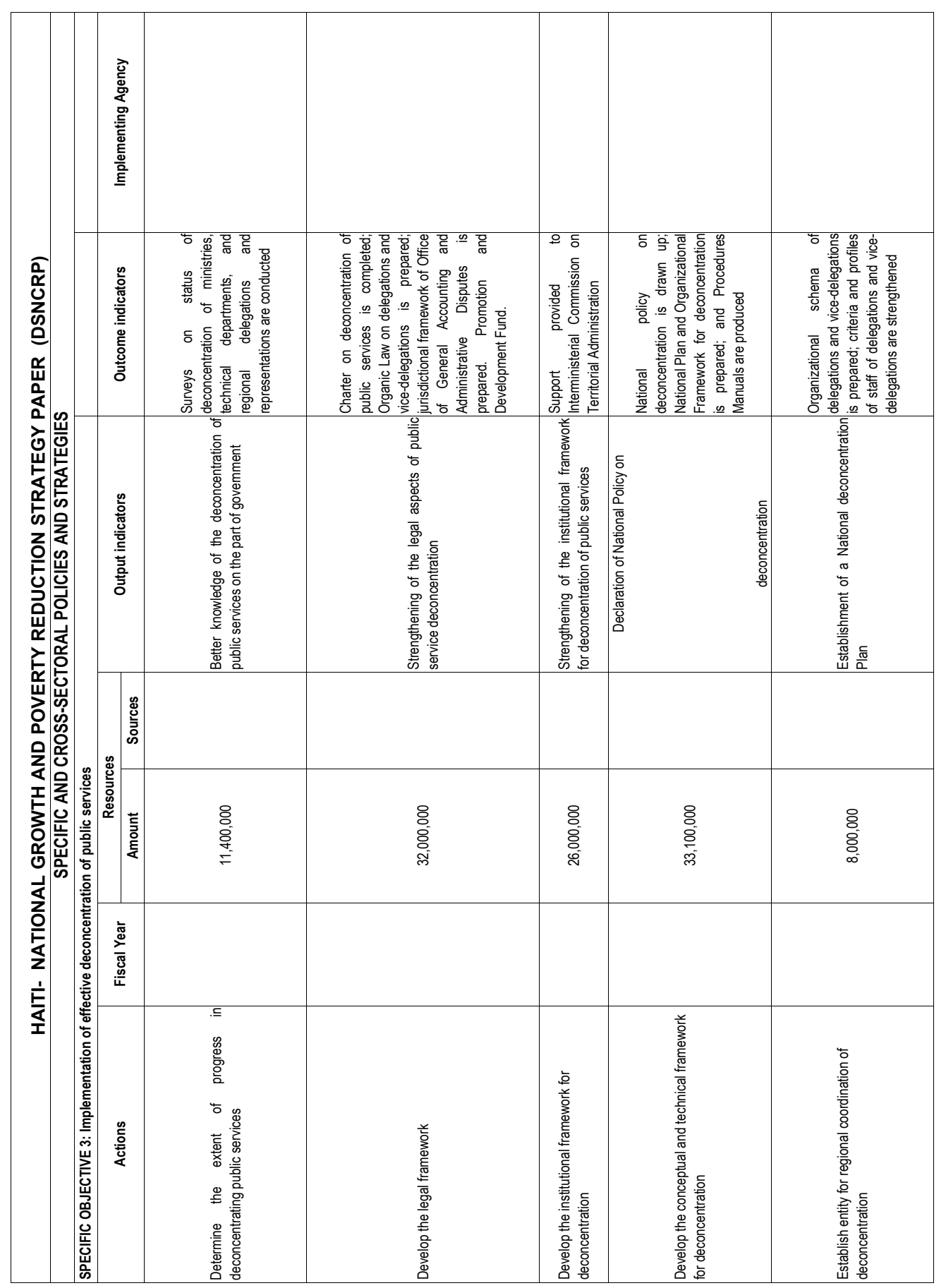

$\frac{1}{n}$
$\frac{\pi}{0}$ 


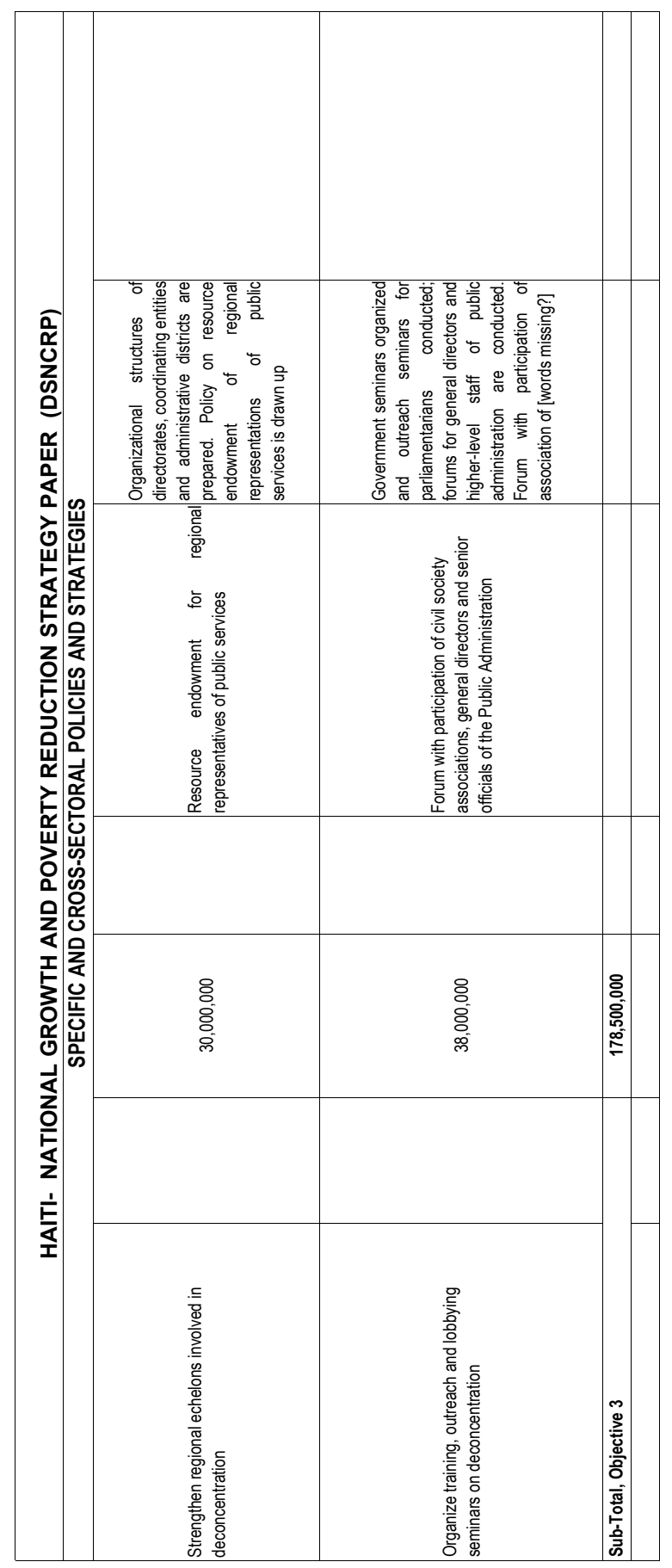

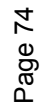




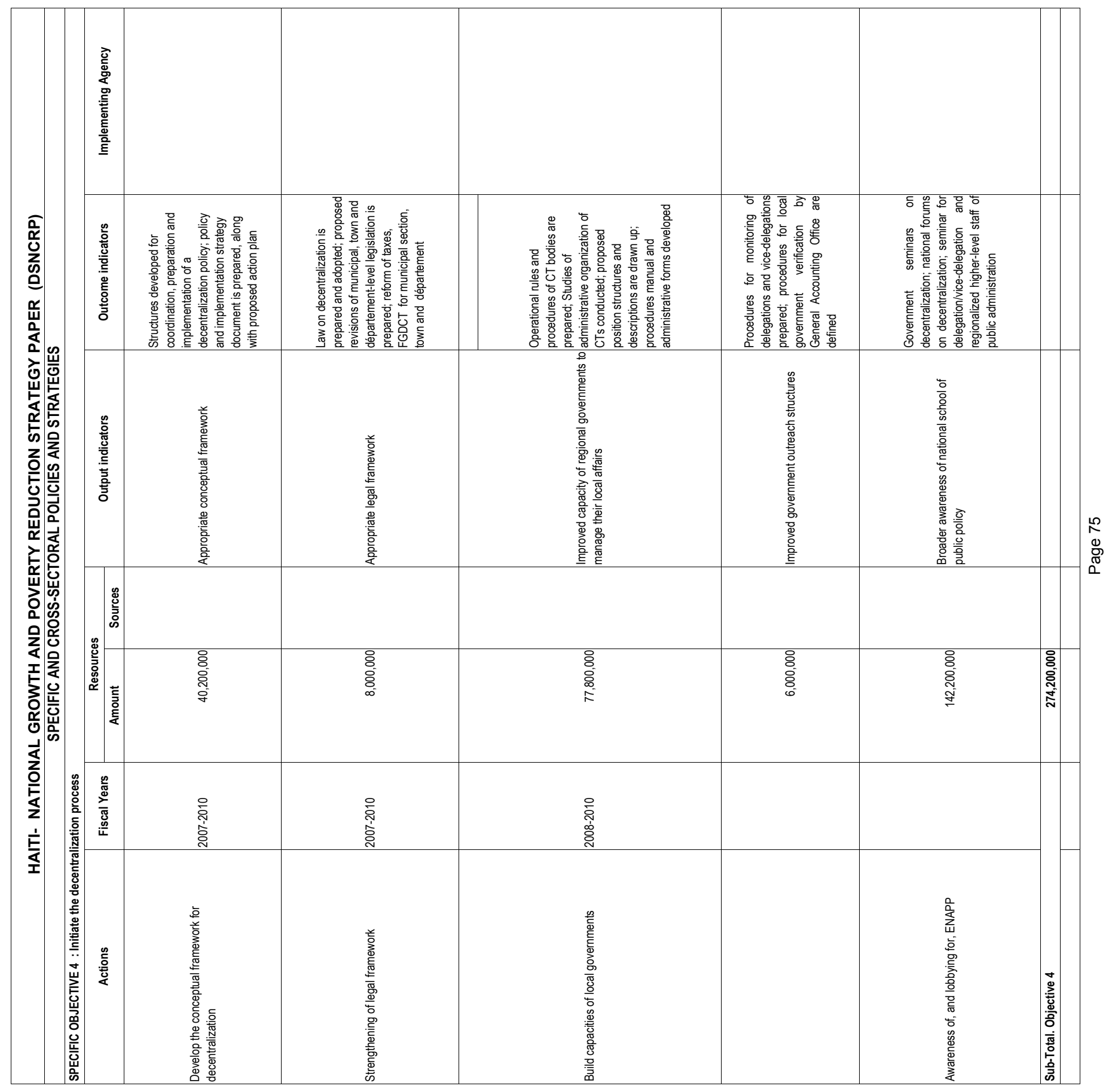




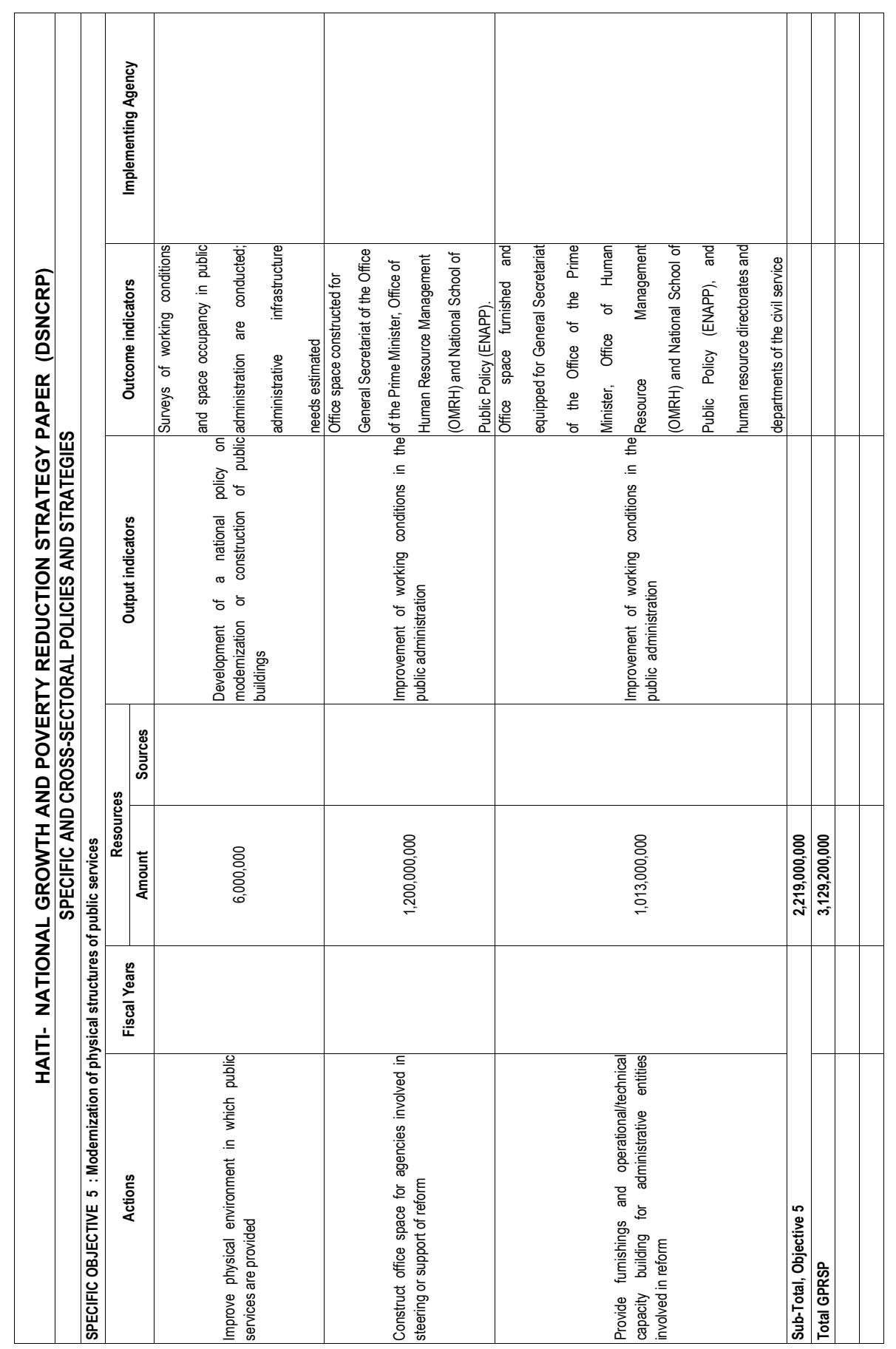

$\frac{\pi}{0}$
$\frac{\pi}{0}$ 


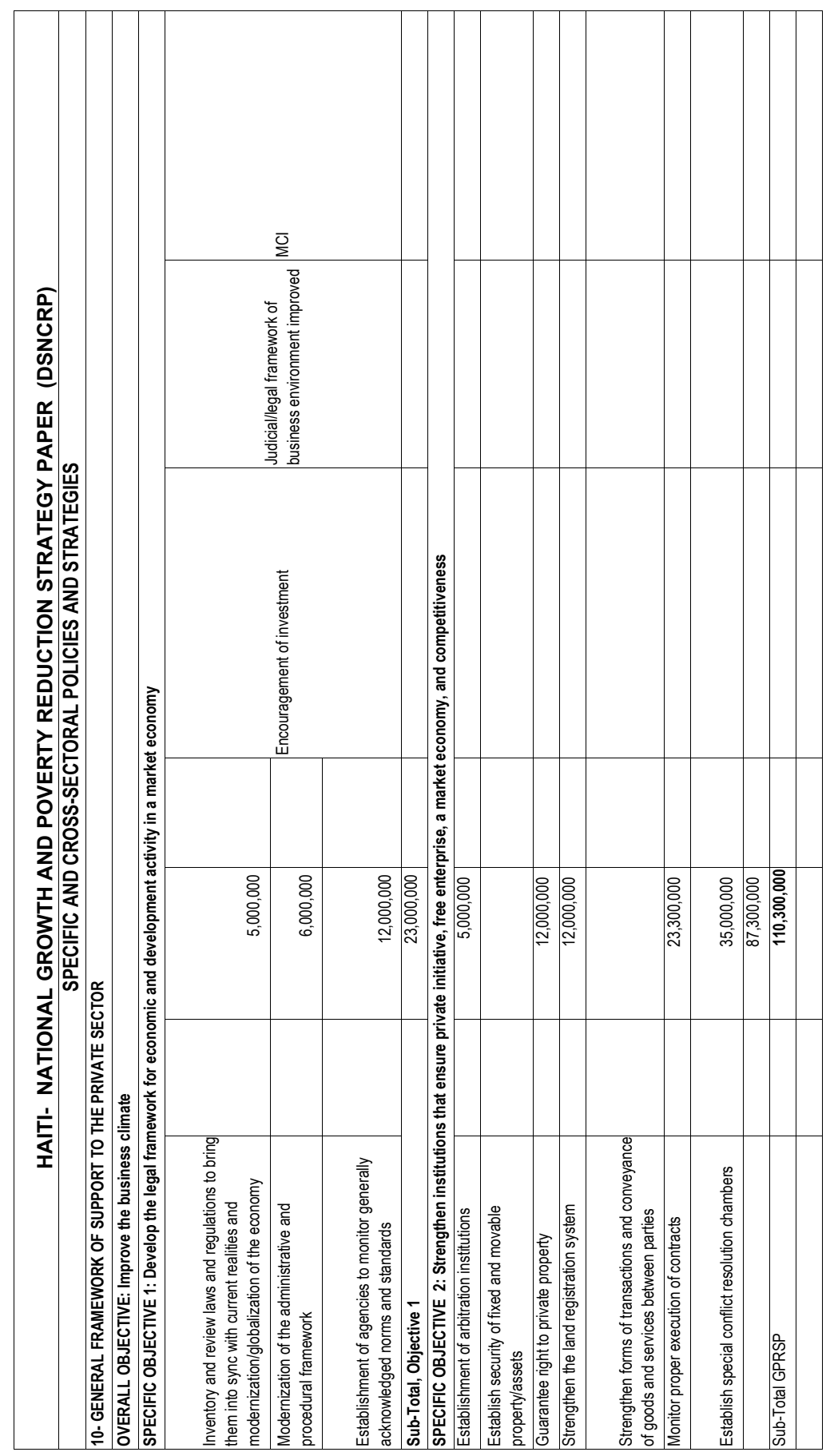

\begin{tabular}{l} 
ก \\
\multirow{2}{0}{} \\
0
\end{tabular} 
NATIONAL STRATEGY DOCUMENT FOR GROWTH AND POVERTY REDUCTION (DSNCRP/HATTI)

ACTION PLANS TO REFORMTHE PUBLIC FINANCIAL MANAGEMENT SYSTEM

ANNEX III

English Translation of Official Original Document in French 
NATIONAL STRATEGY DOCUMENT FOR GROWTH AND POVERTY REDUCTION (DSNCRP/HATT)

ACTION PLANS TO REFORMTHE PUBLIC FINANCIAL MANAGEMENT SYSTEM

1-STRENGTHENING THE PUBLIC FINANCIAL MANAGEMENT SYSTEM

\begin{tabular}{|c|c|c|c|c|c|}
\hline MEASURES TO BE TAKEN & $\begin{array}{l}\text { EXECUTING } \\
\text { AGENCIES }\end{array}$ & $\begin{array}{l}\text { PERFORMANCE } \\
\text { INDICATORS }\end{array}$ & $\begin{array}{l}\text { START } \\
\text { DATE }\end{array}$ & $\begin{array}{l}\text { NEED FOR } \\
\text { ASSISTANCE }\end{array}$ & $\begin{array}{l}\text { DONORS } \\
\text { CONCERNED }\end{array}$ \\
\hline \multicolumn{6}{|l|}{ A. BUDGET PREPARATION } \\
\hline $\begin{array}{l}\text { A.1. Integrate the operating and investment budgets and take account of the } \\
\text { multiyear nature of spending in the annual budget law. }\end{array}$ & $\begin{array}{l}\text { DGB/MPCE/MEF } \\
\text { SPENDING } \\
\text { INSTITUTIONS }\end{array}$ & $\begin{array}{l}\text { In the context of the } \\
2009 / 2010 \text { budget law, } \\
\text { a pilot test is launched } \\
\text { in line with these } \\
\text { criteria }\end{array}$ & $\begin{array}{l}\text { Starting } \\
2009 / 2010\end{array}$ & High & \\
\hline $\begin{array}{l}\text { A.2. Strengthen the capacity of the spending institutions in (i) the } \\
\text { preparation of investment and operating budgets and (ii) the } \\
\text { formulation of budget strategies and their budgetization. }\end{array}$ & $\begin{array}{l}\text { DGB/MPCE/MEF } \\
\text { SPENDING } \\
\text { INSTITUTIONS }\end{array}$ & $\begin{array}{l}\text { Pilot project underway } \\
\text { for the decentralization } \\
\text { and installation of the } \\
\text { new version of the } \\
\text { budget preparation } \\
\text { system "ELABUD" in } \\
\text { seven ministries for the } \\
\text { preparation of the next } \\
\text { budget. } \\
\text { Phase } 1 \text { of } \\
\text { strengthening the } \\
\text { planning and } \\
\text { budgetization structures } \\
\text { of the spending } \\
\text { institutions is in effect. } \\
\text { In the } 2007-2008 \text { draft } \\
\text { budget law, the PIP } \\
\text { includes a capacity } \\
\text { building program for } \\
\text { the sectoral } \\
\text { programming units of } \\
\text { the SPENDING } \\
\text { INSTITUTIONS }\end{array}$ & $\begin{array}{cc}\text { - } & \text { H1 } \\
& 2008\end{array}$ & High & \\
\hline
\end{tabular}


NATIONAL STRATEGY DOCUMENT FOR GROWTH AND POVERTY REDUCTION (DSNCRP/HATTI)

ACTION PLANS TO REFORMTHE PUBLIC FINANCIAL MANAGEMENT SYSTEM

\begin{tabular}{|c|c|c|c|c|c|}
\hline MEASURES TO BE TAKEN & $\begin{array}{l}\text { EXECUTING } \\
\text { AGENCIES }\end{array}$ & $\begin{array}{l}\text { PERFORMANCE } \\
\text { INDICATORS }\end{array}$ & $\begin{array}{l}\text { START } \\
\text { DATE }\end{array}$ & $\begin{array}{l}\text { NEED FOR } \\
\text { ASSISTANCE }\end{array}$ & $\begin{array}{l}\text { DONORS } \\
\text { CONCERNED }\end{array}$ \\
\hline $\begin{array}{l}\text { A.3. Devise tools to improve harmonize linkages between the } \\
\text { macroeconomic framework, the growth and poverty reduction policies } \\
\text { and strategies, and the public investment program (PIP). }\end{array}$ & MPCE/DGB/DEE & $\begin{array}{l}\text { Starting } 2009 / 2010, \\
\text { these tools will be used } \\
\text { in preparing the budget. }\end{array}$ & Q1 2008 & $\begin{array}{l}\text { High, in particular } \\
\text { for } \\
\text { macroeconomic } \\
\text { modeling. MTEF, } \\
\text { Program } \\
\text { Approach }\end{array}$ & \\
\hline $\begin{array}{l}\text { A.4. Adhere to the budget timeframe to facilitate greater involvement of all } \\
\text { actors and submit the budget law to the vote before the start of the } \\
\text { budget year concerned. }\end{array}$ & \begin{tabular}{|l|} 
DGB/MPCE/MEF \\
SPENDING \\
INSTITUTIONS/ \\
Office of the \\
Prime \\
Minister/Parliame \\
nt/Council of \\
Ministers \\
\end{tabular} & $\begin{array}{l}\text { Budget process } \\
\text { complied with. }\end{array}$ & \begin{tabular}{|l|l} 
Starting \\
$2009 / 2010$
\end{tabular} & Low & \\
\hline $\begin{array}{l}\text { A.4. Add, as an annex to the budget law, income and expenditure estimates } \\
\text { for all funds managed through special accounts, namely, CAS, FDU, } \\
\text { PENSION CIVILE, FER, and CFGDT. }\end{array}$ & DGB/DT/MEF & $\begin{array}{l}\text { The } 2008 / 2009 \text { revised } \\
\text { budget law contains } \\
\text { such an annex. }\end{array}$ & $\begin{array}{l}\text { March } \\
2008\end{array}$ & Low & \\
\hline $\begin{array}{l}\text { A.5. Systematically annex to the budget law for the following year the } \\
\text { cumulative results of the budget for the year }(\mathrm{N}-2) \text {. }\end{array}$ & $\begin{array}{l}\mathrm{DGB} / \mathrm{DT} / \mathrm{MEF} / \mathrm{M} \\
\mathrm{PCE}\end{array}$ & $\begin{array}{l}\text { The result of the } \\
2006 / 2007 \text { budget is } \\
\text { annexed to the } \\
2008 / 2009 \text { budget law. }\end{array}$ & $\begin{array}{rr}\text { June } \\
2008\end{array}$ & Low & \\
\hline $\begin{array}{l}\text { A.6. Formalize the process of evaluating tax revenue in an administrative } \\
\text { text. }\end{array}$ & $\begin{array}{l}\text { DGI/AGD/DGB/ } \\
\text { MEF/DIF }\end{array}$ & $\begin{array}{l}\text { An administrative text } \\
\text { is prepared and } \\
\text { distributed. }\end{array}$ & $\begin{array}{cc}\text { H1 } \\
2008\end{array}$ & Medium & \\
\hline $\begin{array}{l}\text { A.7. Conduct an economic analysis of domestic and external borrowing and } \\
\text { define a sustainable level of debt compatible with the macroeconomic } \\
\text { framework established. }\end{array}$ & $\begin{array}{l}\mathrm{DD} / \mathrm{DT} / \mathrm{MEF} / \mathrm{DE} \\
\mathrm{E} / \mathrm{MPCE} / \mathrm{BRH}\end{array}$ & $\begin{array}{l}\text { Analysis conducted and } \\
\text { formalized in a report. }\end{array}$ & $\begin{array}{l}\text { Starting } \\
2008 / 2009\end{array}$ & High & \\
\hline $\begin{array}{l}\text { A.8. Set spending caps for the spending institutions at the start of the budget } \\
\text { preparation process so as to improve the quality of their proposals. }\end{array}$ & DGB/MEF/MPCE & $\begin{array}{l}\text { Caps are set and } \\
\text { communicated in } \\
\text { writing to each } \\
\text { spending institution. }\end{array}$ & $\begin{array}{l}\text { Starting } \\
2008 / 2009\end{array}$ & Low & \\
\hline A.9. Expand the framework for transactions recorded in the budget. & $\begin{array}{l}\text { DGB/DT/MEF + } \\
\text { SPENDING } \\
\text { INSTITUTIONS }\end{array}$ & & $\begin{array}{l}\text { September } \\
2009\end{array}$ & & \\
\hline
\end{tabular}


NATIONAL STRATEGY DOCUMENT FOR GROWTH AND POVERTY REDUCTION (DSNCRP/HATTI) ACTION PLANS TO REFORMTHE PUBLIC FINANCIAL MANAGEMENT SYSTEM

\begin{tabular}{|c|c|c|c|c|c|}
\hline MEASURES TO BE TAKEN & $\begin{array}{l}\text { EXECUTING } \\
\text { AGENCIES }\end{array}$ & $\begin{array}{l}\text { PERFORMANCE } \\
\text { INDICATORS }\end{array}$ & $\begin{array}{l}\text { START } \\
\text { DATE }\end{array}$ & $\begin{array}{l}\text { NEED FOR } \\
\text { ASSISTANCE }\end{array}$ & $\begin{array}{l}\text { DONORS } \\
\text { CONCERNED }\end{array}$ \\
\hline A.10. Design and implement an information system on programs and projects & $\begin{array}{l}\text { MPCE/ } \\
\text { DGB }\end{array}$ & $\begin{array}{l}\text { An exhaustive project } \\
\text { database is set up at the } \\
\text { MPCE }\end{array}$ & $\begin{array}{cc}\mathrm{H} 2 \\
2008\end{array}$ & Medium & \\
\hline $\begin{array}{l}\text { A.11. Improve the budget nomenclature for expenditures: } \\
\text { - Improve budget classification by putting in place three main } \\
\text { segments: } \\
\text { - functional classification broken down into sub-functions, } \\
\text { corresponding to the broad strategic areas of intervention } \\
\text { - identified by the line ministries, in the various technical fields; } \\
\text { - } \quad \text { administrative and territorial classification; } \\
\text { - Finalize the budget nomenclature by making it compatible with the } \\
\text { chart of accounts } \\
\text { - Fine-tune the definition of budget lines for poverty spending by } \\
\text { defining sub-functions of the functional nomenclature } \\
\text { corresponding to the main objectives established by the ministries. } \\
\text { - Identify and classify the sources of financing }\end{array}$ & DGB/DT/MEF & $\begin{array}{l}\text { The budget } \\
\text { nomenclature for } \\
\text { expenditures is } \\
\text { supplemented with the } \\
\text { segments referred to } \\
\text { and training sessions } \\
\text { are organized for all } \\
\text { users. }\end{array}$ & $\begin{array}{cc}\text { - } & \text { Q4 } \\
2007\end{array}$ & Medium & \\
\hline $\begin{array}{l}\text { A.12. Improve the budget nomenclature for expenditures: } \\
\text { - Add a nomenclature for programs to the budget nomenclature. }\end{array}$ & $\begin{array}{l}\text { DGB/DT/MEF/M } \\
\text { PCE }\end{array}$ & $\begin{array}{l}\text { A text is signed and } \\
\text { circulated for } \\
\text { implementation of the } \\
\text { new budget } \\
\text { nomenclature for } \\
\text { expenditures. }\end{array}$ & $\begin{array}{cc}\mathrm{H} 2 \\
2008\end{array}$ & Medium & \\
\hline $\begin{array}{l}\text { A.13. Improve the budget nomenclature for revenue: } \\
\text { - Consider the implementation of a budget classification, with two } \\
\text { main segments: } \\
-\quad \text { administrative and territorial classification; } \\
-\quad \text { economic classification. In discussion with the entities } \\
\text { concerned. }\end{array}$ & $\begin{array}{l}\text { DGB/DT/DGI } \\
\mathrm{AGD} / \mathrm{MEF}\end{array}$ & $\begin{array}{l}\text { A text is signed and } \\
\text { circulated for } \\
\text { implementation of the } \\
\text { new budget } \\
\text { nomenclature for re } \\
\text { venue. }\end{array}$ & $\begin{array}{cc}\text { Q1 } \\
2008\end{array}$ & Medium & \\
\hline $\begin{array}{l}\text { A.14. Plan the development of a medium-term expenditure framework } \\
\text { (MTEF). }\end{array}$ & $\begin{array}{l}\text { MPCE/DGB/MEF } \\
\text { SPENDING } \\
\text { INSTITUTIONS }\end{array}$ & $\begin{array}{l}\text { A plan for phased } \\
\text { introduction in the } \\
\text { priority sectors is } \\
\text { established. }\end{array}$ & $\begin{array}{l}\text { Starting } \\
2008 / 2009\end{array}$ & High & \\
\hline B. BUDGET EXECUTION & & & & & \\
\hline
\end{tabular}


NATIONAL STRATEGY DOCUMENT FOR GROWTH AND POVERTY REDUCTION (DSNCRP/HATT) ACTION PLANS TO REFORMTHE PUBLIC FINANCIAL MANAGEMENT SYSTEM

\begin{tabular}{|c|c|c|c|c|c|}
\hline MEASURES TO BE TAKEN & $\begin{array}{l}\text { EXECUTING } \\
\text { AGENCIES }\end{array}$ & $\begin{array}{l}\text { PERFORMANCE } \\
\text { INDICATORS }\end{array}$ & $\begin{array}{l}\text { START } \\
\text { DATE }\end{array}$ & $\begin{array}{c}\text { NEED FOR } \\
\text { ASSISTANCE }\end{array}$ & $\begin{array}{c}\text { DONORS } \\
\text { CONCERNED }\end{array}$ \\
\hline $\begin{array}{l}\text { B.1. Continue the AGD reform process by (i) preparing staff regulations for } \\
\text { customs personnel, (ii) revising the Customs Code dating from 1987, (iii) } \\
\text { joining the WTO, (iv) setting qualifications for customs personnel, (v) } \\
\text { putting in place a new customs clearance procedure to facilitate the } \\
\text { processing of cases by the AGD in } 48 \text { hours maximum and (vi) } \\
\text { establishing an information and dispute settlement mechanism. Awaiting } \\
\text { feedback from the AGD }\end{array}$ & AGD & $\begin{array}{l}\text { The new AGD reform } \\
\text { is finalized and } \\
\text { implemented. It meets } \\
\text { all the criteria } \\
\text { described in the } \\
\text { corresponding section } \\
\text { of the "Measures to be } \\
\text { taken" column. }\end{array}$ & $\begin{array}{cc} & \text { Q4 } \\
2007\end{array}$ & High & \\
\hline B.2. Acquire and install the new version of ASYCUDA. & AGD & $\begin{array}{l}\text { The new version of } \\
\text { ASYCUDA is } \\
\text { installed. } \\
\text { The IT Unit has already } \\
\text { linked the three offices } \\
\text { of the AGD to the } \\
\text { metropolitan network } \\
\text { and is currently } \\
\text { working on the } \\
\text { installation of } \\
\text { ASYCUDA in some } \\
\text { regional offices. }\end{array}$ & $\begin{array}{cc}\text { - } & \mathrm{H} 2 \\
& 2008\end{array}$ & High & \\
\hline $\begin{array}{l}\text { B.3. Strengthen the control capacities of the AGD (Installation of } \\
\text { ASYCUDA, establishment of inspection brigades and fixed control } \\
\text { posts) in particular to raise the level of revenue in local and regional } \\
\text { customs offices. These offices need to be computerized. Awaiting } \\
\text { feedback from the AGD. }\end{array}$ & $\begin{array}{l}\text { AGD; DIF; } \\
\text { DGI/Direction de } \\
\text { Vérification } \\
\text { fiscale (Tax Audit } \\
\text { Directorate). }\end{array}$ & $\begin{array}{l}\text { The level of customs } \\
\text { revenue in the offices } \\
\text { in the interior of the } \\
\text { country increase from } \\
10 \% \text { of total customs } \\
\text { revenue to: } \\
-25 \% \text { at September } 30, \\
2008 \\
-40 \% \text { at September } 30, \\
2009 \\
-60 \% \text { at September } 30, \\
2010 \\
\text { Figures to be } \\
\text { reviewed... }\end{array}$ & $\begin{array}{cc}-\quad & \text { Q4 } \\
& 2007\end{array}$ & High & \\
\hline
\end{tabular}


NATIONAL STRATEGY DOCUMENT FOR GROWTH AND POVERTY REDUCTION (DSNCRP/HATT) ACTION PLANS TO REFORMTHE PUBLIC FINANCIAL MANAGEMENT SYSTEM

\begin{tabular}{|c|c|c|c|c|c|}
\hline MEASURES TO BE TAKEN & $\begin{array}{l}\text { EXECUTING } \\
\text { AGENCIES }\end{array}$ & $\begin{array}{l}\text { PERFORMANCE } \\
\text { INDICATORS }\end{array}$ & $\begin{array}{l}\text { START } \\
\text { DATE }\end{array}$ & $\begin{array}{c}\text { NEED FOR } \\
\text { ASSISTANCE }\end{array}$ & $\begin{array}{c}\text { DONORS } \\
\text { CONCERNED }\end{array}$ \\
\hline B.4. Detail in the public accounts disbursements for public interventions. & $\begin{array}{l}\text { Minister of } \\
\text { Finance, Prime } \\
\text { Minister, } \\
\text { President. }\end{array}$ & $\begin{array}{l}\text { Public interventions are } \\
\text { detailed in the public } \\
\text { accounts. }\end{array}$ & $\begin{array}{l}\text { December } \\
2007\end{array}$ & Low & \\
\hline $\begin{array}{l}\text { B.5. Update and circulate the legal and normative public investment } \\
\text { framework. }\end{array}$ & MPCE/MEF & $\begin{array}{l}\text { The legal framework is } \\
\text { updated and distributed } \\
\text { to the spending } \\
\text { institutions. }\end{array}$ & $\begin{array}{l}\text { H2 of } 2007- \\
2008 \text { fiscal } \\
\text { year. }\end{array}$ & Low & \\
\hline B.6. Prepare a public expenditure procedures manual. & $\begin{array}{l}\text { DGB/DT/MEF/ } \\
\text { MPCE }\end{array}$ & $\begin{array}{l}\text { A public expenditure } \\
\text { procedures manual is } \\
\text { developed and made } \\
\text { available to all those } \\
\text { involved in the } \\
\text { expenditure chain. }\end{array}$ & $\begin{array}{l}\text { September } \\
2008\end{array}$ & High & \\
\hline $\begin{array}{l}\text { B.7. Produce the budget review law (loi de règlement) for the previous budget } \\
\text { year }(2005 / 2006) \text { and prepare the draft budget review law on a regular } \\
\text { basis as prescribed in the decree of February } 16,2005 \text { on the preparation } \\
\text { and execution of budget laws. }\end{array}$ & $\begin{array}{l}\text { DGB/DT/ } \\
\text { CSC/CA/MPCE }\end{array}$ & $\begin{array}{l}\text { The budget review law } \\
\text { is submitted to } \\
\text { Parliament. }\end{array}$ & $\begin{array}{l}\text { Each month } \\
\text { of June and } \\
\text { starting from } \\
\text { June } 2008 \\
\end{array}$ & High & \\
\hline
\end{tabular}


NATIONAL STRATEGY DOCUMENT FOR GROWTH AND POVERTY REDUCTION (DSNCRP/HATTI) ACTION PLANS TO REFORMTHE PUBLIC FINANCIAL MANAGEMENT SYSTEM

\begin{tabular}{|c|c|c|c|c|c|}
\hline MEASURES TO BE TAKEN & $\begin{array}{l}\text { EXECUTING } \\
\text { AGENCIES }\end{array}$ & $\begin{array}{l}\text { PERFORMANCE } \\
\text { INDICATORS }\end{array}$ & $\begin{array}{l}\text { START } \\
\text { DATE }\end{array}$ & $\begin{array}{l}\text { NEED FOR } \\
\text { ASSISTANCE }\end{array}$ & $\begin{array}{l}\text { DONORS } \\
\text { CONCERNED }\end{array}$ \\
\hline $\begin{array}{l}\text { B.8. Gradually implement the principle of decentralized management, as } \\
\text { provided for by the Constitution, by appointing the ministers chief } \\
\text { authorizing officers for expenditure. }\end{array}$ & $\mathrm{DGB} / \mathrm{MEF} / \mathrm{UI}$ & $\begin{array}{l}\text { All spending ministries } \\
\text { and agencies are } \\
\text { currently connected to } \\
\text { the SYSDEP system } \\
\text { for the execution and } \\
\text { monitoring of their } \\
\text { respective budgets via } \\
\text { the metropolitan } \\
\text { network. } \\
\text { A project on } \\
\text { deconcentration of the } \\
\text { secure printing of } \\
\text { Treasury checks in the } \\
\text { Regional Directorates } \\
\text { will be prepared in Q2 } \\
\text { 2008. } \\
\text { Decrees appointing the } \\
\text { ministers have been } \\
\text { supplemented with the } \\
\text { mention of their } \\
\text { capacity as chief } \\
\text { authorizing officers for } \\
\text { their ministry's budget. }\end{array}$ & $\begin{array}{cc}\text { H1 } \\
2008\end{array}$ & Low & \\
\hline $\begin{array}{l}\text { B.9. Make quarterly appropriations or commitment caps available in a timely } \\
\text { manner, on the basis of the budget, commitments made and cash flow } \\
\text { plans. }\end{array}$ & DGB/MEF/DT & $\begin{array}{l}\text { The quarterly } \\
\text { appropriations status } \\
\text { reports are made } \\
\text { available to the public. }\end{array}$ & \begin{tabular}{|l|l} 
Starting \\
$2007 / 2008$
\end{tabular} & Low & \\
\hline B.10. Improve the reliability of the personnel database & $\begin{array}{l}\text { DGB and Office } \\
\text { of Human } \\
\text { Resources } \\
\text { Management } \\
(\text { OMRH)/DT/UI }\end{array}$ & $\begin{array}{l}\text { The personnel database } \\
\text { is up-to-date. }\end{array}$ & $\begin{array}{cc} & \mathrm{H} 1 \\
& 2008\end{array}$ & Low & \\
\hline $\begin{array}{l}\text { B.11. Complete the inventory of salary arrears and impose sanctions for } \\
\text { unauthorized recruitments. }\end{array}$ & DGB/DT/ & $\begin{array}{l}\text { The results of the } \\
\text { inventory and the } \\
\text { sanctions imposed are } \\
\text { published. }\end{array}$ & $\begin{array}{cc} & \mathrm{H} 1 \\
& 2008\end{array}$ & Low & \\
\hline
\end{tabular}


NATIONAL STRATEGY DOCUMENT FOR GROWTH AND POVERTY REDUCTION (DSNCRP/HATTI) ACTION PLANS TO REFORMTHE PUBLIC FINANCIAL MANAGEMENT SYSTEM

\begin{tabular}{|c|c|c|c|c|c|}
\hline MEASURES TO BE TAKEN & $\begin{array}{l}\text { EXECUTING } \\
\text { AGENCIES }\end{array}$ & $\begin{array}{l}\text { PERFORMANCE } \\
\text { INDICATORS }\end{array}$ & $\begin{array}{l}\text { START } \\
\text { DATE }\end{array}$ & $\begin{array}{c}\text { NEED FOR } \\
\text { ASSISTANCE }\end{array}$ & $\begin{array}{c}\text { DONORS } \\
\text { CONCERNED }\end{array}$ \\
\hline $\begin{array}{l}\text { B.12. Strengthen the capacity of the administration in charge of the Civil } \\
\text { Service to enable it to carry out its functions. }\end{array}$ & $\begin{array}{l}\text { DGB/DT and } \\
\text { Civil Service } \\
\text { Commission (to } \\
\text { be set up) }\end{array}$ & $\begin{array}{l}\text { A training plan is } \\
\text { available }\end{array}$ & \begin{tabular}{|c|c|}
- & $\mathrm{Q} 2$ \\
& 2008
\end{tabular} & Medium & \\
\hline $\begin{array}{l}\text { B.13. Use bank transfer as the preferred payment method in order to } \\
\text { strengthen payment security. }\end{array}$ & DT/MEF/OMRH & $\begin{array}{l}\text { A text is adopted to that } \\
\text { effect and circulated. }\end{array}$ & $\begin{array}{cc} & \mathrm{H} 2 \\
& 2008\end{array}$ & Low & \\
\hline $\begin{array}{l}\text { B.14. Manage the "own resources" of the SPENDING INSTITUTIONS } \\
\text { in the same way as other government revenue, that is, record them, } \\
\text { include them in the budget, and use them in conformity with government } \\
\text { accounting procedures. }\end{array}$ & $\begin{array}{l}\text { DT/SPENDING } \\
\text { INSTITUTIONS/ } \\
\text { DGB }\end{array}$ & $\begin{array}{l}\text { The 2007/2008 budget } \\
\text { law includes the } \\
\text { amount of all "own } \\
\text { resources". } \\
\text { A text requiring that } \\
\text { these sums be managed } \\
\text { in accordance with } \\
\text { government accounting } \\
\text { rules is adopted and } \\
\text { published. } \\
\end{array}$ & $\begin{array}{cc} & \mathrm{H} 2 \\
& 2008\end{array}$ & Low & \\
\hline $\begin{array}{l}\text { B.15. Establish and implement a new human resource management } \\
\text { framework including qualifications, skills assessment, and a capacity } \\
\text { building program. Develop a transparent, merit-based procedure for } \\
\text { recruitment and promotion. }\end{array}$ & DGB/OMRH & $\begin{array}{l}\text { A text detailing the new } \\
\text { mode of human } \\
\text { resource management } \\
\text { is adopted and } \\
\text { published. } \\
\end{array}$ & $\begin{array}{cc} & \mathrm{H} 2 \\
2008\end{array}$ & High & \\
\hline $\begin{array}{l}\text { B.16. Build the capacity of the DGB and the MPCE to strengthen the } \\
\text { performance of their role of controller, particularly regarding the } \\
\text { preparation of FIOPs and for physical, technical and financial } \\
\text { inspections. }\end{array}$ & DGB/MPCE/DT & $\begin{array}{l}\text { Investment expenditure } \\
\text { is carried out in } \\
\text { conformity with the } \\
\text { same procedures as } \\
\text { operating expenditure. } \\
\text { A staff training plan for } \\
\text { the DGB and MPCE is } \\
\text { approved. }\end{array}$ & $\begin{array}{cc}-\mathrm{H} 1 \\
\quad 2008\end{array}$ & High & \\
\hline
\end{tabular}


NATIONAL STRATEGY DOCUMENT FOR GROWTH AND POVERTY REDUCTION (DSNCRP/HATTI) ACTION PLANS TO REFORMTHE PUBLIC FINANCIAL MANAGEMENT SYSTEM

\begin{tabular}{|c|c|c|c|c|c|}
\hline MEASURES TO BE TAKEN & $\begin{array}{l}\text { EXECUTING } \\
\text { AGENCIES }\end{array}$ & $\begin{array}{l}\text { PERFORMANCE } \\
\text { INDICATORS }\end{array}$ & $\begin{array}{l}\text { START } \\
\text { DATE }\end{array}$ & $\begin{array}{c}\text { NEED FOR } \\
\text { ASSISTANCE }\end{array}$ & $\begin{array}{c}\text { DONORS } \\
\text { CONCERNED }\end{array}$ \\
\hline $\begin{array}{l}\text { B.17. Devise and put in place an accounting and financial framework for } \\
\text { investment projects financed through external resources. The framework } \\
\text { will, in particular, include: (i) a detailed budget classification, (ii) a } \\
\text { connection to SYSDEP, (iii) a specific charter for project accountants } \\
\text { required to report to MEF, (iv) the obligation to open all project accounts } \\
\text { with the BRH and (v) the organization of information gathering for on- } \\
\text { site inspections. }\end{array}$ & MPCE, DGB, DT & $\begin{array}{l}\text { An accounting and } \\
\text { financial framework for } \\
\text { externally-financed } \\
\text { projects is designed and } \\
\text { implemented, } \\
\text { consistent with the } \\
\text { points listed in the in } \\
\text { the corresponding } \\
\text { section of the } \\
\text { "Measures to be taken" } \\
\text { column. } \\
\end{array}$ & $\begin{array}{cc}\text { - } & \mathrm{H} 1 \\
& 2008\end{array}$ & High & \\
\hline \multicolumn{6}{|l|}{ C. GOVERNMENT ACCOUNTING AND FINANCIAL REPORTING } \\
\hline $\begin{array}{l}\text { C.1. Produce the General Government Accounts and the aggregate balance of } \\
\text { accounts as provided for in the PCGE and attach all relevant information } \\
\text { required by law before submitting the end-year treasury account (compte } \\
\text { de gestion) to the CSCCA. Produce the quarterly reports within four } \\
\text { weeks after the period concerned. }\end{array}$ & DGB/DT/MEF & $\begin{array}{l}\text { The general } \\
\text { government accounts } \\
\text { and the aggregate } \\
\text { balance of accounts as } \\
\text { well as their annexes } \\
\text { are produced. } \\
\text { The quarterly reports } \\
\text { are produced within } \\
\text { four weeks. }\end{array}$ & \begin{tabular}{|l|} 
Starting \\
$2006 / 2007$
\end{tabular} & High & \\
\hline $\begin{array}{l}\text { C.2. Improve the presentation of public debt in the annual financial statements } \\
\text { by including debt service obligations and the outstanding debt balance. }\end{array}$ & $\mathrm{DD}, \mathrm{DT} / \mathrm{MEF}$ & $\begin{array}{l}\text { Debt service } \\
\text { obligations and the } \\
\text { outstanding debt } \\
\text { balance are included in } \\
\text { the annual financial } \\
\text { statements. } \\
\end{array}$ & March 2008 & High & \\
\hline $\begin{array}{l}\text { C.3. Integrate the current accounts into the double-entry accounting system } \\
\text { and produce monthly bank reconciliations. }\end{array}$ & DT/MEF & $\begin{array}{l}\text { The current accounts } \\
\text { are integrated into the } \\
\text { double-entry } \\
\text { accounting system and } \\
\text { bank reconciliations are } \\
\text { produced monthly. }\end{array}$ & H1 2008 & High & \\
\hline
\end{tabular}


NATIONAL STRATEGY DOCUMENT FOR GROWTH AND POVERTY REDUCTION (DSNCRP/HATTI) ACTION PLANS TO REFORMTHE PUBLIC FINANCIAL MANAGEMENT SYSTEM

\begin{tabular}{|c|c|c|c|c|c|}
\hline MEASURES TO BE TAKEN & $\begin{array}{l}\text { EXECUTING } \\
\text { AGENCIES }\end{array}$ & $\begin{array}{l}\text { PERFORMANCE } \\
\text { INDICATORS }\end{array}$ & $\begin{array}{l}\text { START } \\
\text { DATE }\end{array}$ & $\begin{array}{l}\text { NEED FOR } \\
\text { ASSISTANCE }\end{array}$ & $\begin{array}{l}\text { DONORS } \\
\text { CONCERNED }\end{array}$ \\
\hline $\begin{array}{l}\text { C.4. Complete the deployment of government accountants to the SPENDING } \\
\text { INSTITUTIONS. }\end{array}$ & DT/MEF & $\begin{array}{l}\text { All SPENDING } \\
\text { INSTITUTIONS have } \\
\text { a government } \\
\text { accountant }\end{array}$ & $\begin{array}{cc}\mathrm{H} 2 \\
2008\end{array}$ & Medium & \\
\hline $\begin{array}{l}\text { C.5. Reorganize the DT into a Directorate-General of the Treasury for the } \\
\text { effective exercise of its attributions. }\end{array}$ & DT/MEF & $\begin{array}{l}\text { The Directorate- } \\
\text { General of the Treasury } \\
\text { is created. }\end{array}$ & $\begin{array}{cc}\mathrm{H} 2 \\
2008\end{array}$ & Low & \\
\hline $\begin{array}{l}\text { C.6. Conduct a review of IPSAS to determine the appropriate areas for the } \\
\text { adoption of international standards and propose the revision of existing } \\
\text { rules. Awaiting feedback. }\end{array}$ & DT/MEF & $\begin{array}{l}\text { A review of IPSAS is } \\
\text { conducted. }\end{array}$ & $2009-2010$ & High & \\
\hline $\begin{array}{l}\text { C.7. In coordination with the government accountants already deployed in the } \\
\text { SPENDING INSTITUTIONS, annex the details of current account } \\
\text { expenditure to the annual financial statements. }\end{array}$ & $\begin{array}{l}\text { DGB/DT/MEF + } \\
\text { SPENDING } \\
\text { INSTITUTIONS/ } \\
\text { UI }\end{array}$ & \begin{tabular}{|l|} 
Details on the non- \\
requisition, current \\
account expenditure of \\
the seven ministries, \\
the Office of the PM, \\
and the Presidency are \\
attached to the annual \\
financial statements. \\
The IT unit has \\
developed a current \\
account expenditure \\
management module \\
currently being used by \\
the government \\
accountants. \\
\end{tabular} & March 2008 & Low & \\
\hline $\begin{array}{l}\text { C.8. Adopt a reliable accounting system for inventory and skilled personnel, } \\
\text { as well as a reliable procedures manual and management software } \\
\text { program. For that purpose, identify and train inventory accountants. } \\
\text { Centralize, information on government property, both real and personal, } \\
\text { at the DT. Conduct annual inventories and send the reports to MEF and } \\
\text { to the CSCCA. Awaiting feedback. }\end{array}$ & $\begin{array}{l}\text { DT/SPENDING } \\
\text { INSTITUTIONS }\end{array}$ & $\begin{array}{l}\text { An inventory } \\
\text { accounting system is } \\
\text { put in place and is } \\
\text { operational. } \\
\text { Information is } \\
\text { centralized at the DT } \\
\text { and an annual } \\
\text { inventory report is } \\
\text { submitted to MEF and } \\
\text { the CSCCA. }\end{array}$ & $\begin{array}{cc}\mathrm{H} 2 \\
2008\end{array}$ & High & \\
\hline
\end{tabular}


NATIONAL STRATEGY DOCUMENT FOR GROWTH AND POVERTY REDUCTION (DSNCRP/HATTI)

ACTION PLANS TO REFORMTHE PUBLIC FINANCIAL MANAGEMENT SYSTEM 
NATIONAL STRATEGY DOCUMENT FOR GROWTH AND POVERTY REDUCTION (DSNCRP/HATTI) ACTION PLANS TO REFORMTHE PUBLIC FINANCIAL MANAGEMENT SYSTEM

\begin{tabular}{|c|c|c|c|c|c|}
\hline D. DEBT AND CASH MANAGEMENT & & & & & \\
\hline $\begin{array}{l}\text { D.1. Prepare an inventory and monitor all government bank accounts, } \\
\text { including donor-financed projects, open with commercial banks in the } \\
\text { banking private system. } \\
\text { It would be preferable to appoint to the DT a government accountant } \\
\text { responsible for recording borrowing operations and ensuring that cash is } \\
\text { managed in compliance with the limits set by the Budget Law. }\end{array}$ & $\begin{array}{l}\text { MPCE/MEF/+ } \\
\text { SPENDING } \\
\text { INSTITUTIONS }\end{array}$ & $\begin{array}{l}\text { An inventory of all } \\
\text { government bank } \\
\text { accounts is drawn up. } \\
\text { The cash section, } \\
\text { Central Accounting } \\
\text { Unit, is elevated to the } \\
\text { rank of a Cash and } \\
\text { Debt Management } \\
\text { Unit. }\end{array}$ & Q1 2008 & Low & \\
\hline $\begin{array}{l}\text { D.2. Set up a cash planning and control committee, comprising } \\
\text { representatives of the DGI, the AGD (revenue forecast), DEE, DGB, and } \\
\text { DT (expenditure forecast) as well as of the BRH (liquidity position of the } \\
\text { accounts of the DT). This committee shall prepare cash-flow plans in } \\
\text { coordination with the SPENDING INSTITUTIONS and monitor their } \\
\text { implementation on a monthly or quarterly basis. }\end{array}$ & $\begin{array}{l}\text { DT/DGB/DGI+ } \\
\text { AGD/DEE/BRH+ } \\
\text { SPENDING } \\
\text { INSTITUTIONS }\end{array}$ & $\begin{array}{l}\text { A cash planning and } \\
\text { monitoring committee } \\
\text { is established. }\end{array}$ & $\begin{array}{|cc|}- & \mathrm{Q} 4 \\
& 2007\end{array}$ & Medium & \\
\hline $\begin{array}{l}\text { D.3. Appoint to the DT a government accountant responsible for debt } \\
\text { management and for establishing channels for information sharing } \\
\text { between himself and the director for debt. Monitor all debt flows } \\
\text { recorded in the government accounting books and records. }\end{array}$ & DT/DE/MEF & $\begin{array}{l}\text { A government } \\
\text { accountant responsible } \\
\text { for debt is appointed } \\
\text { and functioning. }\end{array}$ & $\begin{array}{|cc|}- & \mathrm{H} 2 \\
& 2008\end{array}$ & Low & \\
\hline E. INFORMATION SYSTEMS & & & - & & \\
\hline $\begin{array}{l}\text { E1. Design and implement a financial management master plan to serve as a } \\
\text { medium-term framework for organizing the improvements needed to the } \\
\text { financial management systems. This plan will prepare the institutions for } \\
\text { the necessary changes and establish the sequence of technical } \\
\text { improvements and the review of administrative and control procedures. It } \\
\text { will also coordinate the technical assistance and financial needs. }\end{array}$ & $\begin{array}{l}\text { DGB/DE/MPCE+ } \\
\text { DGI/AGD/DD+ } \\
\text { SPENDING } \\
\text { INSTITUTIONS }\end{array}$ & $\begin{array}{l}\text { A computerized } \\
\text { financial management } \\
\text { master plan is designed } \\
\text { and implemented. }\end{array}$ & \begin{tabular}{|cc}
$\cdot$ & $\mathrm{Q} 2$ \\
& 2008
\end{tabular} & High & \\
\hline $\begin{array}{l}\text { E.2. Reduce the exceptions that make it possible to avoid recording } \\
\text { expenditures in SYSDEP, such as the current accounts of the } \\
\text { SPENDING INSTITUTIONS. Authorize the execution of current } \\
\text { accounts expenditure through SYSDEP. }\end{array}$ & $\begin{array}{l}\text { DGB/SPENDING } \\
\text { INSTITUTIONS/ } \\
\text { DT }\end{array}$ & $\begin{array}{l}\text { All current account } \\
\text { expenditures are } \\
\text { recorded in SYSDEP. }\end{array}$ & $\begin{array}{cc}-\quad & \text { Q1 } \\
2008\end{array}$ & Low & \\
\hline
\end{tabular}


NATIONAL STRATEGY DOCUMENT FOR GROWTH AND POVERTY REDUCTION (DSNCRP/HATT) ACTION PLANS TO REFORMTHE PUBLIC FINANCIAL MANAGEMENT SYSTEM

\begin{tabular}{|l|l|l|l|l|}
\hline $\begin{array}{l}\text { E.3. Develop and put in place the other modules of SYSDEP, in particular the } \\
\text { accounting applications. }\end{array}$ & DT/MEF & $\begin{array}{l}\text { Accounting } \\
\text { applications are added } \\
\text { to SYSDEP. } \\
\text { Sysdep is strengthened } \\
\text { by the following } \\
\text { applications: } \\
\text { Accounting, Fixed } \\
\text { objective of the DT for 2007-2008) in the context of the PCGE - ongoing } \\
\text { and should strengthen SYSDEP } \\
\text { Fund Management }\end{array}$ & $\begin{array}{l}\text { H2 } \\
2008\end{array}$ \\
\hline $\begin{array}{l}\text { E.4. Finalize the installation of SYSDEP in the other SPENDING } \\
\text { INSTITUTIONS. }\end{array}$ & $\begin{array}{l}\text { DGB/DT/SPENDI } \\
\text { NG } \\
\text { INSTITUTIONS }\end{array}$ & $\begin{array}{l}\text { All SPENDING } \\
\text { INSTITUTIONS } \\
\text { equipped with } \\
\text { SYSDEP. }\end{array}$ & $\begin{array}{l}\text { H1 } \\
2008\end{array}$ \\
\hline $\begin{array}{l}\text { E.5. Extend SYSDEP to the regional level, with the possibility for checks to } \\
\text { be issued by the regional directorates of MEF. }\end{array}$ & $\begin{array}{l}\text { DGB.DT/UI- } \\
\text { MEF/UCDD/SPE } \\
\text { NDING } \\
\text { INSTITUTIONS }\end{array}$ & $\begin{array}{l}\text { All Regional } \\
\text { Directorates of } \\
\text { SPENDING } \\
\text { INSTITUTIONS have } \\
\text { access to SYSDEP and } \\
\text { can issue checks. }\end{array}$ \\
\hline
\end{tabular}


NATIONAL STRATEGY DOCUMENT FOR GROWTH AND POVERTY REDUCTION (DSNCRP/HATT) ACTION PLANS TO REFORMTHE PUBLIC FINANCIAL MANAGEMENT SYSTEM

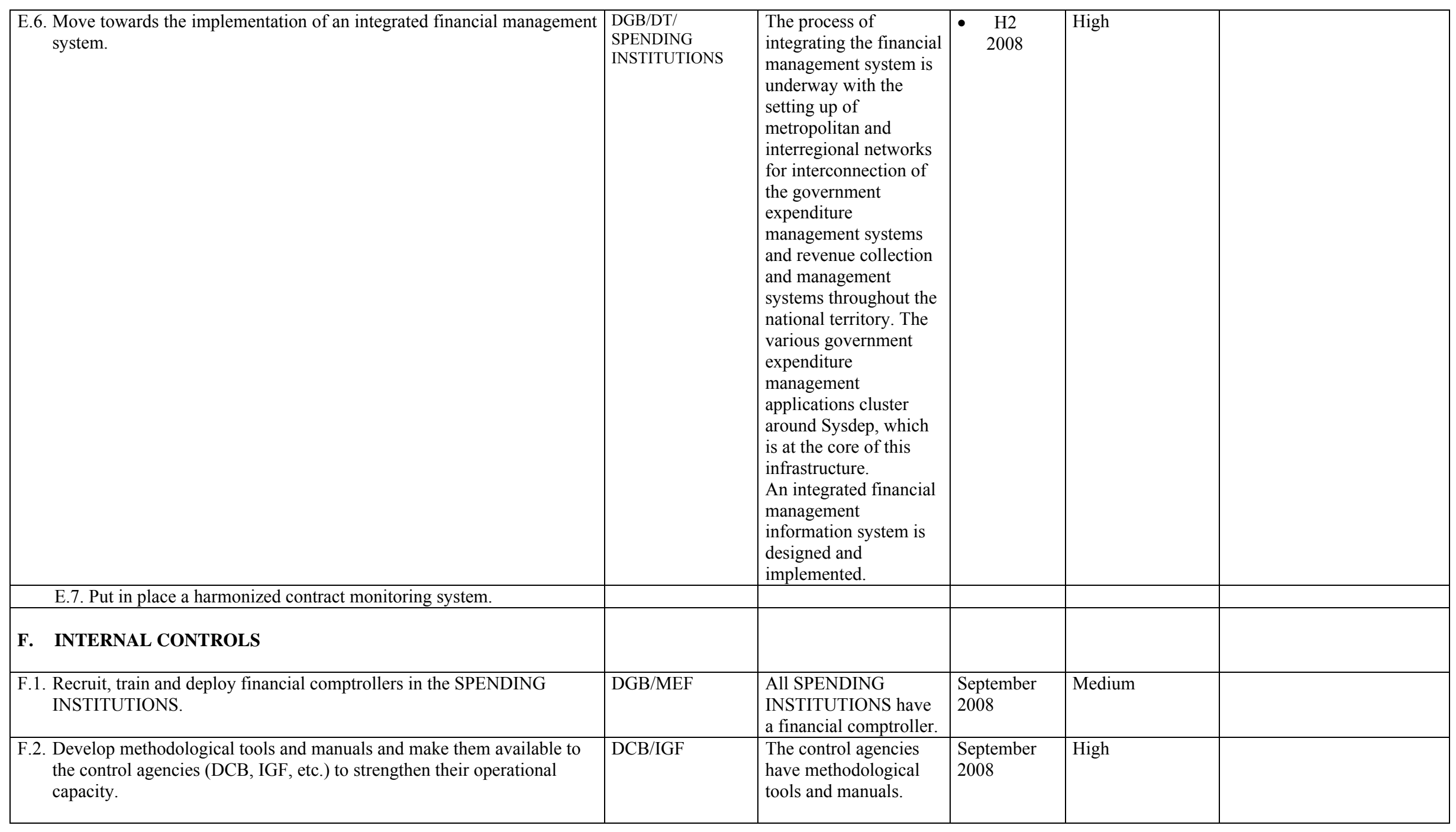


NATIONAL STRATEGY DOCUMENT FOR GROWTH AND POVERTY REDUCTION (DSNCRP/HATT) ACTION PLANS TO REFORMTHE PUBLIC FINANCIAL MANAGEMENT SYSTEM

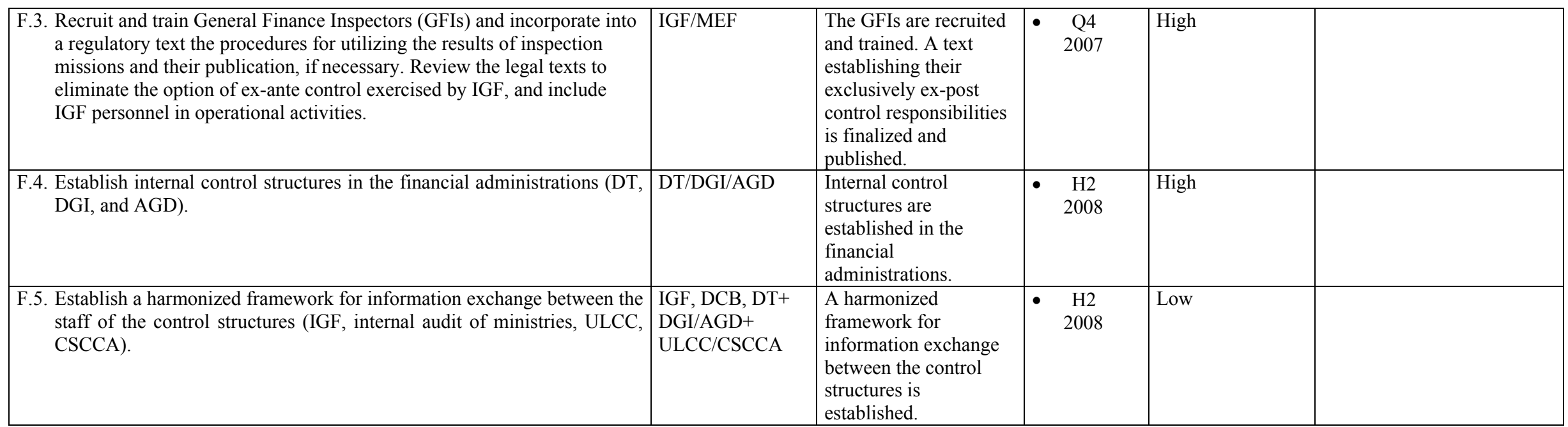


NATIONAL STRATEGY DOCUMENT FOR GROWTH AND POVERTY REDUCTION (DSNCRP/HATTI) ACTION PLANS TO REFORMTHE PUBLIC FINANCIAL MANAGEMENT SYSTEM

\section{G. EXTERNAL CONTROLS (JURISDICTIONAL CONTROL)}

G.1. Adopt a law on the attributions of the CSCCA

Use the draft law submitted to the Senate by the CSCCA to introduce changes. The main measures required are as follows:

- Assign the counselors of the CSCCA the same rank as Supreme Court (Cour de Cassation) judges in order to align their status with that of the highest administrative and financial jurisdiction of the Republic, in accordance with the rules established by the Constitution;

- Insist on the need for any democratic country desirous of entrenching good governance in public financial management to have an operational and effective administrative and financial jurisdiction; in particular by creating the Conseil d'Etat (Council of State) which will be the highest instance of said jurisdiction.

- Limit Senate control to overseeing the accounts of the CSCCA. The Senate can always have the benefit of technical assistance from the $\mathrm{CSC} / \mathrm{CA}$ as provided for by the Constitution of 1987. This collaboration between the $\mathrm{CSC} / \mathrm{CA}$, the Parliament and the government can be exercised in several ways. The most common practice is through the preparation of reports on the controls effected. These reports are submitted to Parliament, MEF, the President of the Republic and the Prime Minister's Office.

- The CSC/CA is consulted on all draft contracts of works, goods procurement, agreements, subventions, grants, etc. with the exception of administrative contracts that the Court is competent to approve.

The regulatory texts governing the functioning of the Chambers, the rules of procedure, the status of the judges and other officers of the court, and the internal rules of the CSCCA, including its organizational chart, should be prepared and approved as soon as possible.

Analyze the texts governing the $\mathrm{CSC} / \mathrm{CA}$, the organization and functioning of the structures of the Court, their relevance, their efficacy, and their practical aspects and existing competencies.

CSCCA

CCA

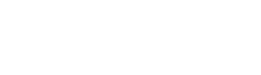

The new law on the

functioning of the

CSCCA is approved. It

takes into account the

points listed in the in

the corresponding

section of the

"Measures to be taken"

column.

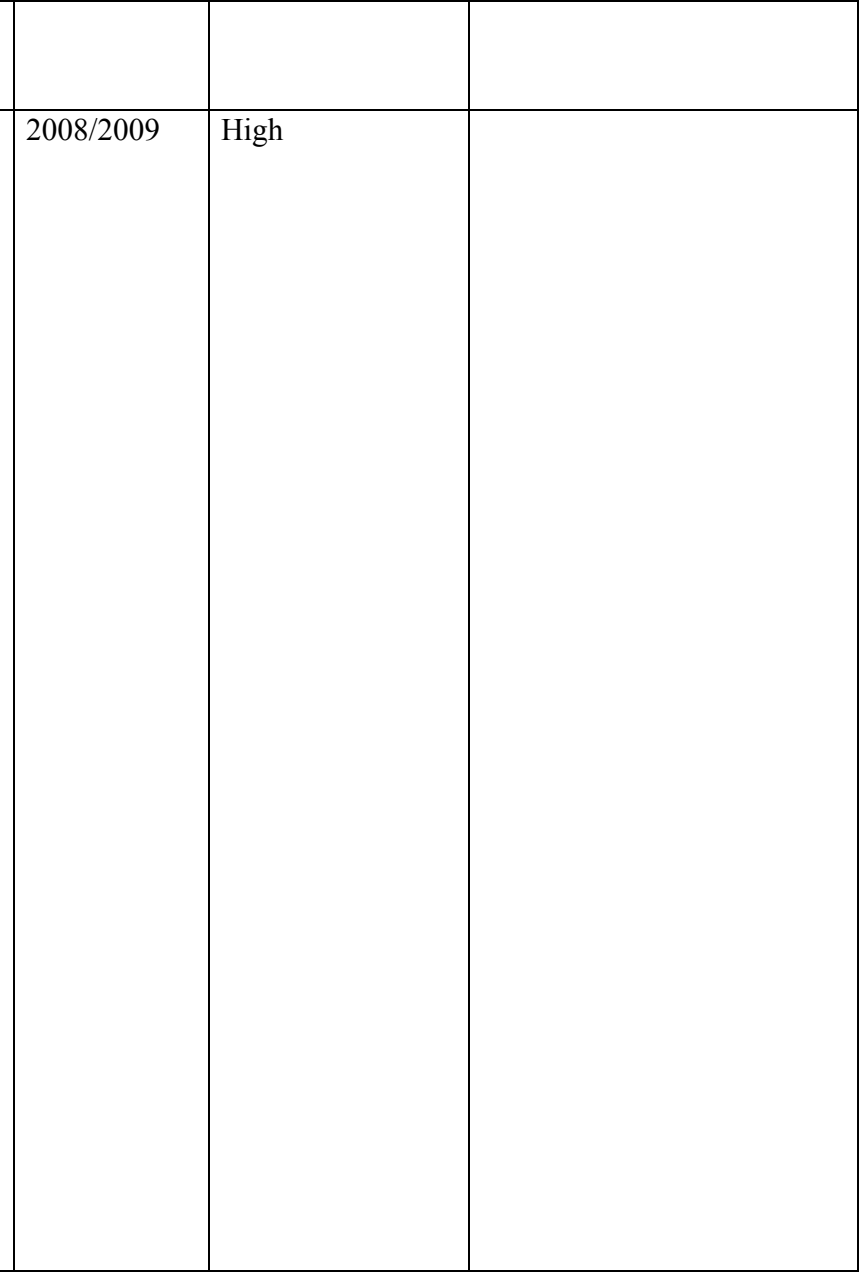


NATIONAL STRATEGY DOCUMENT FOR GROWTH AND POVERTY REDUCTION (DSNCRP/HATT) ACTION PLANS TO REFORMTHE PUBLIC FINANCIAL MANAGEMENT SYSTEM

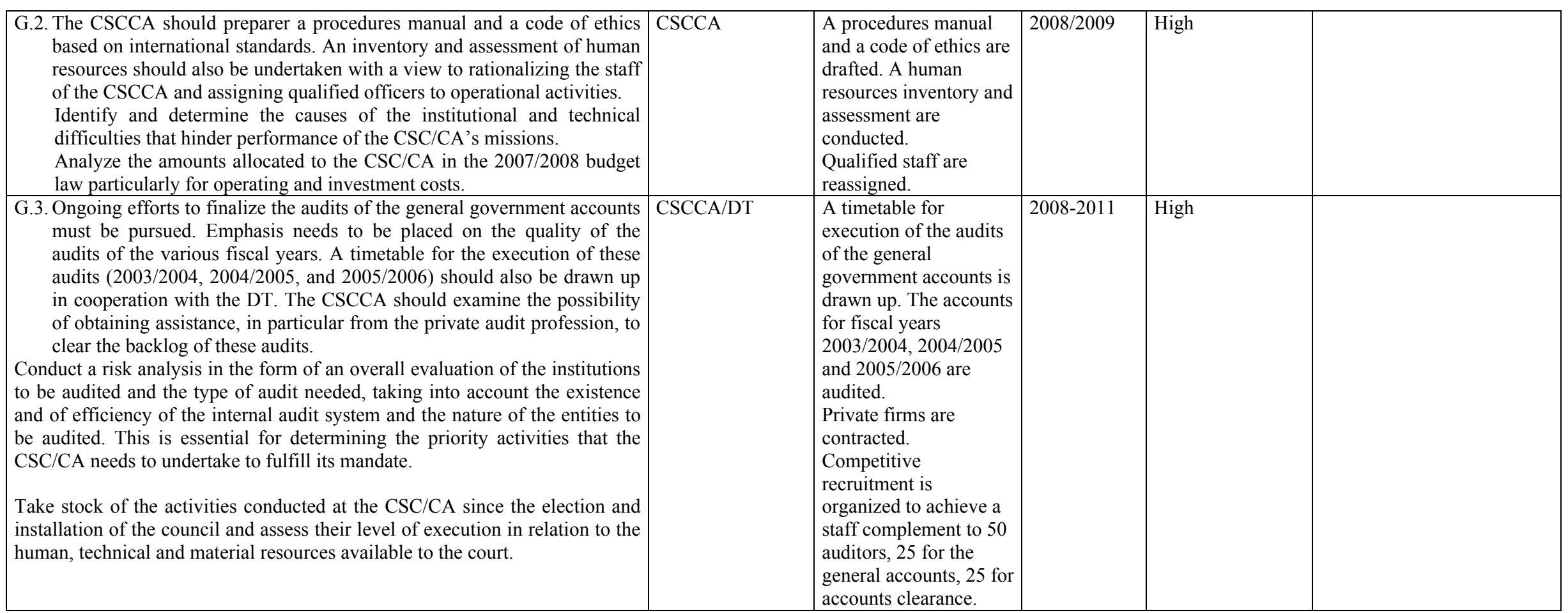


NATIONAL STRATEGY DOCUMENT FOR GROWTH AND POVERTY REDUCTION (DSNCRP/HATT) ACTION PLANS TO REFORMTHE PUBLIC FINANCIAL MANAGEMENT SYSTEM

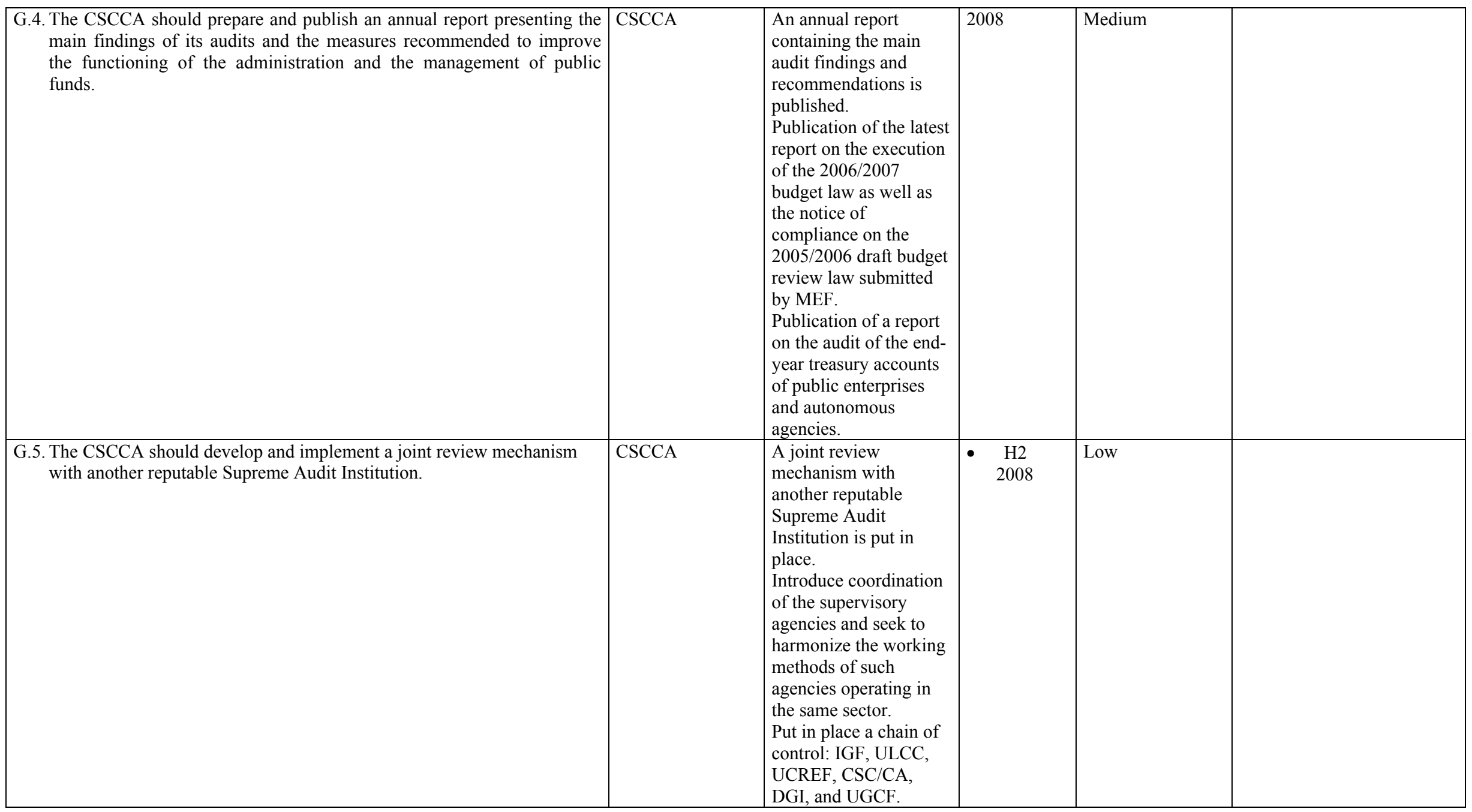


NATIONAL STRATEGY DOCUMENT FOR GROWTH AND POVERTY REDUCTION (DSNCRP/HATT) ACTION PLANS TO REFORMTHE PUBLIC FINANCIAL MANAGEMENT SYSTEM

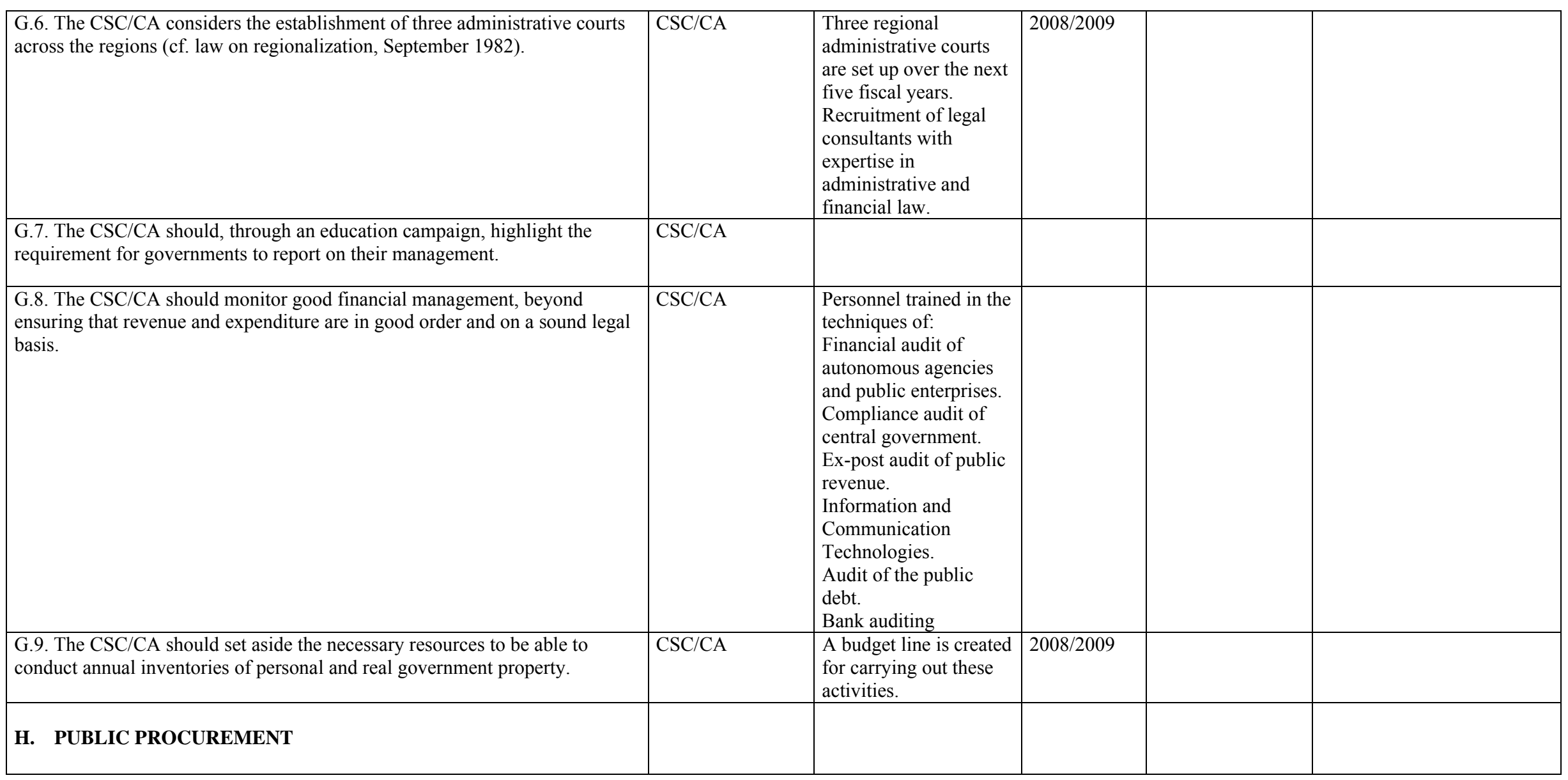


NATIONAL STRATEGY DOCUMENT FOR GROWTH AND POVERTY REDUCTION (DSNCRP/HATTI) ACTION PLANS TO REFORMTHE PUBLIC FINANCIAL MANAGEMENT SYSTEM

\begin{tabular}{|c|c|c|c|c|c|}
\hline $\begin{array}{l}\text { H.1. Make the new legal framework for public procurement effective: } \\
\text { - Validate the documents prepared in the context of the reform of the } \\
\text { procurement system, namely, the preliminary draft law on } \\
\text { procurement of April 2007, enabling texts of the law, and standard } \\
\text { tender documents } \\
\text { - Conduct an information campaign for MPs on the new legal } \\
\text { framework } \\
\text { - Submit the legal framework to Parliament } \\
\text { - Disseminate the legal framework and the Regulation }\end{array}$ & $\begin{array}{l}\text { CNMP/Executive } \\
\text { - Prime Minister's } \\
\text { Office/MEF/Parlia } \\
\text { ment }\end{array}$ & $\begin{array}{l}\text { Law voted in the } \\
\text { Parliament. } \\
\text { Publication and } \\
\text { application of the legal } \\
\text { framework. } \\
\text { Spending institutions } \\
\text { have new legal } \\
\text { instruments that they } \\
\text { are applying. }\end{array}$ & $2007-2008$ & Low & \\
\hline $\begin{array}{l}\text { H.2. Strengthen the capacity of all parties involved in public procurement: } \\
\text { - Intensify training in procurement to include all Ministerial } \\
\text { Commissions, Specialized Commissions and the Town Halls and } \\
\text { Regional Directorates involved in procurement. } \\
\text { - Adapt procurement training to include the private sector and civil } \\
\text { society }\end{array}$ & $\begin{array}{l}\text { CNMP/CEFOPAF } \\
\text { OP/ENAF }\end{array}$ & $\begin{array}{l}\text { Better presentation of } \\
\text { procurement files and } \\
\text { increased approval rate } \\
\text { of submissions. } \\
\text { Fewer complaints from } \\
\text { businesspeople. }\end{array}$ & 2007 & High & IDB? \\
\hline $\begin{array}{l}\text { H.3. Develop a public sector career structure in procurement to facilitate an } \\
\text { increase in the number of staff with qualifications in procurement } \\
\text { appropriate for their level of responsibility. }\end{array}$ & $\begin{array}{l}\text { Office of the } \\
\text { Prime Minister - } \\
\text { Human } \\
\text { Resources/CNMP }\end{array}$ & $\begin{array}{l}\text { Incorporation of } \\
\text { procurement expertise } \\
\text { at the spending } \\
\text { institutions. } \\
\end{array}$ & $2008-2009$ & High & \\
\hline $\begin{array}{l}\text { H.4. Integration of public procurement into the financial management } \\
\text { process in Haiti, mainly through the preparation and execution of } \\
\text { procurement plans linked to sectoral policies }\end{array}$ & $\begin{array}{l}\text { DGB/MPCE/MEF } \\
\text { /spending } \\
\text { institutions }\end{array}$ & $\begin{array}{l}\text { Procurement plans in } \\
\text { place in all spending } \\
\text { institutions. }\end{array}$ & $2007-2008$ & Medium & \\
\hline $\begin{array}{l}\text { H.5. Facilitate the process of control of public procurement: } \\
\text { - Strengthen the Technical Secretariat (ST) of the CNMP } \\
\text { - Deploy legal expertise at the CNMP } \\
\text { - Supplement the administrative staff of the CNMP } \\
\text { - Install a management accounting program } \\
\text { - Design, develop and install a computerized tool for monitoring the } \\
\text { - } \text { public procurement process } \\
\text { - } \text { Estabe the threshold requiring approval from the CNMP } \\
\text { Sud) }\end{array}$ & $\begin{array}{l}\text { CNMP/Executive } \\
\text { - Prime Minister's } \\
\text { Office }\end{array}$ & $\begin{array}{l}\text { CNMP becomes fully } \\
\text { functional. } \\
\text { CNMP operates in } \\
\text { conformity with the } \\
\text { standards governing } \\
\text { public institutions. } \\
\text { Simplification of } \\
\text { procedures for } \\
\text { acquisitions of average } \\
\text { size. }\end{array}$ & $2007-2008$ & Low & \\
\hline
\end{tabular}


NATIONAL STRATEGY DOCUMENT FOR GROWTH AND POVERTY REDUCTION (DSNCRP/HATTI) ACTION PLANS TO REFORMTHE PUBLIC FINANCIAL MANAGEMENT SYSTEM

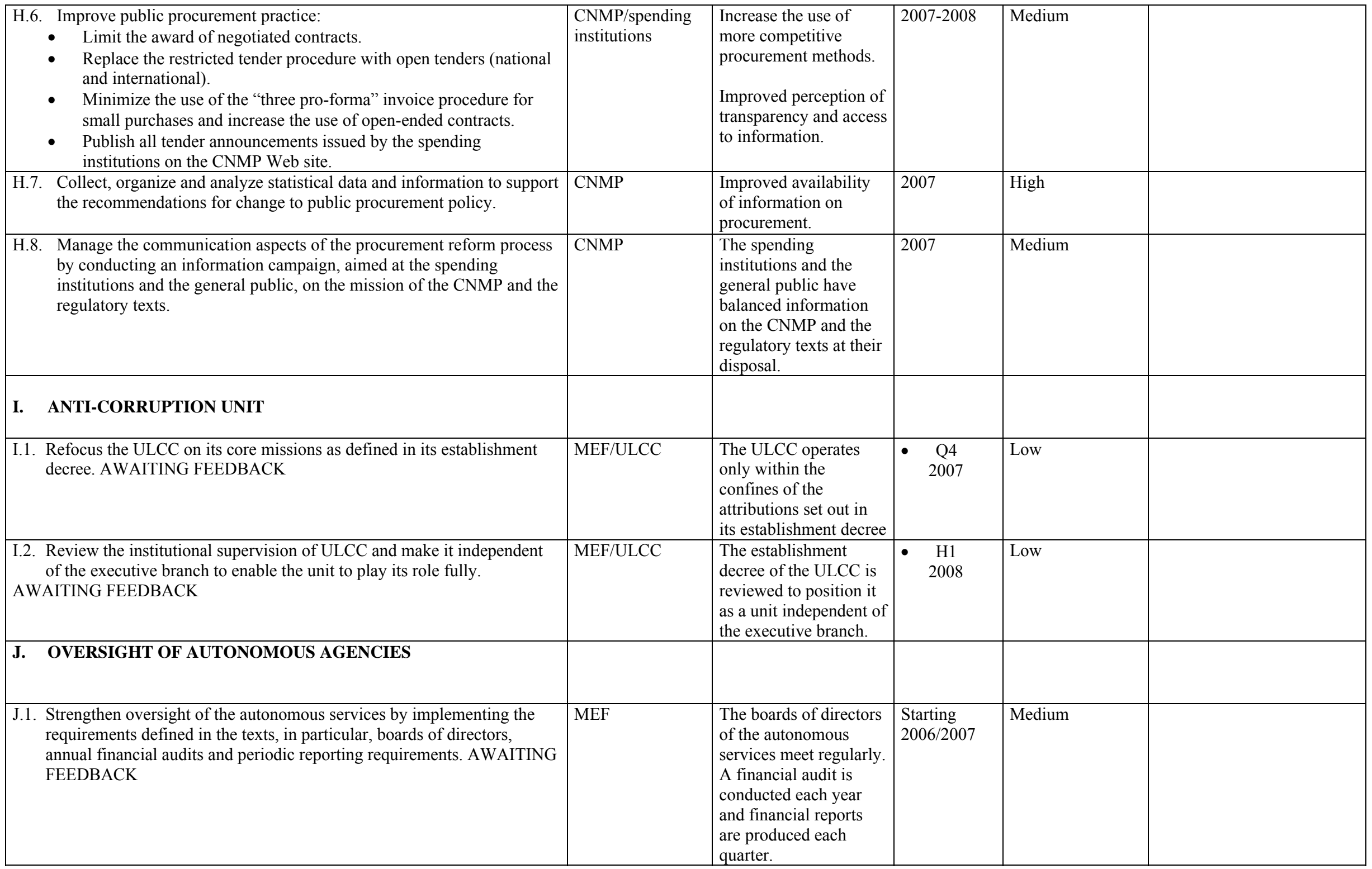


NATIONAL STRATEGY DOCUMENT FOR GROWTH AND POVERTY REDUCTION (DSNCRP/HATTI)

ACTION PLANS TO REFORMTHE PUBLIC FINANCIAL MANAGEMENT SYSTEM

\begin{tabular}{|l|l|l|l|l|}
\hline J.2. Strengthen the capacities of the commissions of the public enterprises. & MEF & $\begin{array}{l}\text { A training plan on } \\
\text { management } \\
\text { techniques is approved. }\end{array}$ & $\bullet \begin{array}{l}\text { H1 } \\
\text { AWAITING FEEDBACK }\end{array}$ &
\end{tabular}


NATIONAL STRATEGY DOCUMENT FOR GROWTH AND POVERTY REDUCTION (DSNCRP/HATTI)

ACTION PLANS TO REFORMTHE PUBLIC FINANCIAL MANAGEMENT SYSTEM

PEMFAR

INFRASTRUCTURE SECTOR

TRANSPORT SUB-SECTOR

\section{Priority Action Plan}

\begin{tabular}{|c|c|c|c|c|c|c|c|}
\hline Objective & Actions & $\begin{array}{l}\text { Fiscal } \\
\text { Years }\end{array}$ & $\begin{array}{c}\text { Available } \\
\text { Resources }\end{array}$ & $\begin{array}{l}\text { Input } \\
\text { Indicator }\end{array}$ & $\begin{array}{l}\text { Output } \\
\text { Indicator }\end{array}$ & $\begin{array}{l}\text { Performance } \\
\text { Indicator }\end{array}$ & $\begin{array}{c}\text { Implementing } \\
\text { Agency }\end{array}$ \\
\hline \multirow{3}{*}{$\begin{array}{l}\text { 1. Strengthen the } \\
\text { links between the } \\
\text { allocation of } \\
\text { resources and } \\
\text { government } \\
\text { priorities defined in } \\
\text { the DNSCRP and the } \\
\text { sectoral strategy }\end{array}$} & $\begin{array}{l}\text { Preparation of } \\
\text { the budget on } \\
\text { the basis of the } \\
\text { sectoral } \\
\text { strategy and } \\
\text { the DSNCRP }\end{array}$ & 2007-2008 & Public Treasury & $\begin{array}{l}\text { DSNCRP } \\
\text { and sectoral } \\
\text { strategy }\end{array}$ & $\begin{array}{l}\text { Quarterly } \\
\text { expenditure } \\
\text { framework } \\
\text { reflects the } \\
\text { strategic vision } \\
\text { of the transport } \\
\text { sub-sector } \\
\end{array}$ & $\begin{array}{l}\text { Budgets } \\
\text { prepared }\end{array}$ & MTPTC \\
\hline & $\begin{array}{l}\text { Strengthen the } \\
\text { capacity of the } \\
\text { MTPTC in } \\
\text { budget } \\
\text { preparation and } \\
\text { monitoring }\end{array}$ & 2007-2008 & Public Treasury & $\begin{array}{l}\text { Deployment } \\
\text { of an } \\
\text { additional } \\
\text { officer for } \\
\text { budget } \\
\text { preparation } \\
\text { and } \\
\text { monitoring }\end{array}$ & $\begin{array}{l}\text { Officer } \\
\text { recruited }\end{array}$ & $\begin{array}{l}\text { Timely } \\
\text { preparation of } \\
\text { the budgets of } \\
\text { the MTPTC and } \\
\text { annual } \\
\text { monitoring of } \\
\text { execution }\end{array}$ & MTPTC/MEF \\
\hline & $\begin{array}{l}\text { Link } \\
\text { investments to } \\
\text { maintenance } \\
\text { expenditure }\end{array}$ & 2008-2009 & Public Treasury & $\begin{array}{l}\text { Identification } \\
\text { of the } \\
\text { network to be } \\
\text { rehabilitated } \\
\text { and/or built + } \\
\text { minutes of } \\
\text { meetings }\end{array}$ & $\begin{array}{l}\text { Network } \\
\text { rehabilitated } \\
\text { and/or built + } \\
\text { FER has } \\
\text { sufficient } \\
\text { resources to } \\
\text { ensure } \\
\text { maintenance }\end{array}$ & $\begin{array}{c}\text { Network } \\
\text { rehabilitated } \\
\text { and/or built } \\
\text { maintained }\end{array}$ & MTPTC/FER \\
\hline
\end{tabular}


NATIONAL STRATEGY DOCUMENT FOR GROWTH AND POVERTY REDUCTION (DSNCRP/HATTI) ACTION PLANS TO REFORMTHE PUBLIC FINANCIAL MANAGEMENT SYSTEM

Priority Action Plan

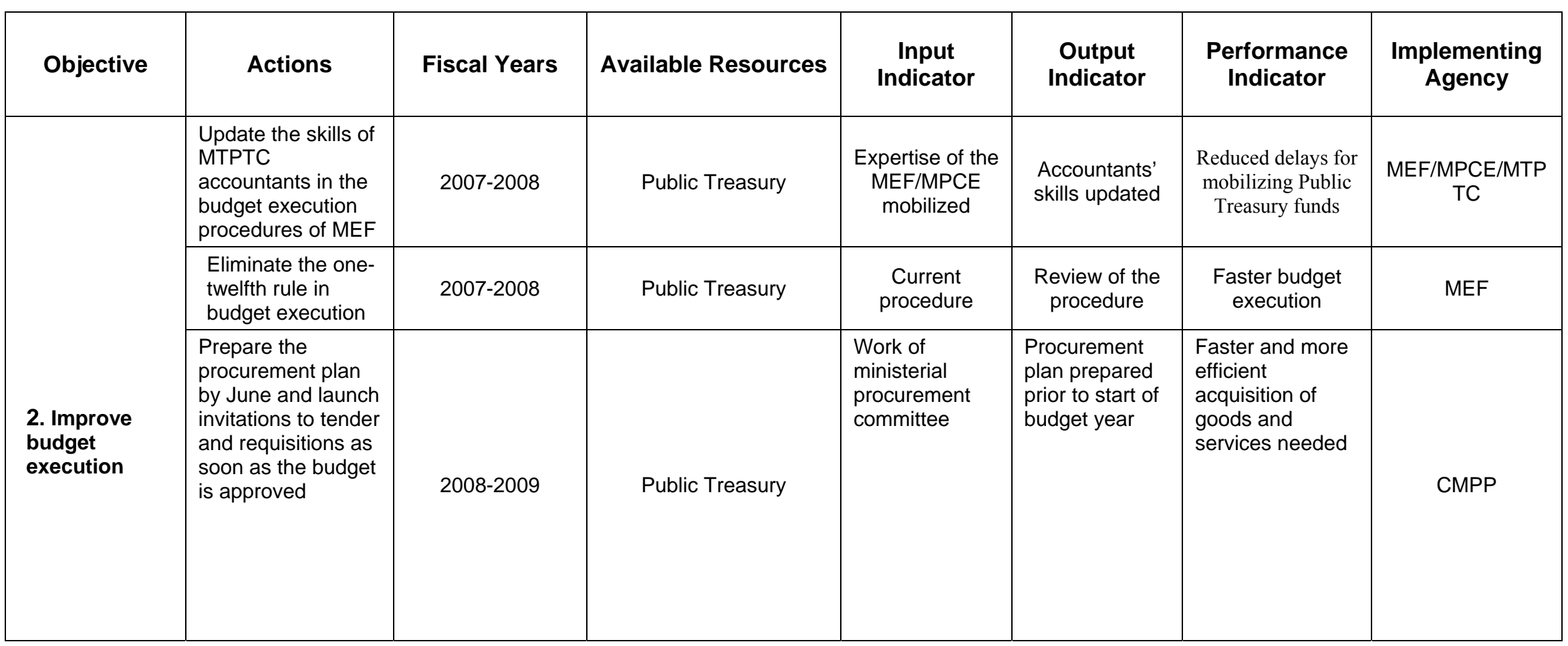


NATIONAL STRATEGY DOCUMENT FOR GROWTH AND POVERTY REDUCTION (DSNCRP/HATT) ACTION PLANS TO REFORMTHE PUBLIC FINANCIAL MANAGEMENT SYSTEM

Priority Action Plan

\begin{tabular}{|l|l|c|c|c|c|c|}
\hline Objective & Actions & Fiscal Years & $\begin{array}{c}\text { Available } \\
\text { Resources }\end{array}$ & $\begin{array}{c}\text { Input } \\
\text { Indicator }\end{array}$ & $\begin{array}{c}\text { Output } \\
\text { Indicator }\end{array}$ & $\begin{array}{c}\text { Performance } \\
\text { Indicator }\end{array}$ \\
\hline & $\begin{array}{l}\text { Close the } \\
\text { current } \\
\text { accounts }\end{array}$ & $2009-2010$ & Public Treasury & $\begin{array}{c}\text { Identification } \\
\text { of projects, } \\
\text { Letter from } \\
\text { the Minister }\end{array}$ & $\begin{array}{c}\text { Accounts } \\
\text { closed }\end{array}$ & $\begin{array}{c}\text { One single } \\
\text { project account } \\
\text { exists with sub- } \\
\text { accounts }\end{array}$ \\
\hline
\end{tabular}


NATIONAL STRATEGY DOCUMENT FOR GROWTH AND POVERTY REDUCTION (DSNCRP/HATTI)

ACTION PLANS TO REFORMTHE PUBLIC FINANCIAL MANAGEMENT SYSTEM

Priority Action Plan

\begin{tabular}{|c|c|c|c|c|c|c|c|}
\hline Objective & Actions & $\begin{array}{l}\text { Fiscal } \\
\text { Years }\end{array}$ & $\begin{array}{c}\text { Available } \\
\text { Resources }\end{array}$ & Input Indicator & $\begin{array}{l}\text { Output } \\
\text { Indicator }\end{array}$ & $\begin{array}{l}\text { Performance } \\
\text { Indicator }\end{array}$ & Implementing Agency \\
\hline $\begin{array}{l}\text { 4. Gradually } \\
\text { integrate } \\
\text { externally- } \\
\text { funded } \\
\text { expenditure } \\
\text { into the } \\
\text { sectoral } \\
\text { budget }\end{array}$ & $\begin{array}{l}\text { Involve principal } \\
\text { donors in the } \\
\text { budget preparation } \\
\text { process }\end{array}$ & 2008-2009 & Public Treasury & $\begin{array}{l}\text { Technical coordinating } \\
\text { meetings held during the } \\
\text { budget preparation } \\
\text { process }\end{array}$ & $\begin{array}{l}\text { Reports of working } \\
\text { meetings }\end{array}$ & $\begin{array}{l}\text { External investment } \\
\text { expenditure } \\
\text { correctly budgeted }\end{array}$ & MPCE/MTPTC \\
\hline
\end{tabular}


NATIONAL STRATEGY DOCUMENT FOR GROWTH AND POVERTY REDUCTION (DSNCRP/HATT) ACTION PLANS TO REFORMTHE PUBLIC FINANCIAL MANAGEMENT SYSTEM

Priority Action Plan

\begin{tabular}{|c|c|c|c|c|c|c|c|}
\hline Objective & Actions & Fiscal Years & $\begin{array}{c}\text { Available } \\
\text { Resources }\end{array}$ & Input Indicator & $\begin{array}{l}\text { Output } \\
\text { Indicator }\end{array}$ & $\begin{array}{l}\text { Performance } \\
\text { Indicator }\end{array}$ & $\begin{array}{c}\text { Implementing } \\
\text { Agency }\end{array}$ \\
\hline \multirow{3}{*}{$\begin{array}{l}\text { 5. Evaluate the } \\
\text { impact of the } \\
\text { budgetary } \\
\text { spending and } \\
\text { monitor } \\
\text { budget } \\
\text { outcomes }\end{array}$} & $\begin{array}{l}\text { Strengthen the } \\
\text { competencies of } \\
\text { the MTPTC }\end{array}$ & 2008-2009 & $\begin{array}{l}\text { Public } \\
\text { Treasury/IDB }\end{array}$ & $\begin{array}{l}\text { Appointment of } \\
\text { an officer to the } \\
\text { UTPP }\end{array}$ & $\begin{array}{l}\text { Progress } \\
\text { reports from } \\
\text { the officer } \\
\text { appointed }\end{array}$ & $\begin{array}{l}\text { Better knowledge } \\
\text { of the link between } \\
\text { sectoral investment } \\
\text { and poverty } \\
\text { reduction }\end{array}$ & MTPTC \\
\hline & $\begin{array}{l}\text { Train HR MTPTC } \\
\text { in performing } \\
\text { impact studies and } \\
\text { strategic planning }\end{array}$ & 2008-2009 & DEFI-IDB & $\begin{array}{c}\text { Conduct of support } \\
\text { missions by } \\
\text { international and } \\
\text { national } \\
\text { consultants and } \\
\text { training sessions }\end{array}$ & $\begin{array}{l}\text { Reports on } \\
\text { missions and } \\
\text { training sessions }\end{array}$ & $\begin{array}{l}\text { Less recourse to } \\
\text { external expertise } \\
\text { for impact } \\
\text { assessment }\end{array}$ & MTPTC \\
\hline & $\begin{array}{l}\text { Specific impact } \\
\text { studies to be } \\
\text { conducted }\end{array}$ & 2008-2009 & DEFI-IDB & $\begin{array}{l}\text { Conduct of support } \\
\text { missions by } \\
\text { international and } \\
\text { national } \\
\text { consultants }\end{array}$ & $\begin{array}{l}\text { Report on } \\
\text { specific impact } \\
\text { studies }\end{array}$ & $\begin{array}{l}\text { Better knowledge } \\
\text { of the link between } \\
\text { sectoral investment } \\
\text { and poverty } \\
\text { reduction }\end{array}$ & MTPTC \\
\hline
\end{tabular}


NATIONAL STRATEGY DOCUMENT FOR GROWTH AND POVERTY REDUCTION (DSNCRP/HATTI) ACTION PLANS TO REFORMTHE PUBLIC FINANCIAL MANAGEMENT SYSTEM

PRIORITY ACTION PLAN - DRINKING WATER SECTOR AND REHABILITATION OF THE AUTOMONOMOUS METROPOLITAN DRINKING WATER PLANT (CAMEP)

\begin{tabular}{|c|c|c|c|c|c|c|c|}
\hline Objectives & Actions & Fiscal years & $\begin{array}{l}\text { Financial } \\
\text { resources }\end{array}$ & Input indicator & Output indicator & $\begin{array}{c}\text { Performance } \\
\text { indicator }\end{array}$ & $\begin{array}{c}\text { Implementing } \\
\text { agency }\end{array}$ \\
\hline \multirow[t]{3}{*}{$\begin{array}{l}\text { 1.- Strengthen the } \\
\text { linkages between the } \\
\text { allocation of resources } \\
\text { and the priorities of the } \\
\text { government as defined in } \\
\text { the DSNCRP and the } \\
\text { sectoral strategy }\end{array}$} & $\begin{array}{l}\text { A- Upgrading of the drinking } \\
\text { water supply in Pèlerin, Pétion- } \\
\text { Ville, Péguy-Ville, Frères and } \\
\text { Haut de Delmas }\end{array}$ & $\begin{array}{l}2007 / 2008 \\
2008 / 2009 \\
2009 / 2010\end{array}$ & $\begin{array}{l}\text { Not yet } \\
\text { available }\end{array}$ & $\begin{array}{l}\text { Construction of } \\
\text { reservoirs. } \\
\text { Drilling equipment } \\
\text { Installation of brand new } \\
\text { networks } \\
\begin{array}{l}\text { Construction of pumping } \\
\text { stations }\end{array}\end{array}$ & $\begin{array}{l}\text { Increase in production } \\
\text { Improvement in the } \\
\text { quality of the water } \\
\text { supply } \\
\text { Distribution by tiers }\end{array}$ & $\begin{array}{l}\text { Number of } \\
\text { complaints about the } \\
\text { quality of water } \\
\text { flowing from the } \\
\text { faucets } \\
\text { Increase in the } \\
\text { number of paying } \\
\text { customers }\end{array}$ & CAMEP \\
\hline & $\begin{array}{l}\text { B- Upgrading of the drinking } \\
\text { water network and } \\
\text { rehabilitation of "Bas de la } \\
\text { Ville" including Mariani, Mon } \\
\text { Repos, Mahotière, Waney, } \\
\text { Bizoton, Diquini, Fontamara, } \\
\text { Martissant, Bolosse and the } \\
\text { neighborhoods surrounding } \\
\text { Blvd. J. J. Dessalines }\end{array}$ & $\begin{array}{l}2008 / 2009 \\
2009 / 2010 \\
2010 / 2011 \\
2011 / 2012\end{array}$ & $\begin{array}{l}\text { Not yet } \\
\text { available }\end{array}$ & $\begin{array}{l}\text { Drilling and drilling } \\
\text { equipment } \\
\begin{array}{l}\text { Laying of new water } \\
\text { mains }\end{array} \\
\begin{array}{l}\text { Establishment of a } \\
\text { regulation system }\end{array}\end{array}$ & $\begin{array}{l}\text { Increase in production } \\
\text { Establishment of } \\
\text { community standpipes } \\
\text { where users can } \\
\text { purchase water } \\
\text { Increased protection } \\
\text { against fires }\end{array}$ & $\begin{array}{l}\text { Network yield and } \\
\text { coverage } \\
\text { Increase in the } \\
\text { population with } \\
\text { access to water } \\
\text { Growth in revenue }\end{array}$ & CAMEP \\
\hline & $\begin{array}{l}\text { C- Rehabilitation of the } \\
\text { Downtown network, including } \\
\text { the major arteries, such as } \\
\text { Lalue, Canapé Vert, Turgeau, } \\
\text { Bois Patate, Armand Holly, and } \\
\text { Blvd. Harry Truman }\end{array}$ & $\begin{array}{l}2010 / 2011 \\
2011 / 2012 \\
2012 / 2013 \\
2013 / 2014 \\
2014 / 2015\end{array}$ & $\begin{array}{l}\text { Not yet } \\
\text { available }\end{array}$ & $\begin{array}{l}\text { Drilling in Gressier. } \\
\text { Creation of new } \\
\text { backflow centers } \\
\text { Strengthening and } \\
\text { development of the } \\
\text { supply network. }\end{array}$ & $\begin{array}{l}\text { Increased production } \\
\text { Creation of standpipes } \\
\text { where users can } \\
\text { purchase water }\end{array}$ & $\begin{array}{l}\text { Increase in the } \\
\text { population with } \\
\text { access to water } \\
\text { Growth in revenue }\end{array}$ & CAMEP \\
\hline
\end{tabular}


NATIONAL STRATEGY DOCUMENT FOR GROWTH AND POVERTY REDUCTION (DSNCRP/HATTI)

ACTION PLANS TO REFORMTHE PUBLIC FINANCIAL MANAGEMENT SYSTEM

AUTONOMOUS METROPOLITAN DRINKING WATER PLANT (CAMEP)

\begin{tabular}{|c|c|c|c|c|c|c|c|}
\hline Objectives & Actions & Fiscal years & $\begin{array}{l}\text { Financial } \\
\text { resources }\end{array}$ & Input indicator & Output indicator & $\begin{array}{l}\text { Performance } \\
\text { indicator }\end{array}$ & $\begin{array}{c}\text { Implementing } \\
\text { agency }\end{array}$ \\
\hline \multirow[t]{2}{*}{$\begin{array}{l}\text { 2.- Improve budget } \\
\text { execution }\end{array}$} & $\begin{array}{l}\text { A- Prepare along with he } \\
\text { budget a procurement plan } \\
\text { for construction supplies, } \\
\text { fuel, material, and } \\
\text { equipment }\end{array}$ & $\begin{array}{l}2007 / 2008 \\
\text { and onward }\end{array}$ & CAMEP & $\begin{array}{l}\text { The work of the } \\
\text { Specialized Commission }\end{array}$ & $\begin{array}{l}\text { Plan prepared ahead of } \\
\text { the fiscal year }\end{array}$ & $\begin{array}{l}\text { Quicker and more } \\
\text { efficient purchase of } \\
\text { approved goods and } \\
\text { services }\end{array}$ & CAMEP \\
\hline & $\begin{array}{l}\text { B.- Reduce the number of } \\
\text { contractors by transferring } \\
\text { management to certain } \\
\text { professional companies }\end{array}$ & $\begin{array}{l}2007 / 2008 \text { and } \\
\text { onward }\end{array}$ & CAMEP & $\begin{array}{l}\text { Sourcing and selection of } \\
\text { the companies }\end{array}$ & $\begin{array}{l}\text { Signing of service } \\
\text { contracts }\end{array}$ & $\begin{array}{l}\text { More streamlined } \\
\text { management of the } \\
\text { stakeholders }\end{array}$ & $\begin{array}{l}\text { CAMEP and } \\
\text { selected } \\
\text { companies }\end{array}$ \\
\hline
\end{tabular}




\section{NATIONAL STRATEGY DOCUMENT FOR GROWTH AND POVERTY REDUCTION (DSNCRP/HATTI)}

ACTION PLANS TO REFORMTHE PUBLIC FINANCIAL MANAGEMENT SYSTEM

PRIORITY ACTION PLAN- DRINKING WATER SECTOR AND REHABILITATION OF THE AUTONOMOUS METROPOLITAN DRINKING WATER PLANT (CAMEP)

PRIORITY ACTION PLAN - DRINKING WATER SECTOR AND REHABILITATION OF THE AUTONOMOUS METROPOLITAN DRINKING WATER PLANT (CAMEP)

\begin{tabular}{|c|c|c|c|c|c|c|c|}
\hline Objectives & Actions & Fiscal years & $\begin{array}{l}\text { Financial } \\
\text { resources }\end{array}$ & Input indicator & Output indicator & $\begin{array}{c}\begin{array}{c}\text { Performance } \\
\text { indicator }\end{array} \\
\end{array}$ & $\begin{array}{c}\text { Implementing } \\
\text { agency }\end{array}$ \\
\hline \multirow[t]{3}{*}{$\begin{array}{l}\text { 3.- Improve transparency } \\
\text { in fiscal reporting }\end{array}$} & $\begin{array}{l}\text { A- Transfer staff payroll } \\
\text { management to a reputable } \\
\text { bank }\end{array}$ & $\begin{array}{l}2007 / 2008 \text { and } \\
\text { onward }\end{array}$ & CAMEP & $\begin{array}{l}\text { Preparation of the list of } \\
\text { employees to be paid }\end{array}$ & $\begin{array}{l}\text { Payment of the } \\
\text { employees by the bank } \\
\text { selected }\end{array}$ & $\begin{array}{l}\text { Satisfaction of the } \\
\text { paid employee }\end{array}$ & $\begin{array}{l}\text { CAMEP and } \\
\text { the bank } \\
\text { selected }\end{array}$ \\
\hline & $\begin{array}{l}\text { B.- Upgrade and maintain } \\
\text { the customer management } \\
\text { software }\end{array}$ & $\begin{array}{l}2007 / 2008 \text { and } \\
\text { onward }\end{array}$ & CAMEP & $\begin{array}{l}\text { Renewal of the contract } \\
\text { with the company }\end{array}$ & $\begin{array}{l}\text { The software is } \\
\text { operational }\end{array}$ & $\begin{array}{l}\text { More streamlined } \\
\text { customer } \\
\text { management }\end{array}$ & $\begin{array}{l}\text { CAMEP and } \\
\text { the company } \\
\text { selected }\end{array}$ \\
\hline & $\begin{array}{l}\text { C.- Begin operations of the } \\
\text { Specialized Government } \\
\text { Procurement Commission }\end{array}$ & $\begin{array}{l}2007 / 2008 \text { and } \\
\text { onward }\end{array}$ & CAMEP & $\begin{array}{l}\text { Appoint the members of } \\
\text { the Commission }\end{array}$ & $\begin{array}{l}\text { Specialized } \\
\text { Commission issues } \\
\text { calls for bids }\end{array}$ & $\begin{array}{l}\text { More effective } \\
\text { government } \\
\text { procurement } \\
\text { management }\end{array}$ & $\begin{array}{l}\text { CAMEP and } \\
\text { CNMP }\end{array}$ \\
\hline
\end{tabular}

\begin{tabular}{|c|c|c|c|c|c|c|c|}
\hline Objectives & Actions & Fiscal years & $\begin{array}{l}\text { Financial } \\
\text { resources }\end{array}$ & Input indicator & Output indicator & $\begin{array}{c}\text { Performance } \\
\text { indicator }\end{array}$ & $\begin{array}{c}\text { Implementing } \\
\text { agency }\end{array}$ \\
\hline $\begin{array}{l}\text { 4.- Gradually integrate } \\
\text { externally funded } \\
\text { expenditures into the } \\
\text { sector budget }\end{array}$ & $\begin{array}{l}\text { A- Involve main donors and } \\
\text { lenders in the preparation of } \\
\text { the budget }\end{array}$ & $\begin{array}{l}2007 \text { / } 2008 \text { and } \\
\text { onward }\end{array}$ & CAMEP & $\begin{array}{l}\text { Technical consultations } \\
\text { organized before and } \\
\text { throughout the budget } \\
\text { preparation process }\end{array}$ & $\begin{array}{l}\text { Financing agreement } \\
\text { from the donors and } \\
\text { lenders consulted }\end{array}$ & $\begin{array}{l}\text { Externally funded } \\
\text { capital expenditure } \\
\text { carried correctly in } \\
\text { the budget }\end{array}$ & $\begin{array}{l}\text { CAMEP and } \\
\text { MPCE }\end{array}$ \\
\hline
\end{tabular}


NATIONAL STRATEGY DOCUMENT FOR GROWTH AND POVERTY REDUCTION (DSNCRP/HATT)

ACTION PLANS TO REFORMTHE PUBLIC FINANCIAL MANAGEMENT SYSTEM

PRIORITY ACTION PLAN - DRINKING WATER SECTOR AND REHABILITATION OF THE AUTONOMOUS METROPOLITAN DRINKING WATER PLANT (CAMEP)

\begin{tabular}{|l|l|l|l|l|l|l|l|}
\hline \multicolumn{1}{|c|}{ Objectives } & \multicolumn{1}{|c|}{ Actions } & Fiscal years & \multicolumn{1}{|c|}{$\begin{array}{l}\text { Financial } \\
\text { resources }\end{array}$} & \multicolumn{1}{c|}{$\begin{array}{c}\text { Input indicator } \\
\text { Output indicator }\end{array}$} & \multicolumn{1}{c|}{$\begin{array}{c}\text { Performance } \\
\text { indicator }\end{array}$} & $\begin{array}{l}\text { Implementing } \\
\text { agency }\end{array}$ \\
\hline $\begin{array}{l}\text { 5.- Assess the impact of } \\
\text { fiscal expenditures and } \\
\text { monitor fiscal } \\
\text { performance }\end{array}$ & $\begin{array}{l}\text { A- Carry out targeted impact } \\
\text { studies }\end{array}$ & $\begin{array}{l}2007 / 2008 \text { and } \\
\text { onward }\end{array}$ & CAMEP & $\begin{array}{l}\text { Selection of auditing } \\
\text { firms }\end{array}$ & Result of the audit & $\begin{array}{l}\text { Achievement of the } \\
\text { objectives }\end{array}$ & $\begin{array}{l}\text { CAMEP } \\
\text { Audit firms }\end{array}$ \\
\hline
\end{tabular}




\section{NATIONAL STRATEGY DOCUMENT FOR GROWTH AND POVERTY REDUCTION (DSNCRP/HATTI)}

ACTION PLANS TO REFORMTHE PUBLIC FINANCIAL MANAGEMENT SYSTEM

PRIORITY ACTION PLAN - TELECOMMUNICATIONS SECTOR

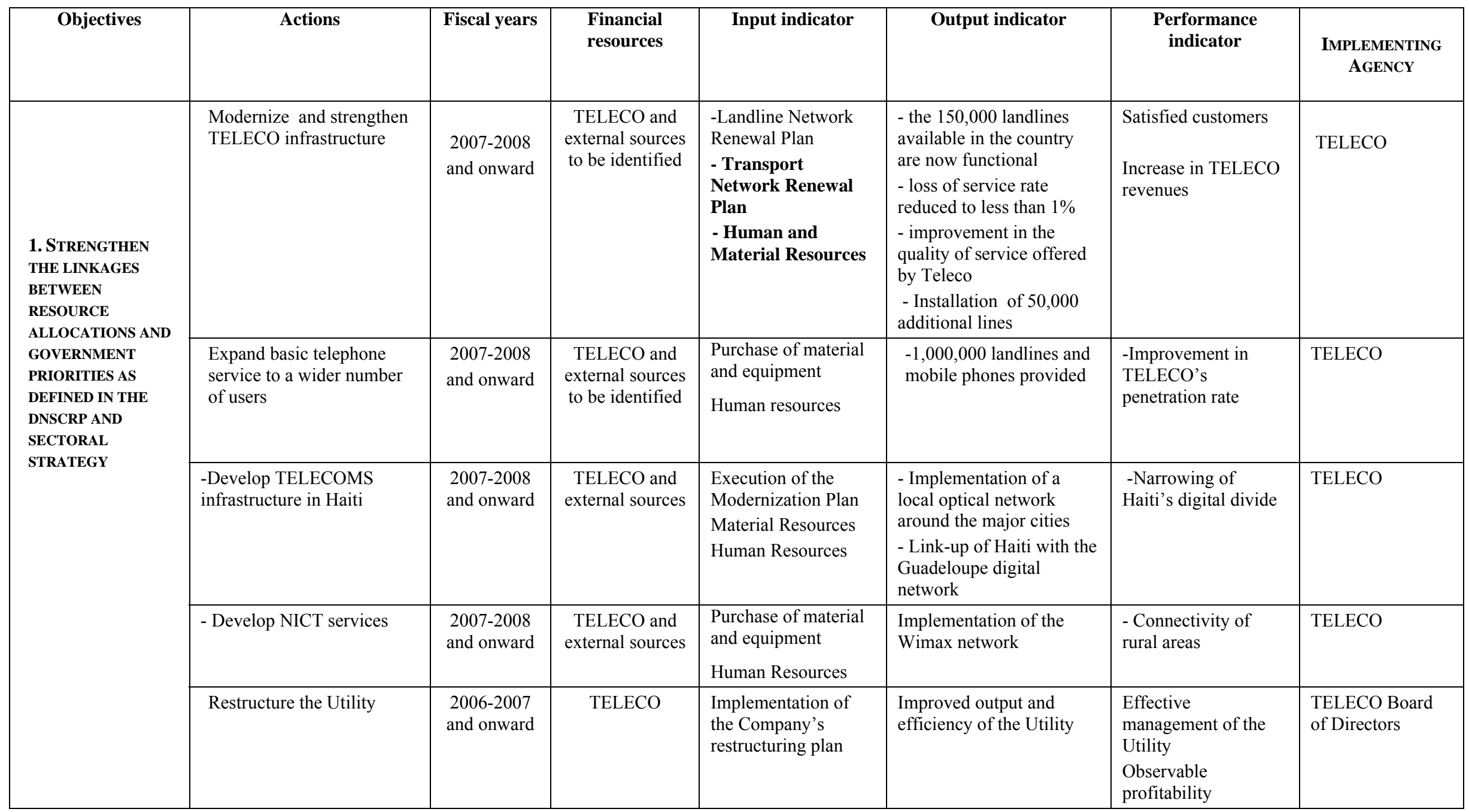


NATIONAL STRATEGY DOCUMENT FOR GROWTH AND POVERTY REDUCTION (DSNCRP/HATT) ACTION PLANS TO REFORMTHE PUBLIC FINANCIAL MANAGEMENT SYSTEM

\begin{tabular}{|c|c|c|c|c|c|c|c|}
\hline \multirow{3}{*}{ Objectives } & \multicolumn{7}{|c|}{ PRIORITY ACTION PLAN - TELECOMMUNICATIONS SECTOR } \\
\hline & Actions & $\begin{array}{l}\text { Fiscal } \\
\text { years }\end{array}$ & $\begin{array}{l}\text { Financial } \\
\text { resources }\end{array}$ & Input indicator & Output indicator & $\begin{array}{l}\text { Performance } \\
\text { indicator }\end{array}$ & $\begin{array}{l}\text { IMPLEMENTINC } \\
\text { AGENCY }\end{array}$ \\
\hline & Supervise execution of the budget & $\begin{array}{c}\text { 2007-2008 } \\
\text { and } \\
\text { onward }\end{array}$ & $\begin{array}{l}\text { Resources to } \\
\text { be identified }\end{array}$ & $\begin{array}{l}\text { TELECO Board of } \\
\text { Directors }\end{array}$ & $\begin{array}{l}\text { Approval and } \\
\text { monitoring of the } \\
\text { execution of the } \\
\text { TELECO budget }\end{array}$ & $\begin{array}{l}\text { Efficient execution of } \\
\text { the budget }\end{array}$ & TELECO \\
\hline \multirow{4}{*}{$\begin{array}{l}\text { 2. IMPROVE } \\
\text { BUDGET } \\
\text { EXECUTION }\end{array}$} & $\begin{array}{l}\text { Ensure disbursements under the } \\
\text { budget are made on time }\end{array}$ & $\begin{array}{l}2007-2008 \\
\text { and } \\
\text { onward }\end{array}$ & Own resources & TELECO & $\begin{array}{l}\text { Monitoring of the } \\
\text { implementation of the } \\
\text { TELECO investment } \\
\text { program }\end{array}$ & $\begin{array}{l}\text { Implementation of the } \\
\text { projects under the } \\
\text { Investment Program }\end{array}$ & TELECO \\
\hline & $\begin{array}{l}\text { Make revenue generated by } \\
\text { TELECO available on time }\end{array}$ & $\begin{array}{c}2007-2008 \\
\text { and } \\
\text { onward }\end{array}$ & Own resources & $\begin{array}{l}\text { Call for bids for financial } \\
\text { management platform }\end{array}$ & $\begin{array}{l}\text { Timely collection of } \\
\text { revenue generated }\end{array}$ & $\begin{array}{l}\text { Execution of the } \\
\text { planned expenditures }\end{array}$ & TELECO \\
\hline & $\begin{array}{l}\text { Authorize the opening of accounts } \\
\text { by projects }\end{array}$ & $\begin{array}{c}\text { 2007-2008 } \\
\text { and } \\
\text { onward }\end{array}$ & $\begin{array}{l}\text { Resources to } \\
\text { be identified }\end{array}$ & $\begin{array}{l}\text { Purchase of modern } \\
\text { financial management } \\
\text { tools }\end{array}$ & $\begin{array}{l}\text { Improved project } \\
\text { implementation }\end{array}$ & $\begin{array}{l}\text { Implementation of the } \\
\text { projects under the } \\
\text { investment program }\end{array}$ & \\
\hline & $\begin{array}{l}\text { Prepare the procurement plan on } \\
\text { time for the purchase of planned } \\
\text { material and equipment }\end{array}$ & $\begin{array}{c}\text { 2007-2008 } \\
\text { and } \\
\text { onward }\end{array}$ & Own resources & $\begin{array}{l}\text { Work of the TELECO } \\
\text { procurement steering } \\
\text { committees }\end{array}$ & $\begin{array}{l}\text { Projects under the } \\
\text { program budget } \\
\text { available at the } \\
\text { beginning of the fiscal } \\
\text { year }\end{array}$ & $\begin{array}{l}\text { Implementation of the } \\
\text { projects under the } \\
\text { investment program }\end{array}$ & TELECO \\
\hline
\end{tabular}


NATIONAL STRATEGY DOCUMENT FOR GROWTH AND POVERTY REDUCTION (DSNCRP/HATTI) ACTION PLANS TO REFORMTHE PUBLIC FINANCIAL MANAGEMENT SYSTEM

PRIORITY ACTION PLAN - TELECOMMUNICATIONS SECTOR

\begin{tabular}{|c|c|c|c|c|c|c|c|}
\hline Objectives & Actions & Fiscal years & $\begin{array}{l}\text { Financial } \\
\text { resources }\end{array}$ & Input indicator & Output indicator & $\begin{array}{l}\text { Performance } \\
\text { indicator }\end{array}$ & $\begin{array}{c}\text { Implementing } \\
\text { agency }\end{array}$ \\
\hline \multirow[t]{3}{*}{$\begin{array}{l}\text { 3. IMPROVE } \\
\text { TRANSPARENCY IN } \\
\text { FISCAL REPORTING }\end{array}$} & $\begin{array}{l}\text { Ensure information on the } \\
\text { budget is disseminated }\end{array}$ & $\begin{array}{l}2007-2008 \\
\text { and onward }\end{array}$ & Own resources & TELECO Intranet & $\begin{array}{l}\text {-Project expenditure } \\
\text { report } \\
\text { - Financial statement }\end{array}$ & $\begin{array}{l}\text { Transparency in } \\
\text { financial management }\end{array}$ & TELECO \\
\hline & $\begin{array}{l}\text { Put in place tools and } \\
\text { procedures for the fiscal } \\
\text { monitoring of investment } \\
\text { projects }\end{array}$ & $2007-2008$ & To be identified & Call for bids & $\begin{array}{l}\text { Accounting software } \\
\text { and accounting } \\
\text { procedures manual for } \\
\text { investment projects }\end{array}$ & $\begin{array}{l}\text { Timely production of } \\
\text { budget execution } \\
\text { reports for investment } \\
\text { projects }\end{array}$ & TELECO \\
\hline & $\begin{array}{l}\text { Prepare software for capital } \\
\text { investment budget } \\
\text { management and } \\
\text { monitoring }\end{array}$ & $2007-2008$ & To be identified & Call for bids & Software installed & $\begin{array}{l}\text { Ability to produce in } \\
\text { real time consolidated } \\
\text { statements of the } \\
\text { execution of the capital } \\
\text { expenditure budget }\end{array}$ & TELECO \\
\hline
\end{tabular}


NATIONAL STRATEGY DOCUMENT FOR GROWTH AND POVERTY REDUCTION (DSNCRP/HATTI)

ACTION PLANS TO REFORMTHE PUBLIC FINANCIAL MANAGEMENT SYSTEM

PRIORITY ACTION PLAN - TELECOMMUNICATIONS SECTOR

\begin{tabular}{|c|c|c|c|c|c|c|c|}
\hline Objectives & Actions & Fiscal years & $\begin{array}{l}\text { Financial } \\
\text { resources }\end{array}$ & Input indicator & Output indicator & $\begin{array}{l}\text { Performance } \\
\text { indicator }\end{array}$ & $\begin{array}{l}\text { IMPLEMENTING } \\
\text { AGENCY }\end{array}$ \\
\hline \multirow{5}{*}{$\begin{array}{l}\text { 1. STRENGTHEN } \\
\text { THE LINKAGES } \\
\text { BETWEEN } \\
\text { RESOURCE } \\
\text { ALLOCATIONS AND } \\
\text { GOVERNMENT } \\
\text { PRIORITIES AS } \\
\text { DEFINED IN THE } \\
\text { DNSCRP AND } \\
\text { SECTORAL } \\
\text { STRATEGY }\end{array}$} & $\begin{array}{l}\text { Modernize and strengthen } \\
\text { TELECO infrastructure }\end{array}$ & $\begin{array}{l}2007-2008 \\
\text { and onward }\end{array}$ & $\begin{array}{l}\text { TELECO and } \\
\text { external sources } \\
\text { to be identified }\end{array}$ & $\begin{array}{l}\text { - Landline network } \\
\text { renewal plan } \\
\text { - Transport network } \\
\text { renewal } \\
\text { - Human and } \\
\text { material resources }\end{array}$ & $\begin{array}{l}\text { - the } 150,000 \text { landlines } \\
\text { available in the country } \\
\text { are functional } \\
\text {-Loss of service rate } \\
\text { reduced to less than } 1 \% \\
\text { - improvement in the } \\
\text { quality of service offered } \\
\text { by Teleco } \\
\text { - Installation of } 50,000 \\
\text { additional lines }\end{array}$ & $\begin{array}{l}\text { Satisfied customers } \\
\text { Increase in TELECO } \\
\text { revenue }\end{array}$ & TELECO \\
\hline & $\begin{array}{l}\text { Expand basic telephone } \\
\text { service to a wider number } \\
\text { of users }\end{array}$ & $\begin{array}{l}2007-2008 \\
\text { and onward }\end{array}$ & $\begin{array}{l}\text { TELECO and } \\
\text { external sources } \\
\text { to be identified }\end{array}$ & $\begin{array}{l}\text { Purchase of material } \\
\text { and equipment } \\
\text { Human resources }\end{array}$ & $\begin{array}{l}-1,000,000 \text { landlines and } \\
\text { mobile phones provided }\end{array}$ & $\begin{array}{l}\text { - Improvement in the } \\
\text { penetration rate of the } \\
\text { TELECO network }\end{array}$ & TELECO \\
\hline & $\begin{array}{l}\text {-Develop TELECOMS } \\
\text { infrastructure in Haiti }\end{array}$ & $\begin{array}{l}2007-2008 \\
\text { and onward }\end{array}$ & $\begin{array}{l}\text { TELECO and } \\
\text { external sources }\end{array}$ & $\begin{array}{l}\text { Execution of the } \\
\text { Modernization Plan } \\
\text { Material Resources } \\
\text { Human Resources }\end{array}$ & $\begin{array}{l}\text { - Implementation of a } \\
\text { local optical network } \\
\text { around the major cities } \\
\text { - Link-up of Haiti with the } \\
\text { Guadeloupe digital } \\
\text { network }\end{array}$ & $\begin{array}{l}\text {-Narrowing of } \\
\text { Haiti's digital divide }\end{array}$ & TELECO \\
\hline & - Develop NICT services & $\begin{array}{c}2007-2008 \\
\text { and onward }\end{array}$ & $\begin{array}{l}\text { TELECO and } \\
\text { external sources }\end{array}$ & $\begin{array}{l}\text { Purchase of material } \\
\text { and equipment } \\
\text { Human Resources }\end{array}$ & $\begin{array}{l}\text { Implementation of the } \\
\text { Wimax network }\end{array}$ & $\begin{array}{l}\text { - Connectivity of } \\
\text { rural areas }\end{array}$ & TELECO \\
\hline & Restructure the Company & $\begin{array}{l}2006-2007 \\
\text { and onward }\end{array}$ & TELECO & $\begin{array}{l}\text { Implementation of } \\
\text { the Company's } \\
\text { restructuring plan }\end{array}$ & $\begin{array}{l}\text { Improved output and } \\
\text { production of TELECO }\end{array}$ & $\begin{array}{l}\text { Effective } \\
\text { management of the } \\
\text { Company } \\
\text { Observable } \\
\text { profitability }\end{array}$ & $\begin{array}{l}\text { TELECO } \\
\text { Board of Directors }\end{array}$ \\
\hline
\end{tabular}


NATIONAL STRATEGY DOCUMENT FOR GROWTH AND POVERTY REDUCTION (DSNCRP/HATTI) ACTION PLANS TO REFORMTHE PUBLIC FINANCIAL MANAGEMENT SYSTEM

PRIORITY ACTION PLAN - TELECOMMUNICATIONS SECTOR

\begin{tabular}{|c|c|c|c|c|c|c|c|}
\hline Objectives & Actions & $\begin{array}{l}\text { Fiscal } \\
\text { years }\end{array}$ & $\begin{array}{l}\text { Financial } \\
\text { resources }\end{array}$ & Input indicator & Output indicator & $\begin{array}{l}\text { Performance } \\
\text { indicator }\end{array}$ & $\begin{array}{l}\text { IMPLEMENTINC } \\
\text { AGENCY }\end{array}$ \\
\hline & $\begin{array}{l}\text { Supervise the execution of the } \\
\text { budget }\end{array}$ & $\begin{array}{c}2007-2008 \\
\text { and } \\
\text { onward }\end{array}$ & $\begin{array}{l}\text { Resources to } \\
\text { be identified }\end{array}$ & $\begin{array}{l}\text { TELECO Board of } \\
\text { Directors }\end{array}$ & $\begin{array}{l}\text { Approval and } \\
\text { monitoring of the } \\
\text { TELECO budget }\end{array}$ & $\begin{array}{l}\text { Efficient execution of } \\
\text { the budget }\end{array}$ & TELECO \\
\hline \multirow{4}{*}{$\begin{array}{l}\text { 2. IMPROVE } \\
\text { BUDGET } \\
\text { EXECUTION }\end{array}$} & $\begin{array}{l}\text { Ensure disbursements made as part } \\
\text { of the execution of the budget are } \\
\text { made on time }\end{array}$ & $\begin{array}{l}\text { 2007-2008 } \\
\text { and } \\
\text { onward }\end{array}$ & Own resources & TELECO & $\begin{array}{l}\text { Monitoring of the } \\
\text { implementation of the } \\
\text { TELECO capital } \\
\text { expenditure program }\end{array}$ & $\begin{array}{l}\text { Implementation of the } \\
\text { projects under the } \\
\text { Investment Program }\end{array}$ & TELECO \\
\hline & $\begin{array}{l}\text { Ensure timely availability of } \\
\text { revenue generated by TELECO }\end{array}$ & $\begin{array}{c}\text { 2007-2008 } \\
\text { and } \\
\text { onward }\end{array}$ & Own resources & $\begin{array}{l}\text { Call for bids for financial } \\
\text { management platform }\end{array}$ & $\begin{array}{l}\text { Timely collection of } \\
\text { revenue generated }\end{array}$ & $\begin{array}{l}\text { Execution of the } \\
\text { planned expenditures }\end{array}$ & TELECO \\
\hline & $\begin{array}{l}\text { Authorize the opening of accounts } \\
\text { by project }\end{array}$ & $\begin{array}{l}\text { 2007-2008 } \\
\text { and } \\
\text { onward }\end{array}$ & $\begin{array}{l}\text { Resources to } \\
\text { be identified }\end{array}$ & $\begin{array}{l}\text { Purchase of modern } \\
\text { financial management } \\
\text { tools }\end{array}$ & $\begin{array}{l}\text { Improved project } \\
\text { implementation }\end{array}$ & $\begin{array}{l}\text { Implementation of the } \\
\text { projects under the } \\
\text { investment program }\end{array}$ & \\
\hline & $\begin{array}{l}\text { Prepare the procurement plan on } \\
\text { time for the planned purchase of } \\
\text { material and equipment }\end{array}$ & $\begin{array}{l}\text { 2007-2008 } \\
\text { and } \\
\text { onward }\end{array}$ & Own resources & $\begin{array}{l}\text { Work of the TELECO } \\
\text { procurement steering } \\
\text { committees }\end{array}$ & $\begin{array}{l}\text { Projects under the } \\
\text { program budget } \\
\text { available at the } \\
\text { beginning of the fiscal } \\
\text { year }\end{array}$ & $\begin{array}{l}\text { Implementation of the } \\
\text { projects under the } \\
\text { investment program }\end{array}$ & TELECO \\
\hline
\end{tabular}


NATIONAL STRATEGY DOCUMENT FOR GROWTH AND POVERTY REDUCTION (DSNCRP/HATTI) ACTION PLANS TO REFORMTHE PUBLIC FINANCIAL MANAGEMENT SYSTEM

PRIORITY ACTION PLAN - TELECOMMUNICATIONS SECTOR

\begin{tabular}{|c|c|c|c|c|c|c|c|}
\hline Objectives & Actions & Fiscal years & $\begin{array}{l}\text { Financial } \\
\text { resources }\end{array}$ & Input indicator & Output indicator & $\begin{array}{l}\text { Performance } \\
\text { indicator }\end{array}$ & $\begin{array}{c}\text { Implementing } \\
\text { agency }\end{array}$ \\
\hline \multirow[t]{3}{*}{$\begin{array}{l}\text { 3. IMPROVE } \\
\text { TRANSPARENCY IN } \\
\text { FISCAL REPORTING }\end{array}$} & $\begin{array}{l}\text { Ensure information on the } \\
\text { budget is disseminated }\end{array}$ & $\begin{array}{l}2007-2008 \\
\text { and onward }\end{array}$ & Own resources & TELECO Intranet & $\begin{array}{l}\text {-Project expenditure } \\
\text { report } \\
\text { - Financial statement }\end{array}$ & $\begin{array}{l}\text { Transparency in } \\
\text { financial management }\end{array}$ & TELECO \\
\hline & $\begin{array}{l}\text { Implement tools and } \\
\text { procedures for the fiscal } \\
\text { monitoring of investment } \\
\text { projects }\end{array}$ & $2007-2008$ & To be identified & Call for bids & $\begin{array}{l}\text { Accounting software } \\
\text { and accounting } \\
\text { procedures manual for } \\
\text { investment projects }\end{array}$ & $\begin{array}{l}\text { Timely production of } \\
\text { budget execution } \\
\text { reports for investment } \\
\text { projects }\end{array}$ & TELECO \\
\hline & $\begin{array}{l}\text { Prepare software to manage } \\
\text { and monitor the capital } \\
\text { expenditure budget }\end{array}$ & $2007-2008$ & To be identified & Call for bids & Software installed & $\begin{array}{l}\text { Ability to produce in } \\
\text { real time consolidated } \\
\text { statements on the } \\
\text { execution of the } \\
\text { investment budget }\end{array}$ & TELECO \\
\hline
\end{tabular}


NATIONAL STRATEGY DOCUMENT FOR GROWTH AND POVERTY REDUCTION (DSNCRP/HATTI) ACTION PLANS TO REFORMTHE PUBLIC FINANCIAL MANAGEMENT SYSTEM

PRIORITY ACTION PLAN - TELECOMMUNICATIONS SECTOR

\begin{tabular}{|c|c|c|c|c|c|c|c|}
\hline ОВJECTIVES & Objectives & Actions & Fiscal years & Financial resources & Input indicator & Output indicator & $\begin{array}{c}\text { Performance } \\
\text { indicator }\end{array}$ \\
\hline \multirow{5}{*}{$\begin{array}{l}\text { 1. STRENGTHEN } \\
\text { THE LINKAGES } \\
\text { BETWEEN } \\
\text { RESOURCE } \\
\text { ALLOCATIONS AND } \\
\text { GOVERNMENT } \\
\text { PRIORITIES AS } \\
\text { DEFINED IN THE } \\
\text { DNSCRP AND } \\
\text { SECTORAL } \\
\text { STRATEGY }\end{array}$} & $\begin{array}{l}\text { Modernize and strengthen } \\
\text { TELECO infrastructure }\end{array}$ & $\begin{array}{l}\text { 2007-2008 } \\
\text { and onward }\end{array}$ & $\begin{array}{l}\text { TELECO } \\
\text { external sources } \\
\text { to be identified }\end{array}$ & $\begin{array}{l}\text { - Landline network } \\
\text { renewal plan } \\
\text { - IP Plan } \\
\text { Transport network } \\
\text { renewal } \\
\text { - Human and material } \\
\text { resources }\end{array}$ & $\begin{array}{l}\text { - the } 150,000 \text { landlines } \\
\text { available in the country } \\
\text { are functional } \\
\text {-Loss of service rate } \\
\text { reduced to less than } 1 \% \\
\text { - improvement in the } \\
\text { quality of service offered } \\
\text { by Teleco } \\
\text { - Installation of } 50,000 \\
\text { additional lines }\end{array}$ & $\begin{array}{l}\text { Satisfied customers } \\
\text { Increase in TELECO } \\
\text { revenue }\end{array}$ & TELECO \\
\hline & $\begin{array}{l}\text { Expand basic telephone } \\
\text { service to a wider number } \\
\text { of users }\end{array}$ & $\begin{array}{l}\text { 2007-2008 } \\
\text { and onward }\end{array}$ & $\begin{array}{l}\text { TELECO and } \\
\text { external sources } \\
\text { to be identified }\end{array}$ & $\begin{array}{l}\text { Purchase of material } \\
\text { and equipment } \\
\text { Human resources }\end{array}$ & $\begin{array}{l}-1,000,000 \text { landlines and } \\
\text { mobile phones provided }\end{array}$ & $\begin{array}{l}\text {-Improvement in } \\
\text { penetration rate of the } \\
\text { TELECO network }\end{array}$ & TELECO \\
\hline & $\begin{array}{l}\text {-Develop Haiti's } \\
\text { TELECOMS infrastructure }\end{array}$ & $\begin{array}{l}2007-2008 \\
\text { and onward }\end{array}$ & $\begin{array}{l}\text { TELECO and } \\
\text { external sources }\end{array}$ & $\begin{array}{l}\text { Execution of the } \\
\text { Modernization Plan } \\
\text { Material Resources } \\
\text { Human Resources }\end{array}$ & $\begin{array}{l}\text { - Implementation of a } \\
\text { local optical network } \\
\text { around the major cities } \\
\text { - Link-up of the country } \\
\text { with the Guadeloupe } \\
\text { digital network }\end{array}$ & $\begin{array}{l}\text {-Narrowing of } \\
\text { Haiti's digital divide }\end{array}$ & TELECO \\
\hline & - Develop NICT services & $\begin{array}{l}\text { 2007-2008 } \\
\text { and onward }\end{array}$ & $\begin{array}{c}\text { TELECO and } \\
\text { external sources }\end{array}$ & $\begin{array}{l}\text { Purchase of material } \\
\text { and equipment } \\
\text { Human resources }\end{array}$ & $\begin{array}{l}\text { Implementation of the } \\
\text { Wimax network }\end{array}$ & $\begin{array}{l}\text { - Connectivity of } \\
\text { rural areas }\end{array}$ & TELECO \\
\hline & Restructure the Company & $\begin{array}{l}\text { 2006-2007 } \\
\text { and onward }\end{array}$ & TELECO & $\begin{array}{l}\text { Implementation of } \\
\text { the Company's } \\
\text { restructuring plan }\end{array}$ & $\begin{array}{l}\text { Improved output and } \\
\text { production of TELECO }\end{array}$ & $\begin{array}{l}\text { Effective } \\
\text { management of the } \\
\text { Company } \\
\text { Observable } \\
\text { profitability }\end{array}$ & $\begin{array}{l}\text { TELECO Board } \\
\text { of Directors }\end{array}$ \\
\hline
\end{tabular}


NATIONAL STRATEGY DOCUMENT FOR GROWTH AND POVERTY REDUCTION (DSNCRP/HATT) ACTION PLANS TO REFORMTHE PUBLIC FINANCIAL MANAGEMENT SYSTEM

PRIORITY ACTION PLAN - TELECOMMUNICATIONS SECTOR

\begin{tabular}{|c|c|c|c|c|c|c|c|}
\hline ОВJECTIVES & Objectives & Actions & Fiscal years & Financial resources & Input indicator & Output indicator & $\begin{array}{l}\text { Performance } \\
\text { indicator }\end{array}$ \\
\hline & Supervise budget execution & $\begin{array}{l}2007-2008 \\
\text { and } \\
\text { onward }\end{array}$ & $\begin{array}{l}\text { Resources to } \\
\text { be identified }\end{array}$ & $\begin{array}{l}\text { TELECO Board of } \\
\text { Directors }\end{array}$ & $\begin{array}{l}\text { Approval and } \\
\text { monitoring of the } \\
\text { execution of the } \\
\text { TELECO budget }\end{array}$ & $\begin{array}{l}\text { Efficient execution of } \\
\text { the budget }\end{array}$ & TELECO \\
\hline \multirow{4}{*}{$\begin{array}{l}\text { 2. IMPROVE } \\
\text { BUDGET } \\
\text { EXECUTION }\end{array}$} & $\begin{array}{l}\text { Ensure disbursements made as part } \\
\text { the execution of the budget are made } \\
\text { on time }\end{array}$ & $\begin{array}{l}\text { 2007-2008 } \\
\text { and } \\
\text { onward }\end{array}$ & Own resources & TELECO & $\begin{array}{l}\text { Monitoring of the } \\
\text { implementation of the } \\
\text { TELECO investment } \\
\text { program }\end{array}$ & $\begin{array}{l}\text { Implementation of the } \\
\text { projects under the } \\
\text { investment program }\end{array}$ & TELECO \\
\hline & $\begin{array}{l}\text { Make revenue generated by } \\
\text { TELECO available on a timely basis }\end{array}$ & $\begin{array}{c}2007-2008 \\
\text { and } \\
\text { onward }\end{array}$ & Own resources & $\begin{array}{l}\text { Call for bids for financial } \\
\text { management platforms }\end{array}$ & $\begin{array}{l}\text { Timely collection of } \\
\text { revenue collected }\end{array}$ & $\begin{array}{l}\text { Execution of planned } \\
\text { expenditures }\end{array}$ & TELECO \\
\hline & $\begin{array}{l}\text { Authorize the opening of accounts } \\
\text { by projects }\end{array}$ & $\begin{array}{c}2007-2008 \\
\text { and } \\
\text { onward }\end{array}$ & $\begin{array}{l}\text { Resources to } \\
\text { be identified }\end{array}$ & $\begin{array}{l}\text { Purchase of modern } \\
\text { financial management } \\
\text { tools }\end{array}$ & $\begin{array}{l}\text { Improved project } \\
\text { implementation }\end{array}$ & $\begin{array}{l}\text { Implementation of the } \\
\text { projects under the } \\
\text { investment program }\end{array}$ & \\
\hline & $\begin{array}{l}\text { Ensure timely preparation of a } \\
\text { procurement plan for the planned } \\
\text { purchase of material and equipment }\end{array}$ & $\begin{array}{c}2007-2008 \\
\text { and } \\
\text { onward }\end{array}$ & Own resources & $\begin{array}{l}\text { Work of the TELECO } \\
\text { procurement steering } \\
\text { committees }\end{array}$ & $\begin{array}{l}\text { Projects under the } \\
\text { program budget } \\
\text { available at the } \\
\text { beginning of the fiscal } \\
\text { year }\end{array}$ & $\begin{array}{l}\text { Implementation of the } \\
\text { projects under the } \\
\text { investment program }\end{array}$ & TELECO \\
\hline
\end{tabular}

PRIORITY ACTION PLAN - TELECOMMUNICATIONS SECTOR 
NATIONAL STRATEGY DOCUMENT FOR GROWTH AND POVERTY REDUCTION (DSNCRP/HATT) ACTION PLANS TO REFORMTHE PUBLIC FINANCIAL MANAGEMENT SYSTEM

\begin{tabular}{|c|c|c|c|c|c|c|c|}
\hline Objectives & Actions & Fiscal years & $\begin{array}{l}\text { Financial } \\
\text { resources }\end{array}$ & Input indicator & Output indicator & $\begin{array}{l}\text { Performance } \\
\text { indicator }\end{array}$ & $\begin{array}{c}\text { Implementing } \\
\text { agency }\end{array}$ \\
\hline \multirow[t]{3}{*}{$\begin{array}{l}\text { 3. IMPROVE } \\
\text { TRANSPARENCY IN } \\
\text { FISCAL REPORTING }\end{array}$} & $\begin{array}{l}\text { Ensure information on the } \\
\text { budget is disseminated }\end{array}$ & $\begin{array}{l}2007-2008 \\
\text { and onward }\end{array}$ & Own resources & TELECO Intranet & $\begin{array}{l}\text {-Project expenditure } \\
\text { reports } \\
\text { - Financial statement }\end{array}$ & $\begin{array}{l}\text { Transparency in } \\
\text { financial management }\end{array}$ & TELECO \\
\hline & $\begin{array}{l}\text { Implement tools and } \\
\text { procedures for fiscal } \\
\text { monitoring of investment } \\
\text { projects }\end{array}$ & 2007-2008 & To be identified & Call for bids & $\begin{array}{l}\text { Accounting software } \\
\text { and accounting } \\
\text { procedures for } \\
\text { investment projects }\end{array}$ & $\begin{array}{l}\text { Timely production of } \\
\text { budget execution } \\
\text { reports for investment } \\
\text { projects }\end{array}$ & TELECO \\
\hline & $\begin{array}{l}\text { Prepare software for the } \\
\text { management and } \\
\text { monitoring of the } \\
\text { investment budget }\end{array}$ & $2007-2008$ & To be identified & Call for bids & Software installed & $\begin{array}{l}\text { Ability to produce in } \\
\text { real time consolidated } \\
\text { statements on the } \\
\text { execution of the } \\
\text { investment budget }\end{array}$ & TELECO \\
\hline
\end{tabular}


NATIONAL STRATEGY DOCUMENT FOR GROWTH AND POVERTY REDUCTION (DSNCRP/HATTI) ACTION PLANS TO REFORMTHE PUBLIC FINANCIAL MANAGEMENT SYSTEM

PRIORITY ACTION PLAN - TELECOMMUNICATIONS SECTOR

\begin{tabular}{|c|c|c|c|c|c|c|c|}
\hline Objectives & Actions & $\begin{array}{l}\text { Fiscal } \\
\text { years }\end{array}$ & $\begin{array}{l}\text { Financial } \\
\text { resources }\end{array}$ & Input indicator & $\begin{array}{c}\text { Output } \\
\text { indicator }\end{array}$ & Performance indicator & $\begin{array}{l}\text { Implementing } \\
\text { agency }\end{array}$ \\
\hline \multirow{7}{*}{$\begin{array}{l}\text { 1. STRENGTHEN } \\
\text { THE LINKAGES } \\
\text { BETWEEN } \\
\text { RESOURCE } \\
\text { ALLOCATIONS AND } \\
\text { GOVERNMENT } \\
\text { PRIORITIES AS } \\
\text { DEFINED IN THE } \\
\text { DNSCRP AND } \\
\text { SECTORAL } \\
\text { STRATEGY }\end{array}$} & $\begin{array}{l}\text { i) Prepare a law for the regulation } \\
\text { of the electricity sector and that } \\
\text { encourages private investment } \\
\text { and free competition }\end{array}$ & $\begin{array}{l}2007- \\
2008\end{array}$ & $\begin{array}{c}\text { TO BE } \\
\text { IDENTIFIED }\end{array}$ & $\begin{array}{l}\text { Legal and economic } \\
\text { expertise mobilized }\end{array}$ & $\begin{array}{l}\text { Regulatory law } \\
\text { submitted to } \\
\text { Parliament }\end{array}$ & Expansion of the sector & MTPTC/EDH \\
\hline & $\begin{array}{l}\text { ii) Ensure that the strategy paper } \\
\text { for the development of the } \\
\text { electrical subsector is } \\
\text { disseminated }\end{array}$ & $\begin{array}{l}2007- \\
2008\end{array}$ & $\begin{array}{c}\text { TO BE } \\
\text { IDENTIFIED }\end{array}$ & $\begin{array}{l}\text { Communication and } \\
\text { resource plan to foster the } \\
\text { validation and buy-in } \\
\text { process }\end{array}$ & $\begin{array}{l}\text { Validation and } \\
\text { ownership of } \\
\text { electricity } \\
\text { strategy paper }\end{array}$ & $\begin{array}{l}\text { The electricity strategy } \\
\text { paper is disseminated } \\
\text { and adopted }\end{array}$ & MTPTC/ EDH \\
\hline & $\begin{array}{l}\text { iii) Prepare a budget in the } \\
\text { electricity sector }\end{array}$ & $\begin{array}{l}2007- \\
2008\end{array}$ & $\begin{array}{c}\text { TO BE } \\
\text { IDENTIFIED }\end{array}$ & $\begin{array}{l}\text { Needs identified and } \\
\text { priorities defined }\end{array}$ & $\begin{array}{l}2007-2008 \\
\text { Budget is } \\
\text { coherent, } \\
\text { realistic, drafted } \\
\text { and disseminated } \\
\text { in a timely } \\
\text { fashion }\end{array}$ & $\begin{array}{l}\text { The budget programs are } \\
\text { executed }\end{array}$ & $\begin{array}{l}\text { Budget } \\
\text { Department EDH }\end{array}$ \\
\hline & $\begin{array}{l}\text { iv) Boost material resources and } \\
\text { specialized human resources at the } \\
\text { budget level }\end{array}$ & $\begin{array}{l}2007- \\
2008\end{array}$ & $\begin{array}{c}\text { TO BE } \\
\text { IDENTIFIED }\end{array}$ & $\begin{array}{l}\text { Purchase computers, } \\
\text { software, and retool staff } \\
\text { for budget preparation and } \\
\text { monitoring }\end{array}$ & $\begin{array}{l}\text { Department } \\
\text { activity report }\end{array}$ & $\begin{array}{l}\text { Electricity budget } \\
\text { prepared on time; } \\
\text { regular reports on its } \\
\text { execution }\end{array}$ & $\begin{array}{l}\text { Budget } \\
\text { Department EDH }\end{array}$ \\
\hline & $\begin{array}{l}\text { v) Conduct a survey of available } \\
\text { resources (human and material) and } \\
\text { existing procedures }\end{array}$ & $\begin{array}{l}2007- \\
2008\end{array}$ & $\begin{array}{c}\text { TO BE } \\
\text { IDENTIFIED }\end{array}$ & External expertise & Expert report & $\begin{array}{l}\text { Consistency between } \\
\text { planned activities and } \\
\text { available resources }\end{array}$ & EDH / MTPTC \\
\hline & $\begin{array}{l}\text { vi) Strengthen commercial and } \\
\text { network systems }\end{array}$ & $\begin{array}{l}2007- \\
2012\end{array}$ & $\begin{array}{c}\text { TO BE } \\
\text { IDENTIFIED }\end{array}$ & $\begin{array}{l}\text { Implementation of the } \\
\text { new system }\end{array}$ & $\begin{array}{l}\text { New system } \\
\text { implemented }\end{array}$ & $\begin{array}{l}\text { Reduced losses and } \\
\text { improved revenue } \\
\text { Reduced subsidies from } \\
\text { the Haitian Government. } \\
\text { Better service to the } \\
\text { population }\end{array}$ & EDH \\
\hline & $\begin{array}{l}\text { vii) Ensure regular supply of oil and } \\
\text { fuel to the plants (PAP+PROV) }\end{array}$ & $\begin{array}{l}2007- \\
2012\end{array}$ & $\begin{array}{c}\text { TO BE } \\
\text { IDENTIFIED }\end{array}$ & $\begin{array}{l}\text { Budget estimates of } \\
\text { available expenditure and } \\
\text { requisitions }\end{array}$ & $\begin{array}{l}\text { Output } \\
\text { expectations met }\end{array}$ & $\begin{array}{l}\text { Improvement in quality } \\
\text { of life and assurance of } \\
\text { economic growth }\end{array}$ & MEF MTPTC \\
\hline
\end{tabular}


NATIONAL STRATEGY DOCUMENT FOR GROWTH AND POVERTY REDUCTION (DSNCRP/HATT) ACTION PLANS TO REFORMTHE PUBLIC FINANCIAL MANAGEMENT SYSTEM

PRIORITY ACTION PLAN - ELECTRICITY SECTOR

\begin{tabular}{|c|c|c|c|c|c|c|c|}
\hline Objectives & Actions & $\begin{array}{l}\text { Fiscal } \\
\text { years }\end{array}$ & $\begin{array}{l}\text { Financial } \\
\text { resources }\end{array}$ & Input indicator & Output indicator & Performance indicator & $\begin{array}{l}\text { Implementing } \\
\text { agency }\end{array}$ \\
\hline \multirow{6}{*}{$\begin{array}{l}\text { 2. IMPROVE } \\
\text { BUDGET } \\
\text { EXECUTION }\end{array}$} & $\begin{array}{l}\text { i) Update, draft if necessary and } \\
\text { disseminate procedures for } \\
\text { management of the capital } \\
\text { expenditure budget }\end{array}$ & $2007-2009$ & $\begin{array}{c}\text { TO BE } \\
\text { IDENTIFIED }\end{array}$ & $\begin{array}{l}\text { National expertise } \\
\text { mobilized }\end{array}$ & $\begin{array}{l}\text { Procedure handbook } \\
\text { prepared }\end{array}$ & $\begin{array}{l}\text { Reduced time needed to } \\
\text { mobilize funds }\end{array}$ & EDH/MEF \\
\hline & $\begin{array}{l}\text { ii) Improve preparation within the } \\
\text { requisition deadlines }\end{array}$ & $2007-2012$ & $\begin{array}{c}\text { TO BE } \\
\text { IDENTIFIED }\end{array}$ & EDH Resources & $\begin{array}{l}\text { Requisitions ready on } \\
\text { time and in } \\
\text { compliance with all } \\
\text { the rules }\end{array}$ & Quicker disbursements & $\begin{array}{l}\text { MTPTC MEF and } \\
\text { BRH }\end{array}$ \\
\hline & $\begin{array}{l}\text { iii) Prepare an annual procurement plan } \\
\text { for the purchase of supplies, fuel, material, } \\
\text { and equipment planned in the budget }\end{array}$ & $2007-2012$ & $\begin{array}{c}\text { TO BE } \\
\text { IDENTIFIED }\end{array}$ & List of projects concerned & & $\begin{array}{l}\text { Quicker and more } \\
\text { efficient purchase of } \\
\text { pre-approved goods and } \\
\text { services }\end{array}$ & $\begin{array}{l}\text { CNMP/EDH MEF } \\
\text { MTPTC }\end{array}$ \\
\hline & $\begin{array}{l}\text { iv) Motivate managers and } \\
\text { supervisors to monitor specific } \\
\text { budgets }\end{array}$ & $2007-2009$ & $\begin{array}{c}\text { TO BE } \\
\text { IDENTIFIED }\end{array}$ & $\begin{array}{l}\text { Motivational session for } \\
\text { managers }\end{array}$ & Follow-up report & $\begin{array}{l}\text { Improved execution of } \\
\text { the fiscal calendar }\end{array}$ & $\mathrm{EDH} / \mathrm{MEF}$ \\
\hline & $\begin{array}{l}\text { v) Train/retool HR in budget } \\
\text { procedures }\end{array}$ & $2007-2012$ & $\begin{array}{c}\text { TO BE } \\
\text { IDENTIFIED }\end{array}$ & $\begin{array}{l}\text { Professional training } \\
\text { cycles in place }\end{array}$ & Training reports & $\begin{array}{l}\text { Consistency in the } \\
\text { budget preparation } \\
\text { between objectives and } \\
\text { mobilized resources }\end{array}$ & $\mathrm{MEF} / \mathrm{EDH}$ \\
\hline & $\begin{array}{l}\text { ix) Ensure it is broadly disseminated } \\
\text { to all directorates and ministries } \\
\text { affected by the budget }\end{array}$ & $2007-2012$ & $\begin{array}{c}\text { TO BE } \\
\text { IDENTIFIED }\end{array}$ & Document reproduced & Document available & $\begin{array}{l}\text { Shorter periods for the } \\
\text { payment of expenses }\end{array}$ & $\begin{array}{l}\text { EDH/MEF } \\
\text { MTPTC }\end{array}$ \\
\hline
\end{tabular}


NATIONAL STRATEGY DOCUMENT FOR GROWTH AND POVERTY REDUCTION (DSNCRP/HATTI) ACTION PLANS TO REFORMTHE PUBLIC FINANCIAL MANAGEMENT SYSTEM

PRIORITY ACTION PLAN - ELECTRICITY SECTOR

\begin{tabular}{|c|c|c|c|c|c|c|c|}
\hline Objectives & Actions & Fiscal years & $\begin{array}{l}\text { Financial } \\
\text { resources }\end{array}$ & Input indicator & Output indicator & $\begin{array}{l}\text { Performance } \\
\text { indicator }\end{array}$ & $\begin{array}{c}\text { Implementing } \\
\text { agency }\end{array}$ \\
\hline \multirow{7}{*}{$\begin{array}{l}\text { 3. IMPROVE } \\
\text { TRANSPARENCY IN } \\
\text { FISCAL REPORTING }\end{array}$} & $\begin{array}{l}\text { i) Exchange accounting } \\
\text { information with MEF for } \\
\text { management of investment } \\
\text { program (IP) projects }\end{array}$ & $2007-2008$ & $\begin{array}{c}\text { TO BE } \\
\text { IDENTIFIED }\end{array}$ & RH EDH and MEF & $\begin{array}{l}\text { IP projects } \\
\text { expenditure report }\end{array}$ & $\begin{array}{l}\text { More compliance with } \\
\text { rules in the } \\
\text { management of CE } \\
\text { projects }\end{array}$ & MEF, EDH \\
\hline & $\begin{array}{l}\text { ii) Establishment and } \\
\text { implementation of a } \\
\text { procedure for the closure of } \\
\text { IP projects }\end{array}$ & $2007-2008$ & $\begin{array}{c}\text { TO BE } \\
\text { IDENTIFIED }\end{array}$ & $\begin{array}{l}\text { National and international } \\
\text { expertise }\end{array}$ & $\begin{array}{l}\text { Procedural manual for } \\
\text { closure of projects and } \\
\text { project accounts in } \\
\text { place }\end{array}$ & $\begin{array}{l}\text { More compliance with } \\
\text { rules in the } \\
\text { management of CE } \\
\text { projects }\end{array}$ & $\mathrm{EDH} / \mathrm{MEF}$ \\
\hline & $\begin{array}{l}\text { iii) Set up an ongoing } \\
\text { communication program }\end{array}$ & $2007-2008$ & $\begin{array}{c}\text { TO BE } \\
\text { IDENTIFIED }\end{array}$ & $\begin{array}{l}\text { Resources hired and } \\
\text { trained }\end{array}$ & $\begin{array}{l}\text { Communication plan } \\
\text { implemented }\end{array}$ & $\begin{array}{l}\text { Better dissemination of } \\
\text { budget information } \\
\text { internally and } \\
\text { externally }\end{array}$ & EDH \\
\hline & $\begin{array}{l}\text { iv) Include procurement } \\
\text { (within the framework of } \\
\text { projects) among the } \\
\text { competencies of the EDH }\end{array}$ & $\begin{array}{l}2007-2008 \\
\text { and onward }\end{array}$ & $\begin{array}{c}\text { TO BE } \\
\text { IDENTIFIED }\end{array}$ & $\begin{array}{l}\text { Budgeting of "government } \\
\text { procurement" items on the } \\
\text { EDH payroll }\end{array}$ & Manager training & $\begin{array}{l}\text { More effective } \\
\text { government } \\
\text { procurement } \\
\text { management }\end{array}$ & $\mathrm{EDH}$ \\
\hline & $\begin{array}{l}\text { v) Create an Internet site } \\
\text { where the information can } \\
\text { be posted }\end{array}$ & $2007-2008$ & $\begin{array}{c}\text { TO BE } \\
\text { IDENTIFIED }\end{array}$ & IT expertise mobilized & $\begin{array}{l}\text { Information on the } \\
\text { budget openly } \\
\text { available to interested } \\
\text { parties }\end{array}$ & $\begin{array}{l}\text { Easier monitoring of } \\
\text { expenditure }\end{array}$ & $\mathrm{EDH} / \mathrm{MEF}$ \\
\hline & $\begin{array}{l}\text { vi) Set up a system for the } \\
\text { monthly } \\
\text { MEF/MTPTC/EDH } \\
\text { tripartite meetings }\end{array}$ & $2007-2008$ & $\begin{array}{c}\text { TO BE } \\
\text { IDENTIFIED }\end{array}$ & $\begin{array}{l}\text { Means of transport and } \\
\text { meeting room available }\end{array}$ & $\begin{array}{l}\text { Summary records of } \\
\text { meetings }\end{array}$ & $\begin{array}{l}\text { Tradeoffs resulting } \\
\text { from more consistent } \\
\text { cash management }\end{array}$ & MEF \\
\hline & $\begin{array}{l}\text { vii) Prepare software for } \\
\text { managing and monitoring } \\
\text { the capital expenditure } \\
\text { budget }\end{array}$ & $2007-2008$ & $\begin{array}{c}\text { TO BE } \\
\text { IDENTIFIED }\end{array}$ & IT expertise mobilized & Software installed & $\begin{array}{l}\text { Ability to produce in } \\
\text { real time consolidated } \\
\text { statements on the } \\
\text { execution of the } \\
\text { investment budget }\end{array}$ & $\mathrm{EDH}$ \\
\hline
\end{tabular}


NATIONAL STRATEGY DOCUMENT FOR GROWTH AND POVERTY REDUCTION (DSNCRP/HATTI) ACTION PLANS TO REFORMTHE PUBLIC FINANCIAL MANAGEMENT SYSTEM

PRIORITY ACTION PLAN - ELECTRICITY SECTOR

\begin{tabular}{|c|c|c|c|c|c|c|c|}
\hline Objectives & Actions & Fiscal years & $\begin{array}{l}\text { Financial } \\
\text { resources }\end{array}$ & Input indicator & Output indicator & $\begin{array}{l}\text { Performance } \\
\text { indicator }\end{array}$ & $\begin{array}{c}\text { Implementing } \\
\text { agency }\end{array}$ \\
\hline \multirow[t]{2}{*}{$\begin{array}{l}\text { 4.- Gradually } \\
\text { integrate externally } \\
\text { funded expenditures } \\
\text { into the sector } \\
\text { budget }\end{array}$} & $\begin{array}{l}\text { (i) Involve the main } \\
\text { donors and lenders and } \\
\text { lenders in the preparation } \\
\text { of the budget }\end{array}$ & $2007-2008$ & $\begin{array}{c}\text { TO BE } \\
\text { IDENTIFIED }\end{array}$ & $\begin{array}{l}\text { Technical consultation } \\
\text { meetings organized during } \\
\text { budget preparation process }\end{array}$ & $\begin{array}{l}\text { Reports on working } \\
\text { meetings }\end{array}$ & $\begin{array}{l}\text { Externally funded } \\
\text { capital expenditures } \\
\text { carried correctly in the } \\
\text { budget }\end{array}$ & $\begin{array}{l}\text { MPCE EDH MEF } \\
\text { MTPTC }\end{array}$ \\
\hline & $\begin{array}{l}\text { (ii) Establish a harmonized } \\
\text { framework for monitoring } \\
\text { investment with external } \\
\text { cooperation }\end{array}$ & $2007-2008$ & $\begin{array}{c}\text { TO BE } \\
\text { IDENTIFIED }\end{array}$ & $\begin{array}{l}\text { National expertise } \\
\text { mobilized and broader } \\
\text { consultation with MTPTC } \\
\text { and donors and lenders }\end{array}$ & $\begin{array}{l}\text { Database and manual } \\
\text { of procedures } \\
\text { prepared and } \\
\text { negotiated with all } \\
\text { donors and lenders }\end{array}$ & $\begin{array}{l}\text { Externally funded } \\
\text { capital expenditures } \\
\text { correctly monitored }\end{array}$ & $\begin{array}{l}\text { MPCE and } \\
\text { MTPTC EDH }\end{array}$ \\
\hline \multirow{3}{*}{$\begin{array}{l}\text { 5. CONDUCT } \\
\text { IMPACT } \\
\text { ASSESSMENT OF } \\
\text { FISCAL } \\
\text { EXPENDITURES AND } \\
\text { MONITOR FISCAL } \\
\text { PERFORMANCE }\end{array}$} & $\begin{array}{l}\text { (i) Conduct targeted } \\
\text { impact studies }\end{array}$ & $2007-2008$ & $\begin{array}{c}\text { TO BE } \\
\text { IDENTIFIED }\end{array}$ & $\begin{array}{l}\text { International and local } \\
\text { consultants conduct } \\
\text { support missions }\end{array}$ & $\begin{array}{l}\text { Report on targeted } \\
\text { impact studies }\end{array}$ & $\begin{array}{l}\text { Greater awareness of } \\
\text { the link between } \\
\text { sectoral capital } \\
\text { expenditure and } \\
\text { poverty reduction }\end{array}$ & $\mathrm{EDH}$ \\
\hline & $\begin{array}{l}\text { (ii) Strengthen human } \\
\text { resources specialized in } \\
\text { impact studies }\end{array}$ & $2007-2008$ & $\begin{array}{c}\text { TO BE } \\
\text { IDENTIFIED }\end{array}$ & $\begin{array}{l}\text { EDH executive delegated } \\
\text { to this activity }\end{array}$ & $\begin{array}{l}\text { Activity report from } \\
\text { delegated executives }\end{array}$ & $\begin{array}{l}\text { Greater awareness of } \\
\text { the link between } \\
\text { sectoral capital } \\
\text { expenditure and } \\
\text { poverty reduction }\end{array}$ & MEF \\
\hline & $\begin{array}{l}\text { (iii) Train EDH HR in } \\
\text { impact studies and } \\
\text { strategic planning }\end{array}$ & $2007-2008$ & $\begin{array}{c}\text { TO BE } \\
\text { IDENTIFIED }\end{array}$ & $\begin{array}{l}\text { National seminars and } \\
\text { workshops conducted }\end{array}$ & $\begin{array}{l}\text { Training seminar } \\
\text { reports }\end{array}$ & $\begin{array}{l}\text { Less dependence on } \\
\text { external expertise for } \\
\text { impact assessments }\end{array}$ & EDH \\
\hline
\end{tabular}


NATIONAL STRATEGY DOCUMENT FOR GROWTH AND POVERTY REDUCTION (DSNCRP/HATTI) ACTION PLANS TO REFORMTHE PUBLIC FINANCIAL MANAGEMENT SYSTEM

PRIORITY ACTION PLAN FOR THE NATIONAL CONSTRUCTION AND PUBLIC WORKS LABORATORY

\begin{tabular}{|c|c|c|c|c|c|c|c|}
\hline OBJECTIVES & Actions & FY & $\begin{array}{l}\text { Available } \\
\text { resources }\end{array}$ & Input indicators & Output indicators & Performance indicator & $\begin{array}{c}\text { Executing } \\
\text { agency }\end{array}$ \\
\hline \multirow[t]{4}{*}{$\begin{array}{l}\text { 1. STRENGTHEN THE } \\
\text { LINKAGES BETWEEN } \\
\text { RESOURCE ALLOCATIONS } \\
\text { AND GOVERNMENT } \\
\text { PRIORITIES AS DEFINED IN } \\
\text { THE DNSCRP AND SECTORAL } \\
\text { STRATEGY }\end{array}$} & $\begin{array}{l}\text { Resume and/or develop } \\
\text { cooperative relations with } \\
\text { foreign partners and } \\
\text { international institutions; }\end{array}$ & $2007 / 2009$ & $\begin{array}{l}\text { LNBTP } \\
\text { Own funds }\end{array}$ & $\begin{array}{l}\text { Identification of the } \\
\text { LNBTP's specific } \\
\text { training and technical } \\
\text { assistance needs; } \\
\text {.Identification of } \\
\text { potential sources of } \\
\text { assistance; } \\
\text { Contacts with } \\
\text { representatives of various } \\
\text { institutions; }\end{array}$ & $\begin{array}{l}\text { Signing of cooperation } \\
\text { agreements; } \\
\text {. Drafting of a training } \\
\text { plan for supervisors and } \\
\text { managers and technicians }\end{array}$ & $\begin{array}{l}\text { Availability of foreign } \\
\text { technical assistance; } \\
\text {. Availability of } \\
\text { resources for } \\
\text { professional training of } \\
\text { the LNBTP's } \\
\text { supervisors and } \\
\text { managers and } \\
\text { technicians }\end{array}$ & LNBTP \\
\hline & $\begin{array}{l}\text { Strengthen operational } \\
\text { capacity of the LNBTP }\end{array}$ & $2004 / 2010$ & $\begin{array}{l}\text { Own funds } \\
\text { of the } \\
\text { LNBTP } \\
\text { Capital } \\
\text { expenditure } \\
\text { budget }\end{array}$ & $\begin{array}{l}\text { Organizational chart of } \\
\text { the institution's } \\
\text { operations; }\end{array}$ & $\begin{array}{l}\text { Setting up of technical } \\
\text { and administrative units } \\
\text { that will be held } \\
\text { accountable } \\
\text {. Internal Regulation } \\
\text { Document available; } \\
\text {. Classification of the staff } \\
\text { completed }\end{array}$ & $\begin{array}{l}\text { Effective management } \\
\text { of the institution from } \\
\text { the following } \\
\text { perspectives : } \\
\text {. research; } \\
\text {. quality control; } \\
\text {. applied research. }\end{array}$ & LNBTP \\
\hline & Refurbish the LNBTP & $2004 / 2010$ & $\begin{array}{l}\text {. LNBTP } \\
\text { Capital } \\
\text { expenditure } \\
\text { budget }\end{array}$ & $\begin{array}{l}\text { Project document for the } \\
\text { refurbishing of the } \\
\text { LNBTP }\end{array}$ & $\begin{array}{l}\text { Expansion of working } \\
\text { areas; } \\
\text {. More vehicles; } \\
\text {. Purchase of test } \\
\text { equipment; } \\
\text {. Availability of stand-by } \\
\text { energy supply }\end{array}$ & $\begin{array}{l}\text { Increase in the } \\
\text { LNBTP's physical } \\
\text { capacities }\end{array}$ & \\
\hline & $\begin{array}{l}\text { Improve the visibility of } \\
\text { the LNBTP in the } \\
\text { infrastructure sector and } \\
\text { construction in general }\end{array}$ & $2007 / 2008$ & $\begin{array}{l}\text { Own funds } \\
\text { of the } \\
\text { LNBTP } \\
\text { Capital } \\
\text { expenditure } \\
\text { budget }\end{array}$ & $\begin{array}{l}\text { Roster of consultants, } \\
\text { construction, and } \\
\text { supervision firms in the } \\
\text { country; } \\
\text {. Laboratory website } \\
\text { Commercial on RTNH } \\
\text {. Launch of the LNBTP } \\
\text { technical review project }\end{array}$ & $\begin{array}{l}\text {. Awareness raising } \\
\text { seminars on quality for } \\
\text { stakeholders; } \\
\text {. Launch of a training } \\
\text { program for supervisors } \\
\text { and managers and } \\
\text { technicians from the } \\
\text { private sector and } \\
\text { construction sector. }\end{array}$ & $\begin{array}{l}\text {. Delegation of some } \\
\text { quality control power to } \\
\text { bona fide oversight } \\
\text { firms; } \\
\text {. Improvement of the } \\
\text { technical capacities of } \\
\text { the local enterprises; } \\
\text {. Increase in the } \\
\text { percentage of public } \\
\text { (and private) works } \\
\text { subject to systematic }\end{array}$ & LNBTP \\
\hline
\end{tabular}


NATIONAL STRATEGY DOCUMENT FOR GROWTH AND POVERTY REDUCTION (DSNCRP/HATTI) ACTION PLANS TO REFORMTHE PUBLIC FINANCIAL MANAGEMENT SYSTEM

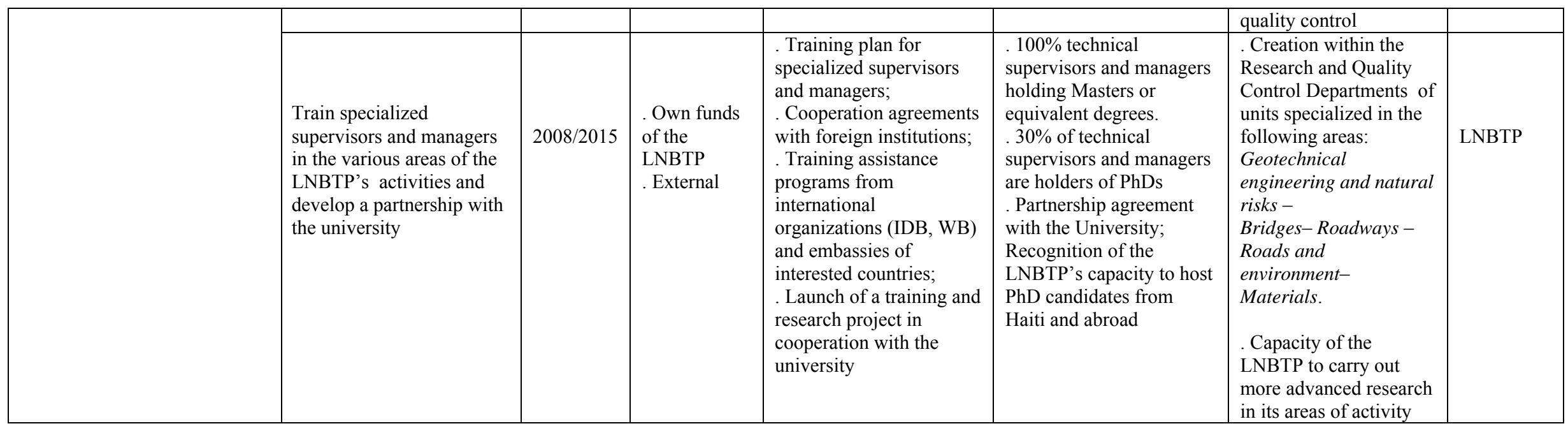

PRIORITY ACTION PLAN FOR THE NATIONAL CONSTRUCTION AND PUBLIC WORKS LABORATORY

\begin{tabular}{|c|c|c|c|c|c|c|c|}
\hline Objectives & Actions & $\begin{array}{l}\text { Fiscal } \\
\text { years }\end{array}$ & $\begin{array}{l}\text { Financial } \\
\text { resources }\end{array}$ & Input indicator & Output indicator & Performance indicator & $\begin{array}{c}\text { Implementing } \\
\text { agency }\end{array}$ \\
\hline \multirow{3}{*}{$\begin{array}{l}\text { 1. STRENGTHEN THE } \\
\text { LINKAGES BETWEEN } \\
\text { RESOURCES ALLOCATIONS AND } \\
\text { GOVERNMENT PRIORITIES AS } \\
\text { DEFINED IN THE DNSCRP AND } \\
\text { SECTORAL STRATEGY }\end{array}$} & $\begin{array}{l}\text { Train technicians and lab } \\
\text { assistants to carry out their } \\
\text { various tasks }\end{array}$ & $2007 / 2008$ & $\begin{array}{l}\text {. LNBTP } \\
\text { own } \\
\text { resources } \\
\text {. External }\end{array}$ & $\begin{array}{l}\text { Internal needs } \\
\text { assessment forms for } \\
\text { training of technicians }\end{array}$ & $\begin{array}{l}.100 \% \text { of the } \\
\text { technicians master the } \\
\text { tests run in the units to } \\
\text { which they are } \\
\text { assigned }\end{array}$ & $\begin{array}{l}\text { Improved Lab and Field } \\
\text { Testing services. }\end{array}$ & LNBTP \\
\hline & $\begin{array}{l}\text { Promote the development of } \\
\text { research applied to materials } \\
\text { and transport infrastructure } \\
\text { and minimization of the risks } \\
\text { entailed in natural disasters }\end{array}$ & $2007 / 2009$ & $\begin{array}{l}\text { LNBTP } \\
\text { Own } \\
\text { resources }\end{array}$ & $\begin{array}{l}\text {. List of main topics of } \\
\text { concern; } \\
\text {. Meetings with other } \\
\text { institutions involved } \\
\text { (Universities, Other } \\
\text { Public Technical } \\
\text { Utilities); } \\
\text {. Formalization of } \\
\text { interinstitutional } \\
\text { partnership frameworks }\end{array}$ & $\begin{array}{l}\text { LNBTP applied } \\
\text { research program } \\
\text { document supported } \\
\text { by all stakeholders; }\end{array}$ & $\begin{array}{l}\text { Creation of an } \\
\text { environment conducive } \\
\text { to developing applied } \\
\text { research in the } \\
\text { construction sector }\end{array}$ & LNBTP \\
\hline & $\begin{array}{l}\text { Set up a quality management } \\
\text { system }\end{array}$ & $2013 / 2015$ & $\begin{array}{l}\text {. LNBTP } \\
\text { own } \\
\text { resources }\end{array}$ & $\begin{array}{l}\text { Recruitment of an } \\
\text { expert in Quality } \\
\text { Management; }\end{array}$ & $\begin{array}{l}\text { Quality manual } \\
\text { implemented; } \\
\text {. ISO } 9000\end{array}$ & $\begin{array}{l}\text { Improvement in the } \\
\text { service offered by the } \\
\text { LNBTP; }\end{array}$ & LNBTP \\
\hline
\end{tabular}


NATIONAL STRATEGY DOCUMENT FOR GROWTH AND POVERTY REDUCTION (DSNCRP/HATT)

ACTION PLANS TO REFORMTHE PUBLIC FINANCIAL MANAGEMENT SYSTEM

\begin{tabular}{|l|l|l|l|l|l|l|l|}
\hline & & & . External & $\begin{array}{l}\text {. Drafting of the LNBTP } \\
\text { Quality Manual }\end{array}$ & certification obtained & $\begin{array}{l}\text {. International } \\
\text { recognition of the } \\
\text { LNBTP. }\end{array}$ & \\
\hline
\end{tabular}

PRIORITY ACTION PLAN FOR THE NATIONAL CONSTRUCTION AND PUBLIC WORKS LABORATORY

\begin{tabular}{|c|c|c|c|c|c|c|c|}
\hline Objectives & Actions & $\begin{array}{l}\text { Fiscal } \\
\text { years }\end{array}$ & $\begin{array}{l}\text { Financial } \\
\text { resources }\end{array}$ & $\begin{array}{c}\text { Input } \\
\text { indicator }\end{array}$ & $\begin{array}{c}\text { Output } \\
\text { indicator }\end{array}$ & Performance indicator & $\begin{array}{c}\text { Implementing } \\
\text { Agency }\end{array}$ \\
\hline $\begin{array}{l}2 . \\
\text { IMPROVE BUDGET EXECUTION }\end{array}$ & & & & & & & LNBTP \\
\hline $\begin{array}{l}3 . \\
\text { IMPROVE TRANSPARENCY IN FISCAL } \\
\text { REPORTING }\end{array}$ & $\begin{array}{l}\text { Develop an IT tool to } \\
\text { calculate the cost } \\
\text { price of the tests }\end{array}$ & $2006 / 2008$ & $\begin{array}{l}\text { LNBTP own } \\
\text { resources } \\
\text {. Capital } \\
\text { expenditure } \\
\text { budget }\end{array}$ & $\begin{array}{l}\text { Creation of a } \\
\text { working group }\end{array}$ & $\begin{array}{l}\text { IT program } \\
\text { in operation }\end{array}$ & $\begin{array}{l}\text { Streamlining of financial and } \\
\text { accounting management of the } \\
\text { institution; } \\
\text {. Possibility of making } \\
\text { provision for replenishment of } \\
\text { assets; } \\
\text {. Transparency in the structure } \\
\text { of the costs applied by the } \\
\text { LNBTP. }\end{array}$ & LNBTP \\
\hline $\begin{array}{l}4 . \\
\text { GRADUALLY INTEGRATE } \\
\text { EXTERNALLY FUNDED } \\
\text { EXPENDITURES INTO THE SECTOR } \\
\text { BUDGET }\end{array}$ & & & & & & & \\
\hline $\begin{array}{l}\qquad 5 . \\
\text { ASSESS THE IMPACT OF FISCAL } \\
\text { EXPENDITURES AND MONITOR } \\
\text { FISCAL PERFORMANCE } \\
\end{array}$ & & & & & & & \\
\hline
\end{tabular}


NATIONAL STRATEGY DOCUMENT FOR GROWTH AND POVERTY REDUCTION (DSNCRP/HATTI)

ACTION PLANS TO REFORMTHE PUBLIC FINANCIAL MANAGEMENT SYSTEM 


\section{NATIONAL STRATEGY DOCUMENT FOR GROWTH AND POVERTY REDUCTION (DSNCRP/HATT)}

ACTION PLANS TO REFORMTHE PUBLIC FINANCIAL MANAGEMENT SYSTEM

Objective

(i) Disseminate the sectoral policy

documents

(ii) Prepare the framework education

law (framework law for capital

expenditure in the education sector over

a 5 - or 10 -year period)

(iii) Prepare a manual of procedures

for budget preparation

Fiscal Resources

years available

2007- Public

2008 Treasury/WB

2009- TO BE

2009 IDENTIFIED

Input indicator

Output indicator

Performance indicator

Reproduction of the

documents

Legal and economic expertise

mobilized

Documents distributed

The stakeholders are informed

Framework law

submitted to Parliamen

The budgets prepared by the

MENFP are validated by the MEF

and approved by Parliament

(iv) Strengthen human resources

specialized in budget preparation

(v) Conduct a survey of available

resources (human and material) and

existing procedures for government

action
2007- WB Actions

2008

Information from the

technical directorates

Expertise in financial

management

Procedure manual The 2008- 2009 budget and

available

Procedure manual and

trainers

Supervisors and

managers trained in

budget preparation

$2007-$

2008 in effect

The 2008- 2009 budget and in effect subsequent budgets are prepared in accordance with the procedure

subsequent budgets are prepared

in accordance with the procedures

Expert report

Consistency between planned

activities and available resources
Implementing

agency

MENFP

MENFP

DAA, Budget, DPCE

DAA, Budget, and MEF

TO BE
IDENTIFIED
(CIDA?)

Expertise in public

management

MENFP/DAA 
NATIONAL STRATEGY DOCUMENT FOR GROWTH AND POVERTY REDUCTION (DSNCRP/HATTI) ACTION PLANS TO REFORMTHE PUBLIC FINANCIAL MANAGEMENT SYSTEM

Objective 2. Improve budget execution Actions

(i) Update, establish, if necessary, and

Fiscal Resources

years available

disseminate fiscal management procedures

(iv) Upgrade IT infrastructure

(Architecture, Information System)

(v) Upgrade the software used to operate the information system

(vi) Prepare the procurement plan for

purchasing supplies, fuel, material, and equipment planned in the Operation and

Capital Expenditure Budgets (including the DDE)
2007- TO BE

2008

IDENTIFIED

2007- IDB/CIDA

2008 AFD/UNESCO

/EU/WB/

$2007-$

$2008 \mathrm{WB} / \mathrm{EU} /$

WB/EU/

CIDA/AFD

Input indicator

National expertise mobilized

equipment, IT plan/architecture

IT expertise

2007- Public

2008 Treasury/WB

Projects, template for plan

provided by the National

Government Procurement

Commission (CNMP)

\section{Output indicator}

Procedure handbook in existence

mproved connection time, as well as DAA and

DPCE

Information system up and running

Possible publication of report distinguishing Commitments from

Payments

Procurement plan prepared ahead of the fiscal year

\section{Performance}

indicator

Less time to

mobilize TP funds

Less time to

commit

expenditure

Less time required

for payment of

expenses

Government

contracts are

awarded on time
Implementing

agency

MEF and MPCE in

collaboration with

MENFP

DAA, budget,

DPCE, MEF

DAA, budget, DPCE, MEF

DAA, Ministeria

Commission 
NATIONAL STRATEGY DOCUMENT FOR GROWTH AND POVERTY REDUCTION (DSNCRP/HATT)

ACTION PLANS TO REFORMTHE PUBLIC FINANCIAL MANAGEMENT SYSTEM

Objective 2. Improve budget execution Actions

(vii) Expand the information system to the departmental level, school districts, area inspectorates, and schools

(ix) Disseminate the 2005 budget lexicon and nomenclature in DDE

(x) Strengthen technical capacities of the

accountants and administrators at the central and departmental levels

$\begin{array}{ll}\begin{array}{l}\text { Fiscal } \\ \text { years }\end{array} & \begin{array}{l}\text { Resources } \\ \text { available }\end{array} \\ 2007- & \text { USAID/IDB/ } \\ 2008 & \text { CIDA/EU/ } \\ & \text { UNESCO/WB } \\ & \text { AFD/UNICEF }\end{array}$

2008-

2009

2008-

2009

Public Treasury

\section{Reproduction of}

the documen

Expertise in public Supervisors and managers trained

finances

DDE, BDS, BIZ, and schools
Performance indicato

"Deconcentrated"

(subnational) expenses paid in less time

Deconcentrated expenses paid in less time

Less time for commitment to

deconcentrated expenditures
Implementing

agency

MENFP, MEF

information system installed in all the

DAA. DGA,

MEF

DAA, DGA,

MEF 
NATIONAL STRATEGY DOCUMENT FOR GROWTH AND POVERTY REDUCTION (DSNCRP/HATTI)

ACTION PLANS TO REFORMTHE PUBLIC FINANCIAL MANAGEMENT SYSTEM

Objective 3. Improve transparency in fiscal reporting

\section{Fiscal Resources}

(i) Integrate procurement

years available

skills into the ministry

Public

(project managers)

2008 Treasury/WB

and

onward

Input indicator

Output

indicator

Budgeting of

the

"Government

procurement"

and

managers

Performance

indicator

Implementing

More effective

agency

items on the

government

the civil

payroll

(ii) Expand the architecture

of the IT system at the

2007

IT and

departmental level

\section{UNESCO/IDB/}

$\mathrm{WB} / \mathrm{EU} / \mathrm{AFD} /$

equipment

expertise

(iii) Create a system of

monthly tripartite

UNICEF

2007- Public Treasury

National and

international

expertise

meetings (?)

(iv) Set up, in tandem with

UCF, procedures and tools

for harmonized monitoring of

2007- USAID/CIDA/

$2008 \quad / \mathrm{IDB} / \mathrm{WB} / \mathrm{EU}$

AFD/

National and

international

expertise

the accounts of the

investment program (IP)

projects

(v) Produce software to

manage and monitor capital

2009

WB/UNESCO/IDB

IT expertise

mobilized

Informatio

Closer

monitoring of

installed in all deconcentrated

he DDE

expenditures

Accounting Tradeoffs

software and resulting from

procedure

more consistent

manual for

cash management

project

accounting

Accounting

software and

Publication of

budget execution

manual of

project

accounting

procedures

Software

reports made

possible

Real time

production of a

consolidated

statement on the

execution of the

capital

expenditure

budget

DPCE, MEF,

DGA

MEF,

Treasury,

DAA

MPCE/MEF

MPCE/MEF 
NATIONAL STRATEGY DOCUMENT FOR GROWTH AND POVERTY REDUCTION (DSNCRP/HATTI) ACTION PLANS TO REFORMTHE PUBLIC FINANCIAL MANAGEMENT SYSTEM

Objective 3. Improve transparency in fiscal reporting

\begin{tabular}{|c|c|c|c|c|c|c|}
\hline Actions & $\begin{array}{l}\text { Fiscal } \\
\text { years }\end{array}$ & $\begin{array}{l}\text { Resources } \\
\text { available }\end{array}$ & Input indicator & Output indicator & $\begin{array}{l}\text { Performance } \\
\text { indicator }\end{array}$ & $\begin{array}{l}\text { Implementing } \\
\text { agency }\end{array}$ \\
\hline $\begin{array}{l}\text { (vi) Appoint } \\
\text { accountants to } \\
\text { manage IP projects }\end{array}$ & $\begin{array}{l}2007- \\
2008\end{array}$ & $\begin{array}{l}\text { Public } \\
\text { Treasury }\end{array}$ & $\begin{array}{l}\text { Public } \\
\text { accountants } \\
\text { appointed to } \\
\text { the DDE and } \\
\text { central MENFP }\end{array}$ & $\begin{array}{l}\text { Expenditure from } \\
\text { IP current } \\
\text { accounts are paid } \\
\text { by public } \\
\text { accountants }\end{array}$ & $\begin{array}{l}\text { More } \\
\text { standardized } \\
\text { management of } \\
\text { funds from IP } \\
\text { current accounts }\end{array}$ & MEF, MENFP \\
\hline $\begin{array}{l}\text { (vii) Establish and } \\
\text { implement a } \\
\text { procedure for closing } \\
\text { IP projects and } \\
\text { accounts }\end{array}$ & $\begin{array}{l}2007- \\
2008\end{array}$ & $\begin{array}{l}\text { IDB/WB/EU/ } \\
\text { CIDA/UNICEF/ } \\
\text { USAID/AFD }\end{array}$ & $\begin{array}{l}\text { National and } \\
\text { international } \\
\text { expertise }\end{array}$ & $\begin{array}{l}\text { Manual of } \\
\text { procedures for } \\
\text { project and } \\
\text { account closure in } \\
\text { existence }\end{array}$ & $\begin{array}{l}\text { Better allocation of } \\
\text { residuals }\end{array}$ & MPCE/MEF/MENFP \\
\hline $\begin{array}{l}\text { (viii) Strengthen } \\
\text { auditing of } \\
\text { transitional accounts }\end{array}$ & $\begin{array}{l}2008- \\
2009\end{array}$ & Public Treasury & $\begin{array}{l}\text { Letter from the } \\
\text { Minister }\end{array}$ & Account audited & $\begin{array}{l}\text { Only one current } \\
\text { account with the } \\
\text { minister's } \\
\text { signature for extra } \\
\text { budgetary } \\
\text { expenditures }\end{array}$ & MENFP, MEF \\
\hline $\begin{array}{l}\text { (ix) Inventory and } \\
\text { specify the procedures } \\
\text { for managing own } \\
\text { resources (especially } \\
\text { deconcentrated } \\
\text { resources) }\end{array}$ & $\begin{array}{l}2007- \\
2008\end{array}$ & $\begin{array}{l}\text { IDB/WB/EU/ } \\
\text { CIDA/UNICEF/ } \\
\text { USAID/AFD }\end{array}$ & $\begin{array}{l}\text { National } \\
\text { expertise }\end{array}$ & $\begin{array}{l}\text { Existence of an } \\
\text { updated inventory } \\
\text { of own resources } \\
\text { and management } \\
\text { procedures manual }\end{array}$ & $\begin{array}{l}\text { Harmonized } \\
\text { management of } \\
\text { own resources, } \\
\text { budgeting made } \\
\text { possible }\end{array}$ & MENFP and MEF \\
\hline
\end{tabular}


NATIONAL STRATEGY DOCUMENT FOR GROWTH AND POVERTY REDUCTION (DSNCRP/HATT) ACTION PLANS TO REFORMTHE PUBLIC FINANCIAL MANAGEMENT SYSTEM

Objective 4. Gradually integrate externally funded expenditures into the sector budget

\begin{tabular}{|c|c|c|c|c|c|c|}
\hline Actions & $\begin{array}{l}\text { Fiscal } \\
\text { years }\end{array}$ & $\begin{array}{l}\text { Resources } \\
\text { available }\end{array}$ & Input indicator & $\begin{array}{l}\text { Output } \\
\text { indicator }\end{array}$ & $\begin{array}{l}\text { Performance } \\
\text { indicator }\end{array}$ & $\begin{array}{l}\text { Implementing } \\
\text { agency }\end{array}$ \\
\hline $\begin{array}{l}\text { (i) Involve the main } \\
\text { donors and lenders } \\
\text { in the preparation of } \\
\text { the budget }\end{array}$ & $\begin{array}{l}2011- \\
2015\end{array}$ & Public Treasury & $\begin{array}{l}\text { Technical } \\
\text { consultations } \\
\text { organized during the } \\
\text { budget preparation } \\
\text { process }\end{array}$ & $\begin{array}{l}\text { Records of } \\
\text { working } \\
\text { meetings }\end{array}$ & $\begin{array}{l}\text { Externally funded } \\
\text { capital } \\
\text { expenditures } \\
\text { carried correctly in } \\
\text { the budget }\end{array}$ & $\begin{array}{l}\text { MPCE, MEF, } \\
\text { MENFP }\end{array}$ \\
\hline $\begin{array}{l}\text { (ii) Establish a } \\
\text { harmonized } \\
\text { framework for } \\
\text { monitoring capital } \\
\text { expenditure funded } \\
\text { through external } \\
\text { cooperation }\end{array}$ & $\begin{array}{l}2007- \\
2008\end{array}$ & $\begin{array}{l}\text { IDB/WB/EU/ } \\
\text { CIDA/UNICEF/ } \\
\text { USAID/AFD }\end{array}$ & $\begin{array}{l}\text { National expertise } \\
\text { mobilized and } \\
\text { expanded consultations } \\
\text { taking place with } \\
\text { technical ministries } \\
\text { and donors and lenders }\end{array}$ & $\begin{array}{l}\text { Database and } \\
\text { procedure } \\
\text { manual prepared } \\
\text { and negotiated } \\
\text { with all the } \\
\text { donors and } \\
\text { lenders }\end{array}$ & $\begin{array}{l}\text { Externally funded } \\
\text { capital } \\
\text { expenditures } \\
\text { carried correctly in } \\
\text { the budget }\end{array}$ & $\begin{array}{l}\text { Prime Minister's } \\
\text { Office, MPCE, } \\
\text { MEF, MENFP }\end{array}$ \\
\hline
\end{tabular}


NATIONAL STRATEGY DOCUMENT FOR GROWTH AND POVERTY REDUCTION (DSNCRP/HATTI) ACTION PLANS TO REFORMTHE PUBLIC FINANCIAL MANAGEMENT SYSTEM

Objective 5. Assess the impact of fiscal expenditures and monitor fiscal performance

\begin{tabular}{|c|c|c|c|c|c|c|}
\hline Actions & $\begin{array}{l}\text { Fiscal } \\
\text { years }\end{array}$ & Resources available & $\begin{array}{l}\text { Input } \\
\text { indicator }\end{array}$ & $\begin{array}{l}\text { Output } \\
\text { indicator }\end{array}$ & $\begin{array}{l}\text { Performance } \\
\text { indicator }\end{array}$ & $\begin{array}{l}\text { Implementing } \\
\text { agency }\end{array}$ \\
\hline $\begin{array}{l}\text { (i) Conduct targeted } \\
\text { impact assessments }\end{array}$ & $\begin{array}{l}2008- \\
2009\end{array}$ & $\begin{array}{l}\text { IDB/WB/EU/ } \\
\text { CIDA/UNICEF/ } \\
\text { USAID/AFD }\end{array}$ & $\begin{array}{l}\text { International } \\
\text { and national } \\
\text { firms and } \\
\text { consultants }\end{array}$ & $\begin{array}{l}\text { Report on } \\
\text { targeted } \\
\text { impact studies }\end{array}$ & $\begin{array}{l}\text { Greater } \\
\text { awareness of the } \\
\text { link between } \\
\text { sectoral } \\
\text { investment and } \\
\text { poverty reduction }\end{array}$ & $\begin{array}{l}\text { MENFP, MEF, } \\
\text { DPCE }\end{array}$ \\
\hline $\begin{array}{l}\text { (ii) Strengthen } \\
\text { human resources } \\
\text { specialized in } \\
\text { impact assessment }\end{array}$ & $\begin{array}{l}2007- \\
2008\end{array}$ & Public Treasury/WB & $\begin{array}{l}\text { Training of } \\
\text { supervisors } \\
\text { and managers } \\
\text { of the DPCE }\end{array}$ & Impact study & $\begin{array}{l}\text { Greater } \\
\text { awareness of the } \\
\text { link between } \\
\text { sectoral } \\
\text { investment and } \\
\text { poverty reduction }\end{array}$ & MENFP/MEF DPCE \\
\hline $\begin{array}{l}\text { (vi) Establish } \\
\text { benchmarks and } \\
\text { standards for impact } \\
\text { assessments in the } \\
\text { education sector } \\
\text { and prepare a } \\
\text { template for the } \\
\text { education sector } \\
\text { (forecast) }\end{array}$ & $\begin{array}{l}2008- \\
2009 \\
\text { and } \\
\text { onward }\end{array}$ & $\begin{array}{l}\text { UNESCO/IDB/CIDA/ } \\
\text { AFD/USAID/WB-EU }\end{array}$ & $\begin{array}{l}\text { Consultant } \\
\text { (international } \\
\text { and national) }\end{array}$ & $\begin{array}{l}\text { Document on } \\
\text { standards for } \\
\text { capital } \\
\text { expenditure } \\
\text { and sectoral } \\
\text { template }\end{array}$ & $\begin{array}{l}\text { Consistency } \\
\text { between } \\
\text { education policy } \\
\text { objectives and the } \\
\text { resources } \\
\text { mobilized }\end{array}$ & MENFP/DPCE \\
\hline $\begin{array}{l}\text { (vii) Establish } \\
\text { benchmarks and } \\
\text { standards between } \\
\text { capital expenditure } \\
\text { on education and } \\
\text { recurring costs }\end{array}$ & $\begin{array}{l}2008- \\
2009 \\
\text { and } \\
\text { onward }\end{array}$ & $\begin{array}{l}\text { UNESCO-IDB-CIDA- } \\
\text { AFD-USAID-WB-EU }\end{array}$ & Consultant & $\begin{array}{l}\text { Document on } \\
\text { standards for } \\
\text { recurring costs }\end{array}$ & $\begin{array}{l}\text { Consistency } \\
\text { between capital } \\
\text { investment } \\
\text { budget and } \\
\text { operations } \\
\text { budgets }\end{array}$ & MENFP/DPCE/DAA \\
\hline
\end{tabular}




\section{NATIONAL STRATEGY DOCUMENT FOR GROWTH AND POVERTY REDUCTION (DSNCRP/HATT)}

ACTION PLANS TO REFORMTHE PUBLIC FINANCIAL MANAGEMENT SYSTEM

ACTION PLAN HEALTH SECTOR

(**Priority Actions)

\begin{tabular}{|c|c|c|c|c|c|c|c|}
\hline Objectives & Actions & $\begin{array}{l}\text { Fiscal } \\
\text { Years }\end{array}$ & $\begin{array}{l}\text { Resources } \\
\text { Available }\end{array}$ & $\begin{array}{l}\text { Input } \\
\text { Indicator }\end{array}$ & $\begin{array}{l}\text { Output } \\
\text { Indicator }\end{array}$ & $\begin{array}{l}\text { Performance } \\
\text { Indicator }\end{array}$ & $\begin{array}{l}\text { Implementing } \\
\text { Agency }\end{array}$ \\
\hline \multirow[t]{3}{*}{$\begin{array}{l}\text { 1.- Strengthen the links } \\
\text { between the allocation } \\
\text { of resources and the } \\
\text { government's priorities } \\
\text { defined in the NSGPR } \\
\text { and the sectoral } \\
\text { strategy }\end{array}$} & $\begin{array}{l}\text { 1.1. -**Hire technical } \\
\text { assistance for the } \\
\text { budgetary exercise, train } \\
\text { staff, and construct a } \\
\text { system for monitoring } \\
\text { execution of the budget }\end{array}$ & $2007-2008$ & IDB-1632 & $\begin{array}{l}\text { TOR for } \\
\text { technical } \\
\text { assistance }\end{array}$ & $\begin{array}{l}\text { Budget 2008- } \\
2009 \text { includes } \\
\text { the links } \\
\text { between the } \\
\text { resources and } \\
\text { the strategy }\end{array}$ & $\begin{array}{l}\text { Have a } \\
\text { sectoral } \\
\text { strategy of a } \\
\text { multi-year } \\
\text { budget with an } \\
\text { estimate of } \\
\text { recurrent } \\
\text { spending and } \\
\text { investment }\end{array}$ & $\begin{array}{l}\mathrm{MSPP} / \mathrm{M} \\
\mathrm{EF}\end{array}$ \\
\hline & $\begin{array}{l}\text { 1.2.- Conduct a study on } \\
\text { the financing of healthcare } \\
\text { for the disadvantaged }\end{array}$ & $2008-2010$ & $\begin{array}{l}\text { Still to be } \\
\text { identified }\end{array}$ & $\begin{array}{l}\text { Recruitment } \\
\text { of a } \\
\text { consultant }\end{array}$ & $\begin{array}{l}\text { Availability of } \\
\text { the study }\end{array}$ & $\begin{array}{l}\text { The MSPP has } \\
\text { relevant } \\
\text { information for } \\
\text { starting a pilot } \\
\text { project on } \\
\text { financing } \\
\text { healthcare for } \\
\text { the } \\
\text { underprivileged }\end{array}$ & MSPP \\
\hline & $\begin{array}{l}\text { 1.3. - Strengthen the } \\
\text { human resources } \\
\text { necessary for the } \\
\text { introduction of mobile } \\
\text { clinics in remotest areas }\end{array}$ & $2008-2010$ & $\begin{array}{l}\text { Still to be } \\
\text { identified }\end{array}$ & $\begin{array}{l}\text { Recruitment } \\
\text { and training } \\
\text { of staff }\end{array}$ & $\begin{array}{l}\text { Human } \\
\text { resources } \\
\text { trained and } \\
\text { available for } \\
\text { the introduction } \\
\text { of mobile } \\
\text { clinics }\end{array}$ & $\begin{array}{l}\text { The MSPP has } \\
\text { resources } \\
\text { capable of } \\
\text { managing, } \\
\text { operating, and } \\
\text { maintaining } \\
\text { clinics in the } \\
\text { areas in which } \\
\text { they are } \\
\text { located }\end{array}$ & MSPP \\
\hline
\end{tabular}


NATIONAL STRATEGY DOCUMENT FOR GROWTH AND POVERTY REDUCTION (DSNCRP/HATT)

ACTION PLANS TO REFORMTHE PUBLIC FINANCIAL MANAGEMENT SYSTEM

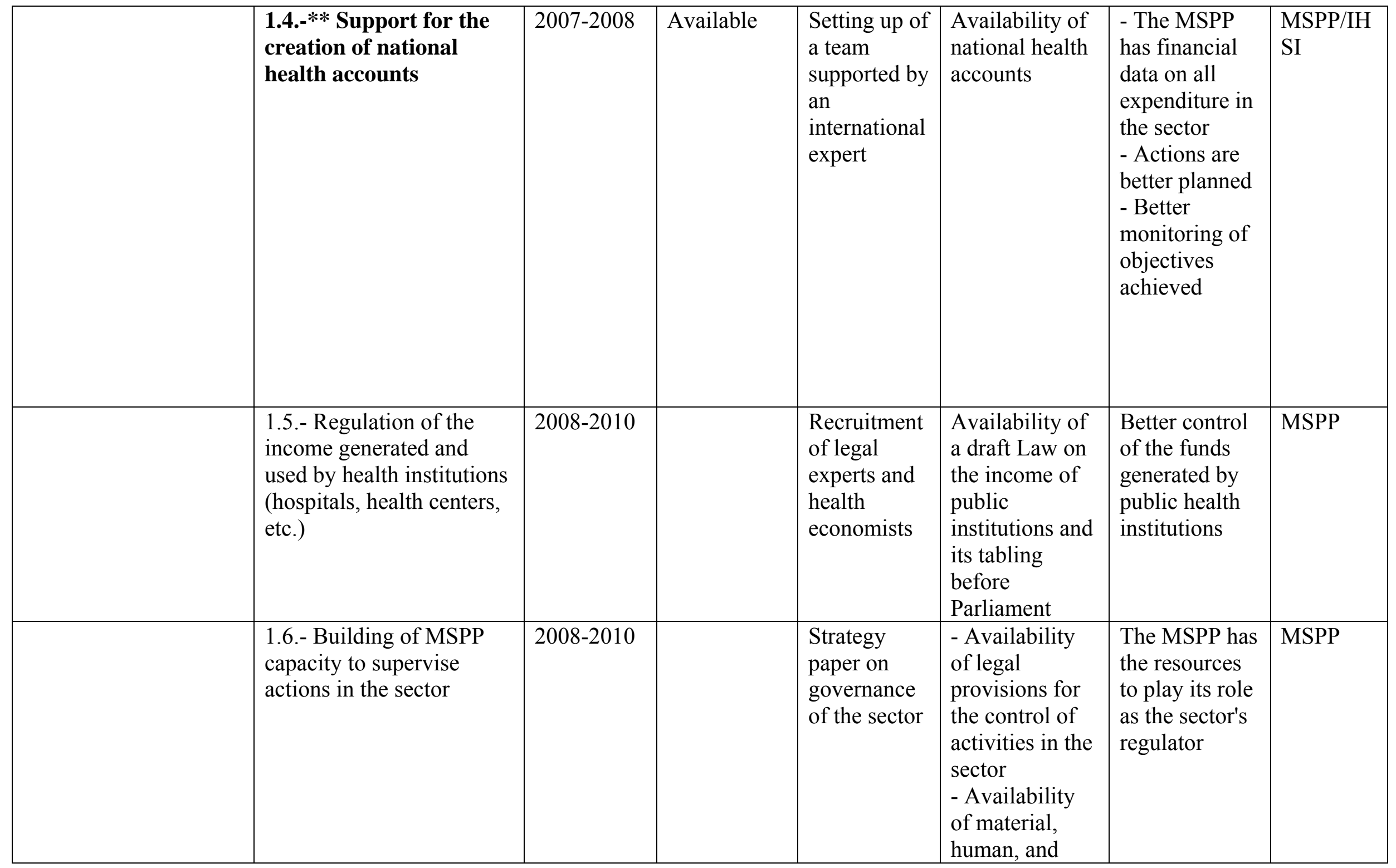


NATIONAL STRATEGY DOCUMENT FOR GROWTH AND POVERTY REDUCTION (DSNCRP/HATTI)

ACTION PLANS TO REFORMTHE PUBLIC FINANCIAL MANAGEMENT SYSTEM

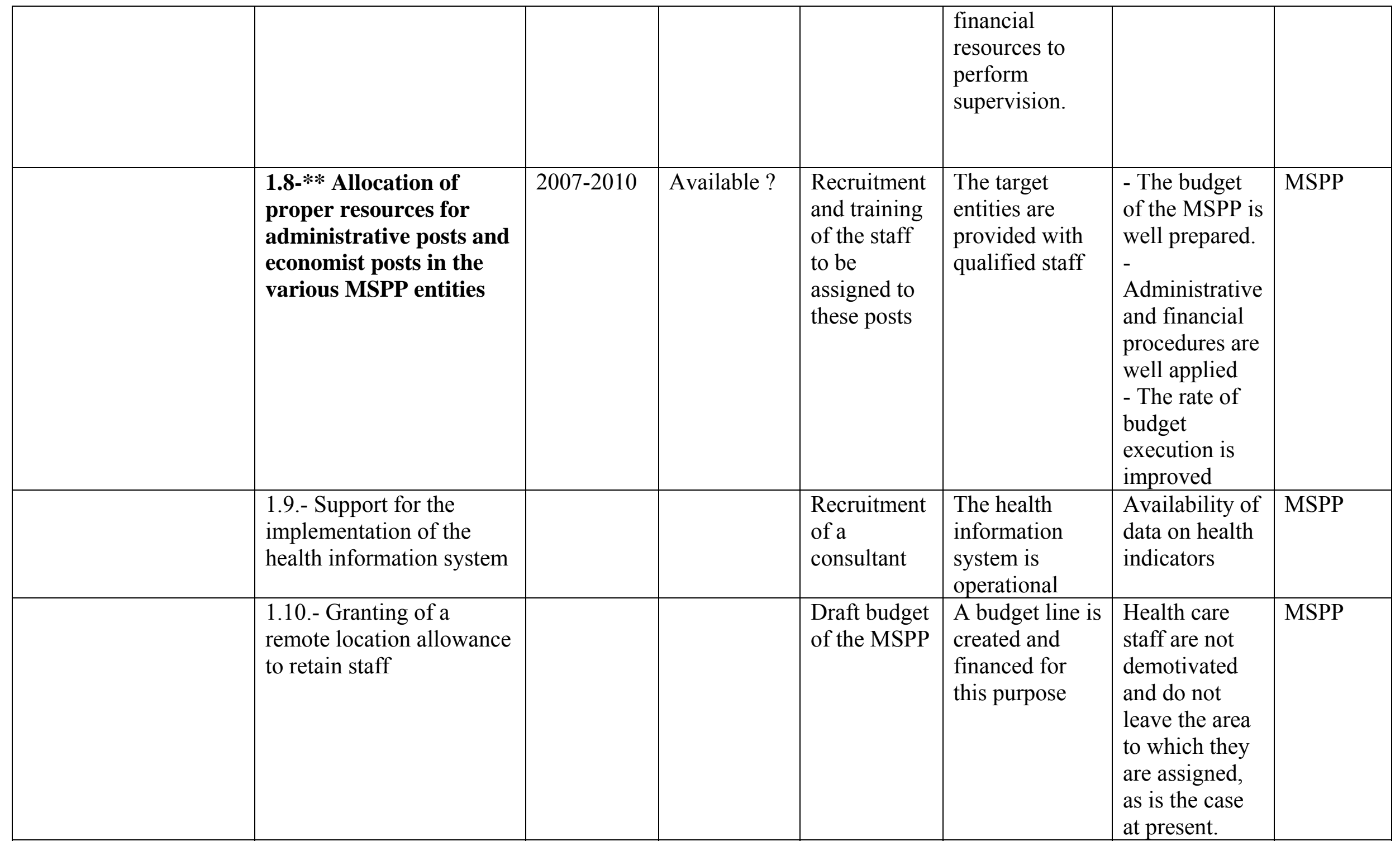


NATIONAL STRATEGY DOCUMENT FOR GROWTH AND POVERTY REDUCTION (DSNCRP/HATTI)

ACTION PLANS TO REFORMTHE PUBLIC FINANCIAL MANAGEMENT SYSTEM

\begin{tabular}{|l|l|l|l|l|l|l|}
\hline & $\begin{array}{l}\text { Drafting of a public health } \\
\text { code (UCSs, hospitals, } \\
\text { insurance companies, etc.) }\end{array}$ & & & $\begin{array}{l}\text { Recruitment } \\
\text { of a } \\
\text { consultant }\end{array}$ & $\begin{array}{l}\text { The draft Law } \\
\text { is updated and } \\
\text { ready to be } \\
\text { brought before } \\
\text { Parliament }\end{array}$ & $\begin{array}{l}\text { The MSPP has } \\
\text { a powerful } \\
\text { tool with } \\
\text { which to } \\
\text { implement its } \\
\text { vision for the } \\
\text { development } \\
\text { of the system }\end{array}$ \\
& & & & &
\end{tabular}


NATIONAL STRATEGY DOCUMENT FOR GROWTH AND POVERTY REDUCTION (DSNCRP/HATTI) ACTION PLANS TO REFORMTHE PUBLIC FINANCIAL MANAGEMENT SYSTEM

ACTION PLAN HEALTH SECTOR

(**Priority Actions)

\begin{tabular}{|c|c|c|c|c|c|c|c|}
\hline Objectives & Actions & $\begin{array}{l}\text { Fiscal } \\
\text { Years }\end{array}$ & $\begin{array}{l}\text { Available } \\
\text { Resources }\end{array}$ & $\begin{array}{l}\text { Input } \\
\text { Indicator }\end{array}$ & Output Indicator & $\begin{array}{l}\text { Performance } \\
\text { Indicator }\end{array}$ & $\begin{array}{l}\text { Implementing } \\
\text { Agency }\end{array}$ \\
\hline $\begin{array}{l}\text { 2. Improve } \\
\text { preparation of } \\
\text { the budget }\end{array}$ & $\begin{array}{l}\text { 2.1.- ** Revision of } \\
\text { the MSPP } \\
\text { budgeting system } \\
\text { (budget taking own } \\
\text { resources into } \\
\text { account) }\end{array}$ & $\begin{array}{l}2007- \\
2008\end{array}$ & & $\begin{array}{l}\text { Setting up of a } \\
\text { working } \\
\text { group } \\
\text { - Terms of } \\
\text { Reference } \\
\text { (TOR) of the } \\
\text { group } \\
\text { - Document } \\
\text { assessing } \\
\text { budget } \\
\text { execution }\end{array}$ & $\begin{array}{l}\text { Manual of } \\
\text { procedures for } \\
\text { preparing } \\
\text { bottom-up } \\
\text { budgeting } \\
\text { mechanisms with } \\
\text { greater } \\
\text { involvement of } \\
\text { senior MSPP } \\
\text { administrators, } \\
\text { prepared and } \\
\text { available. } \\
\text { - Holding of } \\
\text { training seminars } \\
\text { for senior } \\
\text { administrators in } \\
\text { directorates at } \\
\text { headquarters and } \\
\text { in the } \\
\text { départements and } \\
\text { hospital } \\
\text { managers on } \\
\text { procedures for } \\
\text { monitoring } \\
\text { execution of the }\end{array}$ & $\begin{array}{l}\text { Dissemination of the } \\
\text { manual to facilitate } \\
\text { acceptance of } \\
\text { ownership of the } \\
\text { budget and the } \\
\text { monitoring of the } \\
\text { budget }\end{array}$ & MSPP \\
\hline
\end{tabular}


NATIONAL STRATEGY DOCUMENT FOR GROWTH AND POVERTY REDUCTION (DSNCRP/HATTI) ACTION PLANS TO REFORMTHE PUBLIC FINANCIAL MANAGEMENT SYSTEM

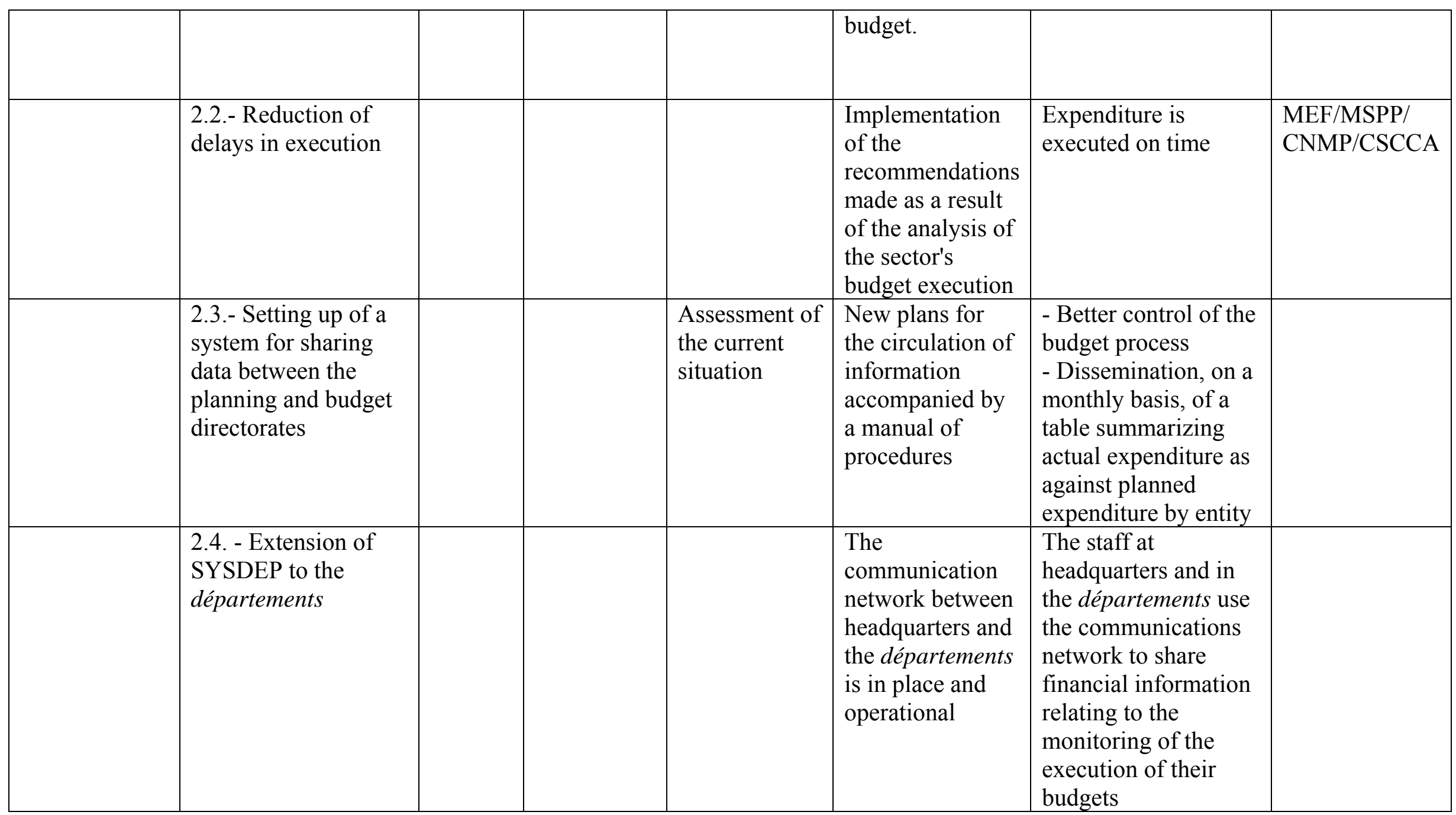


NATIONAL STRATEGY DOCUMENT FOR GROWTH AND POVERTY REDUCTION (DSNCRP/HATTI) ACTION PLANS TO REFORMTHE PUBLIC FINANCIAL MANAGEMENT SYSTEM

ACTION PLAN HEALTH SECTOR

(**Priority Actions)

\begin{tabular}{|c|c|c|c|c|c|c|c|}
\hline Objectives & Actions & $\begin{array}{l}\text { Fiscal } \\
\text { Years }\end{array}$ & $\begin{array}{l}\text { Available } \\
\text { Resources }\end{array}$ & $\begin{array}{l}\text { Input } \\
\text { Indicator }\end{array}$ & $\begin{array}{l}\text { Output } \\
\text { Indicator }\end{array}$ & $\begin{array}{l}\text { Performance } \\
\text { Indicator }\end{array}$ & $\begin{array}{l}\text { Implementing } \\
\text { Agency }\end{array}$ \\
\hline \multirow[t]{4}{*}{$\begin{array}{l}\text { 3.- Improve the } \\
\text { transparency } \\
\text { budget reporting }\end{array}$} & $\begin{array}{l}\text { 3.1-** } \\
\text { Establishment of a } \\
\text { timetable for } \\
\text { reducing the } \\
\text { number of current } \\
\text { accounts }\end{array}$ & $2007-2008$ & IDB-1632 & $\begin{array}{l}\text { The Minister } \\
\text { will issue a } \\
\text { circular } \\
\text { approving the } \\
\text { current } \\
\text { accounts } \\
\text { calendar }\end{array}$ & $\begin{array}{l}\text { Current } \\
\text { accounts are } \\
\text { closed in } \\
\text { accordance } \\
\text { with the } \\
\text { timetable }\end{array}$ & $\begin{array}{l}\text { No more current } \\
\text { accounts }\end{array}$ & MSPP \\
\hline & $\begin{array}{l}\text { 3.2.- Standardization } \\
\text { of financial } \\
\text { procedures relating to } \\
\text { own funds }\end{array}$ & & IDB & $\begin{array}{l}\text { Current } \\
\text { procedures in } \\
\text { question }\end{array}$ & $\begin{array}{l}\text { The } \\
\text { commitment } \\
\text { and } \\
\text { disbursement } \\
\text { procedures } \\
\text { are well } \\
\text { known to } \\
\text { administrative } \\
\text { staff }\end{array}$ & $\begin{array}{l}\text { The commitment } \\
\text { and disbursement } \\
\text { procedures are } \\
\text { monitored by the } \\
\text { sector's } \\
\text { administrative staff }\end{array}$ & MSPP \\
\hline & $\begin{array}{l}\text { 3.3.- Establishment } \\
\text { of an internal audit } \\
\text { unit at the MSPP }\end{array}$ & & & $\begin{array}{l}\text { TOR } \\
\text { available. } \\
\text { - Availability } \\
\text { of the skills }\end{array}$ & $\begin{array}{l}\text { Unit } \\
\text { established } \\
\text { and } \\
\text { operational }\end{array}$ & $\begin{array}{l}\text { Number of audits } \\
\text { conducted and } \\
\text { recommendations. } \\
\text { - Implementation } \\
\text { of } \\
\text { recommendations }\end{array}$ & MSPP \\
\hline & $\begin{array}{l}\text { 3.4.- Introduction of } \\
\text { mechanisms to } \\
\text { ensure sound } \\
\text { management of funds }\end{array}$ & & & $\begin{array}{l}\text { Application } \\
\text { of the } \\
\text { mechanisms } \\
\text { to ensure }\end{array}$ & & $\begin{array}{l}\text { Number of } \\
\text { administrative and } \\
\text { financial staff } \\
\text { applying the }\end{array}$ & $\begin{array}{l}\text { MSPP/MEF } \\
\text { and DGT }\end{array}$ \\
\hline
\end{tabular}


NATIONAL STRATEGY DOCUMENT FOR GROWTH AND POVERTY REDUCTION (DSNCRP/HATTI)

ACTION PLANS TO REFORMTHE PUBLIC FINANCIAL MANAGEMENT SYSTEM

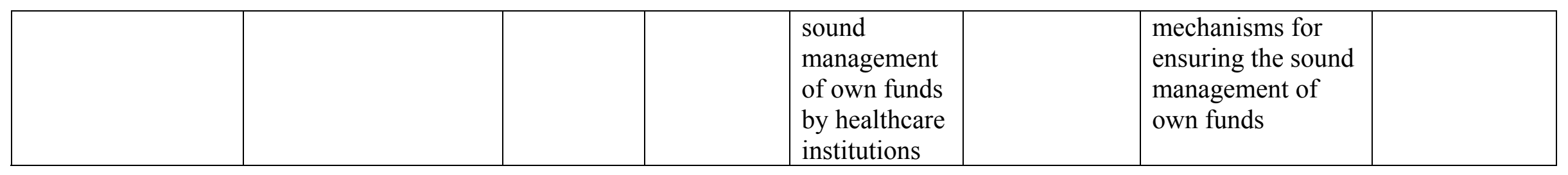


NATIONAL STRATEGY DOCUMENT FOR GROWTH AND POVERTY REDUCTION (DSNCRP/HATTI)

ACTION PLANS TO REFORMTHE PUBLIC FINANCIAL MANAGEMENT SYSTEM

ACTION PLAN HEALTH SECTOR

(**Priority Actions) 
NATIONAL STRATEGY DOCUMENT FOR GROWTH AND POVERTY REDUCTION (DSNCRP/HATTI)

ACTION PLANS TO REFORMTHE PUBLIC FINANCIAL MANAGEMENT SYSTEM

\begin{tabular}{|c|c|c|c|c|c|c|c|}
\hline Objectives & Actions & $\begin{array}{l}\text { Fiscal } \\
\text { Years }\end{array}$ & $\begin{array}{l}\text { Available } \\
\text { Resources }\end{array}$ & Input Indicator & $\begin{array}{l}\text { Output } \\
\text { Indicator }\end{array}$ & $\begin{array}{l}\text { Performance } \\
\text { Indicator }\end{array}$ & $\begin{array}{l}\text { Implementi } \\
\text { ng Agency }\end{array}$ \\
\hline $\begin{array}{l}\text { 4.- Gradually incorporate } \\
\text { expenditure financed by } \\
\text { foreign resources in the } \\
\text { sector's budget }\end{array}$ & $\begin{array}{l}4.1 * * \text { Meeting with } \\
\text { financial the sector's } \\
\text { stakeholders on } \\
\text { incorporating the } \\
\text { expenditure in the } \\
\text { budget }\end{array}$ & $\begin{array}{l}2007- \\
2008\end{array}$ & & $\begin{array}{l}\text { - Number of } \\
\text { meetings held } \\
\text { with financial } \\
\text { stakeholders } \\
\text { - Number of } \\
\text { financial } \\
\text { stakeholders } \\
\text { taking part in the } \\
\text { meetings }\end{array}$ & $\begin{array}{l}\text { Database of } \\
\text { projects } \\
\text { financed } \\
\text { with } \\
\text { financial } \\
\text { projections } \\
\text { through to } \\
\text { the end of } \\
\text { operations }\end{array}$ & $\begin{array}{l}\text { - Number of } \\
\text { partners } \\
\text { incorporating } \\
\text { their resources in } \\
\text { the budget } \\
\text { - The budget } \\
2008-2009 \\
\text { includes foreign } \\
\text { resources }\end{array}$ & MSPP/MEF \\
\hline & $\begin{array}{l}\text { 4.2.- Meeting with the } \\
\text { sector's financial } \\
\text { stakeholders on } \\
\text { inclusion of the } \\
\text { expenditure in the } \\
\text { budget }\end{array}$ & & & $\begin{array}{l}\text { - Number of } \\
\text { meetings held } \\
\text { with the financial } \\
\text { stakeholders } \\
\text { - Number of } \\
\text { financial } \\
\text { stakeholders who } \\
\text { took part in the } \\
\text { meetings }\end{array}$ & $\begin{array}{l}\text { Number of } \\
\text { partners } \\
\text { including } \\
\text { their } \\
\text { resources } \\
\text { in the } \\
\text { budget }\end{array}$ & $\begin{array}{l}\text { - The system's } \\
\text { stakeholders } \\
\text { agree to provide } \\
\text { information on } \\
\text { the resources } \\
\text { they have } \\
\text { available and on } \\
\text { their } \\
\text { procurement plan } \\
\text { for the target } \\
\text { fiscal year } \\
\text { - NGOs and } \\
\text { other } \\
\text { stakeholders } \\
\text { agree to align } \\
\text { their budgets on } \\
\text { the fiscal year of } \\
\text { the Haitian } \\
\text { government }\end{array}$ & $\begin{array}{l}\text { MSPP/MEF } \\
/ \mathrm{MPCE}\end{array}$ \\
\hline
\end{tabular}


NATIONAL STRATEGY DOCUMENT FOR GROWTH AND POVERTY REDUCTION (DSNCRP/HATTI)

ACTION PLANS TO REFORMTHE PUBLIC FINANCIAL MANAGEMENT SYSTEM

\begin{tabular}{|c|c|c|c|c|c|}
\hline & $\begin{array}{l}\text { 4.3.- Carrying out of } \\
\text { specific field surveys } \\
\text { on the sources of } \\
\text { finance, broken down } \\
\text { by expenditure the of } \\
\text { the health institutions, } \\
\text { programs, and projects } \\
\text { implemented within the } \\
\text { sector }\end{array}$ & $\begin{array}{l}\text { Number of } \\
\text { institutions } \\
\text { visited to identify } \\
\text { their sources of } \\
\text { finance }\end{array}$ & $\begin{array}{l}\text { Sources of } \\
\text { financing } \\
\text { properly } \\
\text { identified }\end{array}$ & $\begin{array}{l}\text { The MSPP has } \\
\text { relevant } \\
\text { information to } \\
\text { improve } \\
\text { targeting of the } \\
\text { sector's financing }\end{array}$ & $\begin{array}{l}\text { MSPP/MEF } \\
\text { /MPCE }\end{array}$ \\
\hline & $\begin{array}{l}\text { 4.4.- Inclusion of } \\
\text { sources of financing in } \\
\text { the budget }\end{array}$ & $\begin{array}{l}\text { Finding of the } \\
\text { specific surveys }\end{array}$ & $\begin{array}{l}\text { Preparation } \\
\text { of the MSPP } \\
\text { budget } \\
\text { incorporates } \\
\text { the different } \\
\text { sources of } \\
\text { financing }\end{array}$ & $\begin{array}{l}\text { Financing is } \\
\text { better } \\
\text { coordinated, the } \\
\text { use of resources } \\
\text { is efficient }\end{array}$ & MSPP \\
\hline & $\begin{array}{l}\text { Adoption of the } \\
\text { partnership charter } \\
\text { defining relations } \\
\text { between the MSPP and } \\
\text { all stakeholders } \\
\text { involved in the } \\
\text { provision of care }\end{array}$ & $\begin{array}{l}\text { The existing } \\
\text { partnership } \\
\text { charter }\end{array}$ & $\begin{array}{l}\text { Adoption and } \\
\text { implementation } \\
\text { of the } \\
\text { partnership } \\
\text { charter by all } \\
\text { the sectors' } \\
\text { stakeholders }\end{array}$ & $\begin{array}{l}\text { Financing is } \\
\text { better } \\
\text { coordinated, the } \\
\text { use of resources } \\
\text { is efficient }\end{array}$ & MSPP \\
\hline
\end{tabular}


NATIONAL STRATEGY DOCUMENT FOR GROWTH AND POVERTY REDUCTION (DSNCRP/HATT)

ACTION PLANS TO REFORMTHE PUBLIC FINANCIAL MANAGEMENT SYSTEM

\section{ACTION PLAN HEALTH SECTOR}

(**Priority Actions)

\begin{tabular}{|c|c|c|c|c|c|c|c|}
\hline Objectives & Actions & $\begin{array}{l}\text { Fiscal } \\
\text { Years }\end{array}$ & $\begin{array}{l}\text { Available } \\
\text { Resources }\end{array}$ & Input Indicator & $\begin{array}{l}\text { Output } \\
\text { Indicator }\end{array}$ & $\begin{array}{l}\text { Performance } \\
\text { Indicator }\end{array}$ & $\begin{array}{l}\text { Implementing } \\
\text { Agency }\end{array}$ \\
\hline $\begin{array}{l}\text { 5. Improve the } \\
\text { government } \\
\text { procurement } \\
\text { system }\end{array}$ & $\begin{array}{l}5.1 . * * \text { - Hire a firm to } \\
\text { carry out an } \\
\text { assessment of the } \\
\text { new MSPP } \\
\text { procurement unit }\end{array}$ & $\begin{array}{l}2007- \\
2008\end{array}$ & & $\begin{array}{l}\text { Terms of } \\
\text { reference of the } \\
\text { firm that will } \\
\text { carry out the } \\
\text { assessment and } \\
\text { make } \\
\text { recommendations } \\
\text { to build } \\
\text { procurement } \\
\text { capacity }\end{array}$ & $\begin{array}{l}\text { The } \\
\text { procurement } \\
\text { reform is } \\
\text { implemented } \\
\text { (new } \\
\text { organization, } \\
\text { new tools, } \\
\text { and training } \\
\text { for senior } \\
\text { staff) }\end{array}$ & $\begin{array}{l}\text { Estimate of } \\
\text { the time and } \\
\text { cost of } \\
\text { procurement }\end{array}$ & MSPP \\
\hline
\end{tabular}


NATIONAL STRATEGY DOCUMENT FOR GROWTH AND POVERTY REDUCTION (DSNCRP/HATTI)

ACTION PLANS TO REFORMTHE PUBLIC FINANCIAL MANAGEMENT SYSTEM

ACTION PLAN HEALTH SECTOR

(**Priority Actions)

\begin{tabular}{|l|l|l|l|l|l|l|l|}
\hline Objectives & Actions & Fiscal Years & $\begin{array}{l}\text { Available } \\
\text { Resources }\end{array}$ & $\begin{array}{l}\text { Input } \\
\text { Indicator }\end{array}$ & $\begin{array}{l}\text { Output } \\
\text { Indicator }\end{array}$ & $\begin{array}{l}\text { Performance } \\
\text { Indicator }\end{array}$ & $\begin{array}{l}\text { Implementing } \\
\text { Agency }\end{array}$ \\
\hline $\begin{array}{l}\text { 6. Consolidate } \\
\text { the management } \\
\text { of human } \\
\text { resources and } \\
\text { build the capacity } \\
\text { of the budget and } \\
\text { expenditure } \\
\text { management } \\
\text { procedures }\end{array}$ & $\begin{array}{l}\text { 6.1.- Hire } \\
\text { new } \\
\text { management- } \\
\text { level staff in } \\
\text { accordance } \\
\text { with the } \\
\text { ministry's } \\
\text { human } \\
\text { resources } \\
\text { plan and } \\
\text { principles }\end{array}$ & $2007-2008$ & IDB & $\begin{array}{l}\text { Development } \\
\text { of a human } \\
\text { resources } \\
\text { strategy } \\
\text { indicating } \\
\text { training and } \\
\text { recruitment } \\
\text { management- } \\
\text { level staff } \\
\text { hired and } \\
\text { working }\end{array}$ & $\begin{array}{l}\text { Thanagement- } \\
\text { level staff } \\
\text { improve the } \\
\text { efficiency of } \\
\text { the ministry's } \\
\text { programs and } \\
\text { projects }\end{array}$ & $\begin{array}{l}\text { MSPP/ORH } \\
\end{array}$ \\
\hline
\end{tabular}


NATIONAL STRATEGY DOCUMENT FOR GROWTH AND POVERTY REDUCTION (DSNCRP/HATTI) ACTION PLANS TO REFORMTHE PUBLIC FINANCIAL MANAGEMENT SYSTEM

JUSTICE SECTOR - PRIORITY ACTION PLAN

\begin{tabular}{|c|c|c|c|c|c|c|c|}
\hline Objectives & Actions & Fiscal Years & $\begin{array}{l}\text { Available } \\
\text { Resources }\end{array}$ & Input Indicator & Output Indicator & $\begin{array}{l}\text { Performance } \\
\text { Indicator }\end{array}$ & Implementing Agency \\
\hline \multirow[t]{4}{*}{$\begin{array}{l}\text { 1. Strengthen the } \\
\text { links between } \\
\text { allocation of } \\
\text { resources and the } \\
\text { government's } \\
\text { priorities defined } \\
\text { in the NSGPR } \\
\text { and the sectoral } \\
\text { strategy }\end{array}$} & $\begin{array}{l}\text { 1) Validation by } \\
\text { the institutions } \\
\text { that are } \\
\text { stakeholders in } \\
\text { the strategic } \\
\text { framework of the } \\
\text { justice sector }\end{array}$ & $2007-2008$ & & $\begin{array}{l}\text { Stakeholders and } \\
\text { partners in } \\
\text { International } \\
\text { Cooperation and } \\
\text { Government }\end{array}$ & $\begin{array}{l}\text { Strategy } \\
\text { framework } \\
\text { document } \\
\text { validated. } \\
\text { The document } \\
\text { highlights the } \\
\text { ministry's } \\
\text { responsibility in } \\
\text { the area of public } \\
\text { security. }\end{array}$ & $\begin{array}{l}\text { The elements of the } \\
\text { strategic } \\
\text { framework } \\
\text { document are } \\
\text { considered in the } \\
\text { NSGPR }\end{array}$ & $\begin{array}{l}\text { MJSP } \\
\text { MEF } \\
\text { MPCE }\end{array}$ \\
\hline & $\begin{array}{l}\text { 2) Preparation of } \\
\text { a plan to } \\
\text { harmonize the } \\
\text { budgets of the } \\
\text { sector's different } \\
\text { components }\end{array}$ & $\begin{array}{l}2007-2008 \\
\text { and } \\
\text { subsequent }\end{array}$ & $\begin{array}{l}\text { Still to be } \\
\text { identified }\end{array}$ & $\begin{array}{l}\text { The program } \\
\text { budget documents } \\
\text { of the sector's } \\
\text { different } \\
\text { components }\end{array}$ & $\begin{array}{l}\text { Harmonization } \\
\text { plan available }\end{array}$ & $\begin{array}{l}\text { Budget } \\
\text { consolidated }\end{array}$ & MJSP \\
\hline & $\begin{array}{l}\text { 3) Preparation of } \\
\text { the Public } \\
\text { Investment } \\
\text { Program and of } \\
\text { the recurrent } \\
\text { charges for the } \\
\text { Justice Sector } \\
\text { over three (3) } \\
\text { years }\end{array}$ & $\begin{array}{l}2007-2008 \\
\text { and } \\
\text { subsequent }\end{array}$ & & $\begin{array}{l}\text { Strategic } \\
\text { framework }\end{array}$ & $\begin{array}{l}\text { Investment plan for } \\
\text { the justice sector } \\
\text { submitted to the } \\
\text { MPCE and the } \\
\text { MEF } \\
\text { Document dealing } \\
\text { with recurrent } \\
\text { charges prepared } \\
\text { and disseminated } \\
\text { on time }\end{array}$ & $\begin{array}{l}\text { The investment } \\
\text { budget validated by } \\
\text { the MEF and the } \\
\text { MPCE and adopted } \\
\text { by Parliament }\end{array}$ & MJSP \\
\hline & $\begin{array}{l}\text { 4) Reinforce the } \\
\text { EPU and the } \\
\text { DAAB of the } \\
\text { ministry }\end{array}$ & $2007-2008$ & Public Treasury & $\begin{array}{l}\text { Assessment of the } \\
\text { existing material } \\
\text { and resources and } \\
\text { procedures for } \\
\text { carrying out } \\
\text { investment } \\
\text { management }\end{array}$ & $\begin{array}{l}\text { Availability of } \\
\text { human resources. } \\
\text { Acquisition of } \\
\text { machinery and } \\
\text { equipment. }\end{array}$ & $\begin{array}{l}\text { Preparation of the } \\
\text { MJSP budget } \\
\text { within the required } \\
\text { time limits } \\
\text { Regular reports on } \\
\text { execution of } \\
\text { budgets }\end{array}$ & $\begin{array}{c}\text { MJSP } \\
\text { UEP / DAAB }\end{array}$ \\
\hline
\end{tabular}


NATIONAL STRATEGY DOCUMENT FOR GROWTH AND POVERTY REDUCTION (DSNCRP/HATTI) ACTION PLANS TO REFORMTHE PUBLIC FINANCIAL MANAGEMENT SYSTEM

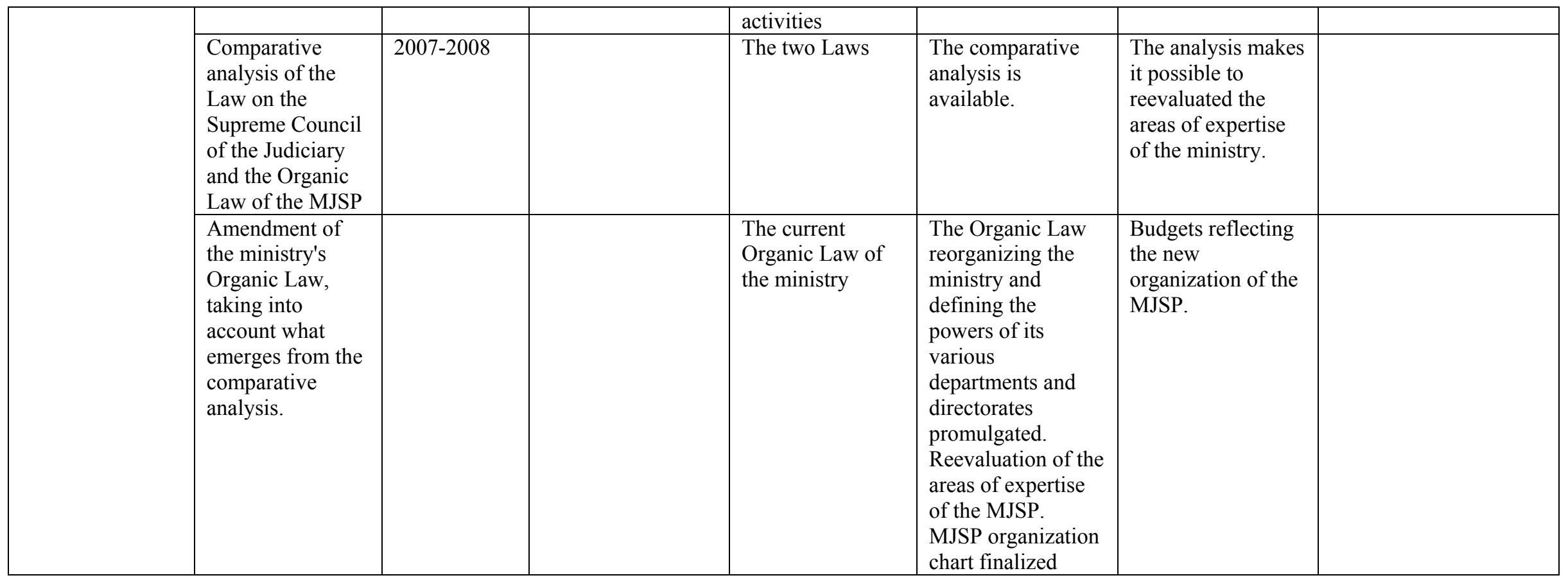


NATIONAL STRATEGY DOCUMENT FOR GROWTH AND POVERTY REDUCTION (DSNCRP/HATT)

ACTION PLANS TO REFORMTHE PUBLIC FINANCIAL MANAGEMENT SYSTEM

JUSTICE SECTOR - PRIORITY ACTION PLAN

\begin{tabular}{|c|c|c|c|c|c|c|c|}
\hline OBJECTIVES & ACTIONS & $\begin{array}{l}\text { FISCAL } \\
\text { YEARS }\end{array}$ & $\begin{array}{l}\text { AVAILABLE } \\
\text { RESOURCES }\end{array}$ & $\begin{array}{l}\text { INPUT } \\
\text { INDICATOR }\end{array}$ & $\begin{array}{l}\text { OUTPUT } \\
\text { INDICATOR }\end{array}$ & $\begin{array}{l}\text { PERFORMANCE } \\
\text { INDICATOR }\end{array}$ & $\begin{array}{l}\text { IMPLEMENTING } \\
\text { AGENCY }\end{array}$ \\
\hline \multirow{3}{*}{$\begin{array}{l}\text { 2.- IMPROVE } \\
\text { BUDGET } \\
\text { EXECUTION }\end{array}$} & $\begin{array}{l}\text { Updating and } \\
\text { dissemination of the } \\
\text { legal framework and } \\
\text { procedures for } \\
\text { management of the } \\
\text { investment budget }\end{array}$ & $2007-2008$ & & $\begin{array}{l}\text { Legal framework } \\
\text { and existing } \\
\text { procedures }\end{array}$ & $\begin{array}{l}\text { Dissemination of } \\
\text { the legal } \\
\text { framework and } \\
\text { of the procedures } \\
\text { and new } \\
\text { mechanisms. }\end{array}$ & $\begin{array}{l}\text { Application of the } \\
\text { framework }\end{array}$ & $\begin{array}{l}\text { MEF, MJSP AND } \\
\text { MPCE }\end{array}$ \\
\hline & $\begin{array}{l}\text { Build the } \\
\text { procurement } \\
\text { capacity of the } \\
\text { MJSP ministerial } \\
\text { committee. }\end{array}$ & $2007-2008$ & & $\begin{array}{l}\text { Recruitment of } \\
\text { specialist staff. } \\
\text { On the job } \\
\text { training } \\
\text { workshop. }\end{array}$ & $\begin{array}{l}\text { The staff is } \\
\text { recruited. } \\
\text { Training } \\
\text { workshop }\end{array}$ & $\begin{array}{l}\text { Better outcome in } \\
\text { the compilation of } \\
\text { public procurement } \\
\text { dossiers. } \\
\text { Increase in the } \\
\text { number of } \\
\text { procurement } \\
\text { contracts awarded. }\end{array}$ & CNMP / MJSP \\
\hline & $\begin{array}{l}\text { Prepare the annual } \\
\text { procurement plan }\end{array}$ & $2007-2010$ & Public Treasury & $\begin{array}{l}\text { The project } \\
\text { documents } \\
\text { available. } \\
\text { Proceedings of } \\
\text { the ministerial } \\
\text { committee on } \\
\text { procurement }\end{array}$ & $\begin{array}{l}\text { Procurement } \\
\text { plan prepared } \\
\text { before the start } \\
\text { of the fiscal year } \\
\text { and published on } \\
\text { the CNMP } \\
\text { website }\end{array}$ & $\begin{array}{l}\text { Acquisition of the } \\
\text { works, goods, and } \\
\text { services concerned } \\
\text { more rapid and } \\
\text { more efficient, in } \\
\text { accordance with } \\
\text { the timetable. }\end{array}$ & CNMP / MJSP \\
\hline
\end{tabular}


NATIONAL STRATEGY DOCUMENT FOR GROWTH AND POVERTY REDUCTION (DSNCRP/HATT)

ACTION PLANS TO REFORMTHE PUBLIC FINANCIAL MANAGEMENT SYSTEM

\section{JUSTICE SECTOR - PRIORITY ACTION PLAN}

\begin{tabular}{|c|c|c|c|c|c|c|c|}
\hline OBJECTIVES & ACTIONS & $\begin{array}{l}\text { FISCAL } \\
\text { YEARS }\end{array}$ & $\begin{array}{l}\text { AVAILABLE } \\
\text { RESOURCES }\end{array}$ & $\begin{array}{l}\text { INPUT } \\
\text { INDICATOR }\end{array}$ & $\begin{array}{l}\text { OUTPUT } \\
\text { INDICATOR }\end{array}$ & $\begin{array}{l}\text { PERFORMANCE } \\
\text { INDICATOR }\end{array}$ & $\begin{array}{l}\text { IMPLEMENTING } \\
\text { AGENCY }\end{array}$ \\
\hline $\begin{array}{l}\text { 3.- IMPROVE } \\
\text { THE } \\
\text { TRANSPARENCY } \\
\text { OF BUDGET } \\
\text { REPORTING }\end{array}$ & $\begin{array}{l}\text { 3) Implementation } \\
\text { of harmonized } \\
\text { accounting } \\
\text { procedures and tools } \\
\text { for investment } \\
\text { projects }\end{array}$ & $2007-2008$ & $\begin{array}{l}\text { Still to be } \\
\text { identified }\end{array}$ & $\begin{array}{l}\text { Recruitment of } \\
\text { adequate staff }\end{array}$ & $\begin{array}{l}\text { Accounting } \\
\text { software and } \\
\text { project } \\
\text { management } \\
\text { manual of } \\
\text { procedures } \\
\text { available }\end{array}$ & $\begin{array}{l}\text { Presentation of } \\
\text { budget execution } \\
\text { reports by project }\end{array}$ & MPCE / MJSP \\
\hline
\end{tabular}


NATIONAL STRATEGY DOCUMENT FOR GROWTH AND POVERTY REDUCTION (DSNCRP/HATT)

ACTION PLANS TO REFORMTHE PUBLIC FINANCIAL MANAGEMENT SYSTEM

\begin{tabular}{|c|c|c|c|c|c|c|c|}
\hline OBJECTIVES & ACTIONS & $\begin{array}{l}\text { FISCAL } \\
\text { YEARS }\end{array}$ & $\begin{array}{l}\text { AVAILABLE } \\
\text { RESOURCES }\end{array}$ & $\begin{array}{l}\text { INPUT } \\
\text { INDICATOR }\end{array}$ & $\begin{array}{l}\text { OUTPUT } \\
\text { INDICATOR }\end{array}$ & $\begin{array}{l}\text { PERFORMANCE } \\
\text { INDICATOR }\end{array}$ & $\begin{array}{l}\text { IMPLEMENTING } \\
\text { AGENCY }\end{array}$ \\
\hline \multirow[b]{2}{*}{$\begin{array}{l}\text { 4.- } \\
\text { GRADUALLY } \\
\text { INCORPORATE } \\
\text { EXPENDITURE } \\
\text { FINANCED BY } \\
\text { FOREIGN } \\
\text { RESOURCES IN } \\
\text { THE SECTOR'S } \\
\text { BUDGET }\end{array}$} & $\begin{array}{l}\text { 1) Involve the main } \\
\text { donors and creditors } \\
\text { in the preparation of } \\
\text { the budget }\end{array}$ & 2008-2009 & $\begin{array}{l}\text { Still to be } \\
\text { identified }\end{array}$ & $\begin{array}{l}\text { Technical } \\
\text { coordination } \\
\text { meetings } \\
\text { organized during } \\
\text { the budget } \\
\text { preparation } \\
\text { process }\end{array}$ & & $\begin{array}{l}\text { Foreign investment } \\
\text { expenditure } \\
\text { budgetized }\end{array}$ & MPCE/MJSP \\
\hline & $\begin{array}{l}\text { 2) Establish a } \\
\text { harmonized } \\
\text { framework for } \\
\text { monitoring external } \\
\text { cooperation } \\
\text { investment }\end{array}$ & $2007-2008$ & $\begin{array}{l}\text { Still to be } \\
\text { identified }\end{array}$ & $\begin{array}{l}\text { National } \\
\text { expertise } \\
\text { mobilized and } \\
\text { broader dialogue } \\
\text { held with } \\
\text { technical } \\
\text { ministries and } \\
\text { donors and } \\
\text { creditors }\end{array}$ & $\begin{array}{l}\text { Database and } \\
\text { manual of } \\
\text { procedures } \\
\text { prepared and } \\
\text { negotiated with } \\
\text { all donors and } \\
\text { lenders }\end{array}$ & $\begin{array}{l}\text { Foreign investment } \\
\text { expenditure } \\
\text { correctly } \\
\text { monitored }\end{array}$ & MPCE/MJSP \\
\hline
\end{tabular}


NATIONAL STRATEGY DOCUMENT FOR GROWTH AND POVERTY REDUCTION (DSNCRP/HATT)

ACTION PLANS TO REFORMTHE PUBLIC FINANCIAL MANAGEMENT SYSTEM

JUSTICE SECTOR - PRIORITY ACTION PLAN

\begin{tabular}{|l|l|l|l|l|l|l|l|}
\hline OBJECTIVES & ACTIONS & $\begin{array}{l}\text { FISCAL } \\
\text { YEARS }\end{array}$ & $\begin{array}{l}\text { AVAILABLE } \\
\text { RESOURCES }\end{array}$ & $\begin{array}{l}\text { INPUT } \\
\text { INDICATOR }\end{array}$ & $\begin{array}{l}\text { OUTPUT } \\
\text { INDICATOR }\end{array}$ & $\begin{array}{l}\text { PERFORMANCE } \\
\text { INDICATOR }\end{array}$ & $\begin{array}{l}\text { IMPLEMENTING } \\
\text { AGENCY }\end{array}$ \\
\hline $\begin{array}{l}\text { 5.- EVALUATE } \\
\text { THE IMPACT } \\
\text { OF BUDGET } \\
\begin{array}{l}\text { EXPENITURE } \\
\text { AND TRACK } \\
\text { BUDGET } \\
\text { OUTTURNS }\end{array}\end{array}$ & $\begin{array}{l}\text { Focus the impact of } \\
\text { investment on the } \\
\text { main priorities of } \\
\text { the NSFGPR. }\end{array}$ & $2008-2009$ & & & & \\
\hline
\end{tabular}

Priority Action Plan for Public Security (PNH) 
NATIONAL STRATEGY DOCUMENT FOR GROWTH AND POVERTY REDUCTION (DSNCRP/HATTI)

ACTION PLANS TO REFORMTHE PUBLIC FINANCIAL MANAGEMENT SYSTEM

\begin{tabular}{|c|c|c|c|c|c|c|c|}
\hline Objective & Actions & Fiscal Years & $\begin{array}{l}\text { Available } \\
\text { Resources }\end{array}$ & Input Indicator & Output Indicator & $\begin{array}{l}\text { Performance } \\
\text { Indicator }\end{array}$ & $\begin{array}{c}\text { Implementing } \\
\text { Agency }\end{array}$ \\
\hline \multirow{4}{*}{$\begin{array}{l}\text { 1. Strengthen the } \\
\text { links between the } \\
\text { allocation of } \\
\text { resources and the } \\
\text { government } \\
\text { priorities defined } \\
\text { in the NSGPR } \\
\text { and the sectoral } \\
\text { strategy }\end{array}$} & $\begin{array}{l}\text { Preparation of a sectoral } \\
\text { strategy for public } \\
\text { security. } \\
\text { P2 }\end{array}$ & 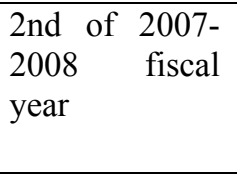 & $\begin{array}{l}\text { Minustah } \\
\text { Public Treasury }\end{array}$ & $\begin{array}{l}\text { National and } \\
\text { international } \\
\text { expertise. }\end{array}$ & Experts' report & $\begin{array}{l}\text { Implementation of the } \\
\text { strategy }\end{array}$ & $\mathrm{PNH}$ \\
\hline & $\begin{array}{l}\text { Design of a career } \\
\text { management plan at the } \\
\text { PNH and a strategy for } \\
\text { putting it into operation. } \\
\text { P4 }\end{array}$ & 2007-2010 & $\begin{array}{l}\text { Minustah } \\
\text { Public Treasury }\end{array}$ & Study available & $\begin{array}{l}\text { Availability of a } \\
\text { management and } \\
\text { operationalization } \\
\text { plan }\end{array}$ & $\begin{array}{l}\text { Availability of pay } \\
\text { scales. } \\
\begin{array}{l}\text { Motivation of police } \\
\text { officers. }\end{array}\end{array}$ & \\
\hline & $\begin{array}{l}\text { Train PNH staff in } \\
\text { public finance. } \\
\text { P3 }\end{array}$ & $\begin{array}{l}\text { 2nd quarter of } \\
\text { fiscal 2007- } \\
2008\end{array}$ & $\begin{array}{l}\text { Minustah } \\
\text { Public Treasury }\end{array}$ & $\begin{array}{l}\text { National and } \\
\text { international } \\
\text { expertise }\end{array}$ & $\begin{array}{l}\text { Report on the } \\
\text { activities of the staff } \\
\text { who have received } \\
\text { training }\end{array}$ & & PNH-MJSP \\
\hline & $\begin{array}{l}\text { Finalization of the } \\
\text { payroll, payment of } \\
\text { salary arrears. } \\
\text { P1 }\end{array}$ & $2007-2009$ & & Current payroll data & $\begin{array}{l}100 \text { percent of staff } \\
\text { included in the } \\
\text { payroll. }\end{array}$ & $\begin{array}{l}\text { The MJSP budget has } \\
\text { earmarked the } \\
\text { resources necessary to } \\
\text { pay liabilities and } \\
\text { salaries. }\end{array}$ & PNH-MJSP \\
\hline
\end{tabular}

Priority Action Plan for Public Security (PNH) 
NATIONAL STRATEGY DOCUMENT FOR GROWTH AND POVERTY REDUCTION (DSNCRP/HATT) ACTION PLANS TO REFORMTHE PUBLIC FINANCIAL MANAGEMENT SYSTEM

\begin{tabular}{|c|c|c|c|c|c|c|c|}
\hline Objective & Actions & Fiscal Years & $\begin{array}{l}\text { Available } \\
\text { Resources }\end{array}$ & Input Indicator & Output Indicator & $\begin{array}{l}\text { Performance } \\
\text { Indicator }\end{array}$ & $\begin{array}{c}\text { Implementing } \\
\text { Agency }\end{array}$ \\
\hline \multirow[t]{3}{*}{$\begin{array}{l}2 . \quad \text { Improve } \\
\text { budget execution }\end{array}$} & $\begin{array}{l}\text { Preparation of a } \\
\text { manual of budget } \\
\text { procedures. } \\
\text { P1 }\end{array}$ & $2007-2008$ & & $\begin{array}{l}\text { Evaluation of the } \\
\text { current system. }\end{array}$ & $\begin{array}{l}\text { Organizational } \\
\text { framework and } \\
\text { missions of the } \\
\text { Budget Department } \\
\text { clearly defined. } \\
\text { Procedures for the } \\
\text { preparation, } \\
\text { execution, and } \\
\text { monitoring of } \\
\text { operating and } \\
\text { investment budgets } \\
\text { available. }\end{array}$ & $\begin{array}{l}\text { Better budget } \\
\text { execution. }\end{array}$ & PNH/MJSP \\
\hline & $\begin{array}{l}\text { Design and } \\
\text { implementation } \\
\text { of a manual of } \\
\text { internal } \\
\text { purchasing } \\
\text { procedures in } \\
\text { compliance with } \\
\text { the rules in force } \\
\text { at the CNMP. } \\
\text { P2 }\end{array}$ & $2007-2008$ & & $\begin{array}{l}\text { Recruitment of a } \\
\text { specialist }\end{array}$ & $\begin{array}{l}\text { Manual of } \\
\text { procedures } \\
\text { available }\end{array}$ & $\begin{array}{l}\text { Reduction in the } \\
\text { proportion of } \\
\text { expenditure } \\
\text { challenged by the } \\
\text { control bodies. } \\
\text { Reduction in the } \\
\text { number of files } \\
\text { returned by the } \\
\text { CNMP } \\
\text { Increase in the } \\
\text { absorption rate of } \\
\text { the sector's } \\
\text { appropriations. } \\
\text { Reduction in the } \\
\text { delays in process } \\
\text { files. } \\
\text { Purchases in } \\
\text { compliance with } \\
\text { the rules in force. }\end{array}$ & PNH/MJSP/CMPP \\
\hline & $\begin{array}{l}\text { Strengthening of } \\
\text { the PNH } \\
\text { specialist } \\
\text { procurement } \\
\text { committee. }\end{array}$ & $2007-2009$ & & $\begin{array}{l}\text { Recruitment of } \\
\text { qualified staff. } \\
\text { On the job } \\
\text { training. }\end{array}$ & $\begin{array}{l}\text { The staff is } \\
\text { recruited. } \\
\text { Training workshop. }\end{array}$ & $\begin{array}{l}\text { Better outcome } \\
\text { in the } \\
\text { compilation of } \\
\text { public } \\
\text { procurement } \\
\text { files. }\end{array}$ & PNH-MJSP-CNMP \\
\hline
\end{tabular}


NATIONAL STRATEGY DOCUMENT FOR GROWTH AND POVERTY REDUCTION (DSNCRP/HATTI) ACTION PLANS TO REFORMTHE PUBLIC FINANCIAL MANAGEMENT SYSTEM

\begin{tabular}{|l|l|l|l|l|l|l|}
\hline & & & & $\begin{array}{l}\text { Increase in the } \\
\text { number of } \\
\text { procurement } \\
\text { contracts } \\
\text { awarded. }\end{array}$ & & \\
& & $\begin{array}{l}\text { Introduce } \\
\text { compulsory } \\
\text { physical asset } \\
\text { inventories, half- } \\
\text { yearly and yearly. }\end{array}$ & $2008-2009$ & $\begin{array}{l}\text { Acquisition of } \\
\text { software for } \\
\text { carrying out and } \\
\text { updating } \\
\text { inventories. } \\
\text { conducted } \\
\text { yearly and yearly. } \\
\text { half- } \\
\text { constantly } \\
\text { updated } \\
\text { information } \\
\text { about } \\
\text { moveable } \\
\text { immoveable } \\
\text { assets. }\end{array}$ \\
and
\end{tabular}

Priority Action Plan for Public Security (PNH)

\begin{tabular}{|c|c|c|c|c|c|c|c|}
\hline Objective & Actions & Fiscal Years & $\begin{array}{l}\text { Available } \\
\text { Resources }\end{array}$ & Input Indicator & $\begin{array}{c}\text { Output } \\
\text { Indicator }\end{array}$ & Performance Indicator & $\begin{array}{c}\text { Implementing } \\
\text { Agency }\end{array}$ \\
\hline \multirow[t]{3}{*}{$\begin{array}{l}\text { 3. Improve the } \\
\text { transparency of } \\
\text { budge reporting. }\end{array}$} & $\begin{array}{l}\text { Have an yearly } \\
\text { procurement plan } \\
\text { P1 }\end{array}$ & 2008-2010 & & $\begin{array}{l}\text { Availability of a } \\
\text { public } \\
\text { procurement } \\
\text { specialist within } \\
\text { the PNH. }\end{array}$ & $\begin{array}{l}\text { Procurement } \\
\text { plan prepared } \\
\text { every year no } \\
\text { later than the } \\
\text { beginning of } \\
\text { September and } \\
\text { published on the } \\
\text { CNMP website. }\end{array}$ & $\begin{array}{l}\text { The PNH can monitor } \\
\text { budget execution better } \\
\text { in future. }\end{array}$ & $\mathrm{PNH} / \mathrm{CNMP} / \mathrm{MJSP}$ \\
\hline & $\begin{array}{l}\text { Data processing, } \\
\text { budget monitoring } \\
\text { and evaluation }\end{array}$ & $2008-2010$ & Public Treasury & $\begin{array}{l}\text { Specialist in the } \\
\text { budget } \\
\text { monitoring and } \\
\text { evaluation } \\
\text { available. }\end{array}$ & $\begin{array}{l}\text { Better use of the } \\
\text { budget }\end{array}$ & $\begin{array}{l}\text { Higher level of budget } \\
\text { execution }\end{array}$ & $\mathrm{PNH}$ \\
\hline & $\begin{array}{l}\text { Presentation and } \\
\text { periodic evaluation } \\
\text { of the progress } \\
\text { report on project }\end{array}$ & $\begin{array}{l}\text { 2nd quarter } \\
2007-2008\end{array}$ & Public Treasury & $\begin{array}{l}\text { FIOP } \\
\text { Assignment of } \\
\text { PNH staff to this } \\
\text { committee. }\end{array}$ & $\begin{array}{l}\text { Progress report } \\
\text { on the projects is } \\
\text { produced on a } \\
\text { half-yearly basis. }\end{array}$ & $\begin{array}{l}\text { The PNH significantly } \\
\text { improves the bailout of } \\
\text { its investment project } \\
\text { account. }\end{array}$ & PNH/MJSP/MPCE \\
\hline
\end{tabular}


NATIONAL STRATEGY DOCUMENT FOR GROWTH AND POVERTY REDUCTION (DSNCRP/HATT) ACTION PLANS TO REFORMTHE PUBLIC FINANCIAL MANAGEMENT SYSTEM

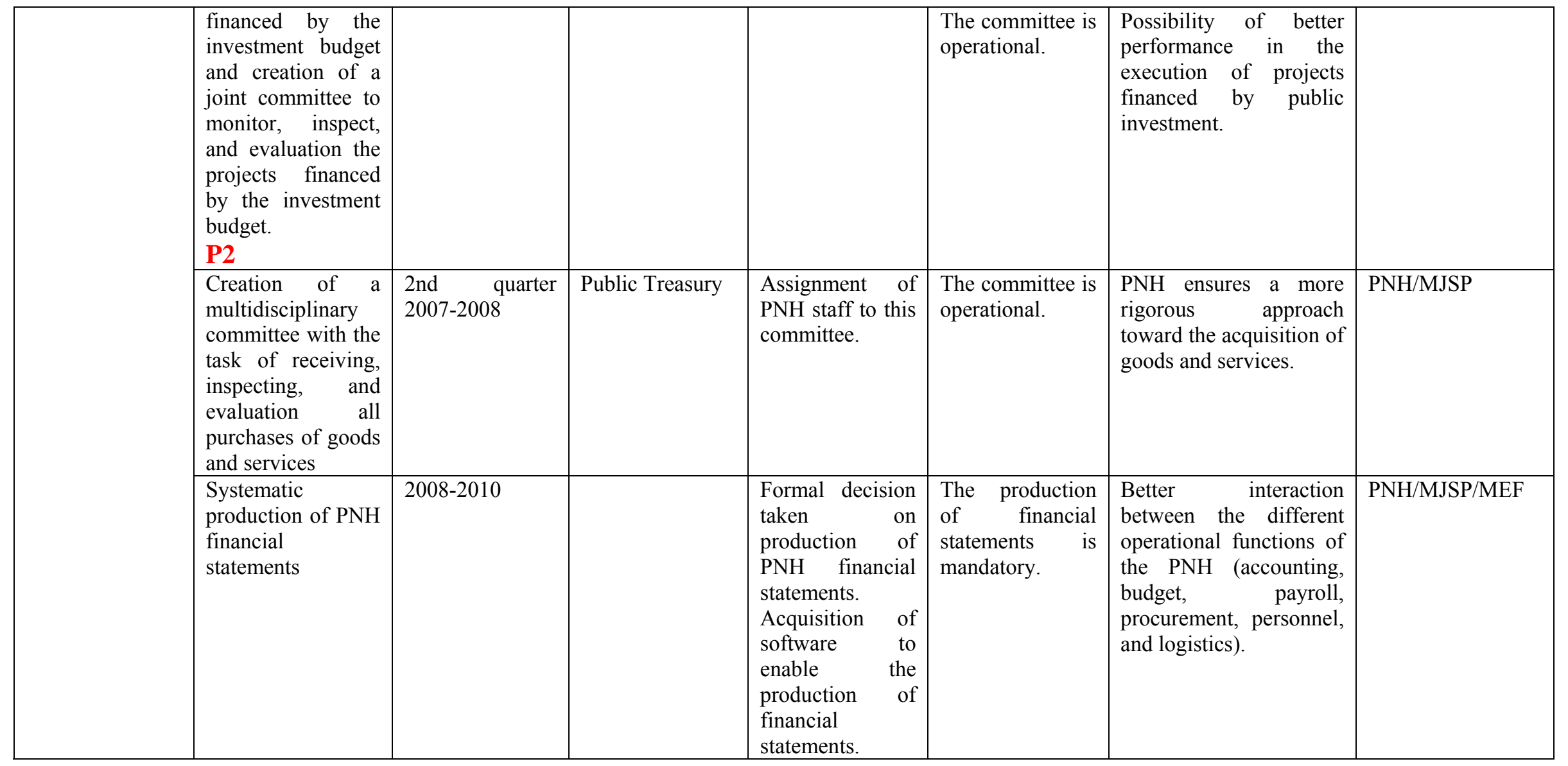


NATIONAL STRATEGY DOCUMENT FOR GROWTH AND POVERTY REDUCTION (DSNCRP/HATT) ACTION PLANS TO REFORMTHE PUBLIC FINANCIAL MANAGEMENT SYSTEM

Priority Action Plan for Public Security (PNH)

\begin{tabular}{|c|c|c|c|c|c|c|c|}
\hline Objective & Actions & Fiscal Years & $\begin{array}{l}\text { Available } \\
\text { Resources }\end{array}$ & Input Indicator & $\begin{array}{c}\text { Output } \\
\text { Indicator }\end{array}$ & $\begin{array}{c}\text { Performance } \\
\text { Indicator }\end{array}$ & $\begin{array}{c}\text { Implementing } \\
\text { Agency }\end{array}$ \\
\hline \multirow[t]{3}{*}{$\begin{array}{l}\text { 4. Gradually } \\
\text { integrate } \\
\text { expenditure } \\
\text { financed by } \\
\text { foreign resources } \\
\text { in the } \\
\text { government } \\
\text { budget }\end{array}$} & $\begin{array}{l}\text { Joint management } \\
\text { of people and } \\
\text { projects financed by } \\
\text { foreign aid }\end{array}$ & $2008-2009$ & & $\begin{array}{l}\text { Preparation of a } \\
\text { memorandum of } \\
\text { understanding } \\
\text { between the PNH } \\
\text { and the different } \\
\text { foreign partners. } \\
\text { Preparation of } \\
\text { manuals } \\
\text { procedures of } \\
\text { allowing this } \\
\text { joint } \\
\text { management. } \\
\text { Legal provisions } \\
\text { governing that } \\
\text { management. }\end{array}$ & $\begin{array}{l}\text { Memorandum of } \\
\text { understanding } \\
\text { signed. } \\
\text { Manual of } \\
\text { procedures } \\
\text { available. } \\
\text { Legal provisions } \\
\text { available. }\end{array}$ & $\begin{array}{l}\text { The government, } \\
\text { through the PNH, } \\
\text { has genuine } \\
\text { control over } \\
\text { actual } \\
\text { expenditure } \\
\text { financed by } \\
\text { foreign aid in the } \\
\text { sector. }\end{array}$ & PNH/MJSP \\
\hline & $\begin{array}{l}\text { Steer expenditure } \\
\text { financed by foreign } \\
\text { resources toward } \\
\text { government } \\
\text { objectives. } \\
\text { P1 }\end{array}$ & $2008-2009$ & & $\begin{array}{l}\text { NSGPR } \\
\text { document, the } \\
\text { PNH strategy } \\
\text { document. }\end{array}$ & $\begin{array}{l}\text { Expenditure is } \\
\text { determined on } \\
\text { the basis of the } \\
\text { priorities defined } \\
\text { by the PNH. }\end{array}$ & $\begin{array}{l}\text { The funds } \\
\text { received from the } \\
\text { international } \\
\text { community are } \\
\text { used to speed up } \\
\text { reform of the } \\
\text { PNH and to } \\
\text { relaunch the } \\
\text { justice system } \\
\text { reform. }\end{array}$ & PNH/MJSP \\
\hline & $\begin{array}{l}\text { Formulate } \\
\text { implement and } \\
\text { framework plan } \\
\text { with a view to } \\
\text { administering, } \\
\text { monitoring, and } \\
\text { evaluating projects } \\
\text { financed by the } \\
\text { various donors and } \\
\text { lenders. }\end{array}$ & $\begin{array}{l}\text { 2nd quarter } \\
2007-2008 \text {. }\end{array}$ & Public Treasury & $\begin{array}{l}\text { Setting up of the } \\
\text { team to prepare } \\
\text { this plan. }\end{array}$ & $\begin{array}{l}\text { The framework } \\
\text { plan is available. }\end{array}$ & $\begin{array}{l}\text { Better regulation } \\
\text { of the financing } \\
\text { of the sector. }\end{array}$ & PNH/MJSP \\
\hline
\end{tabular}


NATIONAL STRATEGY DOCUMENT FOR GROWTH AND POVERTY REDUCTION (DSNCRP/HATT)

ACTION PLANS TO REFORMTHE PUBLIC FINANCIAL MANAGEMENT SYSTEM

Priority Action Plan for Public Security (PNH)

\begin{tabular}{|c|c|c|c|c|c|c|c|}
\hline Objectives & Actions & Fiscal Years & $\begin{array}{l}\text { Available } \\
\text { Resources }\end{array}$ & Input Indicator & Output Indicator & $\begin{array}{l}\text { Performance } \\
\text { Indicator }\end{array}$ & $\begin{array}{c}\text { Implementing } \\
\text { Agency }\end{array}$ \\
\hline $\begin{array}{l}\text { 5.- Evaluate the } \\
\text { impact of } \\
\text { budgetary } \\
\text { expenditure and } \\
\text { track budget } \\
\text { outturns }\end{array}$ & $\begin{array}{l}\text { Put in place a } \\
\text { plan to review } \\
\text { performance with } \\
\text { a view to } \\
\text { ensuring that } \\
\text { budgetary } \\
\text { expenditure } \\
\text { policy is } \\
\text { conducted in a } \\
\text { reliably } \\
\text { disciplined } \\
\text { environment. } \\
\text { As well as tools } \\
\text { to efficiently } \\
\text { monitor the } \\
\text { meeting of } \\
\text { objectives on the } \\
\text { basis of budget } \\
\text { execution }\end{array}$ & $\begin{array}{l}\text { 2nd quarter } \\
2007-2008\end{array}$ & & $\begin{array}{l}\text { Recruitment of a } \\
\text { specialist } \\
\text { Strengthening of } \\
\text { the IGPNH }\end{array}$ & $\begin{array}{l}\text { The plan is available } \\
\text { The IGPNH is } \\
\text { strengthened and can } \\
\text { ensure that the tools } \\
\text { are put into } \\
\text { operation. }\end{array}$ & $\begin{array}{l}\text { Evaluation of the } \\
\text { impact of the } \\
\text { contribution of } \\
\text { justice and public } \\
\text { security to } \\
\text { reducing poverty. } \\
\text { A professional, } \\
\text { efficient, } \\
\text { effective, and } \\
\text { efficient police } \\
\text { force. }\end{array}$ & PNH/MJSP \\
\hline
\end{tabular}

